\title{
Systems Design Description of the Thermal Transient Test Facility (TTTF)
}

\author{
H. C. Young \\ A. G. Grindell
}

\section{MASTER}

\section{OAK RIDGE NATIONAL LABORATORY}

\author{
OPERAIED bY UNION CARBIDE CORPORATION - FOR the U.S. ATOMIC ENERGY COMMISSION
}


Pringed in the United States of America. Avaikble from National Technical Bntomation Service

U.S. Degarturent of Commarce

5285 Port Royis! Rowi, Soringfield, Virginia 22101

Price: Printed Copy \$2.60. Microfiche $\$ 2.25$

This raport was prapared as an acount of wonk spomorod by the United States Goverment. Neithen the United States nor rhe United States Atomic Energy Commiswon, nor any of their amployees, not any of thes conthotors, subontractors, or thair employees, makris anv varranty. express or mplied, or assumes any iegal liablity or lesponsibility for has scuuracy, completeness or usefulness of any information, apparatus, froibuct or grocess disclosed, or i enresents that its use would fort infringe privately owned rights. 


\section{DISCLAIMER}

This report was prepared as an account of work sponsored by an agency of the United States Government. Neither the United States Government nor any agency Thereof, nor any of their employees, makes any warranty, express or implied, or assumes any legal liability or responsibility for the accuracy, completeness, or usefulness of any information, apparatus, product, or process disclosed, or represents that its use would not infringe privately owned rights. Reference herein to any specific commercial product, process, or service by trade name, trademark, manufacturer, or otherwise does not necessarily constitute or imply its endorsement, recommendation, or favoring by the United States Government or any agency thereof. The views and opinions of authors expressed herein do not necessarily state or reflect those of the United States Government or any agency thereof. 


\section{DISCLAIMER}

Portions of this document may be illegible in electronic image products. Images are produced from the best available original document. 
ORNL-TM-4607

UC-79, $-79 e,-79 h,-79 k$

Contract No. W-7405-eng-26

Reactor Division

SYSTEMS DESIGN DESCRIPTION OF THE

THERMAL TRANSIENT TEST FACILITY (TTTF)

H. C. Young A. G. Grinde11

FEBRUARY 1975

- NOTICE

This report was prepared as an account of work sponsored by the United States Government. Neither the United States nor the United States Energy Research and Development Administration, nor any of their employees, nor any of their contractors, subcontractors, or their employees, makes any warranty, express or implied, or assumes any legal liability or responsibility for the accuracy, completeness or usefulness of any information, apparatus, product or process disclosed, or represents that its use would not infringe privately owned rights.

OAK RIDGE NATIONAL LABORATORY

Oak Ridge, Tennessee 37830 operated by

UNION CARBIDE CORPORATION

for the

U. S. ATOMIC ENERGY COMMISSION 
•

5

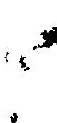

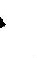




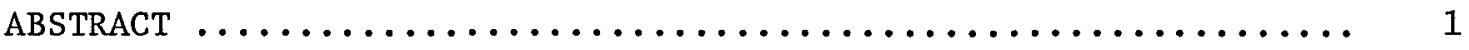

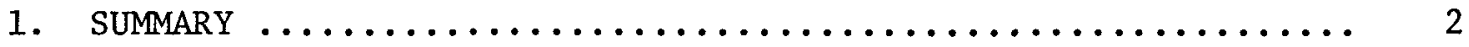

2. FUNCTIONS AND REQUTREMENTS $\ldots \ldots \ldots \ldots \ldots \ldots \ldots \ldots \ldots \ldots \ldots \ldots$

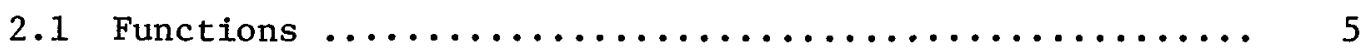

2.2 Operational Requirements $\ldots \ldots \ldots \ldots \ldots \ldots \ldots \ldots \ldots \ldots$

2.3 Structural Requirements ................... 7

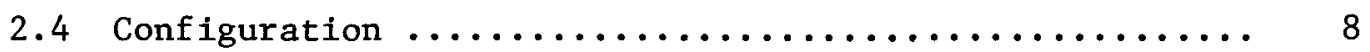

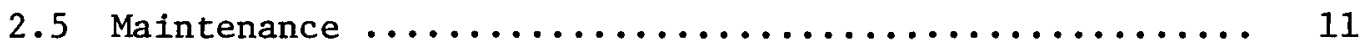

2.6 Instrumentation and Controls ................ 12

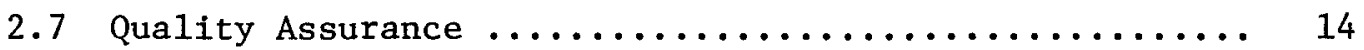

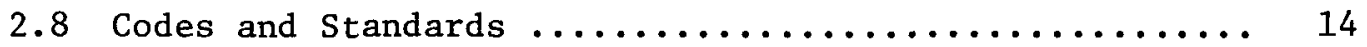

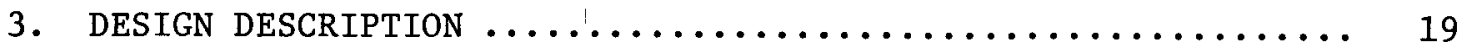

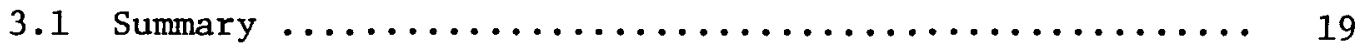

3.2 Detailed Systems Descriptions ................. 19

3.2 .1 Sodium system $\ldots \ldots \ldots \ldots \ldots \ldots \ldots \ldots \ldots \ldots \ldots \ldots \ldots \ldots$

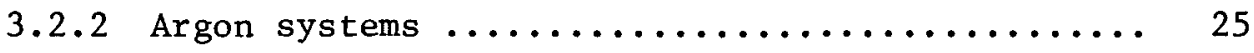

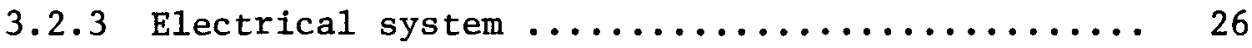

3.2 .4 Cold trap and sodium sampling system ........ 29

3.2 .5 Argon fire-suppression system ............ 31

3.2 .6 Dextir data-acquisition system ........... 32

3.2 .7 Fast data-acquisition system $\ldots \ldots \ldots \ldots \ldots \ldots \ldots 33$

3.3 Detailed Component Description ................. 34

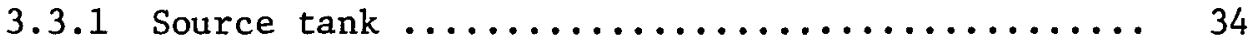

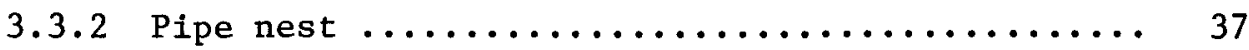

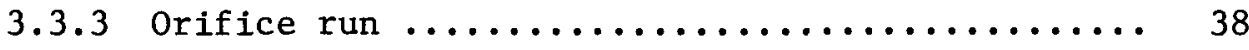

3.3 .4 Test section $\ldots \ldots \ldots \ldots \ldots \ldots \ldots \ldots \ldots \ldots \ldots \ldots . \ldots \ldots$

3.3 .5 Thermal capacitance tank $\ldots \ldots \ldots \ldots \ldots \ldots \ldots \ldots . \ldots . \ldots . \ldots \ldots$

3.3 .6 Sodium shutoff valve $\ldots \ldots \ldots \ldots \ldots \ldots \ldots \ldots \ldots \ldots$

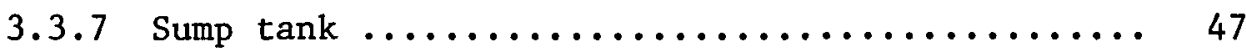

3.3 .8 Test section oven $\ldots \ldots \ldots \ldots \ldots \ldots \ldots \ldots \ldots \ldots \ldots 49$

3.3.9 Protective barriers ................. 51

3.3 .10 Sodium system supports $\ldots \ldots \ldots \ldots \ldots \ldots \ldots \ldots \ldots \ldots$ 
3.4 Instrumentation and Controls $\ldots \ldots \ldots \ldots \ldots \ldots \ldots \ldots, 54$

3.4.1 Test section temperature control and measurement ...................... 54

3.4.2 Pipe nest temperature control ........... 55

3.4 .3 Sodiun liquid-level indlcation ............ 56

3.4 .4 Sodium pressure control ............... 57

3.4 .5 Thermal transient control $\ldots \ldots \ldots \ldots \ldots \ldots \ldots \ldots \ldots$

3.4.6 High-temperature strain measurement ......... 60

3.4 .7 Low pressure argon control ............. 65

3.4 .8 Steady-state data acquisition ............ 66

3.4 .9 Thermal transient data acquisition ......... 67

3.4 .10 Instrument air and nitrogen supplies ........ 68

3.4 .11 Pressure relief valves ................. 69

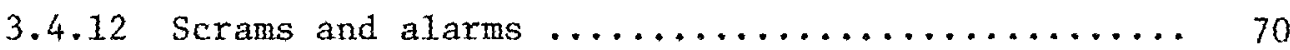

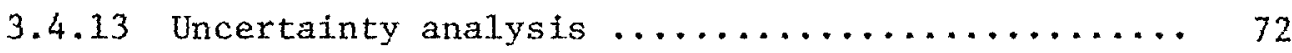

4. FACTLITY LIMTTATIONS, SET POINTS, AND PRECAUTTONS ........ 75

4.1 Limitations and set points ................. 75

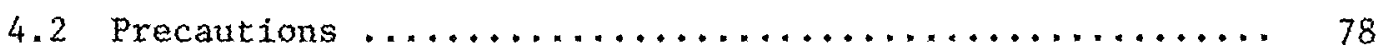

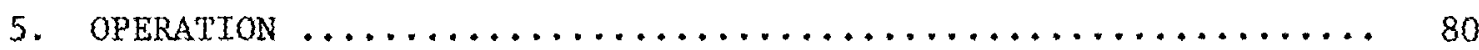

5.1 Initial Fill $\ldots \ldots \ldots \ldots \ldots \ldots \ldots \ldots \ldots \ldots \ldots \ldots \ldots \ldots \ldots$

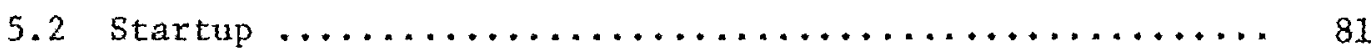

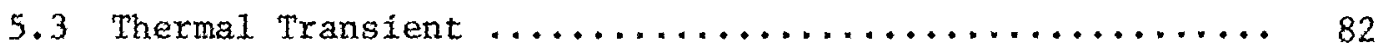

5.4 strain Measurement $\ldots \ldots \ldots \ldots \ldots \ldots \ldots \ldots \ldots \ldots \ldots \ldots \ldots$

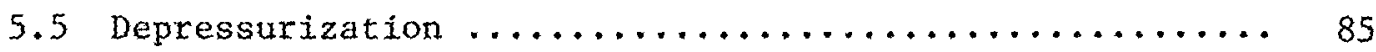

5.6 Refilling the Source Tank .................. 85

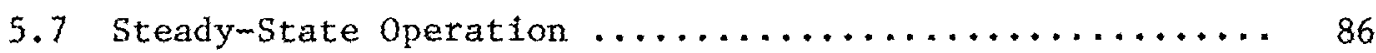

5.8 Sodium Cold Trapplng $\ldots \ldots \ldots \ldots \ldots \ldots \ldots \ldots \ldots \ldots \ldots \ldots$

5.9 Sodium Sampler $\ldots \ldots \ldots \ldots \ldots \ldots \ldots \ldots \ldots \ldots \ldots \ldots \ldots$

5.10 Sodium System Drain ...................... 89

5.10 .1 Normal drain .......................... 89

5.10 .2 Automatic fast drain (scram) .............. 90

5.10 .3 Manual fast drain .................... 91

6. CASUALTY EVENTS AND RECOVERY PROCEDURES .............. 92

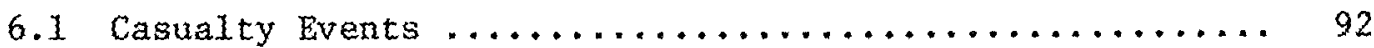

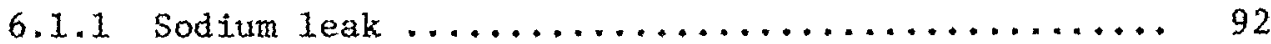


6.1 .2 Sodium fire $\ldots \ldots \ldots \ldots \ldots \ldots \ldots \ldots \ldots \ldots \ldots, 93$

6.1 .3 High sodium pressure $\ldots \ldots \ldots \ldots \ldots \ldots \ldots \ldots . .69 .69$

6.1 .4 High sodium temperature $\ldots \ldots \ldots \ldots \ldots \ldots \ldots \ldots .96 .96$

6.1 .5 Loss of control electrical power ............ 93

6.2 Design Features to Mitigate Effects of Casualty

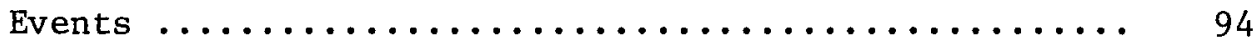

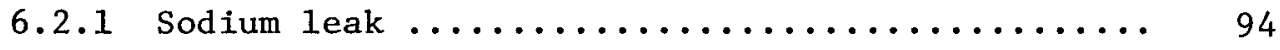

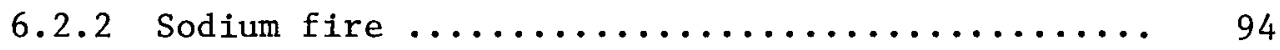

6.2.3 High sodium pressure $\ldots \ldots \ldots \ldots \ldots \ldots \ldots \ldots . \quad 95$

6.2 .4 High sodium temperature $\ldots \ldots \ldots \ldots \ldots \ldots \ldots \ldots .96 .96$

6.2 .5 Loss of control electrical power ........... 96

6.3 Recovery Procedures ........................ 97

6.3 .1 Sodium leak and fire $\ldots \ldots \ldots \ldots \ldots \ldots \ldots \ldots . .6 \%$

6.3 .2 High sodium pressure $\ldots \ldots \ldots \ldots \ldots \ldots \ldots \ldots . .69$

6.3.3 High sodium temperature $\ldots \ldots \ldots \ldots \ldots \ldots \ldots \ldots . .69 . \ldots$

6.3.4 Loss of control electrical power ........... 99

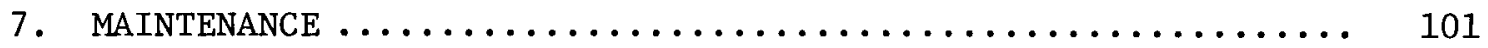

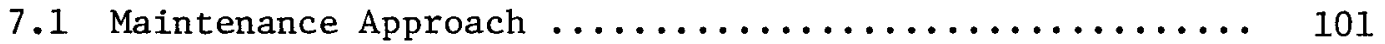

7.2 Corrective Maintenance ...................... 101

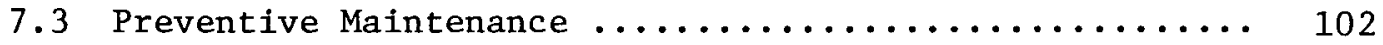

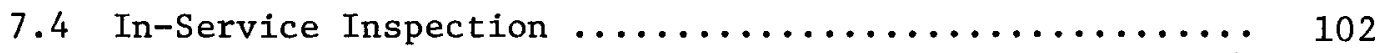

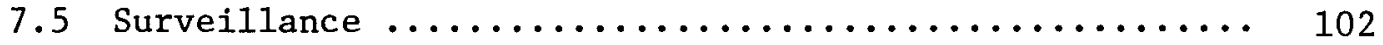

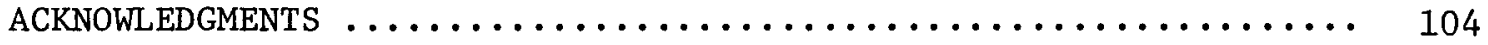

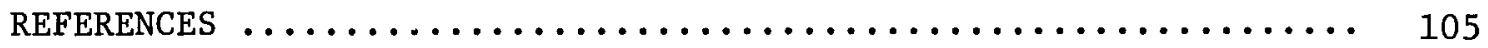

Appendix A. CALCULATIONS OF PIPE NEST GRADIENTS $\ldots \ldots \ldots \ldots \ldots . . .109$

Appendix B. COMPLETE LIST OF MECHANICAL DRAWINGS ........... 117

Appendix C. LIST OF INSTRUMENTATION AND CONTROL DRAWINGS ...... 121

Appendix D. LIST OF ELECTRICAL DRAWINGS $\ldots \ldots \ldots \ldots \ldots \ldots \ldots \ldots, 131$

Appendix E. ENGINEERING DATA FOR COLD TRAP AND SAMPLING

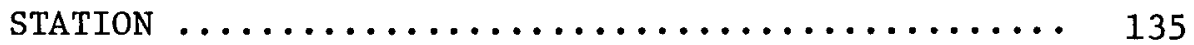

Appendix F. MEMORANDA ON MOMENTARY OVERPRESSURE CAPABILITY OF

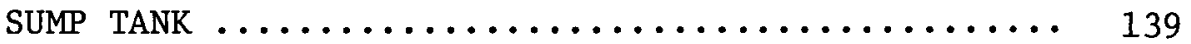

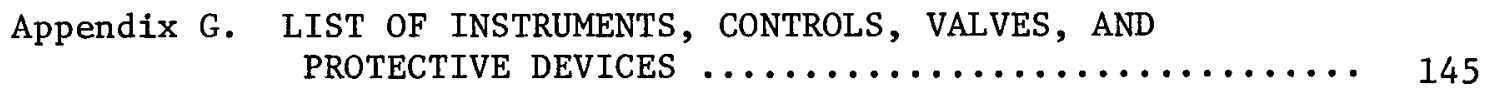

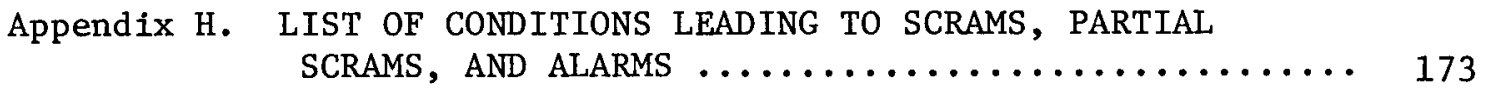


Appendix I. INSTRUMENTATION AND CONTROLS: SET POINTS ....... 177

Appendix $\mathrm{K}$. REFTLLING SOURCE TANK BY EVACUATION METHOD ....... 189

Appendix $l$. TNDEPENDENT REVTEW OF IMPORTANT THERMAL AND STRESS 
SYSTEMS DESIGN DESCRIPTION OF THE

THERMAL TRANSIENT TEST FACILITY (TTTF)

H. C. Young A. G. Grindell

ABSTRACT

The Thermal Transient Test Facility (TTTF) is a hightemperature, high-pressure sodium test facility designed to subject test specimens to internal pressure and intermittent thermal downshocks to produce thermal ratchetting. The facility was built as a part of the ORNL High-Temperature Structural Design Methods for Liquid-Metal Fast Breeder Reactor (LMFBR) Components (189a No. 10556) program. The purpose of the program is to develop a verified design technology, including methods and criteria, applicable to the high-temperature, long-term operating conditions expected for LMFBR vessels, components, and core structures.

In the TTTF, a test specimen is filled with static sodium at pressures to $700 \mathrm{psig}$ and at temperatures to $1100^{\circ} \mathrm{F}$ and subjected to a thermal downshock at temperature rates to $30^{\circ} \mathrm{F} / \mathrm{sec}$ by forcing colder temperature-graded sodium through the test section while maintaining the test section at pressure. The high-pressure portion of the system contains approximately 250 gal of sodium; when the system is drained, the low-pressure sump tank contains approximately 750 gal of sodium.

Strain rates are measured on the test section by hightemperature capacitance-type strain gages. A fast-scan dataacquisition system is used to record pertinent test measurements on magnetic tape for computer processing. The facility is equipped with automatic control and alarm equipment to permit unattended operation.

This report presents the design description of the various systems that make up the TTTF: the sodium system, the highand low-pressure argon systems, the sodium purification svstem, the test section, the electrical system, and the instrumentation and control systems.

Key words: sodium, test facility, LMFBR, strain, ratchetting, thermal downshock, valves, unattended operation, electrical heaters, systems design description. 


\section{SUMMARY}

The Erequent thermal transients that can occur in IMmb gystems create a unique high-temperature structural design problem. Owing to the good heat transfer charactoristics of the sodjum coolant, reactor power changes, particularly during shutdows and scrams, can cause rapid tomm perature drops throughout the coolant system. Thuse intermitient themal dowshocks can, in turn, produce progressive incremental inelastic detormations (ratchetting) and significant creepufatigue damage in the systam componmis. To evaluate these effects, the designer must have adequale analysis methods and design rukes. The purpose of the TwT is to provide vitally needed thermal ratchetring test data fon evalnaling inelastie structural analysis technicues used to predict ratcheting in piping and other HWEBR components and also for evaluating losign rules intended to prevent, or limit, ratchelting.

The spectmens initially being tested in the jurp are straight lengths of 8-in.-diam pipe subjected to internal pressure and hroughmthemall themal histories that are protolypils of or mote severa than, those expected undor IMFan conditions. A seris's of these tests is planned; type 304 stainless steel specimens wilk be tested first, followed by specimens of type 316 staloless ateel, $21 / 4 \mathrm{Cr}-1$ Mo steeks, and other materials of interest. Each spectmen will be subjectcd to one of a variety of loading histories to examine kay conditions from the overall viewpoint.

The initial specinens will be from a well-characterized reference RDT standard keat of type 304 stainless steel (beat 912796) that is being used throughout the onN. high-temperature structural design methods program. The wall thickness of these specimens will be $0.375 \mathrm{in}$, which corresgonds to probable pipe wall thicknesses in the Fast Flux Test Facility (FFr), so that the thermal effects will bu slosely duplicated. The test facility is capable of subjecting these specimens to sodiun temperature downshocks 
up to a maximum rate of $30^{\circ} \mathrm{F} / \mathrm{sec}^{*}$ and internal pressure values up to 700 psi ${ }^{\dagger}$ at $1100^{\circ} \mathrm{F}$.

The first specimen tested in the facility was subjected to these severe maximum conditions. The temperature and pressure were normally maintained at $1100^{\circ} \mathrm{F}$ and $700 \mathrm{psi}$, respectively, but at 168-hr intervals, the specimen was subjected to a thermal downshock to $800^{\circ} \mathrm{F}$ at the nominal rate of $30^{\circ} \mathrm{F} / \mathrm{sec}$. At $800^{\circ} \mathrm{F}$, the internal pressure was removed and reapplied, and the temperature was slowly returned to $1100^{\circ} \mathrm{F}$ at a rate of $50^{\circ} \mathrm{F} / \mathrm{hr}$. The specimen was then held at $1100^{\circ} \mathrm{F}$ and subjected to the internal pressure of 700 psi for $160 \mathrm{hr}$ before the next transient was initiated. Fourteen cycles of this type were imposed on the specimen, giving a total specimen test time of $2352 \mathrm{hr}$. Subsequent tests will be performed under less severe, more realistic test conditions.

Particular attention has been given to the absolute necessity of obtaining accurate and reliable temperature, strain, and dimensional change data as a function of time throughout each test. Provisions are made for recording temperatures in the sodium as well as temperature responses through the specimen wall thickness during both the short-time thermal transient portions of the tests and the periods of steady-state, or creep, operation. The primary strain-measuring devices used in the tests are Boeing high-temperature capacitive strain gages mounted circumferentially and axially on the outer surfaces of the test sections. To assure that meaningful data are being obtained and to evaluate other potential hightemperature strain-measuring devices, the capacitive gages are backed up by a number of other devices. These will vary from test to test, but on the first specimen they included Ailtech (Microdot) weldable resistance strain gages, strain-gage-based air-cooled extensometers, mechanical extensometers with remote monitoring, special Prewitt scratch gages, and several pairs of gage tabs for gross "before and after" strain measurements

*The $30^{\circ} \mathrm{F} / \mathrm{sec}$ value is considerably larger than the maximum downshock rates expected in actual LMFBR components.

${ }^{\dagger}$ An internal pressure of $700 \mathrm{psi}$ at $1100^{\circ} \mathrm{F}$ will produce about $77 \%$ of the maximum allowable design stress intensity (Ref. 1) in the 8-in.diam, $0.375-i n .-w a 11$ type 304 stainless steel specimens at $1100^{\circ} \mathrm{F}$. 
with Demec mechanical extensometers at room temperature. Wost of these backup devices were developmental and were expected, at best, to provide only confirmatory data during certain segments of each cycle. The capacitive gages, on the other hand, were expected to provide, and did provide, a continuous history of strain data throughout the rest.

This report describes in detail the functions and operational requirem ments of the TTTF and the design, operation, and maintenance of the fadility. Specific descriptions of individual tests and the associated test specimen instrumentation will be given in the test programs written for each test. In adoition, the test results for each specimen and an evaluation of the instrumentation used on that particular specimen will be given in a topical report witten for each test. 


\section{FUNCTIONS AND REQUIREMENTS}

\subsection{Functions}

The prime function of the facility is to provide sodium, whose purity is controlled by the cold trapping system, to an installed test section at the various temperature and pressure conditions specified in approved test programs. Figure 2.1 presents the pressure and temperature conditions for

ORNL DWG $74-7444$
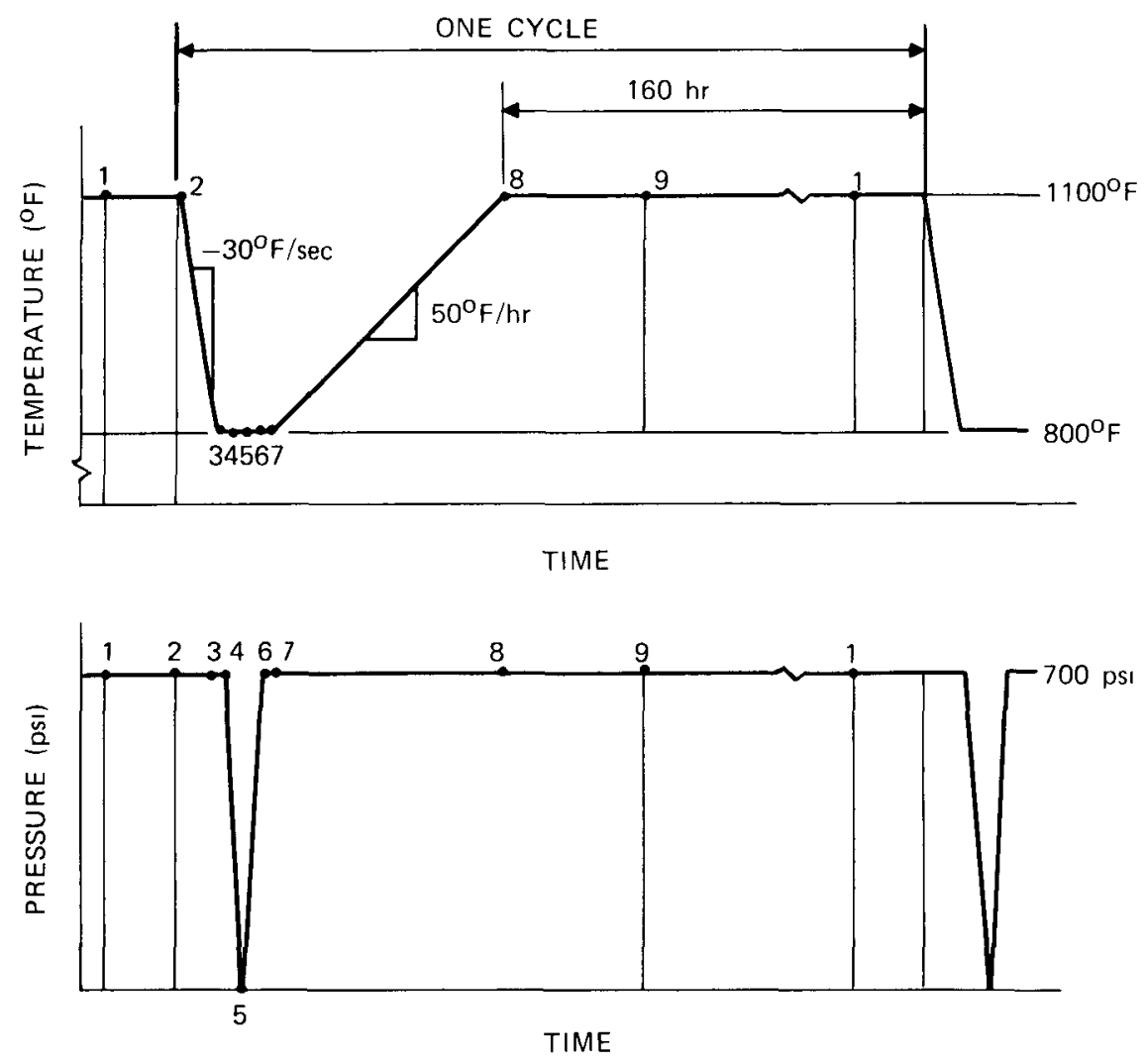

POINT DESCRIPTION

$1 \sim$ ONE DAY BEFORE THERMAL TRANSIENT

2 BEGINNING OF THERMAL TRANSIENT

3 SPECIMEN REACHES UNIFORM $800^{\circ} \mathrm{F}$

4 BEGINNING OF PRESSURE REMOVAL

5 ZERO PRESSURE

6700 PSI PRESSURE RESTORED

7 BEGINNING OF $50^{\circ} \mathrm{F} / \mathrm{hr}$ TEMPERATURE INCREASE

8 BEGINNING OF STEADY-STATE OPERATION

9 AFTER $48 \mathrm{hr}$ OF STEADY-STATE OPERATION

Fig. 2.1. Typical ratchetting test cycle for test section in the LMFBR Thermal Transient Test Facility. 
the fixst tests performed in the facility. These conditions are typical and imply the need for steadyustate operation at elevated temperature and high pressure wth themal downshock carability. Depressurization is necessary to permit returning the sodium used during the thermal transient to the source tank.

Wigh-speed data-acquisition systems are provided, particularly tor the thexmal transient operation; conventional instrumentation is used to acquire data during steady state (creep) operation.

The walls of the facility provide protection for personel and propexty against both sodium fires and highmvelocity jets of high-temperature sodium. The Facility structure and contatment and the sodium aystem are designed to readily facilitate the installation of parallel sodium system components to permit the simultaneous operation of two test sections. The source tank, pipe nest, and sump tank would be comon to both test sextions; botever, each test section would require its own orffice run, thermal capacitance tank, and sodium shutoff valve.

The design of the controls and instrumentation provides for both attended operation of the facility and unattended opexation undex steadystate conditions.

\subsection{Operational Requirements}

The test facility is capable of providing solium to the test section at the temperature and pressure conditions required by the test program; the conditions for a typical test cycle are presented in Fig. 2.1. During steady-state (cresp) operation, the sodium temperature and pressure are maintained at $1100^{\circ} \mathrm{F}$ and $700 \mathrm{psi}$ respectively. A themal downshock from 1100 to $800^{\circ} \mathrm{F}$ at a rate of $30^{\circ} \mathrm{F} / \mathrm{sec}$ was selected for the initial test. A heating rate of $50^{\circ} \mathrm{F} / \mathrm{hr}$ was chosen to prevent differential thermal expansion effects. Lowex levels of both membrane stress and rate of thermal downhock can be obtained by decreasing the argon pressure in the source tank appropsiately and for changing the size of flow-control orifices.

The maximum temperature, pressure, stress, and themal downshock rate are all much more severe than those currently expected for the FFTf. The $30^{\circ}$ isec value was an early design number quoted for both the FFrs and the 
SPTF at the Liquid Metals Engineering Center. More recent maximum downshock rates of approximately $12^{\circ} \mathrm{F} / \mathrm{sec}$ have been predicted for the FFTF under the most drastic emergency conditions. The above severe conditions were selected for the first test to bound the magnitude of the ratchetting problem. In addition, the larger ratchetting strains provide more likelihood of success in measuring the strains as well as experience with the high-temperature strain-measuring devices.

The utilization of an available sump tank having low pressure capability requires that the sodium system be depressurized to replenish the source tank with sodium after a thermal transient. Thus the membrane stress is removed from the test section for a very short time period during each test cycle. A batch recharge tank to replenish the source tank without depressurizing the test section may be installed in the future.

A11 procedures required to set the various sodium temperature and pressure conditions are written in step-by-step and check-list forms and are performed by the project leader and the assigned engineering technician. When steady-state conditions are obtained, the system can be operated continuously in the unattended mode. In this mode, the loss of sodium or smoke from a sodium fire will depressurize the system, drain the sodium into the sump tank, turn off all electrical heater power, turn on the argon fire-suppression system and the building ventilation $\mathrm{fans}$, and alarm the Y-12 Plant* Shift Superintendent (PSS). The PSS, in turn, notifies the project leader or other assigned personnel of the situation so that they can return the facility to a safe condition. In addition, when certain sodium temperature and pressure signals are outside prescribed limits, an alarm will alert the PSS to bring assigned personnel to the facility to investigate and rectify the condition.

\subsection{Structural Requirements}

The sump tank, which was constructed of 304L stainless steel for use in another project, has only low pressure capability. The oxide-removal cold trap system is constructed of Inconel. The remainder of the sodium

*The TTTF is located in Building 9201-3 in the Y-12 Plant area. 
corponanes, rusexpa to as the sodium system, axe constructed of 304 atainless steel axopt for the pipe nest, source tank, and sodium shutorf valve, which are constructed of 316 stainlesg steel. The intital test section was mancactured from a referance heat of 304 stainfoss stael, 9T2796. A11 the materials meet the ASME requirements ot $0.04 \%$ minimum carbon and $1900^{\circ}$ ameal and fast quench for b-grade austemitic atainless steel.

The design and opcrating temperatures and prossines for the highand lownresare portions of the aodium systam and for the cold trap system are presented in Table 2.1.

Table 2.1. Design and operating conditions for the rwT

\begin{tabular}{|c|c|c|c|c|}
\hline & \multicolumn{2}{|c|}{ Design } & \multicolumn{2}{|c|}{ Operating } \\
\hline & $\begin{array}{c}\text { Temperature } \\
\left({ }^{\circ} \mathrm{E}\right)\end{array}$ & $\begin{array}{c}\text { Pressure } \\
\text { (psig) }\end{array}$ & $\begin{array}{c}\text { Temperature } \\
\left({ }^{\circ}\right)\end{array}$ & $\begin{array}{c}\text { Pressure } \\
\text { (psig) }\end{array}$ \\
\hline High-pressuro portion & 1100 & 800 & 3100 & $700( \pm 25)$ \\
\hline Grspipressure portion & 800 & 15 & 800 & 10 \\
\hline Cold trap sysen & 800 & 42 & 800 & 10 \\
\hline
\end{tabular}

\subsection{Configuration}

The configuration is gexerally that show in Pig. 2.2. The height of the facility was chosen so as to maximize the slope of the piping in the pipe nest and to clear an overhead traveling bridge crane that is very useful in both facility construction and test section installation.

The pipe nest comecting the sturage tank to the test rection con sists of a serpentine run of pipe in two paralel vertical planes. The lowest part of the ripe nest torms a solium trap, from which an independont dratn line is connoced to the sump tank through a shutofe valve. 


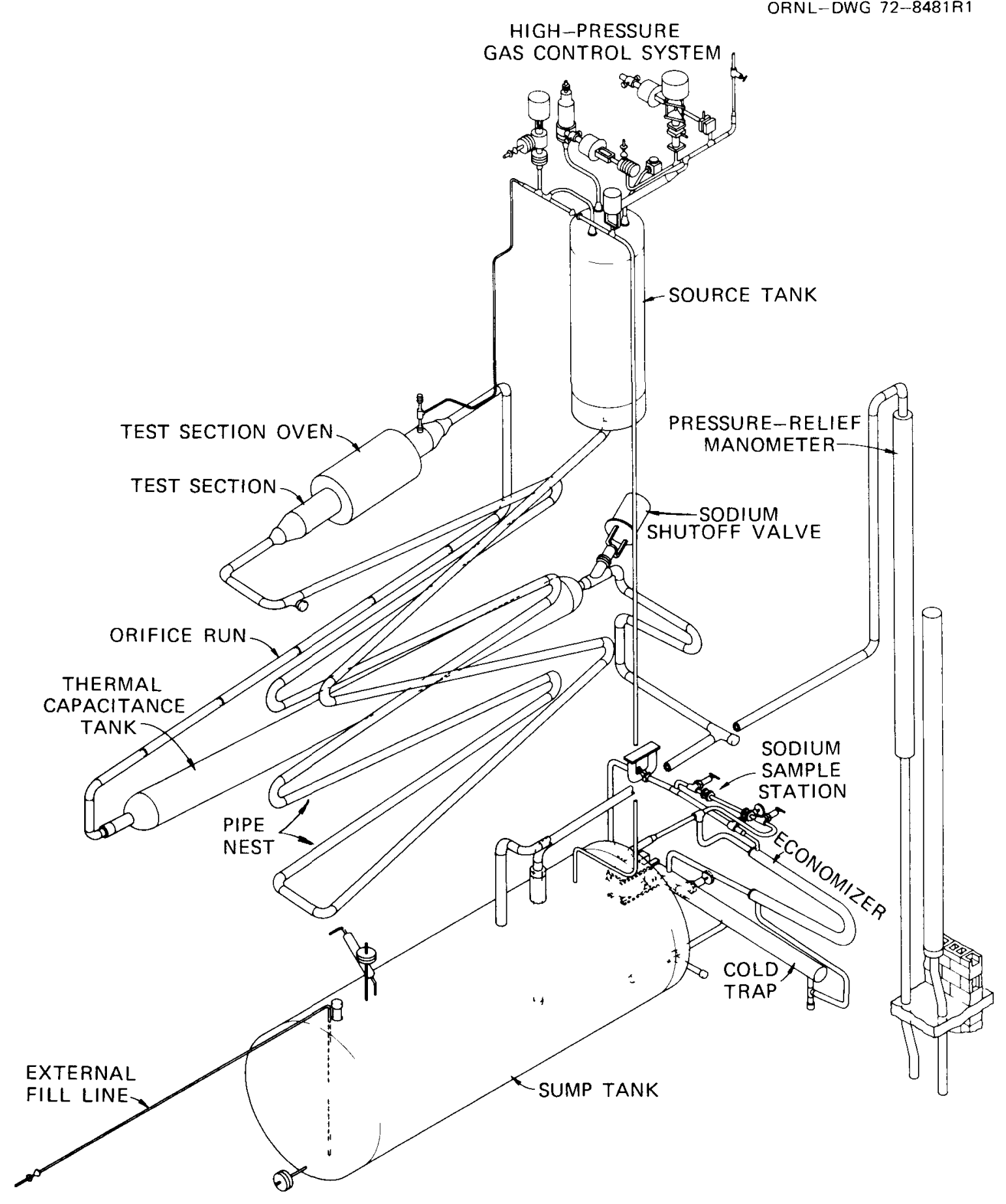

Fig. 2.2. Schematic of the sodium system of the LMFBR Thermal Transient Test Facility, showing arrangement of the principal sodium system components and connecting piping. 
The slope of pipe in the nest is a compromse between the vertical orienm tation that permits the most stable storage of temperature-graded sodium and the maximum slope available within the crane height limitation mentioned above.

The configuration of the sodium system components is designed for ather no flow or batch flow of sodium through the test section. Steadystate operation of the facility is characterized by the no-flow node and thermal transient operation by the batch-flow mode.

For steady-state operation the system is filled with sodium, the shutoff valve is closed, and the source tank is pressurized as required with axgon. After the temperature of the sodium in the pipe nest is appropriately adjusted, the thermal transient is initiated by opening the shutoff valve to permit the system sodium to flow muber the presane potential existing between the source and the sump tanks. The orifices in the orifice run have sufficient resistance to regulate sodium flow to the proper value for the transient. The sodium flow is stopped by closing the shutoff valve when the tast section temperatures approach the lower transient limit. The sodizm discharged to the sump tank during the transient is teturned to the source tank before injtiating steaby-state oparation of the rest sycle.

The key component in the sodtum system, the sodium shutoff valve, is the only one requiring mechanical motion of an interal part. The closed valve must be sufficiently leak thght to retain an inventory of sodium in the source tank that is adequate for the themal transient even at the end of the relatively long steady-state portion of the test cycle.

The harge, heavy controt and relief yalves in the high-pressure argon system located on top of the source tank are supported so as to accomodate the thermal expansion assoctatad with high-temperature operation of the tacility and also the thrust forces caused by the highvelocity gas jet that accompanies venting aring an emergency drain.

The piping and components are supported with haners and vibzation dampers to minimize the effects on the rest section of the forces and moments caused by therazl expansion and also the vibxation induced by the flow of the sodum during the themal trassiant. 
The containment of the high-pressure portion of the facility consists of heavy steel plates welded and bolted to the structural steel so as to protect both personnel and adjacent equipment from the effects of pipe whip and jetting sodium associated with a rupture in the sodium system. There are no line-of-sight openings in the containment despite the many penetrations made in it to accommodate the instrument, control, and electrical leads and gas lines. To protect the instrumentation leads, the ambient temperature within the containment is maintained at less than $150^{\circ} \mathrm{F}$ by the thermal convection of room air through the enclosure. The smoke detectors for the automatic emergency drain are placed in the exhaust of this air flow.

As mentioned previously, the configuration is designed to permit, with little disruption of the present sodium system, the installation of a second parallel sodium system for simultaneous operation of two test sections.

\subsection{Maintenance}

The test facility enclosure is designed with adequate access and clearance to permit maintenance of the sodium system. It is located in a high-bay area and within the working reach of a 20-ton traveling bridge crane. Several of the heavy shield plates are hinged and latched to permit convenient access for routine maintenance without the need for craft services to unbolt and hoist the plates. Steps, walkways, and ladders provide access to facility platforms at three different elevations.

Spare trim is kept on hand for the gas control and vent valves, and a spare sodium shutoff valve is available. Temperature and pressure recorders and controllers are recalibrated on a routine schedule. The functioning of the automatic controls is checked during facility downtime, and major maintenance is scheduled during the downtime associated with changing test sections. This maintenance is performed by properly supervised and experienced craftsmen, wearing prescribed safety clothing and working to written procedures, prepared as required. 


\subsection{Instrumentation and Controls}

The installed instrumentation and controls are adequate for the operation of the facility in both the attended and the unattended modes and for the protection of the facility in the event of a sodium leak, loss of control electrical power, or failure of the electrical heater power or the high pressure gas systems.

The temperature of the test section is maintained at $1100 \pm 5^{\circ} \mathrm{F}$ during steady-state operation with an electrically heated oven regulated with an automatic temperature control system. The argon pressure in the source tank that acts through the sodiun to supply the test section membrane stress is controlled automatically to $700 \div 5$ psig during steady-state operation and to $700+25$ psig during thermal transients. The sodium system is protected against the simultaneous failure of both the supply and vent valves in the high-pressure argon system by the operation of an appropriate pressure--elief valve.

The temperature of all sodium system components, other than the test section, is controlled by monitoring appropriate thermocouples and manually adjusting autotxansformexs that control the voltage supplied to individual electrical trace heaters. The instrument air, the fire-suppression gas system, and the sump tank low pressure argon system are supplied through manually adjustable pressure regulators and isolation and throtting valves. A11 these systems are equipped with pressure-relief valves as necessary.

A push button station is provided in the control system for initiating the themal transient. After the required quantity of themal txansient sodium has flowed from the souxce tank, the operation of a switch in the liquid-level measuring system in the tank closes the shutaff valve to stop the transient.

During the themal transients a fast-scan datamacquisition system is used to record the level of sodium and the gas pressure in the source tank. the temperatures at various locations in the test section, and the output of electrical strain-measuring devices that are installed on the external surface of the test section. Several of these transient data measurements are also recorded on $X-Y$ plotters and Moseley recorders to provide backup 
records in the event of malfunction of the fast-scan system. For the initial thermal transients, fast-scan data were recorded on an available ANSCAN, * which is shared with another test facility.

During steady-state operation all the measurements necessary for the test program are recorded on the Dextir data-acquisition system, a relatively slow system that can scan about 8 data points per second. The Dextir is described briefly in Sect. 3.2.6. Facility operating data are read out on single-point and multipoint recorders and on multipoint indicators.

The instrumentation and controls are designed for both attended and unattended operation. During attended operation, they permit the operators to prepare the facility for a thermal transient, to subject it to a thermal transient, or to prepare it for steady-state operation. During unattended operation, they permit facility operation at steady-state conditions. Automatic systems are provided to protect the sodium system against sodium leaks and fires, loss of electrical control power, and malfunctions of the temperature and pressure control systems. These systems function automatically during both attended and unattended operation. However, during unattended operation these protective devices are monitored remotely by the Y-12 Plant Shift Superintendent (PSS), with prompt communication to the assigned responsible engineering and technician personnel (operating personne1), and during attended operation the monitoring is performed by the operating personnel.

The degree of the response of the individual protective system is commensurate with the need not only to protect the facility but also to protect the test section from the deleterious effects of spurious scrams. An automatic fast drain (scram) depressurizes the high-pressure argon in the sodium source tank, drains the sodium into the sump tank, and turns off all electrical heater power, and thus removes the membrane stress from the test section and imposes unwanted temperature excursions on it. Only sodium fire and leak signals are permitted to scram the sodium system, and to minimize spurious scrams from these signals their normal power supply is backed up with a guaranteed power system, an ac-to-dc inverter paralleled

\footnotetext{
*Analog Scanner, Beckman model 3700.
} 
with storage batteries supplying a dc-to-ac converter that is connected to the control power loads.

\subsection{Quality Assurance}

The quality assurance program plan used to guide the analytical studies, design, procurement, fabrication, and construction of the facility is presented in ORNL-CF-72-3-8, Quality Assurance Program Plan for the Thermal Transient Test Facility (EJN-10596). Very briefly, the facility was designed according to the rules of the ASME Boiler and Pressure Vessel Code, Section VIII, Division 1. Although the engineering drawings called for the sodium system materials to be produced to RDT standards, the exigency of the programmatic need for the facility required us to obtain these materials to the specifications of the ASME Boiler and Pressure Vessel Code, Section II, and to upgrade them in house to the significant quality provisions of the RDT standards. The inspection and test activities for the fabrication of the components and the construction of the facility met the requirements of the program plan. The operating and maintenance activities are being performed to the requirements of ROT Standard F2-2T.

The principal test facility components and associated quality level designations are listed in Table 2.2.

\subsection{Codes and Standards}

The design, fabrication, inspection, and testing of the sodium system were performed in accordance with quality level II, as defined in ORNL Quality Assurance Procedure QA Lm1-102, Guide for the selection of Quality Levels. The system was constructed of 304 and 316 stainless steel and was designed to meet the requirements of the ASME Boiler and Pressure Vessel Code, Section VIII, Division 1, and the Code for Pressure piping, ANS 1 USAS B31.1.

As noted in Sect. 2.2, the facility is designed for operating pressures up to $700 \mathrm{psi}$ at $1100^{\circ} \mathrm{F}$ and for a range of sodium temperature downshocks up to a maximum of $30^{\circ} \mathrm{F} / \mathrm{sec}$. Figure 2.2 shows the general layout 
Table 2.2. Quality leve1 designations for the TTTF

\begin{tabular}{ll}
\hline \multicolumn{1}{c}{ Component } & $\begin{array}{c}\text { Quality } \\
\text { level }\end{array}$ \\
\hline $\begin{array}{l}\text { High-pressure sodium source tank } \\
\text { Test section }\end{array}$ & II \\
Pipe nest for thermally graded sodium & II \\
Sodium flow control valve ${ }^{a}$ (sodium containment) & II \\
Thermal capacitance tank & II \\
High-pressure interconnecting pipe and fittings for & II \\
sodium & II \\
Cold trap and piping & II \\
Low-pressure sodium storage tank ${ }^{a}$ (existing) & II \\
High-pressure gas system piping and valves & III \\
High-pressure gas system control valves & III \\
Pressure-relief devices & III+ \\
Low-pressure gas system (existing in large measure) & III \\
Instrumentation for high-pressure gas & III \\
Strain measurement instrumentation & III \\
Preheaters & III \\
Preheater instrumentation and controls & III \\
Structure & IV \\
Shield and catch pan & IV \\
\hline
\end{tabular}

${ }^{a}$ Existing component qualified in previous liquid metal operation.

${ }^{b}$ Quality level III item upgraded by additional inspection, test, or examination. 
of the final facizity design, and Fig. 3.8 depicts the test section, which is replaced for each new ratchetring tast.

The design phllosophy for the Eacility was to limit the thermal down shock and, consequently, the resultant creep ratchetting and creep-fatigue damage to a small portion of the facility. In addition to the rest section, the following components axe subjected to the combination of hightamperature, pressure, and thermal shock conducive to creep ratchetting and cracpuratigue damage.

1. a saction of 2 1/2min., schedmlos, type 316 stainless steel pipe upm stream from the test section;

2. sections of $21 / 2-i n$. , sched-40, rypes 304 and 316 stainless steel pipe betwen the test section and the thermal capacitance tank and including the orifice run;

3. the inlet nozzle to the thermal capacitance tank. Consider fixst the $21 / 2-i n$. sched-10s plpe, whick has a wall thickness of only $0.120 \mathrm{in}$. Since the thermal stresses due to the sodium therm mal downshock are much less in this thin wall than in the 0.375-in. wall of the test specimen, the secondary stresses associated with the downshock axe small. Based on the thermal transient response charts given in kef. 2 , the 2 1/2 in. straight pipe easily meets the ratchetting criteria for Glastic analysis given in the ASME High Temperature Code Case 1331-8 (Eq. 13, paragraph 5.2b). 1 on the same basis, however, conditions in the 8-in. test section exceed the allowable limit by more than a factor of 2 . An elastic creepuratigue evaluation of the 2 1/2-in. sched-10s pipe indicates that the pipe could operate with an internal pressure of 700 psi and be subjected to a thermal downshock at $30^{\circ} \mathrm{F} / \mathrm{sec}$ once a week for more than 30 years.

Constdex next the $21 / 2 m i n$. schedm40 pipe sextions. These have wall thickneases of $0.203 \mathrm{kn}$, and consequently the secondary stresses are con siderably larger than those for the sched-los pipe. Since botb the type 304 and 316 stainless steel straight pipe sections exceed the elastic analysts xacheting criteria slightly, they were examined using the o'bounell -Porowskt method. ${ }^{3}$ In eack case, more than 30 years would be required to accumblate a strain of $1 \%$. An elastic creep-fatigue evaluation wats also performed for each section, and in each case the pipes could be 
subjected to $700 \mathrm{psi}$ internal pressure and $30^{\circ} \mathrm{F} / \mathrm{sec}$ thermal downshock once a week for 30 years with a usage factor much less than unity.

Fina11y, consider the inlet nozzle to the thermal capacitance tank (more fully described in Sect. 3.3.5). Since this is the only nozzle, outside of the test section, that experiences a thermal shock, it has received special design attention. First, the inlet nozzle operates normally at $800^{\circ} \mathrm{F}$ (below the creep range), and the thermal shock that it experiences is simply a brief, somewhat blunted thermal spike. Since the nozzle is downstream of the orifice run, the pressure is near zero (gage) during the spike; consequently, any structural problem with the nozzle is one of thermal stress fatigue without creep. To reduce the thermal stress in the nozzle, we have included a thermal sleeve in the design. This thermal sleeve and the final nozzle dimensions are the results of several design iterations based on approximate thermal and structural analyses.

A full two-dimensional thermal transient analysis ${ }^{4}$ and a detailed inelastic analysis ${ }^{5,6}$ were performed for the final nozzle configuration. The inelastic analysis showed that after the initial loading, the cyclic response of the inlet nozzle region is entirely elastic.

The test section itself must, of course, be subjected to the full set of thermal ratchetting conditions. On the basis of the type of analyses discussed above, conditions in the 8-in. test section exceed the allowable limit by more than a factor of 2. However, the entire test section (Fig. 3.8), including the inlet and outlet sections, will be raplaced after each test. It should be emphasized that, although the ratchetting limits (strain limits for inelastic analysis) ${ }^{l}$ may be slightly exceeded in the test section for some of the tests, we do not intend that these be failure tests nor do we expect failures in the test section.

The internal pressure of $700 \mathrm{psi}$ is over three times higher than the normal pressure in the FFTF piping system. The important quantities are the pressure-induced stress levels. For example, in both the 8-in. test section and the $21 / 2-i n$. facility piping, the radius-to-thickness ratio, which governs the membrane pressure stresses, is about half that of the 16- by 0.375-in.-wall FFTF piping. The resulting pressure stresses for the maximum pressure level of 700 psi are about 1.5 times the stresses in the FFTF piping. It should be emphasized, however, that these are still 
below those allowed by the code. Although all tests will not be run at 700 psi, the facility was designed so that the full range of allowable conditions could be examined.

In summary, precautions have been taken to limit the conditions imposed on the sacility to safe and acceptable levels, and the more severely strassed and strained regions kave received special design attantion. Nonetheless, the test sections themselves will be subjected to conditions that may exceed allowable limits, and it. must also be recognized that there is an alement of the unknow associated with thermal ratcheting and its effects. This, of course, is the rcason for undertaking the thermal transient tests. Therefore, the entire facility as well as the test procedures are being designed and planned to guard against the consequences of a structural failure.

The principal hazards arlse from a rupture of the sodium system and the consequent jetting of high-velocity, highmtemperature sodium, or the uncontrolled motion of the upstream end of a ruptured pipe or component due to the jet action of the leaking sodium. Our basic approach is to minimize the amount of stored energy in the high-pressure gas in the sodium source tank during steady-state operation and to conduct the thermal transient tests in an expedient manner with a minimum number of personnel. A shielded enclosure will be provided to contain any sodium jet spray, to resist any anticipated motion of the piping in the case of a doublemended rupture, and to protect personnel from contacting high-temperature equipment. Strain surveillance by means of mechanical gages and comparative measurements will be provided for the pipe nest outlet, the orifice run, and the entrance to the thermal capacitance tank. Measurements will be taken at the begining and end of every individual pipe thermal ratchetting test, and these will be evaluated before the following test is started. 


\section{DESIGN DESCRIPTION}

\subsection{Summary}

The facility is located in Building 9201-3 in the Y-12 Plant of the USAEC at Oak Ridge, Tennessee. It consists of a sodium system, a highpressure argon system, instrumentation and controls systems, dataacquisition systems, and appropriate electrical heating, low-pressure argon, and sodium oxide cold trapping systems. The components of the sodium system are supported on a heavy steel structure about $30 \mathrm{ft}$ high (Fig. 3.1), and the complete system is contained in an enclosure made of 1/16-, 1/4-, and 3/4-in.-thick steel plates, as appropriate, mounted onto the steel structure as shown in Fig. 3.2. Cabinets for the heating system instrumentation and controls are located on the east side of the facility, as shown in Fig. 3.2. The automatic controls for thermal transient operation and other temperature and pressure measuring and control devices are installed in cabinets located on the west side of the facility, as shown in Fig. 3.3. The facility is served by both a 20 -ton traveling bridge crane and the utilities installed in the building as appropriate.

\subsection{Detailed Systems Descriptions}

\subsubsection{Sodium system}

Figure 3.4, a schematic diagram of the sodium system showing the component arrangement, serves as a basis for discussing the principal operating modes of the facility. The low-pressure sump tank is at the lowest elevation, and the high-pressure high-temperature source tank is at the highest elevation. The system also contains the sodium shutoff valve close coupled to the thermal capacitance tank, the orifice run, the test section, and the pipe nest, which is several lengths of pipe connected with pipe bends of approximately $180^{\circ}$. In addition, there are the highpressure and auxiliary gas systems, the electrical pipe heater system, appropriate instrumentation and controls, data-acquisition systems, and support structure, splash and missile shielding, and catch pan. 


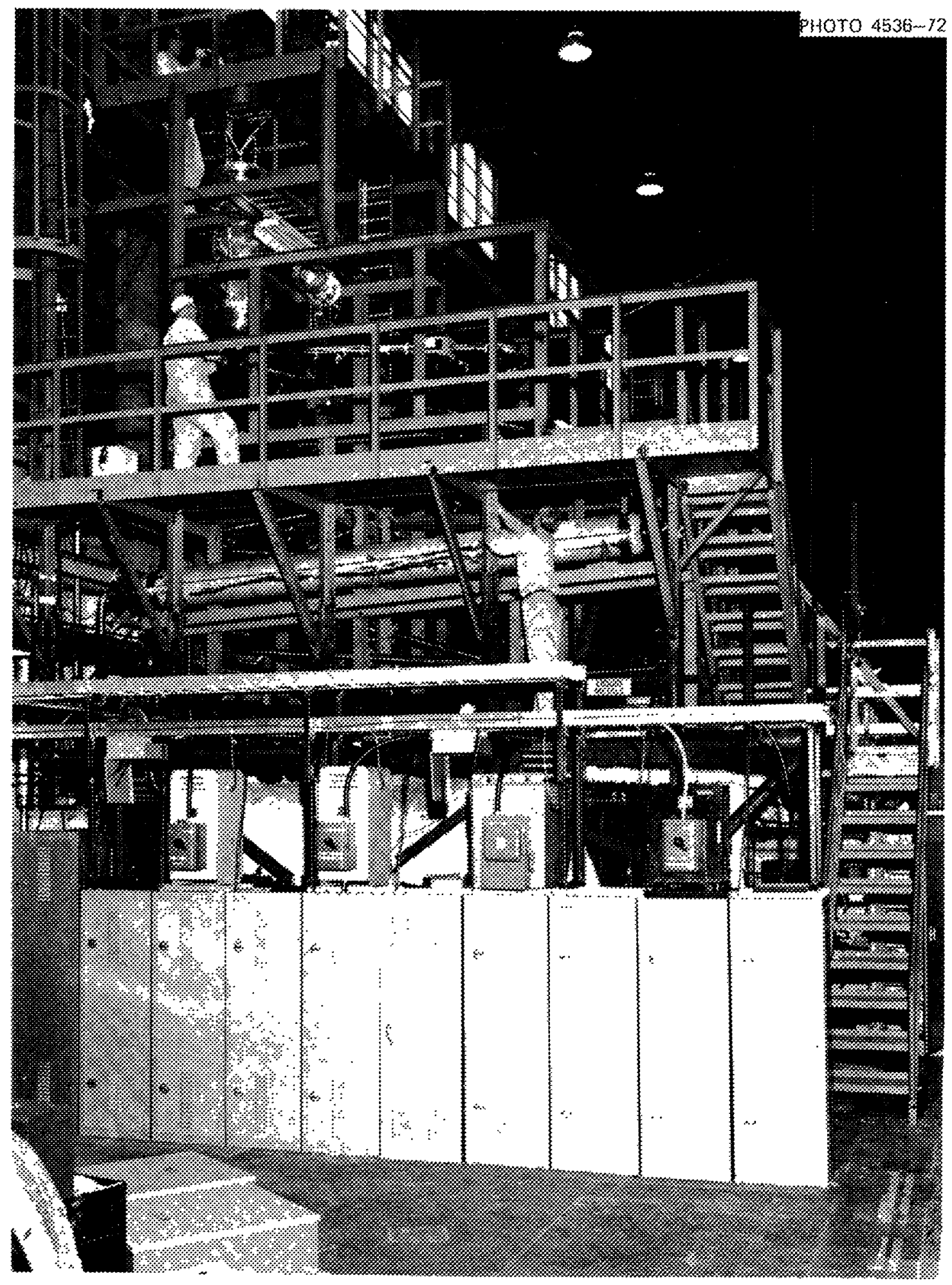

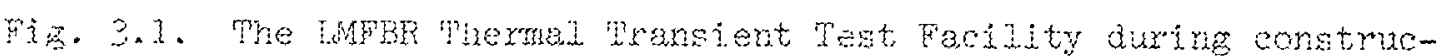

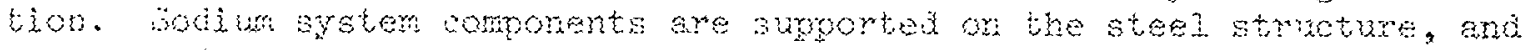

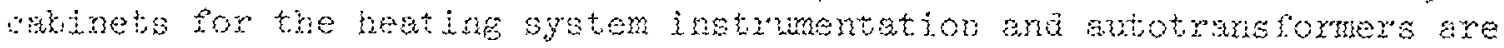
show mounted on the ploot in the tront of the photosraph. 


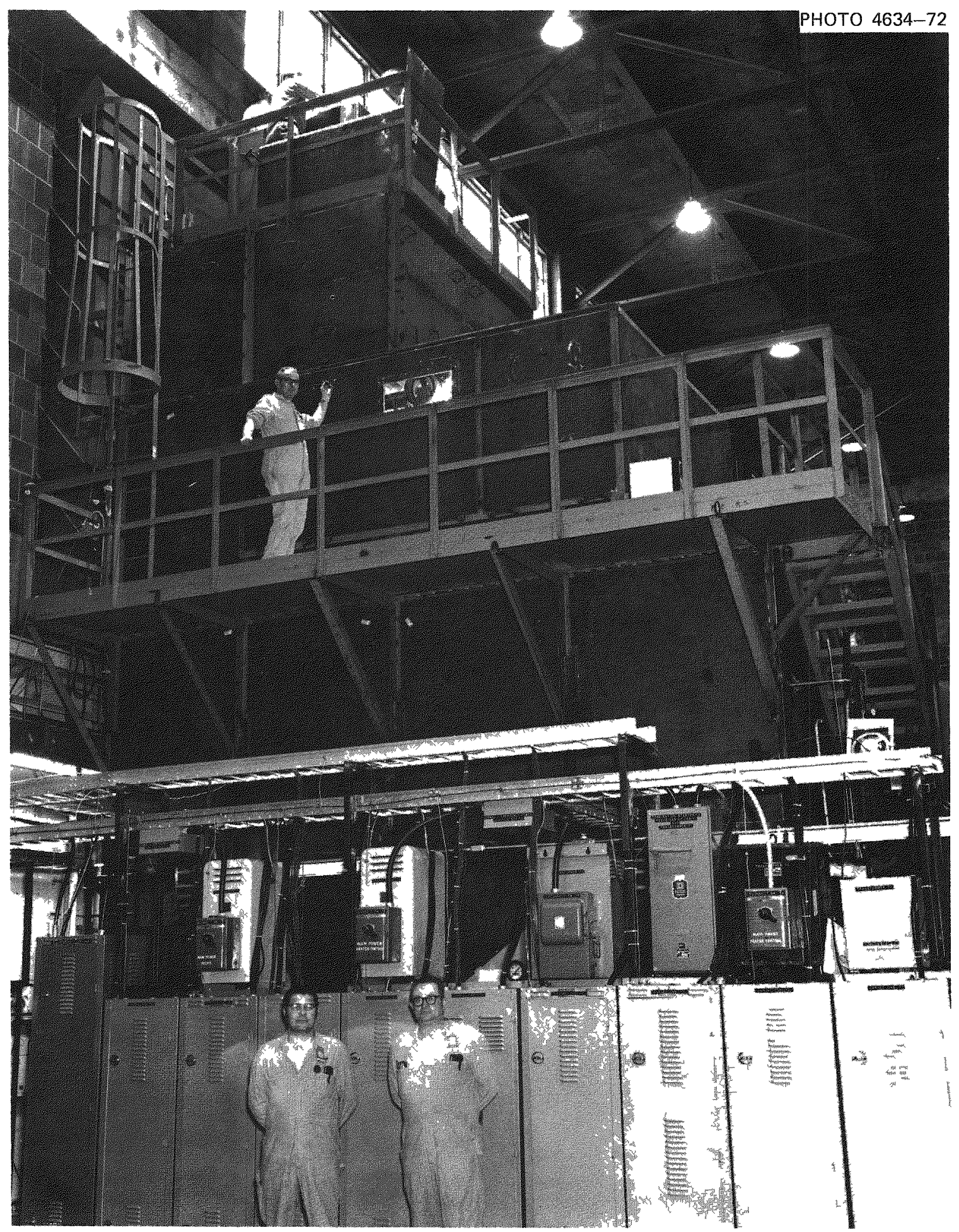

Fig. 3.2. The LMFBR Thermal Transient Test Facility just prior to operation. A later view of Fig. 3.1 showing the heavy steel containment plates installed. 


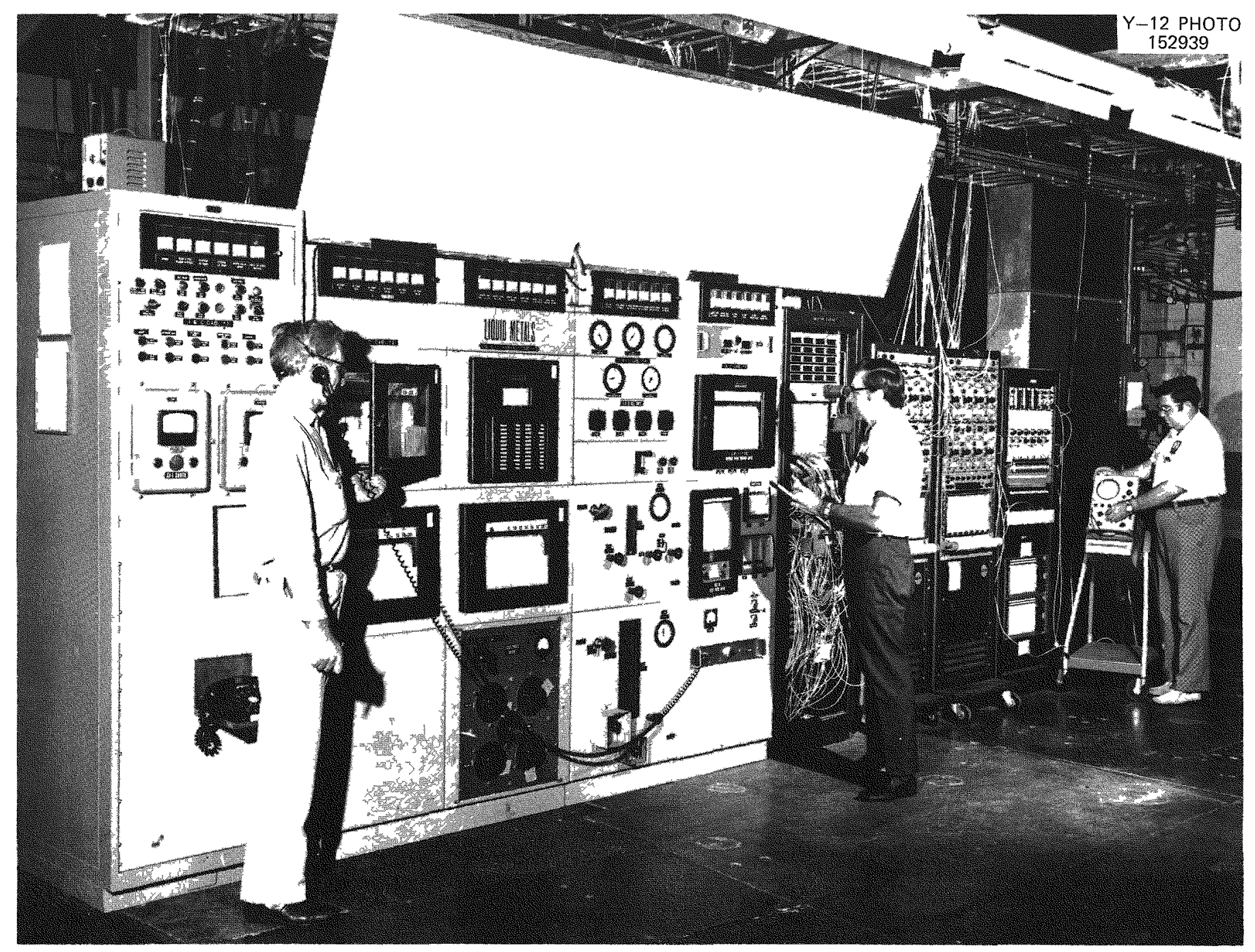

Fig. 3.3. The LMFBR Thermal Transient Test Facility, showing the control cabinets installed on the west side. 


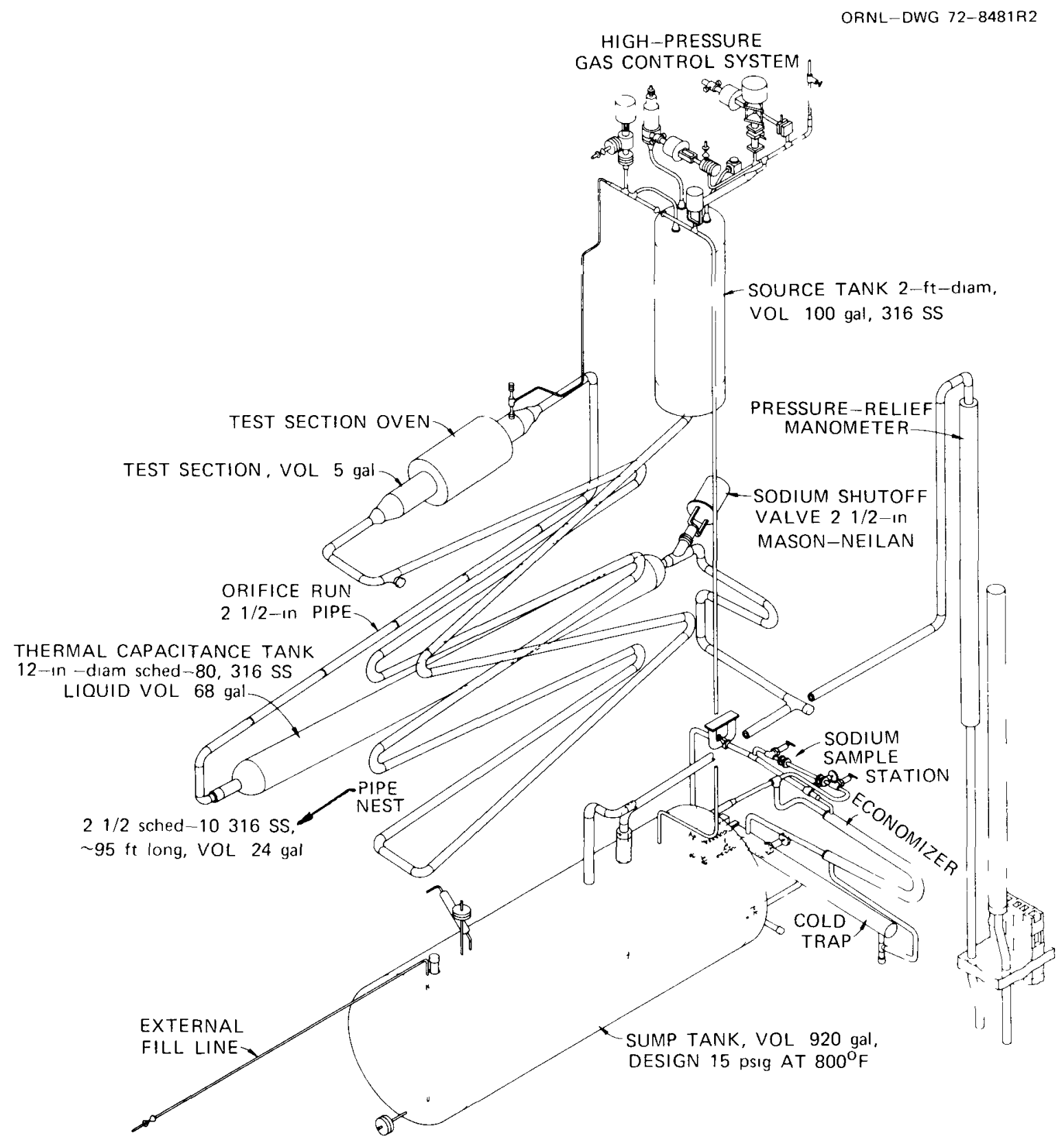

Fig. 3.4. Schematic of the sodium system of the Thermal Transient Test Facility, showing arrangement of the principal sodium system components and connecting piping.

The facility is equipped for filling and draining sodium and for steady-state and thermal transient operation. Sodium is transferred by gas pressure from the sump tank to fill the sodium system to an appropriate level in the sodium source tank. The system is drained mainly through the drain line past the sodium shutoff valve; the sodium that is trapped in 
the pipe nest and a small heel in the test section are draned independently through ladividual brain lines. During steakymstate operation, the sodium, which is pressuxized with argon gas in the source tank to produce the required mabrane strsss in the test section, is held in the system by the closed sodium shutoff valve.

Tn preparing for a thermal transient, the sodum in the pipa nest is temperature graded by urilizing temperature measurements taken from thermocouples attached along the length of the piping. Autotranstomers control the 40 individual hearer groups that supply the phe nest with heat. The automatic operatton of the transient is initiated by a push button, which opens the sodium shutoff valve. The sodium is accelerated to a flow rate of approximately $315 \mathrm{gpm}$ in less than $0.2 \mathrm{sec}$, and this flow continues for approximately 30 sec (three times the length of the thermal transient itself). When the temperature of the test section sodizm has leveled out at apgroxinately $800^{\circ} \mathrm{F}$, the sodium shutogk valve is closed automatically. After the transient is completed, the system pressure is reduced to transfer the sodium from the sump tank back into the sodium system to prepare for the naxt test cycle.

The fundamental precept in the erolution of the sodium syatem was the use of a pipe nest of temperaturemgraded sodium to impose a variety of thermal. transients on the test section. The operation of the facility has con fitmed the soundness of the pipe nest concep. The gradients used in the pipe nest to inpose a $30^{\circ} \mathrm{F} / \mathrm{sec}$ transient for 10 see on the first kest section were starting from the test section at 3100 " $\mathrm{F}$ and proceding through the pipe nest to the source tank at $800^{\circ}$, as sbow below, (The analytical model on wich the calculations are based is described in Apm pendix $\left.A_{0}\right)$

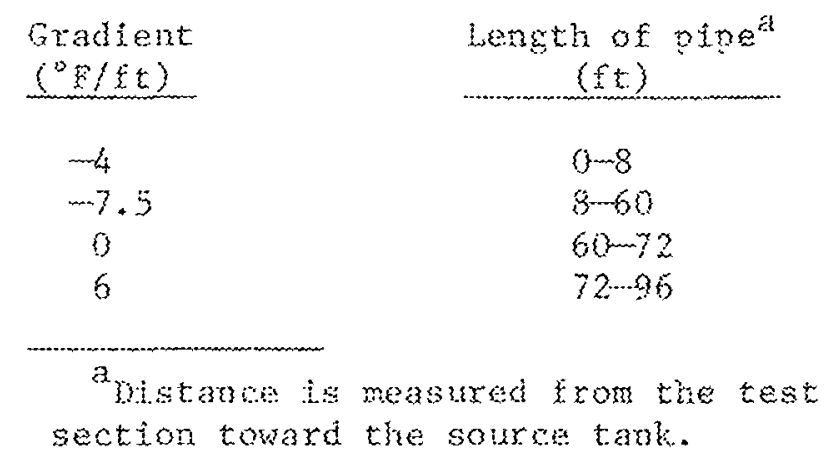


Test results show that the desired linearity of temperature vs time for the duration of the transient is achieved with the pipe nest method. A decrement of approximately $28^{\circ} \mathrm{F} / \mathrm{sec}$ was achieved and repeated consistently throughout operation with the first test section. Since the required gradient was $30^{\circ} \mathrm{F} / \mathrm{sec}$, it is evident that the analytical method used to predict the gradient is in error by about $7 \%$. This can be adjusted in future test operation by the use of different temperature gradients in the pipe nest.

Pipe tees were installed at the exit from the pipe nest and at the entrance to the sump tank to permit the addition of a second test section in parallel with the existing one. The source tank, pipe nest, and sump tank would be common to both test sections; however, each test section would require its own unique orifice run, thermal capacitance tank, and sodium shutoff valve.

\subsubsection{Argon systems}

There are four separate but interrelated argon systems (see Appendix C, Instrument Application Diagram, Sheet 1). These are (1) a highpressure argon supply that contains several bottles of argon specially analyzed for adherence to minimum impurity levels to maintain the source tank pressure at 700 psig during steady-state and thermal transient operations; (2) a high-pressure reference argon system that provides a standard pressure to which the source tank pressure is compared; (3) a low-pressure argon system used to provide an argon atmosphere in the sump tank and to provide argon purge to portions of the facility where air is to be excluded; and (4) a building argon supply that is designed to flood the catch pan with argon to smother burning sodium in the event of a sodium leak or fire.

The high-pressure argon supply system contains a bottle station in which as many as seven replaceable argon cylinders and one permanently installed accumulator cylinder can be manifolded together to supply argon to the source tank. Argon from the manifold is reduced to a nominal pressure of 740 psig by a large dome-loaded regulator, PV-6, before being introduced into the source tank through pressure control valves PCV-1A 
and PCV-1B. Another permanently installed accumulator cylinder is located on the outlet of regulator PV-6 to increase the gas volume between the control valves and the regulator and thus improve the stability of the pressure control system.

Also considered as part of the high-pressure argon system are pressure control valve PCV-1C; pressure safety valves PSV-3, PSV-4, PSV-10; and rupture disk XX-10. Their functions are described in Sect. 3.4.4.

An additional argon cylinder, labeled "Argon Reference Supply" on the Instrument Application Diagram, supplies argon to the reference side of differential-pressure transmitter PdT-1 and to the dome of PV-6 through pressure regulators $\mathrm{PV}-8$ and $\mathrm{PV}-5$ respectively. This separate argon cylinder is necessary because of the decrease in pressure in the high-pressure supply cylinders that occurs as the argon is used during a transient.

The low-pressure argon systems, which include a low-pressure supply consisting of three high-pressure cylinders with bottle regulators at a nominal pressure of 25 psig and a "building" argon supply at a pressure of nominally $60 \mathrm{psig}$, are described in detail in sect. 3.4.7.

\subsubsection{Electrical system}

Figure 3.5 is a schematic of the electrical power supply to the TTTF, and Fig. 3.6 shows the power distribution schematic at the test facility. The electrical power is normally supplied by the Tennessee Valley Authority (TVA), and during a loss of power, emergency portions of these loads are supplied by the building emergency power system. Control electrical power for instruments and controls that are considered necessary to facility safety and uninterrupted test program operation is supplied from the building inverter-battery power system.

The normal power requirement is supplied by TVA through a 40-MVA transformer to a $13.8-\mathrm{kV}$ bus and then through transformer $13 \mathrm{E}$ to bus duct $M$, which provides $460-\mathrm{V}, 3-$ phase, $60-\mathrm{Hz}$, delta-connected power to the facility. The emergency power is supplied with a diesel-engine-driven generator that supplies $360-\mathrm{kW}, 460-\mathrm{V}, 3-\mathrm{phase}, 60-\mathrm{Hz}$ electricity and is started automatically within $20 \mathrm{sec}$ after the $460-\mathrm{V}$ bus is deenergized. Emergency power is supplied to the electromagnetic pump in the cold trap 


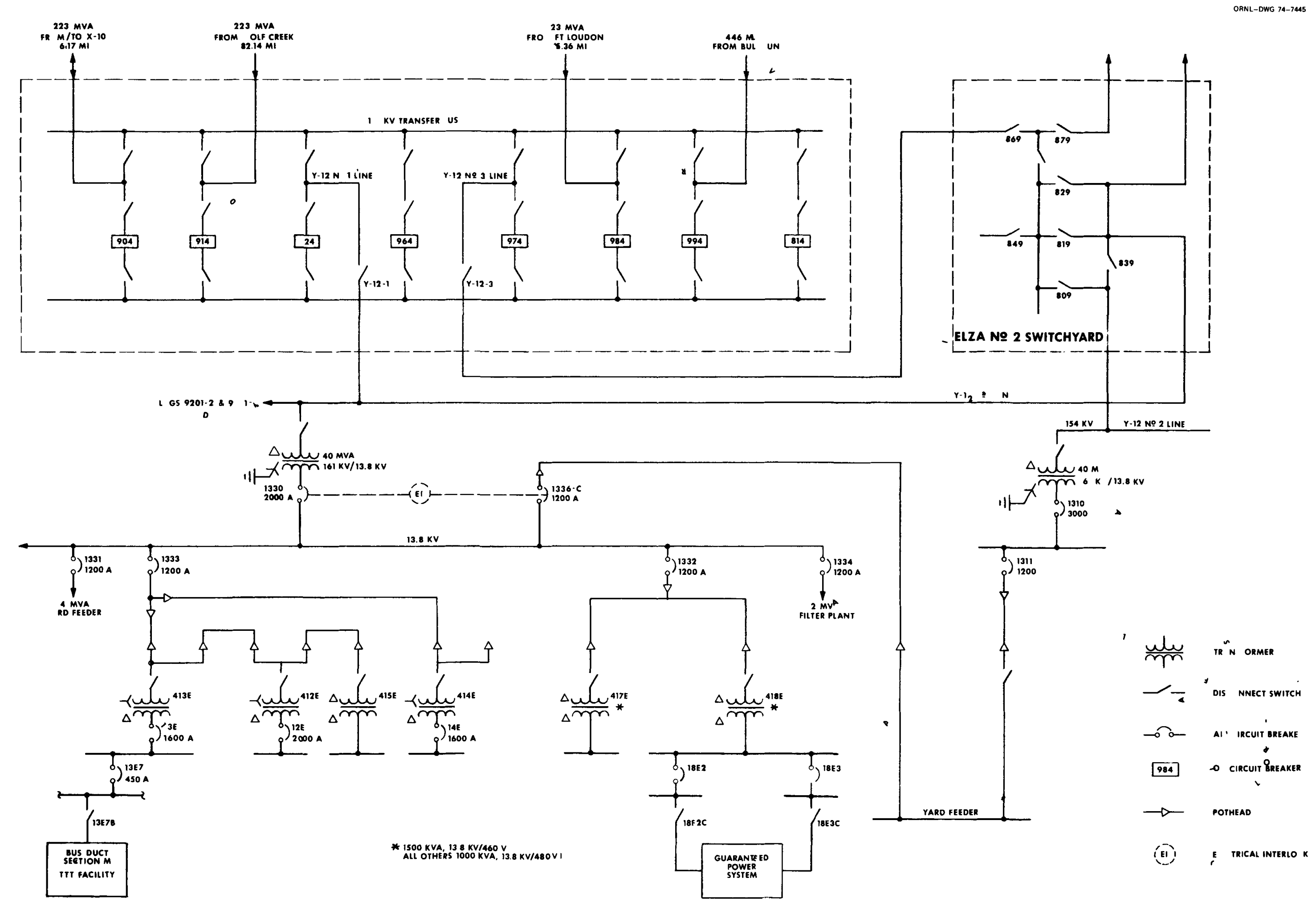

Fig. 3.5. Schematic diagram of the electrical power feed to the Thermal Transient Test Facility. 


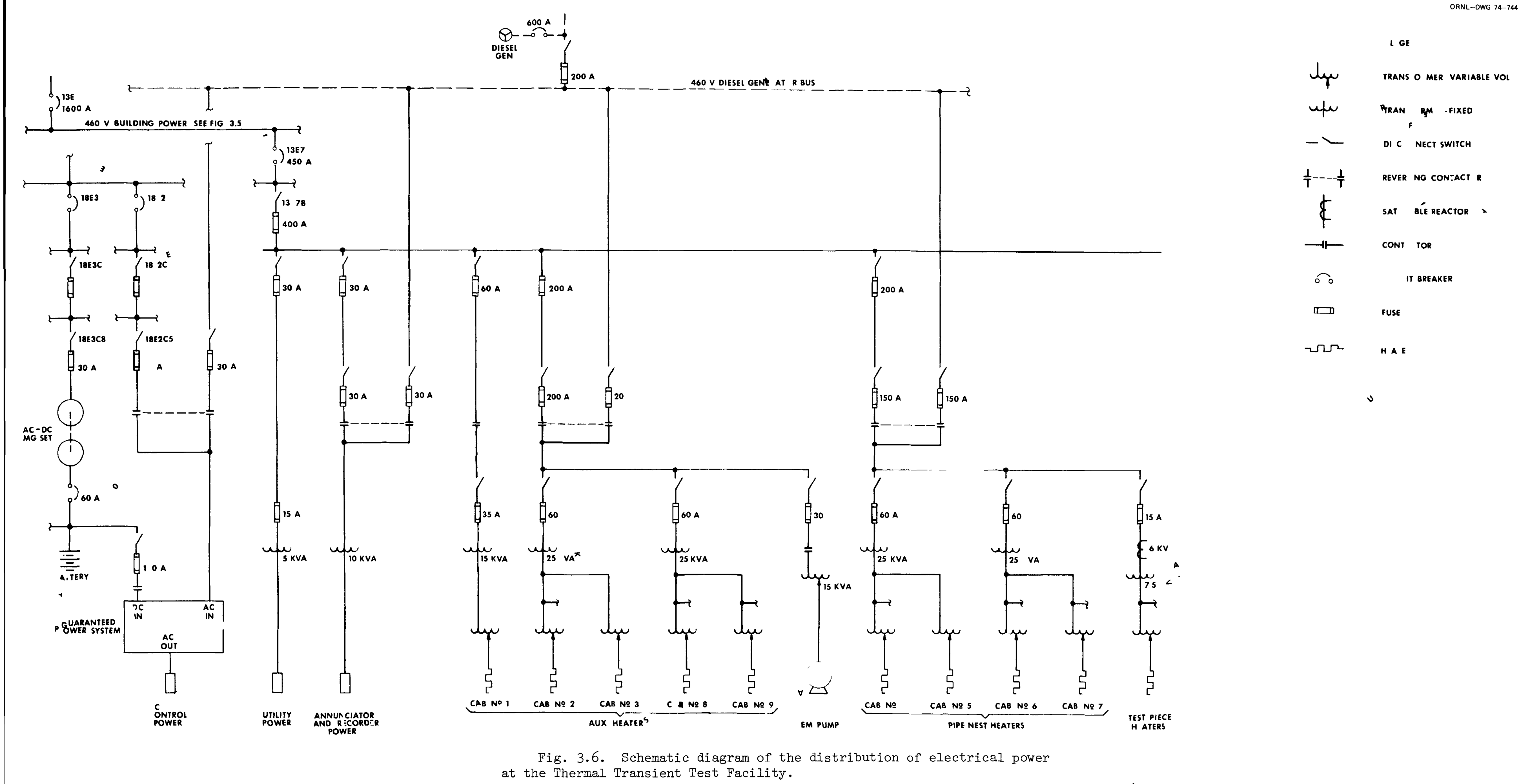


system, the heaters in the test section oven, and all the sodium system heaters except for the sump tank.

The inverter-battery power supply to the control electrical power consists of a solid-state noninterrupted ac output power unit with ac and dc input. Normal input is ac supplied from TVA. The ac input is transferred to the emergency power supply when the normal supply fails. The dc input is fed from the building emergency dc battery system and provides the system with a continuous power source during transfer or outage of the ac infuts. The inverter-battery power supply feeds only the control circuits and critical instruments. Annunciators and noncritical instruments are fed from the normal power source, with transfer to the emergency power supply when the normal supply fails.

All sodium system piping and instrumentation and components containing sodium or sodium vapor are traced with electrical heaters that are supplied through manually adjustable autotransformers and monitored with thermocouples. The test section oven heaters are controlled automatically at a preset temperature by a saturable reactor.

All heaters are tubular, rated $500 \mathrm{~W} / \mathrm{ft}, 230 \mathrm{~V}, 1500^{\circ} \mathrm{F}$ sheath temperature, and are connected to a maximum supply potential of $140 \mathrm{~V}$ per heater, which provides a convenient method for derating commercially available $230-\mathrm{V}$ heaters from 500 to $175 \mathrm{~W} / \mathrm{ft}$. Sufficient heaters are applied to heat the piping and components to $1100^{\circ} \mathrm{F}$. Reversing contactors that are used to transfer heater loads to the emergency power are also used to shut off the heaters when required by the control circuits.

Details for the installation of the heaters are presented in UCC Engineering Standard ES-2.1-1, Installation Specification, Ceramic and Tubular Heaters, and Heater Installation and Checkout Procedure QA-10596RB-008-S-0. All the electrical system drawings are listed in Appendix D.

\subsubsection{Cold trap and sodium sampling system}

The cold trap system, shown schematically in Fig. 3.7, controls the level of oxygen impurity in the sump tank and, indirectly, in the system sodium. A sample station provides a method for measuring the concentration of the oxide impurities in the sodium. The oxide content in the sump tank sodium is maintained in the range of 4 to $5 \mathrm{ppm}$ by continuous circulation 


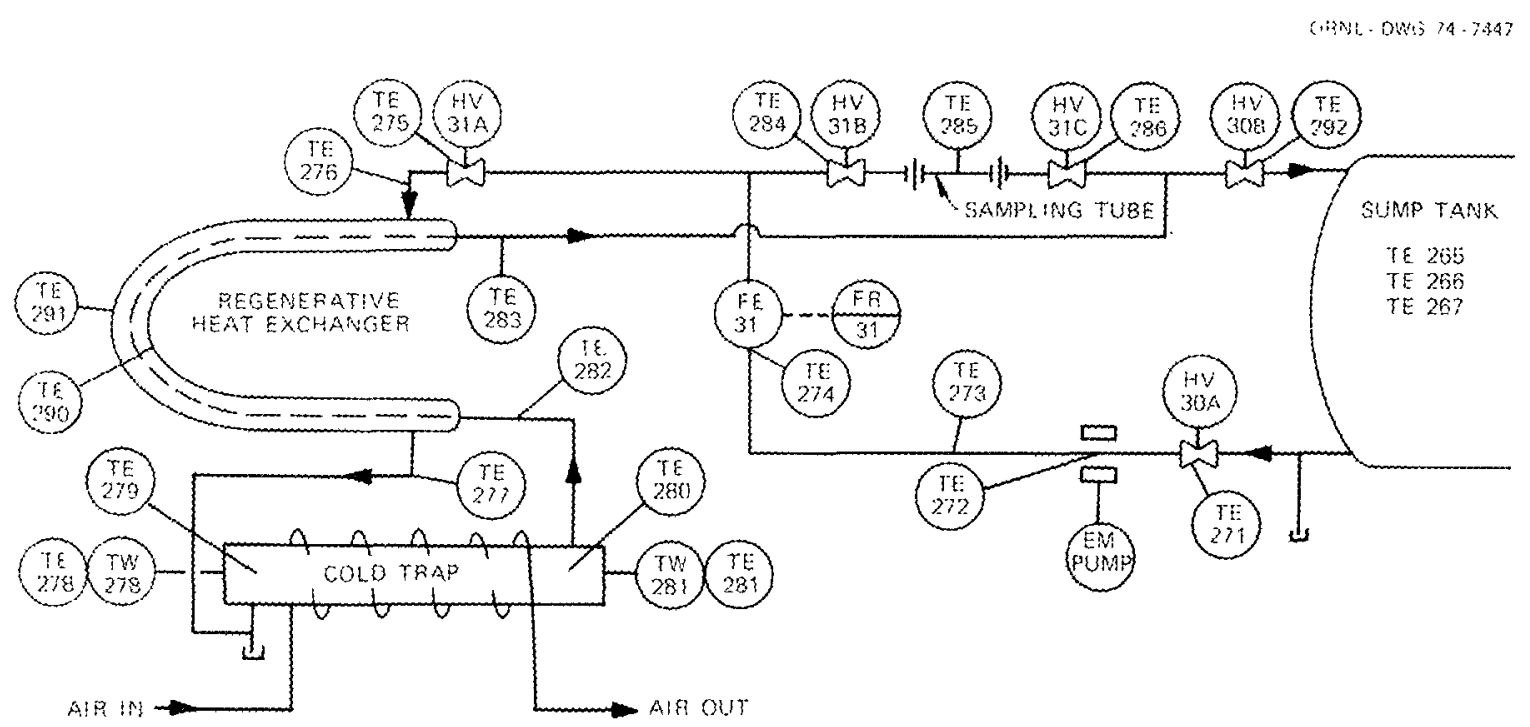

Fi.6. 3.7. Echematic flow diagram of the oxidemremoval cold trap and sodium sampline systen for the Thermal Transient Test Facility.

of the sodium through the cold trap when the facility is being operated. After the sodium system is filled, the sodium may be drained into the sump tank and purified by cold trapping before refilling the system. A sampling tube installed in the sampler line is filled with a small quantity of thoroughly mixed sodium and the sodium is chemically analyzed to derexmine the impurity level of oxides in the sump tank sodium.

Refexting to Fig. 3.7, sodium is pumped from the bottom of the sump tank through the electromagnetic flowmetex. Dowstream of the flowmeter it divides into two portions. One portion may flow through the sampling tube and the other to the cold trap through the annulus of the heat exchanger and back through the inner tube in the heat exchanger to rejoin the sampling tube flow and then enter the sump tank in the gas space above the sodium level. Bellows-sealed liquid-metal valves are provided to isolate the sump tank in the event of a sodium leak in the cold trap circuit, to isolate the sampling station, and to adjust sodium flow rates. The cold trap is cooled by instrument air passing through a helically wrapped tube on the outer surface of the trap and is heated by electric trace heaters.

Although the piping is sloped to facilitate the removal of gas, the beat exchanger and the cold trap form a considerable gas trap that must 
be evacuated before filling with sodium. Since this particular portion of the system is also hard to drain, a capped 1/2-in. pipe nozzle was installed at the low point in the trap to permit draining, if necessary.

The cold trap and the economizer were designed by the ORNL Reactor Division and fabricated from Inconel by the Y-12 Plant shops during 1955 for the Aircraft Nuclear Propulsion Program and, after fabrication, were placed in storage unused. Identical units were operated satisfactorily in that program for thousands of hours.

The cold trap, economizer, electromagnetic pump cell, and 1iquidmetal valves were upgraded for quality level II operation in accordance with QA Procedure 10596-RB-007-S-0.

\subsubsection{Argon fire-suppression system}

In the event of a sodium leak, the burning sodium that is collected by gravity in the catch pan in which the facility stands is smothered by inert argon gas. The catch pan, which has sufficient volume to contain more than all the system sodium, is placed under the sump tank and is supported on steel grating about $8 \mathrm{in.} \mathrm{high.} \mathrm{This} \mathrm{separation} \mathrm{not} \mathrm{only}$ protects the concrete floor from damage by the high temperatures of a sodium fire but also permits the rapid cooling of the burning sodium, which helps control sodium fires. The catch pan is covered with a lid that has an opening $5 \mathrm{in}$. wide by $10 \mathrm{ft}$ long that is fitted with a damper that can be closed manually to conserve argon during the actual smothering of burning sodium. The sheet metal shield in the region of the sump tank is sloped to drain leakage sodium into this long narrow opening.

A schematic diagram of the argon flow system is shown in Appendix $\mathrm{C}$, Instrument Application Diagram, Sheet 1. Argon is supplied from the building argon supply through a pressure regulator and a solenoidcontrolled shutoff valve. When the solenoid is deenergized by the signal from appropriate smoke and leak detectors, an alarm is sounded and the argon valve opens, flooding the catch pan with argon at a preset flow rate. There is a 5-sec delay between the detector signal and the solenoid operation to permit the detection system to eliminate most of the very infrequent false signals that occur. 
When arga 3 lows to the catch pian for any reason, an independent alarm sounds to alert personnel to the possibility that the heavier thanair argon is filling low-lying regions in the building. The Health physics Division has the responsibility for monitoring these lowmlying regtons for oxygen deficiency each the argon flows into the sateh pan exeept for the routine operation of the system for a few seconds to datermine if it functions properly.

\section{2 .6 Dextir data-acquistion system}

This system, presently installed in Building 9201-3, is used to monitor and record test data. The system consists of a Beckman Dextr. data-acquistion system interfaced to a Digital Equizment corporation PDP-8 computex, which has a core memory of 4096 twelvembit words and 32,768 words of manetic disk storage. The data are comorted to engi neering units on line, and a listing of the datiz in engineering units is supplited at the test facility. All data are digitized and racorded on magnetic tape for further processing by the ORNL IBM $360 / 75$ computer. A large library of programs is available for processing the stored data.

The system has a capacity of 2500 analog and 2500 digital inputs and a speed of 8 chamels per second. Overall accuracy is $\pm 0.07 \%$ of full. scale, resolution is one part in 30,000 , ant the input signal range is 0 to 10 mi full scale to 0 to $1 \mathrm{~V}$ full scale in three programable steps.

Datangathering boxes, each with 25 analog and 25 digital channel capacity, can be plugged into the "party line" cable at any point in the netwotk. bigital input capability is provided by both thumbheel sitich and contact ingut modules that can accept decimal or binary coded decimal contact closures from counters, clocks, frequency meters, digital voltmeters, ank other devices that have digital outputs. Thermocouple referm ence junction compensation is provided for all. thermocouple inputs.

The popm computer soltware consists of a realutime multiplemtask executive system with fout levels of priority interrupt. The highest priority is assigned to protection of the operating systen in case of power failure. The second priority is assigned to the acquisition of daka, the third to keyboard input, and the fourth to printer output. 
Another package of computer programs performs the conversion to engineering units and logging tasks. On-1ine utility programs are provided to facilitate punching tape, reading tape, entering data into memory, listing the contents of specified memory locations, clearing specified memory locations, etc.

Three data-gathering boxes, one digital input panel along with the requisite equipment, and one thermocouple reference junction box are provided for the TTTF.

\subsubsection{Fast data-acquisition system}

This system is based on the Digital Equipment Corporation (DEC) PDP$8 / \mathrm{E}$ computer and commercially available peripheral devices and interfaces and has hardware compatible with DEC equipment and software compatible with the TTTF and the FFM. The nucleus of the software system is DEC's FOCAL interpreter with modifications made by the ORNL Instrumentation and Controls Division for the FFM system. Components of the system are listed in Table 3.1 .

The system is capable of scanning, digitizing, and recording dc voltage signals from 128 separate sensor signals in the range of $0 \pm 10 \mathrm{mV} \mathrm{dc}$ to $0 \pm 10 \mathrm{~V} \mathrm{dc}$. The system has a resolution of one part in \pm 2048 , an accuracy of $\pm 0.3 \%$ of full scale (exclusive of electrical noise), and can scan the sensor at the rate of 10,000 samples (channels) per second. The signal multiplexer is field expandable in increments of 8 channels to accept a total of 1024 separate sensor signals. The system is programmed using the FOCAL language, thus facilitating on-site program modification by project personnel. Data are recorded in real time on industrycompatible magnetic tape for detailed analysis on the IBM 360/75 computers in the ORNL Computing Center and may be output on site via the ASR-33 teletype or, one channel at a time, on the Tektronic storage scope.

The system has sufficient computer capacity to provide the preliminary on-site analysis required for guidance of the experimental program. Time code information is recorded with the data for correlation purposes.

To achieve the high scanning rate demanded of the systems, field effect transistors (FETs) are used to switch the low-level (millivolt) signals. These FETs are protected from excess voltage by dindes. Terminals 
Table 3.1. Components of the dataacquistion system (LMFBR-DAS)

\begin{tabular}{|c|c|c|}
\hline Item & Quantity & Description \\
\hline 1 & 1 & $\begin{array}{l}\text { PDP-8E-CA computer, } 4 \mathrm{~K} \text { core memory with cabinet } \\
\text { and teletype control }\end{array}$ \\
\hline 2 & 1 & MC 8E 4K memory with memory extension control \\
\hline 3 & 1 & $\mathrm{MM} 8 \mathrm{E} 4 \mathrm{~K}$ memory \\
\hline 4 & 1 & DK8-EP rea1-time clock, programmable \\
\hline 5 & 1 & KP8 E power failure detect and auto restart \\
\hline 6 & 1 & PE8-A omnibus expandex \\
\hline 7 & 1 & H961-A option cabinet, without end panels \\
\hline 8 & 1 & ASR-33 teletype \\
\hline 9 & 1 & Magnetic tape controller and 1 transport \\
\hline 10 & 1 & $\begin{array}{l}\text { Analog signal input system consisting of a } 128- \\
\text { channel multiplexer, a variable gain arplifier, } \\
\text { an analogmtomdigital converter, and a computer } \\
\text { interface }\end{array}$ \\
\hline 11 & 1 & DF32D $32 \mathrm{~K}$ work disk and controller \\
\hline 12 & 1 & Tektronix model 611 storage scope \\
\hline
\end{tabular}

are provided in the multiplexer to add extra filtering tallored to the needs of each individual channel. However, extra filtering may result in a decreased frequency response and must be used accordingly.

A total of 60 shielded twomconductor cables connect the TTTF to the fast data-acquisition system over a distance of approximately $150 \mathrm{ft}$. It is planned initially to transmit 56 signals to the acquisition system with these cables.

\subsection{Detailed Component Description}

\subsubsection{Source tank}

During the thermal transient, the high-pressure sodium source tank supplies sodium to return the test section temperature to $800^{\circ}$ after an unavoidable undershoot of some $50^{\circ} \mathrm{F}$ to approximately $750^{\circ} \mathrm{F}$. During 
steady-state operation the source tank acts as a thermal expansion tank for the system sodium.

The source tank was sized to provide enough sodium at design flow for a period of time equal to approximately three times the duration of the rapid thermal downshock. This was based on heat transfer calculations made to determine the volume of sodium required to permit the test section temperature to approach $800^{\circ} \mathrm{F}$ asymptotically from the lower temperature imposed by the undershoot. (See Appendix A.)

The pipe nest sodium volume of approximately 27 gal will last nearly $11.3 \mathrm{sec}$ at the planned flow rate of $16.31 \mathrm{~b} / \mathrm{sec}$. To provide sodium for another $19 \mathrm{sec}$ requires an additional $46 \mathrm{gal}$ (or a total of $73 \mathrm{gal}$ ) of thermal transient sodium. The source tank was designed and constructed with an internal volume of $100 \mathrm{gal}$ to accommodate this 73 gal of sodium, plus a 7-gal "heel" in the bottom of the tank, and approximately $25 \%$ gas space volume above the sodium.

The mechanical design of the tank was based on the rules of the ASME Boiler and Pressure Vessel Code, Section VIII, Division 1. The tank was fabricated from a 2-ft-diam cylindrical shell and two ellipsoidal heads. The material chosen was 316 stainless steel, and the lower of the two code-allowable design stress intensity values was used (i.e., 10,300 psi at $1100^{\circ} \mathrm{F}$ ). This value required a wall thickness of 0.86 in. and thus permitted the use of nominal 1-in.-thick plate and heads.

The vessel heads have a total of seven penetrations furnished with reinforcing adapters designed in accordance with paragraph UG-37 of the design code. The top head has four pipe nozzle penetrations; three are 1 in. and the fourth is $11 / 2$ in. The $11 / 2-i n$. nozzle is for the vapor trap and also provides the cover-gas inlet and a connection to lowcapacity vent valve PCV-1C. One of the 1-in. nozzles accommodates the ASME pressure-relief valve, one is for the pressure control system, and the third is for the high-capacity vent valve and for equalizing the source tank with the bladder in the test section and with the sump tank during draining at low pressure. The bottom head has three pipe nozzle penetrations. A 2 1/2-in. nozzle connects the bottom of the source tank to the inlet of the pipe nest, a capped 1-in. nozzle permits the future installation of a high-pressure batch transfer system between the sump and source tanks, and a third accommodates the twin I-tube liquid-level sensor. 
All the closure welds in the source tank are full penetration welds, and all but one were fully radiographed in accordance with paragraphs UW11 and UW-51 of the design code. The exception was the weld between the bottom head and the liquid-level adapter, where a meaningful radiograph could not be obtained. In this case, progressive dyempenetrant inspection was used.

Eight baffle plates are attached to the interfor of the tank near the bottom to prevent vorticity of the sodium during the thermal transient. The vorticity can interfere with the minimum sodium level signal that is used to close the sodium shutoff valve automatically to terminate the transient. During sodium outflow from the tank at low levels, the vorm ticity could also induce gas entrainment in the sodium which we sought to avoid. Table 3.2 sumarizes the design data for the source tank.

Table 3.2. Source tank design data

\begin{tabular}{ll}
\hline Design pressure, psig & 800 \\
Design temperature, ${ }^{\circ} \mathrm{F}$ & 1100 \\
Material, shel1 and heads & $316 \mathrm{sS}$ \\
Material, reinforcing adapters & $304 \mathrm{SS}$ \\
Code-allowable stress, she11, and heads, psi & 10,300 \\
Wall thickness, in. & 1.0 \\
Inside diameter, in. & 22 \\
Length of shel1, in. & 48 \\
Internal volume, gal & 101 \\
Empty weight, lb & 1510 \\
Maximum allowable sodium volume, ${ }^{2}$ gal & 86 \\
Requlred sodium volume (for transient), gal & 73 \\
Test pressure (pneumatic), psig & 1510 \\
\hline
\end{tabular}




\subsubsection{Pipe nest}

The pipe nest stores sodium in a compact configuration that is capable of maintaining a prescribed temperature gradient in the sodium along the length of the nest. The temperature gradient is imposed with electrical trace heaters attached to the pipe and grouped appropriately for control to produce $T\left({ }^{\circ} \mathrm{F}\right)=1100-30 t$ ( $t=t i m e$ in seconds) at the midpoint of the gage length of the test section during the temperature downshock.

The pipe nest, including fittings, is $95 \mathrm{ft}$ long measured from the elbow at the bottom discharge from the source tank to the first reducer at the entrance to the test section. The length was based on the sodium volume required to cool the test section at the desired rate while imposing an axial temperature gradient no larger than $2^{\circ} \mathrm{F} / \mathrm{in}$. over the 20 -in. gage length. The pipe nest is constructed of $21 / 2-i n$. sched-10 pipe made of $316 \mathrm{H}$ austenitic stainless steel. It has an internal sodium volume of 27 gal, which is sufficient to supply sodium for $11.3 \mathrm{sec}$ at the design flow rate of $16.331 \mathrm{bm} / \mathrm{sec}$. The sched-10 pipe was chosen to minimize the heat capacity of the pipe nest while still being adequate to contain the highpressure, high-temperature sodium. The thin wall of the pipe also results in lower thermal stresses during a thermal transient. Thus the pipe nest material should not experience thermal ratchetting according to the criterion in the interpretation of ASME Code Case 1331-8.

The pipe nest consists of two vertical planes of continuous pipe and fittings connected at their lowest (minimum) elevation to form a continuous flow passage from the source tank to the test section. Each plane consists of several nearly horizontal limbs of pipe connected with return elbows to form the continuous path. The bank connected to the source tank consists of three limbs of about $30 \mathrm{ft}$ total length, with each limb having a slope of about $17^{\circ}$ from the horizontal. The other bank, connected to the test section, has six limbs of about $60 \mathrm{ft}$ total length, with each limb having a slope of about $5^{\circ}$ from the horizontal. The larger slope is associated with the shorter run of piping because the vertical space available for both planes is about the same. These pipe slopes minimize the deleterious effects of natural convection on maintaining the required thermal gradients in the pipe nest sodium. 
The calculational method (see Appendix A) accounts for the heat that is transferred unavoidably from the pipe nest material to the temperaturegraded sodium as it flows through the pipe nest and into the test section during a thermal transient. To compensate for this unwanted heat, the sodium temperature at the minimum elevation in the pipe nest is set about $100^{\circ} \mathrm{F}$ less than the $800^{\circ} \mathrm{F}$ sodium in the source tank and about $400^{\circ} \mathrm{F}$ less than the $1100^{\circ} \mathrm{F}$ sodium in the test section. Table 3.3 sumarizes the design data for the pipe nest.

Table 3.3. Pipe nest design data

\begin{tabular}{ll} 
Design pressure, psig & 800 \\
Design temperature, ${ }^{\circ} \mathrm{F}$ & 1100 \\
Material & $316 \mathrm{SS}$ \\
Codemallowable stress, psi & 10,300 \\
Length, including fittings, ft & 95.4 \\
Pipe size, in. & $21 / 2 \times 0.120$ wall \\
Internal volume, gal & 27 \\
\hline
\end{tabular}

\subsubsection{Orifice run}

The orffice run reduces the pressure in the flowing sodium during a thermal transient from the 700 psig value in the source tank to approxim mately 5 psig before the sodium enters the low-pressure sump tank. This is accomplished with five orifices installed in series in a single plpe run, with each orifice having a net pressure drop of approximately 138 psi. The flow resistance of the other sodium system components and piping accounts for the remaining pressure drop.

The detailed orifice design is based on the information by Spink ${ }^{7}$ for sharp, squaremedged, thinmplate, concentric orifices. The number of orifices (five) chosen was based on facility constraints on the length of a single pipe run and on an arbitrary throat velocity of approximately 105 fps. In previous USAEC programs, we had operated some venturi flowmeters with liquid metals and molten salts at throat velocities of 50 to 60 fps for as long as $25,000 \mathrm{hr}$ for one flowneter without deleterious 
effects to the meter. And, inasmuch as the thermal transient test plans call for using the TTTF orifices rather infrequently, once for each one to three weeks of facility operation, we doubled the experience velocity somewhat arbitrarily for these orifices.

Each orifice is pressed into and against the shoulder of a 2.500-in.diam bore machined in the pipe. The pipe sections are weld joined just upstream of each orifice plate to form the run, and the shrinkage caused by the weld locks the orifice plate firmly in place. Additional pipe stock was provided to allow for installation of different orifices in case the orifice size is changed to produce different thermal transient conditions for future tests. The last downstream orifice plate is thick enough to sustain the entire 700 psig of differential pressure between the source and sump tanks to support a sodium freeze valve in the event one is necessary.

A calculation made of the argon gas volume that could come out of solution as the pressure in the flowing sodium is reduced while traversing the orifices indicated that only $0.6 \mathrm{cc}$ of gas would be released downstream of any given orifice and thus only approximately $3 \mathrm{cc}$ for the entire orifice run. The orifice run design data are given in Table 3.4.

Table 3.4. Orifice run design data

$\begin{array}{ll}\text { Number of orifice plates in run } & 5 \\ \text { Gross/net } \Delta \mathrm{P} \text { per orifice, psi } & 156 / 138 \\ \text { Design flow rate, 1b/sec } & 16.33 \\ \text { Throat diameter, in. } & 0.753 \\ \text { Throat velocity, fps } & 2105 \\ \text { Plate thickness, in. } & 0.25^{\mathrm{a}} \\ \text { Minimum recovery length (8 diameters), in. } & 20 \\ \text { Pipe ID, in. } & 2.500 \pm 0.005\end{array}$

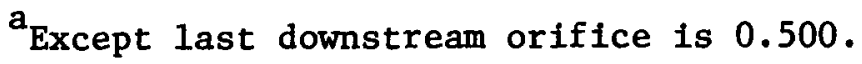




\section{3 .4 Test section}

The test section is operated in the steadyustate and the thermal tranaient modes at programmed conditions of tempexature, pressure, and time and ia instrumented appropriately for the sole purpose of obtaining specific strain and strain rate data. These data are used to evaluate both inelastic structural analysis techniques and the design rules intended to prevent or limit creep ratchetting.

The initial test section (Fig. 3.8) was machined row sched 80 pipe made from the 304 stainless steel, reference heat 972796 , that is being used in the ORNL High-Tempexature Structural Deaign Methods for IMFBR Components program. The rest strain measurement instrumentation is concentrated in the central 20-in. portion of the 30 in.-long pipe, called the "gage length" of the test section. The pipe is welded at each end to transition pieces specially machined for joining the different wall thicknesses of sched 40 and -80 pipe. This assembly, which provides 30 in. of pipe without a weld and $44 \mathrm{in}$. without a change in diameter or thlckness to mintmize the end effects on the gage length, is then weld jolned to concentric pipe reducers at each and. The concentric reducers, which parmit a small amount of sodtum to be trapped in a "bael" in the test section during draining, simplify the analytical effort required to establtsh the stress intensities in the reducers as compared with eccentric pipe reducers.

Five small holes of differing depths are machined radially into the test section at the midpoint of the gage length to accomodate thermocouples to measure the ingtantaneous radial temperature distribution through the test section wall at th:s transverse plane during a thermal transient.

A bladder, constructed from 6min., sched 10,304 utainless steel pipe and fittings, is installed concentrically inside the test section to form an annulus of $0.53 \mathrm{in}$. radial dimension for sodium flow. The bladder reduces the quantity of temperaturemgraded sodium needed for a thermal. transhent by naxly actor of 2 , which is the ratio of full pipentoannular flow areas corrected for the thermal capacitance of the bladder. The bladder is also used to mount thermocouples to measure the temperature 


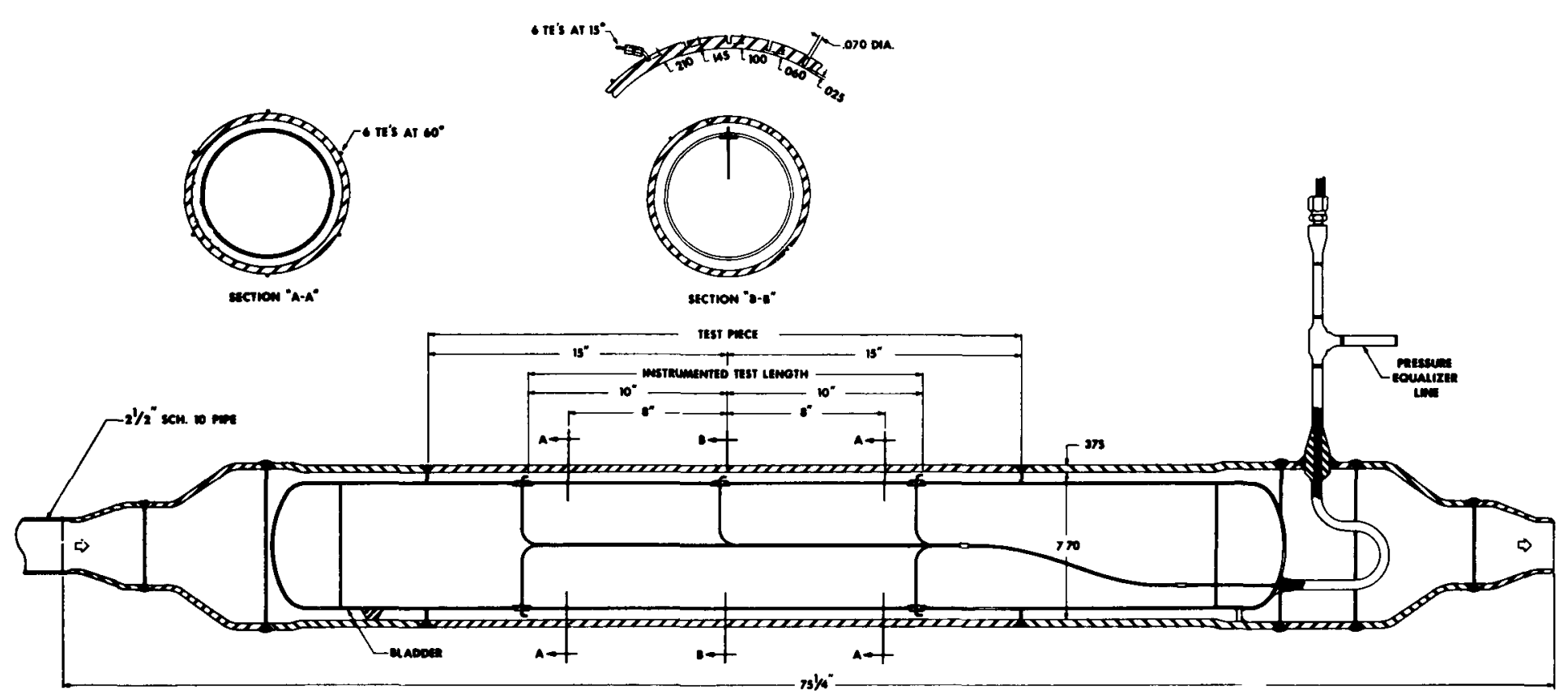

Fig. 3.8. Test section for the Thermal Transient Test Facility. 
of the flowing sodium stream at the entrance, middle, and and of the test section gage length.

For practical purposes, the pressure of the intertor of the bladder is automatically equalized to the sodum pressute in the annulus by connecting the interfor to the gas space in the source tank. Since the bladder pressure would lag behind source tank pressure during the rapid venting of the tank in a system scram (an automatic fast drain), a substantial design pressure was used for the bladder. The design pressure will not be exceeded during facility operation, including a scram, as long as the gas volume in the source tank is maintained greater that $2 \mathrm{ft}^{3}$, which increases the venting time for the tank sufficiently to provide the needed protection. An alarm is actuated whenever the sodium 1 evel in the source tank is kighex than the minimum gas volume of $2 \mathrm{ft}^{3}$ will permit. The litulting stress associated with the design pressure occurs in the thermocouple adapters and the fillet welds by which the adapters are installed.

The test section is positioned with the axial center line inclined $5^{\circ}$ from the horizontal with the sodum outlet at the higher alevation. The small heal. of sodium in the tast section can be drained to the sump tank through an independent dxain line. The gas that may be trapped at the topmost portion of the tast section during filling can be ventad to the sump tank through an independent vent line. When this is done at an

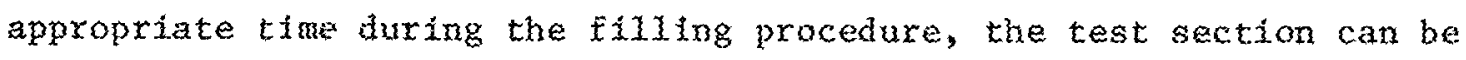
completely filled with sodium.

The rest saction is auported by a fixed support at the sodtum outlet end and is gulded axially at the sodium inlet end. These supports are discussed more fully in Sect. 3.3.10. The design data for the rest section and bladder are summarized in Table 3.5 .

\subsubsection{Thermal capacitance tank}

An early analysts indicated that the themal transient sodium could impose large thermal stresses on the relatively heary body of the shutoff valve and thereby distort the body and cause sodium leakage across the valve seat. This leakage could seriously intertere with both the steadym state operation of the faclitity and the preparation for a thermal transient. 
Table 3.5. Design data for the initial test section and bladder

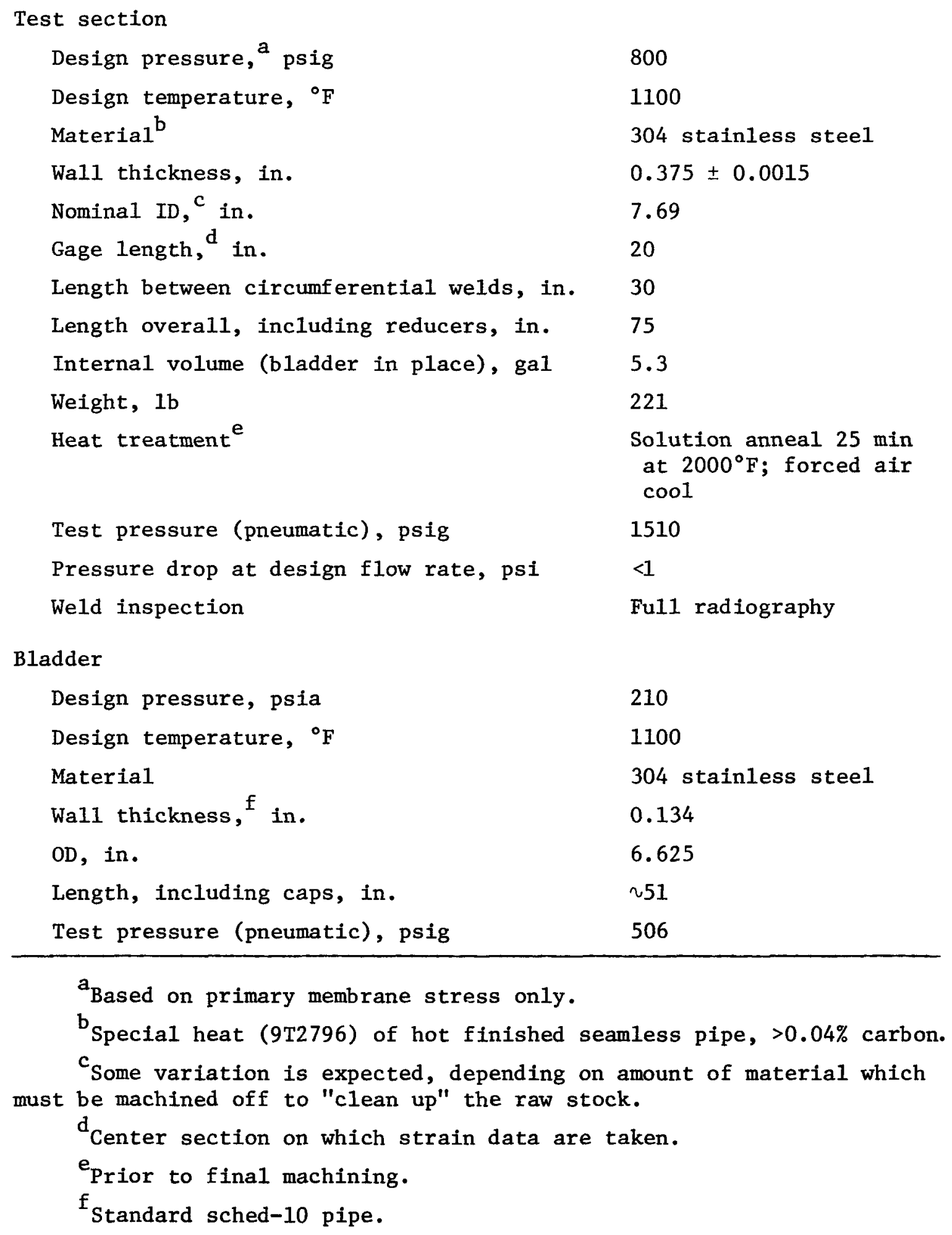


Consideration given to a soditu freeze valve indicated some potential difficulties. Timing the initiation of the sequence of automaticaliy performed activities for the thermal transient to match the probably nonreproducible characteristics for opening a sodium freeze valve and the possible interference of the frozen plug of sodium with the sodium flow during critical portions of the transient were substantlal problems whose resolutions were thought to be both moot and expensive. Also it would be impractical to use the freeze valve to terminate sodium flow at the end of the transient, and special procedures would be necessary to accomodate high-pressure gas flow into the sump tank. Ipon initiation of the thermal transient, the thermal shock to the sodium container materlal for the freeze valve would be much more severe than that planned for the test section. Thexefore, the use of a thermal capacitance tank upstream of the sodium shutoff valve was proposed and adapted to permit nearly isothermal operation of the shutoff valve during the transient.

The thermal capacitance tank is used to store a quantity of isothemal sodium approximately equal to the volume of the thermal cranstent sodium at the same temperature as the downstream shutoff valve. Thus the sodium shutoff valve experiences only isothermal sodium during a thermal transient because the transient is stopped before the thermal transient sodium reaches it. During an actual thermal transient, the shutof valve temperature changed only $25^{\circ} \mathrm{F}$ in $60 \mathrm{sec}$.

The tank is relatively long and slender and has a liquid volume of 68 gal, which is about 5 gal less than the volume of the thermal transient sodium. A large number of Raschig rings (2044 sections of 1 1/2-in. sched 40 stainless pipe, each about 1.9 in. Iong) were installed in the tank to provide a thermal quanch capability of $96 \mathrm{mu} /{ }^{\circ}$ and to promote slug flow of sodium through the tank. The Raschig rings are restrained in place with a flat perforated baffle plate that is welded to the tank just upstream of the head tomshell joint at the outlet end of the tank. The she11, which could be made only 14 ft long because of apace Ifmitations, is a standard 12min., seamwelded, sched-80 pipe made of $316 \mathrm{H}$ stainless steel that was purchased to the approprate RoT material standards. The vessel heads are standard pipe caps. The sodium shutoff valve body is welded to an adapter that, in tum, is welded to the tank 
outlet head. The tank, which is anchored at the outlet end, provides essentially a rigid mount for the valve.

Since the inlet head is subjected to essentially the same thermal transient as the test section, a special thermal sleeve assembly was designed to protect the joint between the head and the sodium system piping. The assembly, which is concentric to the tank, has an outer adapter welded to the head to sustain the pressure stresses and the piping forces and moments associated with high-temperature operation. An inner sleeve that is concentric to the adapter is the flow channel for the transient sodium, keeps it away from the outer adapter, and discharges it approximately $2 \mathrm{ft}$ inside the tank into the Raschig rings. The thermal sleeve was subjected to an inelastic structural analysis by the finite-element method using recommended constitutive equations. ${ }^{8,9}$ A thermal analysis ${ }^{4}$ and a structural analysis ${ }^{5}$ were made also. It was concluded from these analyses that neither ratchetting nor cyclic yielding would occur in the thermal sleeve. No creep calculation was made because the normal sleeve temperature is maintained near $800^{\circ} \mathrm{F}$ during the steady-state operation and is too low for significant creep to occur. Table 3.6 summarizes the design data for the thermal capacitance tank.

\subsubsection{Sodium shutoff valve}

The sodium shutoff valve is used to start and stop the flow of sodium for the thermal transient and, during steady-state operation, to hold the sodium in the high-pressure portion of the sodium system against the 700psig argon pressure in the sodium source tank. At the initiation of the transient, the valve is opened rapidly in about $0.1 \mathrm{sec}$ with an automatically controlled pneumatic operator assisted by the 700-psi pressure difference across the seat in the direction of valve opening. Under this potential the sodium flow is accelerated rapidly to the steady-state value in approximately an additional $0.1 \mathrm{sec}$. To stop the transient, the valve is closed relatively slowly over a period of about $5 \mathrm{sec}$ to minimize the effects of a "water hammer" on the sodium system.

The valve installed into the sodium system was available from a previous USAEC high-temperature liquid metal program. It is a Mason-Neilan model 20-91561, 2 1/2-in. iron pipe size "Y" design in which the bonnet, 
Table 3.6. Design data for thermal capacitance tank

\begin{tabular}{|c|c|}
\hline Design pressure, psig & 800 \\
\hline Design temperature, ${ }^{\circ} \mathrm{F}$ & 1100 \\
\hline Material, she11 and heads & $316 \mathrm{H} \mathrm{SS}$ \\
\hline Material, adapters & 304 SS \\
\hline Code-allowable stress, psi, shell and heads & 10,300 \\
\hline Wall thickness, in. & 0.5 \\
\hline lo, in. & 11.75 \\
\hline overall length, ft & 214 \\
\hline Stze of Raschig rings, ${ }^{a}$ in. & $\begin{array}{l}1.9 \text { oD } \times 01.9 \times 0.145 \\
\text { wall thickness }\end{array}$ \\
\hline Number of Raschig rings & 2044 \\
\hline Heat capacity of Raschig rings, Btu/ ${ }^{\circ} \mathrm{F}$ & 96 \\
\hline Internal volume (rings in place), ${ }^{b}$ gal & 68 \\
\hline Erapty weight (rings in place), lb & 1940 \\
\hline Test pressure (pneumatic), psig & 1510 \\
\hline Pressure drop at design flow rate, psi & $v 1-2$ \\
\hline Weld inspection & Full radiography \\
\hline
\end{tabular}

\footnotetext{
Made Erom 1. 1/2min. sched 40s pipe.

$b_{82 \% \text { void. }}$
}

stem, plug, and seat are located along a line $45^{\circ}$ from the valve piping run. The body is made of $316 \mathrm{H}$ stainless steel, and the stem is bellows sealed to the bonnet with the bellows located on the low-pressure side of the sodium system (i.e., the sump tank side). Calculations made of the valve body for membrane stress and of the stem for buckling while holding the plug closed against the 700 psig sodium pressure indicated that each was satisfactorily strong by a large margin. However, the originally supplied bonnet flanges were not sufficiently strong, and a beaviex lower flange (1 5/16 in. thick) and a l-in.-thick reinforcement xing for the existing upper flange were installed on the valve body.

Leak-tightness tests of the valve seat made with bigh-pressure helium indicated a need for improvement. The seat and plug were machined and 
Japped by Mason-Neilan, and subsequent test cycle operation with sodium in the facility indicated that the rework was satisfactory. The important characteristics of the sodium flow control valve are summarized in Table 3.7 .

Table 3.7. Sodium shutoff valve characteristics

\begin{tabular}{ll}
\hline Manufacturer & Mason-Neilan \\
Size, style & $21 / 2$ in. " $Y "$ \\
Materials & $316 \mathrm{H}$ and $347 \mathrm{H} \mathrm{SS}$ \\
Stem travel, in. & 0.4 \\
Seat diameter, in. & $111 / 16$ \\
Flow coefficient, $\mathrm{C}_{\mathrm{v}}$ (fully open) & $47.5^{\mathrm{a}}$ \\
Pressure drop, full flow, psi & 7.3 \\
Operator & Pneumatic \\
\hline
\end{tabular}

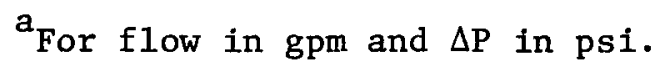

\subsubsection{Sump tank}

The sump tank, which is a relatively low-pressure vessel compared with the high-pressure portion of the sodium system, is the reservoir from which the high-pressure portion of sodium system is filled and into which the system sodium is drained during maintenance or emergencies. It is also the receiver of the sodium displaced from the high-pressure portion of the sodium system during a thermal transient. The sump tank was utilized in a previous test facility, the LMFBR Multiple Assembly Cooling Cast Test, and was modified for the TTTF by installing (1) a thermal sleeve between the drain line nozzle and the tank wall, (2) a pressure-relief manometer, and (3) an oxide-removal cold trap and sodium sampling system (see Sect. 3.2.4).

The thermal sleeve is installed into the top of the sump tank to protect the vessel wall from any possibility of a thermal shock during a thermal transient or inadvertent drain of the sodium system. It consists of the $21 / 2-i n$. sched-40 drain line that is concentric to a short length of 4 -in. sched -40 pipe and pipe cap. The larger pipe is welded 
to the tank at $i$ lower lond and at its upper end is joined to the pipe cap which in turn is welded to the drain 1ine. The drain Ine is extended down tnside the tank to about $18 \mathrm{kn}$. above the bottom to permit approximately $70 \mathrm{gal}$ of sodium displaced during the thermal transient to mix with approximately $500 \mathrm{gal}$ of the tank reserve sodium to remove any possibility of therma11y shocking the tank wall.

The operation of the low-pressure sump tank in conjunction with the highnpressure argon system has sone hazards which the twry design seeks to overcome. Backup controls are provided to prevent the intrusion of the high-pressure gas into the tank past the sodium shutoff valve if the normal. controls fail to function properly. Normally, the closed sodium shutat valve saparates the low and high-pressure portions of the sodium system. As a backup, a pressure sensor is provided in the sump tank gas volume. If the sump tank pressure rises above 6 psig, the pressure sensor is activatad to cause the source tank vent valves to open, the high-pressure argon supply valves on the source cank to close, and the sodium drain valve to close. In addition, the simultaneous failure, somewhat improbable, of the argon supply and sodium shutoff valves in the open mode, which would connect the sump tank to the highmpressure argon system through a drained sodium system, was considered. Two 11nes of defense were devised to con trol the consequences of such a failure in a satisfactory manner. The number of gas cyllnders connected to the high-prassure argon system was minimized, particularly for the themal transient, and a pressure-rellef manometer having low pressure drop and highmflow capabillty was connected to the gas space in the sump tank.

During thermal transient operation a maximun of six full cylinkers of high-pressure gas are connected to the highmressure argon system. Calculations reported in Appendix $\mathrm{F}$ were made of the peak pressure that this amount of gas would produce in the sump tank in the event of the simultaneous valve failures with the pressure-rellef manometer operating. Jnder these conditions and with the relief manometex filled sufficiently with Eluid for 7 psig operation, the momentary pressure in the sump tank would rise to nearly $35 \mathrm{psig}$, which is tolerable on the basis of the momentary pressure capability for the tank of 36 paig as reported in Appendix F. In addition, operating personnel are stationed to close the 
sodium shutoff valve manually if it fails to close automatically to stop the transient. At least $30 \mathrm{sec}$ is available to perform this operation before high-pressure gas begins to enter the sump tank. During steadystate operation, only one cylinder of high-pressure gas is connected to the high-pressure argon system.

The manometer is a "U" configuration of $21 / 2-i n$. sched-40 pipe approximately $35 \mathrm{ft}$ high and is partially filled with Hercolube A fluid to keep air from contacting the sump tank sodium. The manometer can also be filled sufficiently with fluid to provide for vacuum operation of the sump tank. The manometer fluid does not react with sodium and has satisfactory low viscosity, high density, low volatility, high flash point, and good thermal stability properties, and is low in cost.

Additiona1 nozzles are installed onto the sump tank to permit filling and draining the tank, equalizing the gas spaces in the tank with the gas space in the source tank, and connecting the tank to a vacuum system and, separately, to the cold trap and sodium sampling system.

The gas equalizing line is an approximately $30-\mathrm{ft}-1$ ong run of $1 / 2-i n$. sched-40 pipe and contains a check valve that is kept closed by the source tank pressure and an isolation valve that is normally closed. The isolation is opened automatically when the sodium shutoff valve is opened during a manual or an emergency drain, when the source tank pressure is lower than $20 \mathrm{psig}$. In the event that both the check and isolation valves fail in the open mode, the sump tank pressure is maintained well below the 36-psig momentary pressure limit by the action of the pressure-relief manometer. Table 3.8 summarizes the design data for the sump tank.

\subsubsection{Test section oven}

The oven provides a controlled-temperature environment for the 42-in. central length of the test section and protects the high-temperature strain gages attached to the test section gage length from physical damage during handling activities. The physical standoff of the heaters from the test section, which is a principal feature of the oven concept, makes all the test section external surface available for the attachment of strain gages.

The oven consists of a large cylinder of stainless steel sheet metal split in halves along the vertical plane and mounted so as to provide a 
Table 3.8. Design data for sump tank

\begin{tabular}{|c|c|}
\hline Design pressure, psig & 15 \\
\hline Design temperature, ${ }^{a} \mathrm{~F}$ & 800 \\
\hline Materîal & $3042 \mathrm{SS}$ \\
\hline Codemallowable stress, psi & 8100 \\
\hline Wall thickness, sholl and heads, in, & 0.3125 \\
\hline $10,3 n$ & 48 \\
\hline Overall length, $f t$ & 2]1 \\
\hline Intermal volume, gal & 921 \\
\hline Empty weight, $1 \mathrm{~b}$ & 1912 \\
\hline Test pressure (pneumatic), psig & 34 \\
\hline
\end{tabular}

uniform radial gap of $2 \mathrm{in}$. from the test section surface. The two halves are bolted to form the oven. One end of the oven is clamped to the test: section outside the 30 in. length, and the other is free to slide to accomodate differential thermal expansion between the oven and lest section. Two inches of thermal insulation is installed on all the exterior of the oven. The 110 1b weight of the oven is supported with a counterwelght to avoid imposing its load on the test section. A trolley is installed to handle and support a removable half of the oven to provide access for gage maintenance.

The oven has sufficient ponetrations to accomodate the scales and pointers of two mechanical strain gages and the colums of the two air cooled extensometers and also the leads, cables, and latchstrings for various other strain gage devices. All the penetrations are made at the top of the oven to reduce the "chimney effect" thermal convection of amblent air through the oven. The penetrations axe filled with kaowook. blanket insulation to reduce thermal convection further whthout interfering with the mechanical operation of the pointers and columns.

There are 13 tubular electrical heaters supported in thin-walled tubes that are attached directly to the inside surface of each oven kalf. The electrical supply and the temperature control for the heaters are discussed in Sects. 3.2 .3 and 3.4 .1 respectively. Design data for the test section oven are summarlzed in Table 3.9 . 
Table 3.9. Design data for test section oven

\begin{tabular}{ll}
\hline Length (inside), in. & 42 \\
Inside diameter, in. & $125 / 8$ \\
Material & 16 gage SS \\
Insulation thickness, in. & 2 \\
Insulation material & $2-i n$. Marimet-45 ends only \\
& $2-$ in. Kaowool on cylindrical \\
& 22 \\
Number of heaters (42 in. 1ong) & 3.5 \\
Maximum heater power, $\mathrm{kW}$ & 110 \\
Weight (approximate), 1b & \\
Operating temperature (excluding & 1100 \\
heaters), ${ }^{\mathrm{F}}$ &
\end{tabular}

${ }^{a}$ Kaowool may be substituted as required.

\subsubsection{Protective barriers}

The facility is totally enclosed with sheet metal shields and heavy steel plates. The sheet metal shields protect personnel and nearby equipment from sodium leaks, and the heavy steel plates ( $1 / 4$ and $3 / 8$ in. thick) provide protection against missiles that could be produced in a sudden rupture in the high-pressure sodium or argon systems. The light shields (16-gage carbon steel) are applied only where missiles cannot occur, that is, around the sump tank below the elevation of the thermal capacitance tank and to the sides of the facility above the test section and below the high-pressure gas system in the region of the source tank. The heavier steel plates are applied to the remainder of the sides and ceilings to enclose the entire facility.

The design of the light shields followed our past practice for sodium systems employing 16-gage carbon steel sheet metal and carefully avoids any "line-of-sight" penetrations through which a jet of sodium could escape. The shields force any leakage sodium to drain into the catch pan in which the facility stands and where the operation of the argon fire-suppression system should extinguish burning sodium. 
The design of the missile barriers was based on extensive analyses of the piptng aystem. An analysis by Ebasco Services ${ }^{10}$ indicated the tmpracticability of installing conventional bar and plate restraints (matresses) in close proximity to the phoing and recommended instead the use of keavy piates located somewhet rartker away and supported on the facility ${ }^{*}$ atrong steal structure. Analysts indicated that forces between 6000 and $7000 \quad b_{f}$ could be generated by the change in Eluid momentum as the result of a rupture in the high-pressure sodium piping, A constant accelexation model was then used to calculate the impact enexgy ranging from 21,000 to 35,000 ft-lof, and the stantord formula ${ }^{11}$ was used to calculate the steel penetration. It was found that $1 / 4-i n$. steel plates with tensile strength of 70,000 psi would be adequate for all sides and ceilings and that 3/8-in. -thick plates wotsld be adequate on the narrow north and south faces of the facility. To utilize availu able material, we specified hot rolled boiler plate, ASTM A285, grade C, Kaving a tensfle strength range of 55,000 to 65,000 pi. It is felt that the slighty lower strength materlal is justified because of the con siderabla conservatism in the calculated anergtes assochated with the use or a constant acceleration model.

The missile barkiers are bolked to the structural stecl members. gandles are provided on each section (typically 4 by $5 \mathrm{ft}$ ) for ease of handing with the crane. Each of the two platas on opposite stdas of the test section has a doublembick safery glass window to permit televiad observation of the measuring dials of two mechanical extensometers during a thermal transient. The missile barriers also act, of course, as splatter shields for the region they enclose. Both the sheet metal and the heary plate shlelds are demountable to provida convenient accuss for maintenanca.

The temperature of the enclosure atr is matntand near $350^{\circ} \mathrm{F}$ by the thermal convection of room-temperature air through the enclostre. Axr enters near the enclosure bottom through bafiled slotted openings in the sheet metal shield at the top sump tank levation and laves through a baffled opening in the side of the cupola on top of the source tank that shields the highmpressure argon systam. 


\subsubsection{Sodium system supports}

One major objective of the piping layout was to support the system components in a manner that would accommodate the large thermal expansion involved in heating the system from room temperature to design temperature while keeping the associated stresses in the system within acceptable limits, and, in particular, to reduce the forces and moments imposed on the test section by the thermal expansion process to an insignificant level.

A satisfactory piping layout was achieved by anchoring the source tank, thermal capacitance tank, sump tank, and one end of the test section. The flexibility inherent in the serpentine pipe nest configuration was utilized to accommodate the thermal expansion. Each straight run of pipe in the nest was supported at its midpoint with a hanger that carries the weight and also permits horizontal translational and complete rotational flexibilities. The test section is supported by a fixed support at the sodium outlet end and is restrained at the sodium inlet end by pivoting guide rods in the vertical plane and in a horizontal plane to freely accommodate the approximately 1-in. thermal expansion of the test section in the axial direction. The calculated axial force on the test section at the axially unrestrained support is $33 \mathrm{lb}_{\mathrm{f}}$, and the span between inlet and outlet supports is $86 \mathrm{in.} \mathrm{Calculated} \mathrm{vertical} \mathrm{support} \mathrm{loadings} \mathrm{are}$ preset at each end of the test section to accommodate the test section weight. The test section oven is supported on a separate counterweight system. In the flexibility analysis discussed below, it was calculated that the layout limited the stresses at the test section caused by its own weight and the piping system weight and thermal loadings to about 100 psi.

The MEC-21 Piping Flexibility Analysis Program was used to calculate the weight, thermal, and combined weight-thermal stresses for the sodium system. All stresses were determined to be within the limits set by ANSI B31.1, Code for Pressure Piping.

Since the piping system is very flexible, the sodium flow conditions present during a thermal transient can cause excessive vibration and other unwanted forces on the test section. Two three-directional hydraulic damping devices were installed to permit the slow movement of piping due 
to thermal expansion and to dampen any rapid movement due to the transient flow forces. One is located at the inlet to the test section and the other at the midpoint in the orifice run.

\subsection{Instrumentation and Controla}

Thts section describas the automatic and manual controluers that provide regulation of facllity and test section temperatures and pressure conditions, test data acquistion, pressure-relief valves, scrams and alarms, and error analysis. Appendix $C$, which presents gchematic diagrams of the flow sheet, control circuts, and alar sircuits, is a necessary adjunct to the descriptions in this sectlon. All alams are both audible and visual and are referrad to as "the alarm." The audible component is common to all alarm signals, but the visual component is unique for ach alarm signal.

\subsubsection{Tegt section temperature control and measurement}

The test section $\hat{x}$ s heated with a spacially designed oven containing 22 tubulax electrical heaters divided into four zones. Fach zone is supplied through a vartable autotransformer, numbered HCom-19A through HCom 190, to provide some flexiblitty in test section tempexature control.

Total power ingut to the oven is controlled with a saturable reactor, TCo-19, which controls the power into the four autotransformers. The TCo-19 is controlled with an automatic manual tempexature recorder controllex, ThC-19, through a magnetic amplifier, TM-19C. The TRC-19 is an electronic device having an input range fxom $w$ to th mv. Th receives a milivolt signal generated by themoeouple Tem 17 that has been "conditioned" by thermocouple reference TM-19A and a millivolt suppression device, TM-198. Thus the controjler itself functions over a very narrow range of approximately $40^{\circ} \mathrm{F}$ on either slds of the temperature control point, which ts set by adjustment of suppressor W-198. The controllex, TRC-19, may be operatad either in a manual mode (open anded with no faedback) or in an automat $\hat{x}$ mode in which the controllex output $\hat{3}$ s varied auromathally to maintain the temperature at the control point. 
In addition to the temperature control system, the test section is protected against high temperature with a temperature limiting instrument, TM-16, which takes its signal from TE-115. This instrument cuts off al1 electrical heat when the test section exceeds a high-level limit. It also announces the alarm when the temperature exceeds the high limit or drops below a low limit.

The test section temperature is measured with a variety of thermocouples attached to the surface of the section, embedded in the wall of the section, or installed in the sodium annulus between the inside diameter of the test section and the bladder.

The surface thermocouples are type $\mathrm{K}$ with MgO insulation and have stainless steel sheaths except for those supplied with the Boeing capacitance strain gages, which are Platinel. The sodium annulus thermocouples are furnace brazed to individual adapters that are subsequently welded at appropriate locations into the bladder vessel wall. The leads run along the inside of the bladder and the bladder gas equalizing line and into the atmosphere through a commercially available Conax compression fitting. The thermocouples installed in the test section walls are sheathed to within $\sim 1$ in. of the junction, from which point the sheath is removed and the opening sealed with fused glass. The bare wires, 0.010 in. in diameter, are installed in 0.070-in.-diam holes drilled to appropriate depths in the test section wall. In the small holes the wires are insulated with alumina and are attached individually to the bottom of the hole using a capacitance discharge welding procedure. All the thermocouple sheaths are $0.062 \mathrm{in}$. in diameter except the sodium annulus thermocouples, which are 0.040 in.

\subsubsection{Pipe nest temperature control}

A11 the pipe nest heaters were radiographed to determine the exact location and length of the heating elements and were then installed with a heating element "underlap" ranging from $1 / 4$ to $1 / 2 \mathrm{in}$. so as to avoid the heater failures associated with overlapping. The heaters were attached on each side of the piping symmetrically about the horizontal diameter through the pipe center and were applied in a single uniform spacing pattern to each pipe run, including the return bend. 
The heaters are supplled through 38 individual power circuits, each having a manually operated autotransformer to provide nearly continuous control of heater power. The large number of controls is required to ob tain the desired temperature gradients along the length of the pipe nest from source tank to test section. A total of 94 thermocouples are attached in a uniform spacing pattern along the pipe nest. Additional thermocouples are attached to a single pipe run in each of the two pipe nest planes so as to obtain more fine structure information about the temperature gradient in a typical ptpe run. The required temperature gradient is discussed in sect. 3.2.1.

The temperatures are nomally read out on temperature recorders and the Dextir datamacquisition system to provide feedback for adjusting the autotransformers. They may also be read out on a fast-response temperature indicator for final adjustments to the pipe nest gradients just before starting a thermal transient.

\subsubsection{Sodium 1lquid-1evel indication}

The sodium level in the source tank is measured with an electrical resistance element, LE-16, called a "twin I-tube." The level element signal, which is inversely proportional to the sodium level in the source tank and has a range of 10 to $0 \mathrm{mV}$, is recorded on leve 1 recorder $\mathrm{LR}-16$ and also on the Dextir digital data system during steady-state operation and on a highmspeed digital data system during a themal transient. In addition, the signal is converted to a range of 10 to $50 \mathrm{~mA}$ by signal conditioner LM-16 to actuate level switches LS 16A, LS-16B, LS-16C, and LS-160. Switches $\mathrm{LS}-16 \mathrm{~B}$ and $\mathrm{LS}-16 \mathrm{C}$, which are very important to the control of the facility during a thermal transient, are discussed in Sect. 3.4.5. Switches LS-16A and LS-160, which were installed to reduce the pressure potential for a sodium leak, are discussed in Sect. 3.4.12.

The sodium level in the sump tank is measured with a NaK-filled pneumatic differentialmpressure transmitter, $4 T-32$, which has one diaphragm seal connected to the vapor space at the top of the sump tank and the other below the liquid level to the bottom of the tank. The differentialm pressure signal is a direct function of the liquid level in the tank and 
is read out with liquid-1evel indicator LI-32. No alarms or safety actions are actuated by the sump tank liquid-1evel device.

\subsubsection{Sodium pressure control}

The source tank is supplied with argon at the high flow rates required for a thermal transient through valve $P C V-1 \mathrm{~A}\left(\mathrm{C}_{\mathrm{V}}=4\right)$ and for the

much lower, steady-state flow rates through valve $P C V-1 B\left(C_{v}=0.02\right)$. The tank is vented at low flow rates through valve $P C V-1 C\left(C_{V}=0.6\right)$ and at the high flow rates required for emergency venting through $P C V-3\left(C_{v}=\right.$ $5.6)$.

The control scheme is based on measurement of the source tank gas pressure. This pressure is measured with a differential-pressure transmitter, PdT-1, which compares tank pressure to a reference pressure furnished from the argon reference supply described in Sect. 3.2.2. The differential transmitter has good accuracy over the range \pm 15 psid, and thus for a reference pressure of 700 psig provides a measurement of source tank pressure over the range 685 to 715 psig.

The differential-pressure transmitter and other pressure transmitters associated with the source tank are isolated from the source tank sodium vapor by a diaphragm seal filled with silicone fluid that may be operated at temperatures as high as $450^{\circ} \mathrm{F}$. During operation temperature of the diaphragm seal is maintained between 250 and $300^{\circ} \mathrm{F}$ to prevent freezing of sodium vapor in the assembly.

The measurement signal from PdT-1 is transmitted pneumatically to pneumatic recorder-controller PRC-1, which in turn transmits a pneumatic signal to the pneumatic actuators that control the positioning of valves PCV-1A, PCV-1B, and PCV-1C. The signal pressure range required to move these valves from initial opening to full open operation is 10 to $161 / 4$ psig for PCV-1A, 9 to 12 psig for PCV-1B, and 8 to $21 / 4$ psig for PCV-1C. The control system acts to restore source tank pressure automatically upon a departure from equilibrium pressure. With the source tank and reference pressures in equilibrium at $700 \mathrm{psig}$, the output signal of PdT-1 is 9 psig, which produces an output signal of 9 psig from controller PRC-1 when the controller set point is at midscale. The 9-psig controller output signal keeps large supply valve PCV-1A and slow vent valve PCV-1C 
tightly closed and makes slow supply valve PCV-IB just about ready to open. A slight decrease in the source tank pressure acting through PdT-1. Increases the controller output to moxe than 9 paig, thus opening PCV-1B to restore the tank pressure. A continued decrease in the source tank pressure increases the controller signal pressure until at 10 psig large supply valve pCV-lA will begin to open to restore pressure more rapidly.

When the source tank pressure is above the reference pressure, the controller pressure is decreased below 9 psig by the action of PdT-1, and at 8 psig slow vent valve PCV-1C starts to open to reduce tank pressure and is fully open at $21 / 4$ psig. If the pressure increases to $735 \mathrm{psig}$, pressure switch PS-1A deenergizes solenoid valves ESV-IC and ESV-3, which then opens both PCV-1C and large vent valve PSV 3 until the pressure is reduced to within its proper range.

A subsequent modification that was made to the pressure control sysrem to maintain the source tank pressure within \pm 25 psi of the reference pressure during a thermal transient is discussed in sect. 3.4 .5 .

The gas pressure equalization line between the source and sump tanks promotes sodium drainage but communicates only when the two tanks are already nearly equalized at low pressure so as to protect the lowmpessure sump tank. Pressure aqualization valve psv-4 is opened automatically during an emergency drain only after the source tank pressure drops below 20 psig. The check valve, XV 4, remains closed at high pressures in the source tank to protect against the unlikely cailure of PSV-4.

The ASME requirement for vesse1 pressure-rellef protection is furm nished by the sequential and rapid operation of rupture disk $X X-10$ and pressuremrelief valve pV-10.

The sump tank is supplied with lowmpressure axgon through pressure regulator PV-25 to maintain an inert cover over the tank sodium surface. During steady-state operation the pressure is limited by the operation of back-pressure regulator pV-26, which functions as a low flow rate vent to relieve the sump tank gas to approximately $21 / 2 \mathrm{psig}$.

\section{4 .5 Thermal transient control}

The temperature downshock parameters of a thermal transient that can be furnished by the Eacility axe determined by the pipe nest design and 
temperature gradients imposed on the sodium in it and by the pressure potential between source and sump tanks available to establish the sodium flow rate. The flow portion of the transient is governed from initiation to completion by a sequence of automatic actions that take their signals from the liquid level in the sodium source tank. The pressure in the source tank during the thermal transient is maintained by argon from the high-pressure argon system.

When the proper preconditions of pressures and temperatures in the sodium systems are obtained, the thermal transient is initiated by pushing switch HS-A27B to the open position. This action opens solenoid valve ESV-1T, which causes sodium shutoff valve PCV-17 to open rapidly, within approximately $0.1 \mathrm{sec}$, to start the flow of thermal transient sodium. After approximately 70 gal of sodium has flowed from the source tank, the operation of 1iquid-level switch LS-16B closes PCV-17 to stop the transient. The valve is closed relatively slowly, within $5 \mathrm{sec}$, to avoid "pressure hammer" effects on both the test section and the valve. In the event of an operational failure of LS-16B, the sump tank is protected from high pressure by the operation of level switch LS-16C. This switch, which is set at a slightly lower level than LS-16B, shuts off the high-pressure argon supply, opens small vent valve PCV-1C and emergency vent valve PSV-3, and closes sodium shutoff valve PCV-17. The concurrent alarm is the signal to the operating personnel to close PCV-17 manually to give additional protection to the sump tank.

Although the control of the thermal and flow portions of the transient was demonstrated satisfactorily during initial operation of the facility, the classical control for source tank pressure described in Sect. 3.4.4 was not compared with the permissible range of $\pm 25 \mathrm{psi}$ and the pressure oscillated several times before reaching an equilibrium value. Briefly, the flow rate of the sodium being accelerated from the source tank under the 700-psi potential existing between the source and sump tanks was greater than the flow rate of argon into the source tank from the highpressure argon system at the initiation of the transient. A study indicated that the time constants of the pneumatic lines connecting differential-pressure transmitter PdT-1 to pressure-recorder-controller PRC-1 and the latter to the valve actuators were too large to permit the 
argon control valves to open as fast as required to match the sodium flow rate at the initiation of a transient.

The problem was solved by overriding pressuxe controller pacm at the initiation of a transient and supplying the valve positioners dixecty from an independent source that was regulated to 12.3 paig with pVm $52 \mathrm{E}$ and controlled with threemwy valve BSV-1D. It was determined expeximentally that a pressure of 12.3 psig would open the supply valves sufficiently fast to a proper predetermined position at which the flow rate of argon to the source tank would balance the flow rate of sodium from the tank. This dynamic equilibrium is established within approximately 0.2 sec and maxntained for 2 sec, after which the independent source is shut off and the pressure control returned to PRCm1. During the modification, two accumulator tanks were installed into the highmpressure argon systam, one upstream and one downstream of PV G, to enhance the rapid and smooth response of the control system when required to deliver high gas flow rates at the start of a transient. This modification satisfactorily maintained source tank pressure within \pm 25 psig of design value without oscillations during the themal transiant program with the first test section.

\section{4 .6 Migh-temperature strain measurement}

The basic objective of ach pipe thermal ratchetring test is to determine the deformation response of the specimen as it is repeatady subjected to cyclic thermal and mechanical loadings. Thus, the success of each test hinges on obtaining accurate strain and deformation measurements. One of the objectives of the High-Temperature Structural Design Methods program, of which the thermal ratchetting tests are a part, $\hat{i} s$ to develop and evaluate various highmtemperature strain- and displacement-measuring techniques. Several different types of structural tests, in addition to the thermal ratchetting cests, are being performed in which strain- and deformation-measuring devices and techniques are being investigated. One of the major problems has bean the need for a small gige length. However, in the case of the pipe ratchetting specimens, this is not required, and, consequently, the Boeing ${ }^{12}$ highmtemperature capacitive strain gage seamo to be reliable for this application. 
The Boeing capacitive gage is the primary means of obtaining strain measurements in the pipe thermal ratchetting tests, and each specimen has several gages mounted in the circumferential and axial directions on the outer surface of the test section. To assure that meaningful data are being obtained and to evaluate other potential high-temperature strain-measuring devices, the capacitive gages will be backed up, on each test, by a number of other devices. These will vary from test to test, but on the first specimen they included Ailtech (Microdot) weldable resistance strain gages (model SG 425), strain-gage-based air-cooled extensometers, mechanical extensometers with remote TV monitoring, special Prewitt scratch gages, and several pairs of gage tabs for making "before and after" measurements at room temperature with Demec mechanical extensometers. Most of these backup devices were developmental and were expected, at best, to provide confirmatory data only during certain segments of each cycle. The capacitive gages, on the other hand, were expected to provide a continuous measurement of strain history throughout the test, and they apparently performed exceptionally well during the first thermal ratchetting test.

Some of the special strain-measuring devices used on the first test specimen may be seen in Fig. 3.9. The circumferential and axial straingage-based extensometers are located at the upper left, and the circumferential and axial mechanical extensometers are located at the upper right. The Boeing capacitive gages are covered by small sheet metal boxes. A pair of Ailtech gages may be seen on the side of the specimen near the center, and several pairs of Demec tabs are visible. The foil gages, which may be seen in the photograph, were for room-temperature calibrations and were removed prior to heating the specimen.

Specific descriptions and evaluations of the various strain-measuring devices used for each test will be given in the test program that is written for each test series in the High-Temperature Structural Design Methods for the LMFBR program progress reports and in topical reports written for each test series. Only the Boeing high-temperature capacitive gage is described here.

The high-temperature capacitive strain gage is shown schematically in Fig. 3.10; Fig. 3.11 shows one of the gages mounted in the circumferential 


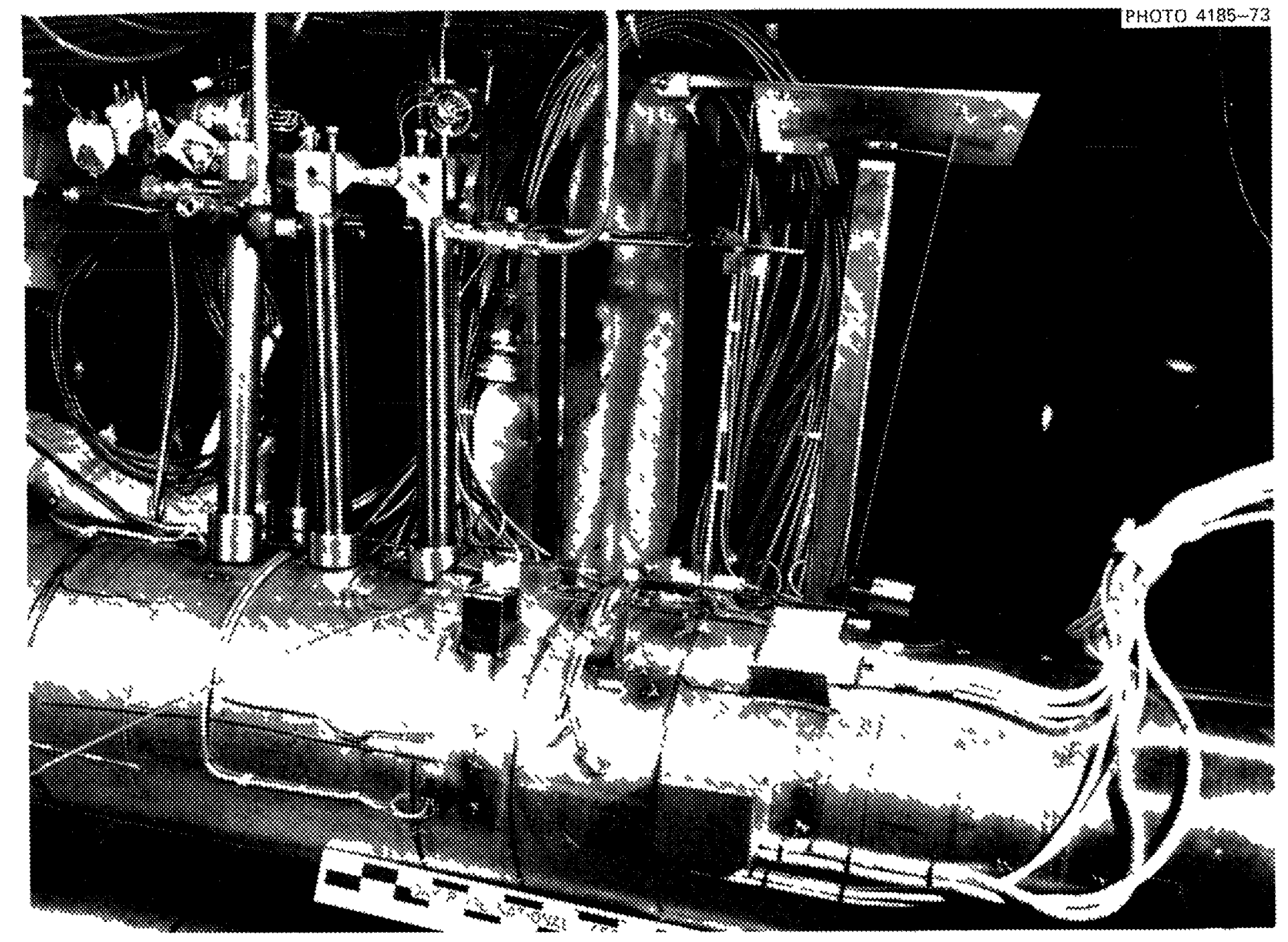

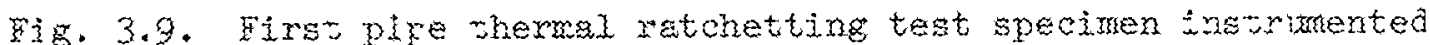
and notmted in the Thermal Trensient Test Pacility. 
OUTER CAPACITOR PLATE. WHEN IN PLACE COVERS ONE HALF OF EACH OF THE INNER PLATES. WHEN SPECIMEN LENGTH CHANGES DUE TO STRAIN, CAPACITANCE TO THE TWO INNER PLATES VARIES DIFFERENTIALLY

INNER CAPACITOR PLATES. EACH HAS CAPACITANCE TO-THE OUTER CAPACITOR PLATE. DIELECTRIC IS AIR. SLOTS ACCOMMODATE THERMAL EXPANSION COEFFICIENT DIFFERENCES BETWEEN INSULATORS AND PLATES

ATTACHMENT RIBBONS

Fig. 3.10. Exploded view of Boeing high-temperature capacitive strain gage. 12

ROD MATERIAL SAME AS MATERIAL OF SPECIMEN UNDER TEST

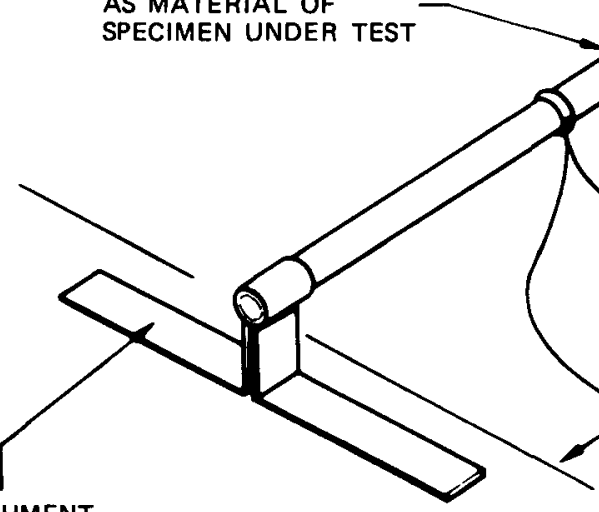

Non

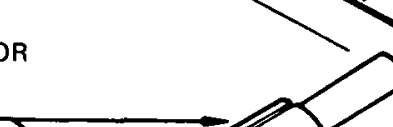

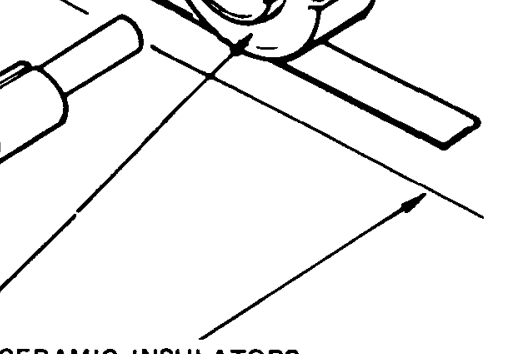

CERAMIC INSULATORS

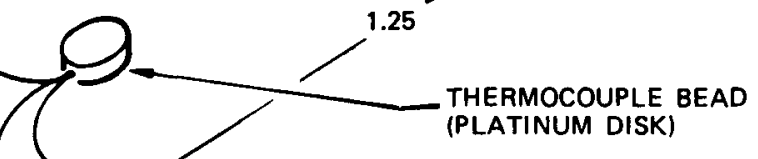

THERMOCOUPLE BEA
(PLATINUM DISK)

\section{SPECIMEN}

THERMOCOUPLE

DIFFERENTIAL

THERMOCOUPLE

direction on the first test specimen. Basically, the gage consists of two variable capacitors connected as a half bridge. The capacitor plates are concentric cylinders and the dielectric is air. The outer cylinder of the gage has capacitance to each of two inner cylinders, which are connected to the opposite end of the gage length by a small rod. As the specimen dimensions change due to strain, the two inner cylinders move axially with respect to the outer cylinder, changing its capacitance to them differentially. The basic gage length is 1 in. Both the rod connecting the two ends of the gage and the specimen surface directly under it are instrumented with thermocouples to provide data for computing corrections required by any temperature differences between the two. The need for temperature compensation during 1sothermal operation is minimized 


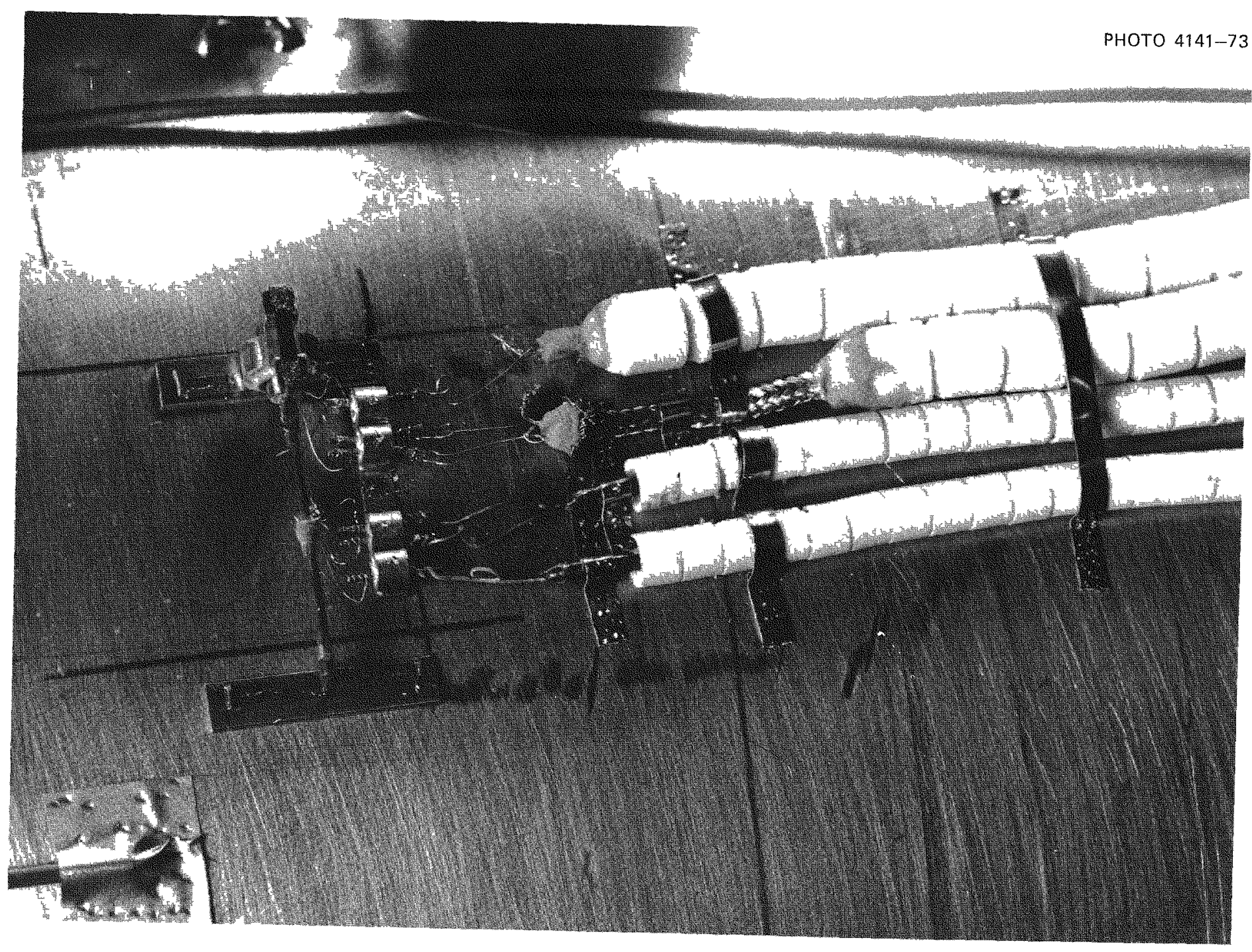

Fig. 3.11. High-temperature capacitive strain gage mounted in the circumferential direction on the first pipe thermal ratchetting test
specimen. 
by fabricating the rod of the same material as the specimen (in this case the actual pipe material was used to make the rods).

The Boeing capacitive gage is a long-term stable device with good resolution over an extraordinarily wide strain range. The gage output is linear over the entire range, and gage sensitivity changes only slightly with temperature. Thus the gage is ideally suited for this application.

The Boeing high-temperature capacitive strain gage system is described in detail in Ref. 12; pertinent parameters for the system are reproduced below.

Strain gage

Overall size

Gage length

Maximum strain range

Loading

Temperature range

Sensitivity

Sensitivity change with temperature
0.6 wide, 0.35 high, 1.25 in. long

1.00 in. nominal

$\pm 20,000 \mu \varepsilon$

$80 \mathrm{~g}$ for $20,000 \mu \varepsilon$

To $1500^{\circ} \mathrm{F}$

$0.018 \mathrm{pF} / 1000 \mu \varepsilon$ (nomina1)

$\pm 4 \%$ at $1500^{\circ} \mathrm{F}$

Strain-measuring system (with dc supply set at $30 \mathrm{~V}$ )

$$
\begin{aligned}
& \text { Nonlinearity } \\
& \text { (zero based) }
\end{aligned}
$$

Drift

Resolution

Thermal output

(apparent strain)

Strain rate $\pm 0.5 \%$ to $3000 \mu \varepsilon$ at $70^{\circ} \mathrm{F}$

$\pm 1 \%$ to $1500 \mu \varepsilon$ at $1500^{\circ} \mathrm{F}$

$\pm 2 \%$ to $20,000 \mu \varepsilon$ at $70^{\circ} \mathrm{F}$

$30 \mu \varepsilon$ maximum in $4 \mathrm{hr}$ with gage at $1200^{\circ} \mathrm{F}$

$0.3 \%$ of minimum full scale of $1500 \mu \varepsilon$ (including $\mathrm{HP} 7035 \mathrm{~B} \mathrm{X}-\mathrm{Y}$ plotter)

$+300 \mu \varepsilon$ to $1500^{\circ} \mathrm{F}$

$<2 \%$ nonlinearity to $30,000 \mu \varepsilon / \mathrm{sec}$ at $70^{\circ} \mathrm{F}$

\subsubsection{Low-pressure argon control}

There are two low-pressure argon supplies to the facility. One consists of three standard gas cylinders, and the other is the building argon 
supply. Each of the three cylinders in the system has a aeparate regum lator ( $P V-20, P V-21$, and $P V-22)$ which is comected to a comnon manifold through manual shutoff valves. The manifold pressure is indicated by pressure gage PI-24A and monitored by pressure switch PS-24, which actuates the alarm whenever the manifold pressure drops below 18 psig.

The low-pressure argon system supplies inert cover gas to the sump tank to protect the stored sodium agalnst the intrusion of atmospheric air and moisture and to raise sodium from the tank into the sodium system during the filling operation. The system is used to purge the highpressure argon vent Iines between valves PCV $1 \mathrm{C}$ and PSV 3 and their respective check valves, $\mathrm{XV}-1$ and $\mathrm{SV} 2$, to prevent the back diffusion of aix tato the sodium system during the evacuation that precedes the sodium filling operation. Lowmpressure argon is introduced to the downstream side of PVC-17 through check valve XV-18 and valve HV-3B to break the sipkon, that is, to drain the sodium that would otherwise fill the line between $p V C-17$ and the sump tank.

The building argon system makes large quantities of the gas aval1able to the argon firemsuppression system. The availability of the supply is monitored by pressure switch $\mathrm{PS} 44$, which is set to alarm at 50 psig. Pressure regulator PV 44 is set to the proper supply pressure. The signal from the simultaneous operation of the two smoke detectors locatad at the baffled opening in the protective cupola near the top of the facility deenergizes solenoid valve FS-44, which permits argon to flow into the catch pan to smother burning sodium.

The pressure setting for PS 44 was chosen to fulfill a second purpose, that is, to alext operating personnel whenever argon flows into the catch pan regardless of the cause. The drop in pressure caused by the flowing of argon is sufficient to activate the alam. Any time this alaxm sounds for more than a few moments, lowmlying areas are to be monttored for oxygen daficiency; see Sect. 6.3.1.

\section{4 .8 Steady-state data acouistiton}

Data generated during the steady-state (creep) test operation of the facility are recorded on panel instruments and on the Dextir digital datam 
acquisition system that is described briefly in sect. 3.2.6. The pane1mounted instruments are installed in cabinets located close to the facility and grouped to serve as a control center.

Steady-state data are those used primarily to operate the facility and those needed in the analysis of the experimental creep test results. Operational data are recorded or indicated principally on the panel instruments, while most of the experimental data are indicated or recorded on panel instruments and are recorded on the Dextir system. of a total of 200 temperatures measured for the facility, 48 experimental points are recorded on the Dextir system.

The TTTF connections to the Dextir system consist of three analog or data gathering boxes, one digital input panel, and one thermocouple reference junction box. Each analog box has 25 input channels that are scanned automatically about once an hour during steady-state operation. The Dextir acquired data are digitized and recorded on magnetic tape for subsequent computer processing.

\subsubsection{Thermal transient data acquisition}

The requirements for data acquisition during a thermal transient are considerably more stringent than for steady-state operation. It is necessary to sample each appropriate channel sufficiently of ten and sufficiently accurate during the transient so that a continuous history of the changes in the sampled measurement can be constructed. The required high-speed data-acquisition capability, far exceeding the 8 channels per second in the Dextir system, is furnished by an ANSCAN and the LMFBR-DAS high-speed digital data systems. The portable ANSCAN is available only on a loan basis and was used only during the first four thermal transients with the first test section. The LMFBR-DAS, recently installed at the site of the Fuel Failure Mockup (FFM), is now the prime system for acquiring thermal transient data.

Connection equipment has been installed so that as many as $60 \mathrm{fa-}$ cility signals can be recorded on either the ANSCAN or the LMFBR-DAS. The equipment permits a signal recorded on the LMFBR-DAS to be recorded on the Dextir system but does not permit a signal recorded on the ANSCAN to be recorded on the Dextir. 
The ANSCAN records the 50 to 60 experimental measurements at the rate of 600 data points pex second over a period of 0.2 sec. Thus the ANSCAN scans and records the data for about 0.1 sec and is then idle for the next $0.1 \mathrm{sec}$, after which the cycle is repeated for as many times as required. The data are recorded on magnetic tape for subsequent computer processing. The ANSCAN has a digital-to-analog converter that peratts retrieving data, one channel at a time, for plotting on an analog instrument such as a stxip-chart or an $X-Y$ plotter.

The LMFBR-DAS, which is described more completely in Sect. 3.2.7, can take 10,000 samples each second for a single channel and can be programmed to utilize this capability for up to 2.28 channels up to the maximum of 10,000 samples per second. For the TTTE it is being programmed to record 9 preselected channels at the rate of 1000 samples per second and then to record the remaining approximately 45 channels in sequence, one at a time, between each scan of the 9 selected channels; thus the recording sequence would be 1 through 9,$10 ; 1$ through 9, 11; 1 through 9, 12; etc. In this manner each of the 9 preselected channels would be recorded at a rate of 1000 samples pex second and each of the remaining points at about 20 samples per second.

\subsubsection{Instrument air and nitrogen supplies}

The instrument air system supplies clean oil-free compressed air to vaxious facility controllers. Air is supplied through pressure regulator QV -51 at 20 psig to level transmittex LT 32 on the sump tank, differentialpressure transmitter PdT-1, pressure-recorder-controller PRC 1 , and presm sure modulator PM-2A. Air is also supplied through pressure regulator PV -49 at 55 psig to the actuators for control valves PCV-1A, PCV-1B, PCV1C, and PSV-3 in the highmpressure argon system. If the instrument air supply fails, the nitrogen system automatically assumes it functions.

The nitrogen supply provides the motive fluid to the actuators for equalizing line shutoff valve PSV-4 and sodium shutoff valve PCV-17. Two cylinders of nitrogen are manifolded to pressure regulator PV -45 to supply nitrogen at 150 psig to the actuators. The nitrogen supply is also connected to the instrument air supply through pressure regulator $9 V-46$ and 
reverse-flow check valve $\mathrm{XV}-46$. When the instrument air pressure falls below 60 psig, the nitrogen supply furnishes the requirements normally handled by the instrument air supply.

The three-way solenoid valve, ESV-17, controls the positioning of sodium shutoff valve PCV-17. It shuts off the nitrogen supply and vents the actuator cylinder to open valve PCV-17 and admits nitrogen and shuts the vent to close the valve. The solenoid is operated electronically in control circuit $\mathrm{C}-27$.

\subsubsection{Pressure-relief valves}

A number of pressure-relief valves are employed to protect various portions of the facility from excessively high pressure. Although all pressure regulators in the high-pressure argon system, except PV-6, are pressure-relieving regulators, the pressure control of the sodium system could be subjected to unwanted upsets by a leak in PV-6 that could permit the pressure between this valve and PCV-1A to build up to the supply cylinder maximum value of 2000 psig. Pressure-relief valve PSV-9, which is installed in the line connecting PV-6 to PCV-1A, is set to relieve at 950 psig to protect against such a leak condition.

The piping and components in the sodium system are protected against excessive pressure by rupture disk assembly $\mathrm{XX}-10$, located just upstream in the relief line from pressure-relief valve PSV-10, both of which are set to relieve at $800 \mathrm{psig}$. An excess flow line containing check valve XV-10 connects the space between the rupture disk and the pressure-relief valve to atmosphere to prevent the buildup of pressure in the event the rupture disk develops a slow leak. Pressure gage PI-10 and pressure switch PS-10 are also installed in this line to monitor pressure and to sound an alarm on an increase in pressure.

The sump tank is protected from excess pressure by back-pressure regulator PV-26 and by a U-tube manometer that is made of $21 / 2-i n$. sched40 pipe and appropriately filled with "Hercolube A," a sodium compatible fluid. Regulator PV-26 protects against a slow pressure increase that could be produced by temperature increases, leaking valves in the lowpressure argon system, etc. The manometer limits the pressure buildup in 
the tank that could be produced by a simultaneous major failure or ma\}function of sodtum shutoff valvo pCy-17 and the highmpessure argon supply valves. This situation could lead to a direct connection between the sump tank and the bighmpressure argon system via a drained solium system through which argon could flow rapldiy into the tank. The manometer can safoly relieve the gas that could flow from ajx gas cylinders connected to the highmpressure argon supply manifold. By admintstrative action, the operating persomel connect only one cyllnder ducing steady-state operation and a maximus of five during a themal transiant. The manometer is rilled with fluid before evacuating the sump tank so as to provide a liquil seal to protect the stored sodium againet the instruston of air and mosture.

The lowmpressure argon system, the nitrogen supply, and the instrument air supply are protected from high pressure by pressure-relief valves PSV -23, PSV 45 , and PSV 47 respectively.

\section{4 .12 Scrams and alanns}

The facility is equipped with alarms and autonatic controls to guard against the consequences of sodium leaks and fires, temperature, prassure, and liquid-level signals outside prescribed boundaries, and loss of elactrical power supplies. All of chese conditions intiate appropriate automatic control response and axe signaled by the audible and visual alarm to the operating pexsonel during attended operation and to the $Y-12$ Blant Shlft Superintendent (PSS) during unattended operation. The automatic controls produce a scram or a less severe partial scram to put the facility into a safe condition uncil the operators can reatoxe proper and sate conditons. Diagrams of the control circutts and annunciators are presented in Appendix $C$, drawings 1-10596-06-003-0-1, -004-13m, and n008 0m2, along wth a sumary of the parameters leading to the automatic actions.

Scram. The scram signal (fast automatic drain) intitites automatic control actions leading to the rapid venting of argon from the source tank to atmospheric pressure, valving off the argon supply, draining of system sodium into the sump tank, opening the gas equalizex valve, turning 
off all heater power, and turning on the argon fire-suppression system and the building exhaust fans. A scram is initiated only by the coincidental operation of the two smoke detectors for a period of $5 \mathrm{sec}$ or longer, by the coincidental operation of either of the smoke detectors for $5 \mathrm{sec}$ or more and the first low-level signal from the source tank, or by the loss of the control power electrical supply. The 5-sec delay eliminates the deleterious effects that unwanted scrams initiated by momentary losses of power can impose on the test section. The smoke detectors are fail-safe and upon the loss of control power will indicate the presence of smoke and initiate a scram.

Partial scram. A scram subjects the test section to the unprogrammed loss of test membrane stress and reduction in temperature and to the reverse effects when the programmed test conditions are regained. Therefore, all signals, other than the scram signals listed above, produce partial scrams that take only the minimum automatic control action required to protect the facility or component from the consequences of the alarm conditions. High temperature in the sodium system, which is monitored at ten locations by ten independent instruments, shuts off all heater power. High source tank pressure, which is monitored by pressure switch PS-1A, vents gas through safety valve PSV-3 to return the pressure to the test value. High sump tank pressure, which is monitored by pressure switch PS-54, vents the source tank pressure to atomspheric level and closes sodium shutoff valve PCV-17, if it is open, to reduce the amount of gas that can flow into the sump tank.

A small decrement in the level of sodium in the source tank, which is monitored with level switches LS-16A and LS-16D, vents the tank gas to reduce the potential available to the leak. Two switches are required because the sodium level is higher during steady-state operation than during preparation for a thermal transient, and each switch is set to operate just below the appropriate operating level. The switches are connected in series but with one or the other bypassed at all times through the operation of manually operable switch HS-A25A. This latter two-pole, double-throw switch permits the operator to select the level switch that is set closer to the operating level in the tank. 
Alarms. A deviation of a number of other parameters from their respective operating ranges may create no tmmediate threat to personnel safety, facility integrity, or test data validity, but it does require recognition and correction by the operating personnel. These parameters are monitored by instruments that produce the audible and the visual alarms. A total of 30 individual indicators are installed; drawing I10596 QGm008mD in Appendix $C$ presents the elementary wiring diagram for the associated control circuits.

An alarm condition is indicated by a ringing bell and by both a redand a whitewighted window in the appropriate annunciator, Acknowledgment of the alarm condition by pressing the "acknowledge" button on the instrument panel silences the be11 and, if the condition still exists, turns off the white light. When the alarm condition clears, the red light turns off and the white light turns on. The white light may then be turned off by pressing a "reset" button on the panel.

\section{4 .13 Uncertainty analysis}

The temperature, pressure, and liquid-level instruments were selected, tested, and applied on the basis of obtaining experimental data having measurement accuracles compatible with the purposes of the ratchetting test program. The sensors, readouts, and the accuracy of the sensor readout combinations for experimental data are discussed below. Facility operating data are taken with conventional instrumentation having appropriate accuracies and are not discussed here.

Temperature measurement. The premium-grade Chrome1-Alumel thermocouples that are used to obtain experimental data from the test section have a specified accuracy of $\pm 3 / 8$ of $1 \%$ reading in the range of interest. They are joined to twistedmpair, double-shielded, equal-resistance extension wires with thermocouplengrade connectors. The signals are referenced to a Research Incorporated, 48-point, $150^{\circ} \mathrm{F}$ reference junction that has a specified accuracy of $+1 / 4^{\circ} \mathrm{F}$.

The signals are recorded on the Dextir digital datamacquisition system during steady-state conditons and on the high-speed digital dataacquisition system (ANSCAN) during thermal transients. The accuracy of 
the Dextir system is $\pm 0.07 \%$ of full scale on the $100-\mathrm{mV}$ range, which is approximately $\pm 31 / 2^{\circ} \mathrm{F}$ in the range of interest. The ANSCAN high-speed data system, which was used for the first four thermal transients in test series 1 , has an accuracy of $\pm 0.09 \%$ of full scale on the $100-\mathrm{mV}$ range at a scan rate of 1000 points per second. The LMFBR-DAS, which will be used with future test sections, has an accuracy of $\pm 0.25 \%$ of full scale in the 40-mV range. Thus the LMFBR-DAS signal has above the same accuracy as the Dextir system, approximately $\pm 4^{\circ} \mathrm{F}$ in the range of interest.

The commercial-grade Chromel-Alumel thermocouples that are used to obtain facility operating information have a specified accuracy of $\pm 3 / 4$ of $1 \%$ of reading in the range of use.

Pressure measurement. The source tank pressure that supplies the membrane stress in the test section is measured with two unbonded strain gage pressure transducers having a specified accuracy of $\pm 1 / 2$ of $1 \%$ when calibrated at operating temperature. Experimental data are taken with pressure transducer PT-55, to which an Endevco mode1 4471.1A bridge conditioning circuit having an integral power supply is applied. The accuracy of the conditioning circuit, which is dependent on power supply stability, is specified to be $\pm 0.03 \%$ of constant supply voltage at constant temperature over a 48-hr period. During steady-state operation, the signal is read out with a Hewlett-Packard model 2402A digital voltmeter having a specified long-term reading accuracy of $0.01 \pm 0.005 \%$ of full scale. Thus during steady-state operation with the first test section, the source tank pressure was read out to an accuracy of $\pm 0.5 \%$ of full scale, or $700 \pm 5$ psig. During a thermal transient the signal will be read out on the LMFBR-DAS with an anticipated accuracy of $\pm 0.6 \%$ of full scale. The calibration of the pressure measurement system, which is made at source tank operating temperature, is checked periodically.

Facility operating data for the source tank pressure are taken with pressure transducer PT-2, which is connected to a Bell and Howell model 18-112A resistance transmitter that converts the transducer millivolt signal to an output current in the range 10 to $50 \mathrm{~mA}$. This signal is then recorded on a Foxboro strip chart to give an accuracy of $\pm 1 \%$ of $f u l l$ scale. 
Sodium level measurement. The source tank sodism level sensor is an electrical resistance "twin I-tube" that was destgned and sabricated in houge. Although the time schedule precluded a Eull calibration of the sensor before installation, prior usage of similar iustruments has astablished that a static measurement accuracy of $+1 \%$ of full scale or better may be expectad by performing inmsitu end point calibrations at operating temperature. However, the instantaneous accuracy of the level measurement is somewhat degraded during rapid level changes by the tendency of the liquid metal to require a finite the to wet the probe completely with increasing level or to drain off completely with decreasing level. These phenomena cause the instantaneously indicated level to lag the actual level by 3 to $4 \%$, depending primarily on the rate of change of level. These dynamic errors always cause tho signal to lag the actual measurement; they are not plusmorminus exrors. Within a short period of time akter a rapid level change, the probe wets or drains appropriately, and the indicated and actual levels are agatn in phase.

The level is recorded on a full-scale Minneapolis-Honaywell stripchart recorder having chart speeds of $24 \mathrm{in}$./hr and $24 \mathrm{in}$./min which axe used, respectively, during steady-atate and thermal-transient operation. The accuracy of the recorder is $+1 / 4 \%$ of full scale. 


\section{FACILITY LIMITATIONS, SET POINTS, AND PRECAUTIONS}

\subsection{Limitations and Set Points}

A list of specified set points and operating ranges for all the TTTF instrumentation and controls is presented in Appendix I. The 1imitations and set points for the two fully automatic control loops, the manual heater controls, and the liquid level in the source tank with sodium are discussed below.

Although the automatic control loops for the source tank pressure and the test section temperature have no self-contained limits, there are safeguards that protect the facility and the test section against the excessive pressure and temperature that can accompany the misoperation of these controls.

Pressure regulator $\mathrm{PV}-7$, which supplies the reference pressure for the differential-pressure transmitter $\mathrm{PdT}-1$ in the source tank pressure control loop, has an adjustable range of 0 to $750 \mathrm{psig}$. The set point of controller PRC-1 adds another $\pm 15 \mathrm{psi}$, so that the maximum pressure that can be introduced into the source tank by the misoperation of the controller is 765 psig even if the automatic vent valve PSV-3 does not function. If pressure regulator PV-5, which controls the output pressure of regulator PV-6, is misoperated or if PV-6 develops a leak across the valve seat, the pressure available to supply control valve PCV-1A can approach that in the gas cylinders connected to the manifold of the high-pressure argon system. However, the source tank is protected against the possibility of such high pressure by the combination of the pressure-relief diaphragm XX-10 and valve PSV-10, which are set to relieve at 735 and 800 psig respectively. In addition, a small relief valve, PSV-9, downstream of $\mathrm{PV}-6$, is set to relieve at 950 psig.

The source tank is pressurized slowly by placing pressure controller PRC-1, which controls supply valves $P C V-1 A$ and $P C V-1 B$ and vent valve PCV$1 C$, in the automatic operating mode and increasing the reference pressure slowly by the manual operation of regulator PV-8. In addition, the pressure furnished to the supply valves by regulators $\mathrm{PV}-5$ and $\mathrm{PV}-7$ is increased to a level only slightly higher than the controlled advance of 
the reference pressure. In this mannex the source tank pressure is maintained very near the reference pressure at all times, and large pressure overshoots are aroided.

Test section tempexature controllex TRC-19 has no absolute limit of its own to prevent a misoperation that could lead to excessively high test section temperatures. A limit switch that is set about $5^{\circ} \mathrm{F}$ above the controller set point protects agalnst controllex failuxe by interrupting the output signal required to apply electric power to the oven heaters until the cemperature again drops below the limit point. Since this switch setting is relative to the controller set point, it does not protect against placing the set point too high nor does it provide an alarm. However, primary protection against high test section temperature is provided by independent temperature monitor TM 16, which turns off all electrical heatex power when its set point of $1115^{\circ} \mathrm{F}$ is exceeded for longer than I min. The time delay prevents spurious shutdowns due to electrical noise and allows time for instrument stabilization following a momentary power outage. The thermal inertia of the test section is sufFiciently large that the increase in temperature at high temperature during the 1-min delay is comfortably small.

Since both the temperature and the pressure controllers are narrow span instruments and respond to relatively sma11 differential signals rather than to full-range signals, controllex dead band is not signtficant. The overshoot of the controlled variables also is small, partly due to the naxrow spans of the controllers and partly due to the administrative con straints in system operation. For example, during system heatup, test section temperature increases are limited to a rate of $50^{\circ} \mathrm{F} / \mathrm{hr}$, which is accomplished administratively by manual. adjustment of four autotransformers to limit the maximum power available to the automatic temperature controller. When the test section is at the required steady-state temperature, the setting of the autotransformer is reduced to further limit the heatup rate in the event the controller fails.

Each of the manual heater controls, which are adjustable autotransformers, is limited by a mechanical stop to prevent applying excessive voltage to the heater circuit. Every separately adjustable heated section or zone is protected with at least one temperature sensor that can actuate 
the alarm on high temperature. The signals from nine additional temperature sensors located strategically on the sodium system piping are scanned by independent temperature monitors that can turn off all electrical heater power on a high-temperature signal.

Although the sodium level in the source tank is not automatically controlled, the sodium level signal is used to initiate other actions pertaining to the safe and orderly operation of the facility. During sodium filling, the source tank is protected by administrative control and a high-sodium level alarm to assist in alerting the operating personnel of an impending overfill. Level switches LS-16A and LS-16D, called the "first low-level" switches and set to actuate on a very small decrease in sodium level, depressurize the source tank and sound an alarm. If, in addition to a low sodium level signal, one or more smoke indications is simultaneous1y signaled, the automatic fast scram described in sect. 5.10.2 is imposed on the sodium system. The function of the first lowlevel switches is bypassed during a programmed drain.

Level switch LS-16B, called the "second low-level" switch and set to terminate the end of a thermal transient, closes the sodium drain valve PCV-17.

Level switch LS-16C, called the "third low-level" switch and set to operate below the lowest sodium level expected during a thermal transient, is a backup to the second low-level switch. It depressurizes the source tank, closes sodium shutoff valve PCV-17, and alerts operating personnel to close the sodium shutoff valve manually and quickly to protect the sump tank from high pressure if the original signal from LS-16C has not already closed the shutoff valve.

As an added safety precaution for the sump tank, pressure switch PS54, which is installed on the sump tank, is set to operate on a pressure increase in the tank above $6 \mathrm{psig.} \mathrm{It} \mathrm{depressurizes} \mathrm{the} \mathrm{source} \mathrm{tank,}$ closes the drain valve PCV-17, if it is open, and sounds an alarm to alert operating personnel. 


\subsection{Precautions}

Although much effort was expended to produce a simple, flexible, yet reliable design of the instrumentation and controls for the TTTF, there are a number of conditions where administrative control must be relied upon either to prevent misoperation of controls or to minimize the consequences of misoperation. Written procedures were prepared for routine operations. This section is devoted to the precautions that apply during and following specific offuesign conditions, failures, and during startup.

If emergency venting of the source tank occurs due to smoke indication, high sump tank pressure, or low liquid level in the source tank, gas supply control valves PCV-1A and PCV-1B wil1 be closed and slow vent valve PCV-1C and pressure safety valve PSV-3 will be opened. During the venting operation the operator may determine that the test pressure condition can be restored because the need for the emergency venting does not exist. The normal tendency to restore the system to the test pressure condition quickly by simultaneously closing the vent valves and opening the supply valve must be avoided because a possible very rapid repressurization of the source tank can lead to collapse damage to the bladder inside the test section. The safe procedure that will be used in this situation is, in order, to (1) close the vent valves, (2) reduce the reference pressure appropriately to the vented pressure condition with regulator PV-8, (3) open the supply control valves, and (4) increase the source tank pressure at a controlled rate by increasing the reference pressure slowly with regulator $\mathrm{PV}-8$.

A similar condition for overcorrection exists upon loss of heater power for several hours, which could lead to substantial decreases in sodium system and test section temperatures and, possibly, freezing of the sodium. When this condition occurs, the operator reduces the power setting of test temperature controller TRC-19 and the autotransformers before reenergizing the heater circuits. The power settings of the controller and the autotransformers for the piping and other components are increased as required to melt the sodium or to meet the $50^{\circ} \mathrm{F} / \mathrm{hr}$ heating Iimitation. 
To minimize the consequence of controller failure, we have adopted the principle of maintaining the potential of the supply to a controller to a level only slightly higher than that required for good control. The supply gas pressure to the pressure control valves for the source tank is normally regulated at no higher than 40 psi above the source tank pressure. When the controller set point is changed, the supply potential is changed appropriately to be consistent with this principle.

During filling of the sodium system, the operating personnel manually control sodium shutoff valve PCV-17 and the high-pressure argon control valves, temporarily bypassing three level switches on the source tank liquid-level indicator. The high-level switch is still activated to sound an alarm to alert the operator of the possibility of overfilling. In the absence of sodium the first low-level switch depressurizes the source tank, the second low-level switch closes the sodium shutoff valve, and the third low-level switch does both. Hand switch HS-1A is closed to bypass the signals that depressurize the source tank, and push button HS-9 is closed to override the signals that close the sodium shutoff valve. When the filling operation is completed, the operating personnel must turn switch HS-1 to the operate position to return the control of depressurization and shutoff valves to the level switches. 


\section{OPERATION}

After all the required preoperational functional tests were performed satisfactorily, the facility was accepted for operation. A manual was prepared detailing the procedures required for all operations, and detalled check 1 ists were prepared as required to support the procedures. The op erating personnel utilize both the manual and the check lists to operate the facility.

The facility is prepared for pipe ratchetting tests in the following general manner. The various systems are started up procedurally: electrical, instrument afr-nitrogen, fire suppression, the low- and high-pressure argon, and the vacuum. The sump tank sodium, which was installed during a previous test program, is melted utilizing electrical heaters. The oxygen impurity level of the sump tank sodium is reduced to 4 to $6 \mathrm{ppm}$ by the sump tank cold trap system. The piping and components of the sodium system are evacuated and preheated with electrical heaters to approximately $500^{\circ} \mathrm{F}$. Gas lines exposed to sodium vapor are heated to approximately $300^{\circ} \mathrm{F}$ to avoid plugging with condensed sodium vapor.

After the system is filled with sodium and heated to $800^{\circ}$ to remove adsorbed moisture and oxygen from the container walls, the sodiun is drained to the sump tank for additional cold trapping. The system is then refilled with sodium and is ready for the pipe ratchetting test program.

The initial portion of a test ratchetting program usually consists of strain gage calibration and isothermal flow transients. The gages are calibrated against pressure at several temperature levels. The proper functioning of the automatic pressure control for the source tank and the automatic flow controls for the sodium flow transient are checked during the isothermal flow tests. After the required test pressure is imposed on the sodium in the source tank, the facility is ready for a thermal transient test. The calculated temperature gradients are imposed on the sodium in the pipe nest, the sodium shutoff valve is opened with the programmed drain push button to initiate the thermal transient, and a signal from an appropriate level in the source tank closes the shutoff valve to end the thermal transient. The highmpressure sodium system is then depressurized to permit the return of the thermal transient sodium to the source 
tank from the sump tank. The facility is repressurized, and the test section is heated at the rate of $50^{\circ} \mathrm{F} / \mathrm{hr}$, utilizing the automatic temperature control of the test section oven, to the test temperature of $1100^{\circ} \mathrm{F}$ to start the steady-state operation (creep test) portion of the pipe ratchetting test cycle. After an appropriate hold time for the creep test, another thermal transient is performed, and the cycle is repeated for the number of times required by the test program.

\subsection{Initial Fill}

The sump tank was filled with approximately 750 gal of sodium during a previous test program. Analyses of the sodium at the outset of the TTTF construction indicated an oxygen content of 15 to $20 \mathrm{ppm}$. Inert-gas purges were maintained carefully during the installation of new piping to the sump tank to avoid increasing the oxygen impurity of the sodium. Prior to raising sodium into the sodium system for the first time, at the outset of a test program, or after any maintenance involving opening the sodium system, the sodium impurity level is reduced as indicated below.

The sump tank sodium is melted, the cold trap system is started, and the sump tank temperature is raised gradua $11 \mathrm{y}$ to $750^{\circ} \mathrm{F}$, while the cold trap temperature is decreased gradually to approximately $300^{\circ} \mathrm{F}$. The cold trapping of sump tank sodium is then continued at the $300^{\circ} \mathrm{F}$ level during the course of the individual test program.

\subsection{Startup}

Prior to filling the system with sodium, it is preheated to approximately $500^{\circ} \mathrm{F}$ and evacuated for a minimum of $24 \mathrm{hr}$ to remove residual moisture. When the oxygen content of the sump tank sodium is verified by analysis of samples to be $<10 \mathrm{ppm}$, the sump tank and sodium system are evacuated, and the temperatures are approximately $600^{\circ} \mathrm{F}$, the sodium system is filled with sump tank sodium to the appropriate level in the source tank utilizing the procedure presented in sect. 5.6. The sodium system is then pressurized to approximately $5 \mathrm{psig}$, heated to $800^{\circ} \mathrm{F}$, and held there for $24 \mathrm{hr}$ to dissolve impurities from the sodium system container walls. 
After this soaking pertod, the sodium is drained and the system is refilled several times to insurte good mixing with sump tank sodium. If necessary, after analysis of a sample, the sodium is cold trapped as required and the sodium system is again refilled.

A11 heater control settings and corresponding temperatures have been at several isothermal temperature levels so that they may be reproduced conveniently during subsequent staxtups.

\subsection{Therma]. Transient}

A thermal transient in the TTTE consists of (1) the manually initiated but automatically stopped flow of a specific quantity of sodium upon which (2) the required temperature gradients have been imposed, while (3) the source tank pressure is controlled within specific limits to maintain the required membrane stress in the test section. The programmed drain check list presented in Appendix $J$ is used by the operating personnel during the preparation for and performance of a thermal transient.

The first step in the preparation is to set the temperature of the sodium in the source tank to $800^{\circ} \mathrm{F}$. The pipe nest sodium temperature gradient, as specified by the calculational method shown in Appendix $A$ and as measured with thermocouples attached at many locations along the pipe nest, is imposed by the manual adjustment of autotransformers that provide individual control of the 38 heater circuits that regulate pipe nest tem perature. The temperature of each heater zone is recorded and read out on a fast-response temperature recorder. The voltage settings of the autatransformers are recorded for subsequent use. Just before intiating a thermal transient, these voltage settings axe fine tuned as required. The source tank pressure is set at the test value if the first thermal transient is being performed or checked prior to subsequent transients. The functioning of automatic pressure controller PRC-1 is checked.

The thermal transient is initiated with push button HS-A27A, which causes the sodium shutoff valve to open fully in a fraction of a second. The sodium is accelerated quickly to design flow rate through the sodium system and into the sump tank by the large pressure potential that exists 
between the source and sump tanks. A liquid-level signal from the source tank closes the shutoff valve to end the transient. Pressure controller PRC-1 maintains the test pressure within specified limits during the transient by admitting gas as fast as liquid sodium leaves the source tank and shutting off the gas supply as soon as the transient flow is stopped. It then operates a vent valve that decreases the pressure caused by the heatup of the room-temperature gas admitted during the transient. If the shutoff valve should not close automatically, an event that is indicated by a signal from a lower liquid level in the source tank, the valve would be closed manually and quickly by the operating personnel to end the transient and thus protect the low-pressure sump tank from high-pressure gas.

The test section and pipe nest temperatures are then adjusted to $800^{\circ} \mathrm{F}$, and the programmed drain push button is reset. The data records are properly identified as to test series, test section, test operation, and thermal transient cycle number. Then the facility is made ready for depressurization to permit refilling the source tank.

\subsection{Strain Measurement}

Diametral measurements are made and recorded at a number of specific positions on each test section just before its installation into the test facility to provide a base line for comparison with experimental data. The diametral measurements are repeated at the same position after the test section is removed to provide gross strain measurements.

Demec gage tabs, each containing a precise gage point similar to a center punch mark, are tack welded to the test section and also to the facility piping at many locations to provide gage lengths for subsequent measurement of accumulated strain at room temperature. Measurements are recorded at the time of installation.

A typical plan for the location of the high-temperature strain gages, described in Sect. 3.4.6, is shown in Fig. 5.1. The gages are calibrated against temporarily installed foil gages at room temperature by pressurizing the test section before its installation into the test facility and before removing the nozzle closures used for pneumatic and leak testing. 


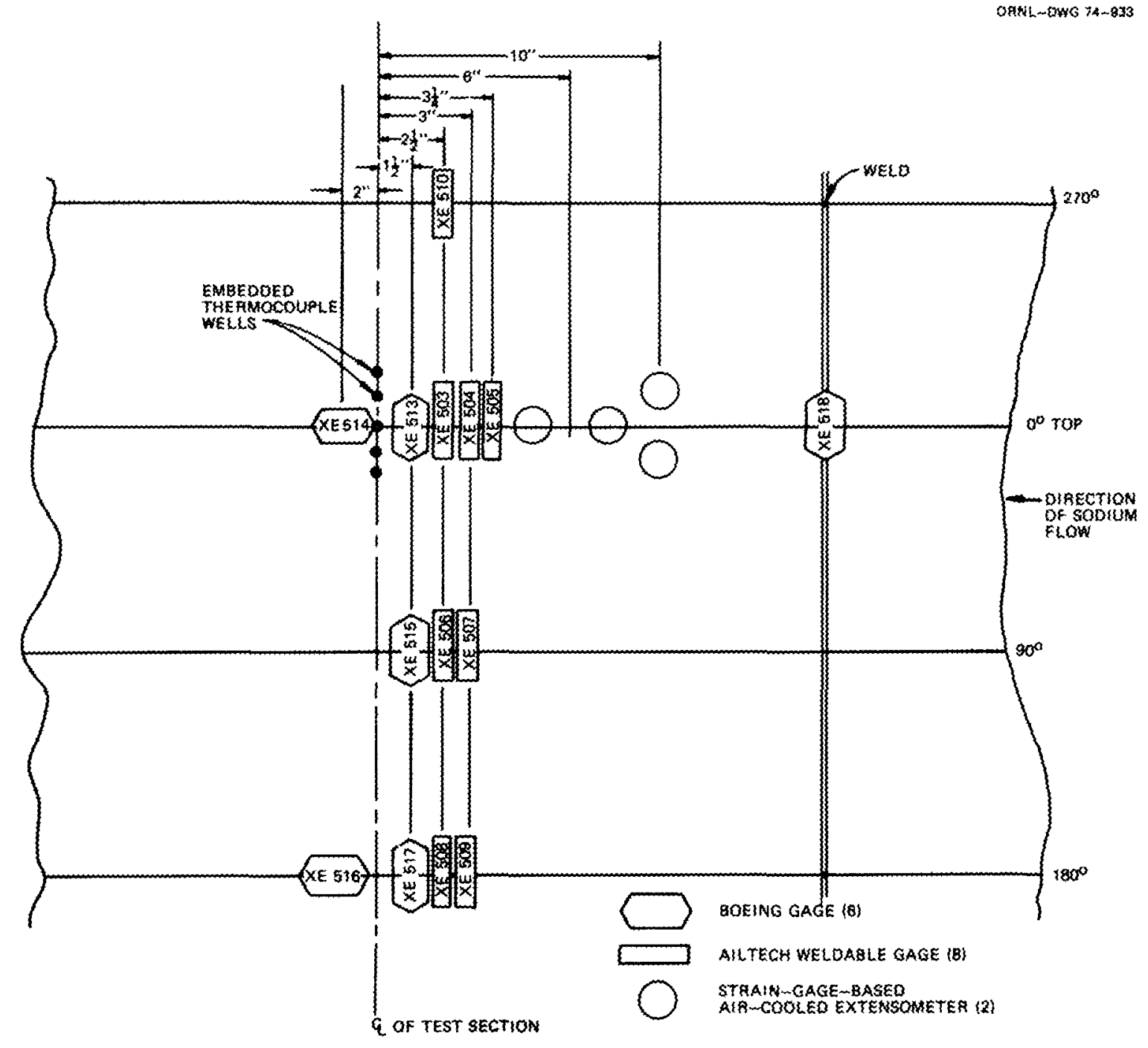

Fig. 5.1. Location of strain gages on test section 3C.

The delicate gages are protected by the test section oven during their installation into the test facility.

After installation, the high-temperature strain gages are callbrated by pressurizing the entire facility piping at room temperature and then at 800 and $1100^{\circ} \mathrm{F}$ after filling the system whith sodium. These calibrations are scheduled in the individual test program for each test series. 


\subsection{Depressurization}

After the scheduled completion of the thermal transient portion of a pipe ratchetting cycle, the source tank gas pressure is reduced to approximately atmospheric to permit refilling the tank with the sodium that has flowed into the sump tank during the transient. The depressurization is required because the low (15 psig) design pressure of the sump tank will not permit high-pressure refilling. Depressurization is accomplished by gradually reducing the setting of reference pressure regulator PV-5 manually after first placing controller PRC-1 in the automatic position. This action opens slow (or control) vent valve PCV-1C and reduces the pressure from the high test level to near atmospheric in approximately $5 \mathrm{~min}$.

Emergency depressurization can be accomplished manually with push button HS-A28B1, which opens emergency (or fast) vent valve PSV-3. However, to prevent rapid repressurization, the high-pressure supply valves are held closed with companion push button HS-A28A1. These push buttons require only momentary pushing.

\subsection{Refilling the Source Tank}

The approximately 70 gal of sodium that flows out of the source tank during a thermal transient must be returned to prepare the facility and test section for the steady-state (creep) portion of the pipe ratchetting cycle.

The differential pressure of approximately $6 \mathrm{psi}$ that is required to raise sodium from the sump tank into the source tank can be supplied by either increasing the sump tank pressure or by evacuating the source tank while maintaining the sump tank pressure constant. We chose the latter method because it can be performed conveniently with the vacuum pump, whereas the former method involves adding more liquid to the pressurerelief manometer to seal it against the higher sump tank pressure and also bypassing high-pressure sump tank switch PS-54 which otherwise would open emergency vent valve PSV-3. In addition, after the refilling operation, 
the high-pressure approach requites undoing the work just done. The detailed procedure for raising sodium into the source tank by the evacuation method is presented in Appendix $k$.

First, the high-pressure supply and vent valves are prepared for the evacuation. The supply pressure is set at 20 psig to decrease the pressure potential for argon leaking past supply valves PCV $1 \mathrm{~A}$ and PCV-1B into the source tank. Argon purges are established downstream of vent valves PCV $1 C$ and PSV-3, so that inert gas rather than atmospheric air may enter the source tank past the vent valves.

After the pressure differential between sump and source tanks is established, sodium shutoff valve PCV-17 is opened several turns manually. (On an inftial fill the level device in the source tank may not indicate the proper level, so the progress of filling the source tank is followed by temperature indications from the thermocouples attached to the external surface of the tank.) After the level sensor is wetted the source tank is filled to approximately the $83 \%$ level and then 1 owered to the $81 \%$ leve 1 before closing the shutoff valve. The thermal expansion of the sodium during thermal adjustments to reach the test conditions increases the level from 81 to $84 \%$. A high-leve1 switch is set to activate an alarm at approximately $86 \%$ to maintain a minimum of $2 \mathrm{ft}^{3}$ of gas space in the source tank to protect the test section bladder from excessive differential pressure during emergency depressurization, as discussed in Sect. 3.3.4.

The facility is now ready to be prepared for steady-state operation.

\subsection{Steady-State Operation}

After the source tank is refilled with sodium, as described in Sect. 5.6, the facility is ready to be prepared for steady-state operation. During this operation the test section is subjected to constant conditions of sodium temperature and pressure for a specified time to provide a period of creep deformation for the test section material. Steady-state operation and the thermal transient are the two principal components of the pipe ratchetting cycle.

The source tank pressure is raised to the required operating level, and the test section temperature is raised at the rate of $50^{\circ} \mathrm{F} / \mathrm{hr}$ maximum 
to the specified level. The pipe nest and source tank temperatures are also raised to the test section temperature. We do the latter in the belief that all scrams, spurious or otherwise, during which all the pipe nest and source tank sodium flows through the test section, should be isothermal in order to minimize the deleterious effects of the scram on the stress-strain history of the test section material. An isothermal scram and rapid recovery of test conditions before the test section temperature changes greatly would impose only one additional depressurizationrepressurization on the test section.

During steady-state operation the appropriate data are recorded on the Dextir digital data-acquisition system, generally on an hourly basis. As the end of the steady-state operation is approached, the facility is prepared for the follow-on thermal transient operation according to the method presented in Sect. 5.3.

\subsection{Sodium Cold Trapping}

The cold trap system, which is appropriately connected to the sump tank, consists of an electromagnetic pump and separate flowmeter, a regenerative heat exchanger, a cold trap, a sodium sampler, and the requisite piping and valving. It is used to remove oxide impurities from the sump tank sodium before filling and after draining the sodium system as required. The system is operated nearly continuously when the sump tank sodium is liquid.

The cold trap system, which is initially isolated from the molten sump tank sodium by closing the liquid isolation valve in the inlet line, is preheated with trace heaters to approximately $300^{\circ} \mathrm{F}$. After the cold trap and the gas space in the sump tank are evacuated, sodium is admitted through the inlet line. The gas isolation valve in the outlet line is closed, and argon is admitted to the sump tank to force sodium into the evacuated cold trap system. The voltage applied to the electromagnetic pump is increased, and the gas isolation valve is opened to establish sodium flow through the cold trap. Then, while the temperature of the sump tank is raised gradually to approximately $750^{\circ} \mathrm{F}$, the outlet temperature of the cold trap is maintained at approximately $290^{\circ} \mathrm{F}$ by a flow of 
cooling air across the trap. The cold trap transit time for the sump tank sodium inventory is approximately $24 \mathrm{hr}$.

The temperatures and the sodium flow rate for the system are read out on multipoint instruments and also recorded periodically by hand to monitor the steady-state operation of the txap.

The applied voltage of the electromagnetic pump is so low that, even if sodium flow is lost for any reason, the pump cell does not overheat. If heater power is lost long enough to permit sodium to freeze, the opexating personnel melt the sodium progressively, starting from a liquid interface, before restarting the cold trap operation.

\subsection{Sodium Samplex}

A sodium sampler is installed in the cold trap system. With this device a sample of flowing sodium from the sump tank cold trap system can be taken, frozen, and removed for chemical and other analyses. The samplex is fed directly from the electromagnetic pump and discharges into the gas space in the sump tank. It consists of a $3 / 8-i n$. diam tubing samplex section and two bellows-sealed liquid metal valves and is connected into the cold trap system with $3 / 8-i n$. Swagelok tubing fittings installed on the cold trap piping.

The samplex is trace heated, and sodium may be flowed through it continuously during cold trap operation. A sample is taken only after sodium flow through the sampler has been established for a minimum of $4 \mathrm{hr}$. Then the two isolation valves are closed, and the sample sodium is frozen. The sampler section is approprlately crimped and then removed by loosening the Swagelok fittings. During removal of the section, appropriate argon purges and quick capping of the exposed ends of both the sampler section and the installed Swagelok fittings are employed to minimize the intrusion of atmospheric impurities into both.

New sampler sections are prepared to quality tevel II requirements and are cleaned with SD-23 grade denatured alcohol and dried with inert gas. A new sampler section is installed with generous argon purges directed at the open end of both the sampler and the installed swagelok 
fittings. All the sampler activities are performed manually by the operating personnel.

\subsection{Sodium System Drain}

There are three modes for draining the system sodium into the sump tank: (1) the manually controlled (or normal) drain, which is a slow drain under the manual control of the operating personnel; (2) an automatic fast drain or scram that is initiated by the operation of appropriate sensors, and (3) a manually initiated fast drain.

\subsection{0 .1 Normal drain}

The normal drain is used for all scheduled drains. The system is depressurized gradually to approximately 10 psig by manually reducing the reference pressure with regulator PV-8. This action signals pressure controller PRC-1 to open slow vent valve PCV-1C in a controlled manner. After the source tank pressure is decreased to $10 \mathrm{psig}$, the pressure controller can no longer regulate the venting operation and must be set for its manual mode. The source tank is further vented down to atmospheri, pressure by placing the pressure controller in manual and opening the slow vent valve. The heater controls are adjusted to bring the system temperatures close to the sump tank temperature before the sodium is drained. The argon purges to the two vent valves are established to protect against the intrusion of air in the event the source tank pressure becomes subatmospheric during the drain operation. Sodium shutoff valve PCV-17 is then opened manually to drain the sodium into the sump tank.

When the sump tank liquid-level device indicates that the sodium system is drained, the shutoff valve is closed and the source tank repressurized to about 3 psig. An auxiliary drain valve is then opened to drain the low point in the pipe nest and closed when gas blows through into the sump tank; then an auxiliary valve is opened to drain the low point in the test section and closed when gas blows through into the sump tank. The shutoff valve is again opened, and, with an impromptu metallic 
stethoscope, the operator listens for the sound of bubbles in the sump tank which indicate that the sodium system is well drained.

The system is secured by closing the shutoff valve to keep the sodium in the sump tank, regulating the sump and source tank pressures to about 2 psig, and either shutting off all heater power or adjusting the heater controls to maintain a desired temperature. pressure controller PRC-1 is placed in its automatic mode and reference pressure regulator PV-8 adjusted to maintain approximately 10 psig argon cover gas pressure on the system.

\subsubsection{Automatic fast drain (scram)}

The scram is initiated automatically by the coincident operation of two independent smoke detectors or the coincident operation of one of the two smoke detectors and a signal from the first low sodium level in the source tank, which is presumed to indicate a sodium leak. The low-level signal alone depressurizes the source tank automatically.

The fast scram performs several operations simultaneously. It alarms locally and, during unattended operation, alerts the Y-12 Plant Shift Superintendent (PSS), who in turn alerts the operating personnel of the condition. It simultaneously opens large pressure vent relief valve PSV-3 and small vent valve PCV-1C, closes gas supply control valves PCV-1A and PCV-1B, opens sodium shutoff valve PCV-17 to drain the system sodium, turns off all heater power, turns on the large building ventilation fans to help remove smoke in case of a sodium fire, and starts the fast flow of argon to the catch pan to smother burning sodium. When the source tank pressure is vented down to 20 psig, block valve PSV-4 in the equalizer line, that connects the gas spaces in the sump and source tanks, is opened automatically to prevent the inadvertent raising of the drained sodium back up into the sodium system when the temperature of the cover gas in the sump tank is raised by the hotter incoming sodium.

The operating personnel investigate the cause of the scram and either recover the proper test section operating conditions or secure the facility as discussed in sect. 5.10.1. 


\subsubsection{Manual fast drain}

In the event the operator becomes aware of a sodium leak that is undetected by the automatic scram system, he can initiate a manual fast drain that is an abbreviated version of the automatic fast drain (scram). The manual fast drain is initiated by pushing gas control buttons HSA28A1 and HS-A28B1 to depressurize the source tank to approximately 20 psig, opening sodium shutoff valve PCV-17 by pushing control button HS-9 to drain the system sodium, and opening block valve PSV 4 in the equalizer line. 


\section{CASUALTY EVENTS AND RECOVLRY PROCEDURES}

A rupture or leak in the sodium system containment at high pressure and high temperature is the principal natural hazard to the operation of a high-temperature high-pressure liquid metal test fachity such as the TTTF. The structural design of the ITTF provides barricr protection to persomel and property against the consequences of a rupture or leak in the sodium system. The instrumentation and controls design provides automatic control protection against the occurrences of excessively bigh temperature and pressure that are the prime causes of the rupture and breaching of soditu containment. The operating personnel have devised procedures for reinstituting the test section operating conditions after the sodum system has been placed into a safe condition as the consequence of a scram or an alarm.

\subsection{Casualty Events}

The casualty events for the Trre include a sodium leak or fire, exces sively high temperature or pressure in the sodium system, and the loss of control electrical power. Although the loss of heater electrical power can lead to frozen sodium, the occurrence is well alarmed so that the operating personnel are alerted in sufficient time to drain the sodium sys tem before freezing happens. Even if localized freezing occurs, the facility has sufficient heater and control capabilities to melt the sodium from an appropriate liquid interface in a safe manner.

\section{1 .1 Sodium leak}

A leak during the high-pressuxe high-temperature operation of the facility can produce a high-velocity sodium jet. A clean rupture in the sodium system plping could lead to pipe whip, which in the extreme case could result in the rapid accaleration of a section of pipe or an elbow by the momentum in the sodium jet. 


\subsubsection{Sodium fire}

When the temperature of leaked sodium is above about $400^{\circ} \mathrm{F}$, usually a fire will result and produce voluminous quantities of acrid smoke that often settles on adjacent structures and equipment as a caustic residue and can be particularly damaging to instruments and controls.

\subsubsection{High sodium pressure}

Excessive pressure in the sodium system when the facility is operating at test temperature can produce a sodium leak or perhaps even a rupture in the sodium system, leading to the consequences mentioned above for a sodium leak and fire.

\subsubsection{High sodium temperature}

High temperature in the sodium system containment when the facility is operating at test pressure can produce a sodium leak or perhaps even a rupture in the sodium system, leading to the consequences noted above for a sodium leak or fire. As indicated in the following table,* the rapidly decreasing strengths of the $316 \mathrm{H}$ and $304 \mathrm{H}$ stainless steel used in the sodium system at temperatures above $1100^{\circ} \mathrm{F}$ give rise to our concern.

\begin{tabular}{lcc} 
& \multicolumn{2}{c}{ Allowable stress (psi) } \\
\cline { 2 - 3 } & $1100^{\circ} \mathrm{F}$ & $1150^{\circ} \mathrm{F}$ \\
\hline $316 \mathrm{H}$ stainless stee1 & 12,400 & 9800 \\
$304 \mathrm{H}$ stainless stee1 & 9,700 & 7700
\end{tabular}

\subsubsection{Loss of control electrical power}

The loss of control electrical power initiates an unscheduled drain and depressurization of the sodium system, which can have unwanted effects on the stress-strain history of the test section material.

*From ASME Pressure Vessel Code Section VIII, Table UHA23. 


\subsection{Design Features to Mitigate Effects of Casualty Events}

The facility shielding is designed to accept the consequences of sodium leaks and fires. Monitors and controls have been devised and installed to sense a sodium fire or leak and excessively high pressure and temperature conditions in the sodium system and to regulate the operation of the high-pressure argon system and the heater electrical power controls, respectively, to regain safe operating conditions. When the normal TVA supply for the control electrical power fails, the power is supplied automatical1y, and without interruption, temporarily from a backup battery supply and then from the building emergency power supply, a diesel engine-driven electrical generator.

\section{2 .1 Sodium leak}

Heavy steel plates up to $3 / 8 \mathrm{in.}$ thick are installed on the facility structure, where required, to contain within the facility enclosure the highmelocity sodium jet associated with a pipe rupture in the sodium sys tem or the missiles generated by the rupture or subsequent pipe whip and accelerated by the momentum in the jet. In the event of a rupture the activation of the first low-level switch in the source tank liquid-1evel. gignal, which is set to operate after only a small amount of sodium has leaked from the tank, rapidly depressurizes the source tank to reduce the pressure potential available for sodium leakage, pipe whip, and misstle acceleration.

Al1 other places in the walls of the facility are covered with 16gage sheet metal shields to deflect leaking sodium into a catch pan that forms the bottom of the facility and in which the facility structure stands.

\subsubsection{Sodium fire}

Sodfum from a leak or rupture is directed by the facility shielding to the catch pan that forms the bottom of the facility. The pan is sized to contain a larger quantity of sodium than is in the facility. Burning sodium in the catch pan can be smothered with argon that is supplied automatically by the argon Eire-suppression system described in Sect. 3.2.5. 
The flow of argon to the pan is started when electrically operated valve FSV-44 is opened by the automatic scram discussed in Sect. 5.10.2. The argon flow can also be started by the operating personnel; valve HV-44C in the argon supply for the suppression system is opened manually to bypass valve FSV-44. The argon flow is continued until the leak is stopped and the operating personnel have determined that the leaked sodium is no longer burning and have secured the remaining sodium in the sump tank.

\subsubsection{High sodium pressure}

The pressure signal from the source tank is used to protect the sodium system from the deleterious effects of excessively high pressure during operation at high temperature. Pressure switch PS-1A, which is set to operate safely below the sodium system design pressure of 800 psig, depressurizes the source tank to a lower safe level. The high-pressure signal also alerts the operating personnel to investigate the cause for the high-pressure condition and to remedy it.

In the event the pressure signal control does not function, pressurerelieving rupture disk $X X-10$ and pressure-relief valve PSV-10, which were installed to meet the requirements of the ASME Boiler and Pressure Vessel Code, will vent the source tank to a lower safe level whenever the pressure reaches 800 psig.

The pressure signal from the sump tank is used to isolate the sump tank from the source tank and to reduce the potential for either highpressure sodium or gas to enter the sump tank. Pressure switch PS-54, which is set to operate at 6 psig, depressurizes the source tank and closes the sodium shutoff valve PVC-17, if it is open. If isolation valve PSV-4 in the gas equalizer line connecting the source and sump tanks is opened inadvertently during high-pressure operation, the sump tank is protected by the operation of check valve $\mathrm{XV}-4$ in the same line. The sump tank is protected from excessively high pressure primarily by the operation of the pressure-relief manometer that is connected to the sump tank gas space with a $21 / 2-i n$. pipe with no valves. The manometer relieves tank gas directly to the atmosphere whenever the tank pressure exceeds that of the liquid seal in the manometer, which is set for 7 psig. 


\section{2 .4 jagh sodium temperature}

As noted in Sect. 6.1.4, an increase in temperature above $1300^{\circ} \mathrm{F}$ substantially decreases the strength of the stainless steel materials in the rest section and sodium system. Independent and inherent controls and administrative procedures are used to protect the test section from excessively high temperature. A signal from independent monitor Mm 16 for the test section surface temperature shuts off all heater power to the test section and the sodium system and gives an alarm for high tem perature. A built-in limit switch in test section temperature controller TRC-19 shuts off the oven heater power whenever the test section temperature rises approximately $5^{\circ} \mathrm{F}$ above the controllex set point and then provides offmon control of the power. The power avatlable to the test section oven is controlled whth four autotransformers that are set to provide slightly more powex than is required to mantain the test section tempexature at the teat condition.

A signal from any of nine addittonal independent monitors for as many selected thermocouples, which indicates a hlgh temperature on the sodium system, turns off all heater power to the facility and gives an alarm.

The independent temperature signals from the many heater clrcuits that control the sodium system temperatures are recorded on a series of multipoint temperature recorders. A temperature signal higher than the recorder set point will give an alarm.

\subsubsection{Loss of control electrical power}

Loss of control electrical power depressurizes the source tank, dratns the system sodium into the sump tank, and turns off electrical power to the test section oven and the sodjum system heaters. In essence, the facility is placed in a safe condition, but the test section is given an unscheduled and unwanted depressurtzation and slow thermal cooldown.

However, the design provides the de-to-ac convertex output portion of the control power supply with three independent power sources. The normal TVA source and the building emergency power system supply the actomb inverter, which in turn feeds the converter. An accumulator battery 
system is connected directly into the converter input at all times that the battery voltage is greater than $95 \%$ of the converter voltage requirement. When the normal TVA source is interrupted, the battery source supplies the converter directly until the building emergency source assumes the TVA load, about 15 to $20 \mathrm{sec}$ after the interruption, and supplies the inverter and thus takes the load away from the battery source.

\subsection{Recovery Procedures}

The operating personnel have prepared plans and procedures to manage the direct immediate consequences of a sodium leak and fire and to recover test conditions after an occurrence of high pressure or temperature in the sodium system or failure of the control electrical power. The longer-term consequences of a sodium leak and fire will require the investigation of the cause and the preparation of procedures that are necessary for major maintenance.

\subsubsection{Sodium leak and fire}

The principal immediate activities in combating a sodium leak and fire (in addition to concern for the safety of personnel and adjacent equipment, which was given strong consideration during the design of the facility) are minimizing the leak, putting out the fire, and securing the test facility.

To approach the facility, the operating personnel don respirators and safety clothing as required, depending on smoke and other conditions. They determine quickly that the facility is in its relatively safety condition, that is, the source tank is depressurized, the heaters for the test section oven and the sodium system are turned off, and the system sodium has drained or is draining into the sump tank. In addition, they make sure that the argon fire-suppression system is supplying argon to the catch pan, the building fans are running, and the sump tank pressure is normal. (The latter is important because we believe that the safest place for the system sodium is in the sump tank.) 
When the project leadex deems it advisable, the operating personnel assess the conditions inside the facility enclosure through safery glabs windows that pernit visual observation of the test section and the sodium system. When most of the leaked sodium has dripped into the catch pan, the damper at the top of the pan is closed to help smother the fire. When the fire is under control, the fire-suppression argon flow is shut of $f$ and ORNL Health Physics Diviston personnel axe notified immediately to monitor the buliding basement and other low-lying areas for oxygen deficiency.

Plans for tnvestigating the cause and the consequences of the fire will then be made, to be followed at the appropriate time by the preparation of matntenance plans and procedures.

\subsubsection{High sodium pressure}

Upon receipt of a high-pressuxe alarm from the source tank, the operator tmmediately checks the present level of the pressure and the characteristics of the pressure perturbation on controller pRC-1.

If the pressure has returned to the test condition level, it is perturbed to a higher pressure condition below the alarm level to check the proper functioning of the control system. The controller should vent the source tank pressure to the test condition.

If, however, the pressure has not returned and is not returning to the rest level, the functioning of the control system is checked in the following manner. The pressure in the piping downstream of the isolation valves is reduced to the test section condition by appropriate use of manual vent valve $\mathrm{HV}_{\mathrm{V}}-9$. The reference pressure is then reduced to a slightly lower level to determine if the control vents the source tank pressure. The rafexence pressure is then returned to the appropriate higher value to determine if the control increases the source tank pressure accordingly. If the control system falls this test, the sourca tank is depressurized manually as described in Sect. 5.10.1. The operating personnel will then investigate the malfunction and have the required maintenance performed to return the control system to service. 


\subsubsection{High sodium temperature}

There are two levels of alarm for protection against excessively high temperatures in the sodium system: one gives the audible and visual alarm and the other turns off all heater power to the test section and the sodium system.

The alarm-only signal requires scanning the annunciator lamps to determine the temperature recorder showing the alarm and then scanning the individually recorded temperatures to identify the particular heater circuit or circuits that originated the alarm. The operator determines the cause of the perturbation and then readjusts the controlling autotransformers to recover the test temperature as quickly as practicable.

The heater power scram requires checking each of ten temperature monitors by the sequential use of individual jumpers to identify the source of the signal. If the high-temperature alarm has cleared, the operator reconnects the power source by pushing hand switch HS-A30B to close the breakers that had opened to shut off the power. The settings of temperature recorder controller TRC-19 and the autotransformers must be readjusted to stop the decrease in temperature and then increased to recover temperatures at a heating rate no higher than the maximum of $50^{\circ} \mathrm{F} / \mathrm{hr}$.

If the system has cooled sufficiently to freeze sodium, the frozen sodium is melted from a liquid interface by appropriate adjustment of the controlling autotransformers while the process is being monitored on appropriate temperature readouts.

If the average sodium temperature has decreased the volume of system sodium sufficiently to activate the first low-level switch, the source tank will be depressurized automatically. Recovery then involves repressurization, as described in Sect. 4.1, and the use of procedures in either Sect. 5.3 to regain the thermal transient conditions or Sect. 5.7 to regain the steady-state conditions.

\subsubsection{Loss of control electrical power}

The electrically operated controls and the pneumatically operated control valves are designed to fail in a condition that provides for the 
safety of the facility in the event of fallure of the control electrical power or the instrument air supply. Either of these failures depressurizes the source tank, drains the system sodtum into the sump tank, and gives the alark. After the failure of control power is diagnosed and corrected, the recovery operation requires following the startup procedures outlined in sect. 5.2, and then those in Sect. 5.3 to obtain thermal transient preconditions or those in sect. 5.7 to regain steady-state conditions. 


\title{
7. MAINTENANCE
}

\subsection{Maintenance Approach}

Preventive maintenance will be performed periodically for the operating controls, the alarm annunciators, and the fast-drain automatic controls. Minor repairs to sodium system instruments and controls can be made during a sodium system depressurization.

Major maintenance, entailing opening the sodium system, will be performed by properly supervised and experienced craftsmen, counseled in the safe ways to perform the work, wearing prescribed safety clothing and devices, and working to written procedures as required.

Personnel entry inside the facility shielded enclosure is controlled by the project leader. A safety work permit and the use of appropriate safety procedures and the safety equipment indicated in the following table are required for entry into the facility enclosure.

\author{
Safety requirements

For enclosure For opening \\ entry \\ system \\ System empty and at ambient temperature \\ a \\ a \\ System empty with heat applied \\ b \\ b \\ System filled with sodium and depressurized \\ b \\ System filled with sodium and pressurized \\ Not permitted

\footnotetext{
a Face shield and gloves.

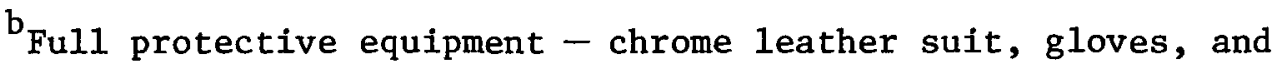
head cover.
}

\subsection{Corrective Maintenance} \\ Major maintenance, involving entry into the sodium system and the \\ placement of thermocouples on the system, will be performed only when the \\ sodium system is depressurized at room temperature, the system sodium is
}


Isolated in the sump tank, and the high-pressure argon system is secured. The high pressure manifold will be isolated from the sodium system with closed hand valves, and the high-pressure gas cylinders will be disconnected from the manifold.

\subsection{Preventive Maintenance}

Temperature recorders, pressure regulators, and pressure-relief valves will be calibrated and inspected on a scheduled basis. Rupture disks will be replaced annually or at the scheduled termination of the current test. When either the automatic temperature or the automatic pressure controller becomes inoperative or defective during a test program, it will be rem placed with a bench-tested module as quickly as practicable to maintain the test conditions with a minimum of change. The automatic controllers and the alarm and scrams circuits will be checked periodically for proper operation.

\subsection{In-Service Inspection}

No in-service inspection will be made of the sodium system at high temperature and high pressure. The shielded enclosure may be entered for brief pexiods when the high-temperature sodium system is depressurized as indicated in sect. 7.1.

\subsection{Surveillance}

The probability that the sodium system piping and components will sustain some damage after ratchetting tests have been performed on several test sections is recognized in the design. The shlelding and support structure are designed to provide access for major maintenance of the sodium system. In addition, after each test section program, measurements of accumulated strain will be made with Demec gage points or tabs installed at several locations on the sodium system in an attempt to anticipate failure of sodium-containing equipment. This surveillance should add to the benefits of the ratchetring test program. 
Thermal transient test data will be compared between cycles for signs of deterioration in the operation of the sodium shutoff valve, the gas control valves, the flow control orifices, and the test section temperature control. These controls will be repaired as required during major maintenance (see Sect. 7.2). 


\section{ACKNOWLEOGMENTS}

We express our thanks to the many persons who contributed to the design, Eabrication, construction, and operation of the TTw. In particular, we acknowledge W. K. Furlong for thermal-hydraulic design; R. D. Stulting for electrical design; G. W. Greene, R. K. Moore, and A. H. Anderson for instrumentation and control design; C. W. Collins for vessel and piping codes advice and the piping flexibility analysis; J. S. Smith for selecting, providing, and checking the strain-measuring instrumentation; T. G. Hil1 for installing, operating, and maintaining the strainmeasuring instrumentation; I. M. Corum, W. L. Greenstreet, and $H$. C. McCurdy for project management and guidance; R. E. MacPherson for guidance and basic contributions to the facility concept; H. J. Klemski and the $X-10$ Machine Shop personnel for fabrication; $T$. K. Walters for fabrication liaison; W. M. Collins and D. L. AuBuchon (Inspection Engineering) and E. M. Lees for quality assurance activities; C. W. Mason, general foreman, and the personnel in the $Y-12$ Maintenance Division for construction activities; W. H. Duckworth, engineering techniclan, for checkout and operation of the facility; and R. H. Jones, draftsman, for loyal and dedicated service; $V$. Maggart for secretarial assistance; and M. Sheldon for editing. 


\section{REFERENCES}

1. Code Case 1331-8, Nuclear Components in Elevated Temperature Service, Interpretations of ASME Boiler and Pressure Vessel Codes, Section III, 1973.

2. D. R. McNeill and J. E. Brock, "Engineering Data File Charts for Transient Temperatures in Pipes," Heating/Piping/Air Conditioning, 43(11), 107-19 (November 1971).

3. RDT Standard F9-4, Requirements for Design of Nuclear System Components at Elevated Temperatures (Supplement to ASME Code Case 1331), Vol. II, Draft 3, Dec. 21, 1973.

4. J. L. Spoormaker, Oak Ridge National Laboratory, unpublished internal document (Sept. 11, 1970).

5. W. K. Sartory, "Inelastic Structural Analyses of TTTF Components," High-Temperature Structural Design Methods for LMFBR Components Quart. Progr. Rep. Sept. 30, 1972, ORNL-TM-4058, pp. 104-13.

6. W. K. Sartory, "Finite Element Program Documentation," High-Temperature Structural Design Methods for LMFBR Components Quart. Progr. Rep. Dec. 31, 1971, ORNL-TM-3736, p. 66.

7. L. K. Spink, Principles and Practice of Flow Meter Engineering, 9th ed., Foxboro Company, Foxboro, Mass., 1967.

8. C. E. Pugh et al., Currently Recommended Constitutive Equations for Inelastic Design Analysis of FFTF Components, ORNL-TM-3602 (September 1972).

9. RDT Standard F9-1T, Requirement for Nuclear Components at Elevated Temperatures (Supplement to ASME Elevated Temperature Code Case 1331), April 1973.

10. R. C. Iotti, Design of Personnel Missile Protection Barrier of the Oak Ridge LMFBR Thermal Transient Test Loop, Ebasco Services, New York, August 1972 .

11. R. W. White and N. B. Botsford, Containment of Fragments from a Runaway Reactor, SRIA-113, Stanford Research Institute (Sept. 15, 1963).

12. Boeing Aerospace Company, Installation and Operation Manual, Capacitive Strain Measuring System, January 1973. 
7

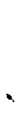

. 
APPENDICES 
•

,

,

$\bullet$ 
Appendix A

CALCULATION OF PIPE NEST GRADIENTS (LMFBR-TTTF) 
- 


\section{Calculation of Pipe Nest Gradient}

It was necessary to write an energy balance on the pipe nest wall and another on the sodium itself at discrete axial nodes and then to solve these coupled equations. The method of Dusinberre ${ }^{1}$ was used to effect the solution. The method permits explicit calculations of the future temperature of each node in terms of present-time parameters. The axial increments were $2 \mathrm{ft}$ long, resulting in 48 nodes in the pipe wall and 49 in the fluid. Mass flow was a constant (the fluid is accelerated by the 700-psig gas to maximum velocity in less than $0.2 \mathrm{sec}$ ).

The convection heat transfer coefficient was based on the we11-known Lyon-Martinelli equation, and the time step used was $0.025 \mathrm{sec}$. The objective of the calculation was to find the initial axial temperature distribution in the pipe nest sodium (and pipe wall) that resulted in the desired temperature-time history of the last node (i.e., that node in the fluid as it enters the test piece). Usually a satisfactory result could be obtained after three or four trials.

A similar calculation was applied to the test section between the entrance and the midplane. Since the material was thick walled (0.375 in.), a wall resistance term was included for the pipe half-thickness (approximated as a slab). The objective of this calculation was to account for the sodium heating between the end of the pipe nest and the midplane of the test section, which was an ideal place to impose the programmed temperature-time history. It was found that the sodium heated approximately $22^{\circ} \mathrm{F}$ in the first half of the test section, and the pipe nest initial temperatures were adjusted downward accordingly (back to the 10cation of minimum pipe nest temperature). The FORTRAN program written to make the calculations discussed above is listed in Table A.1.

\section{Calculation of Test Section Temperatures}

Ideally, the test section should not have any axial temperature gradient because, in the real reactor piping system, the heat capacity of the fluid is very large compared with the heat transferred to it from the pipe wal1s. We recognized, however, that the feasible sodium system 
Table A. 1. ForTRAN program for plpe nest calculations

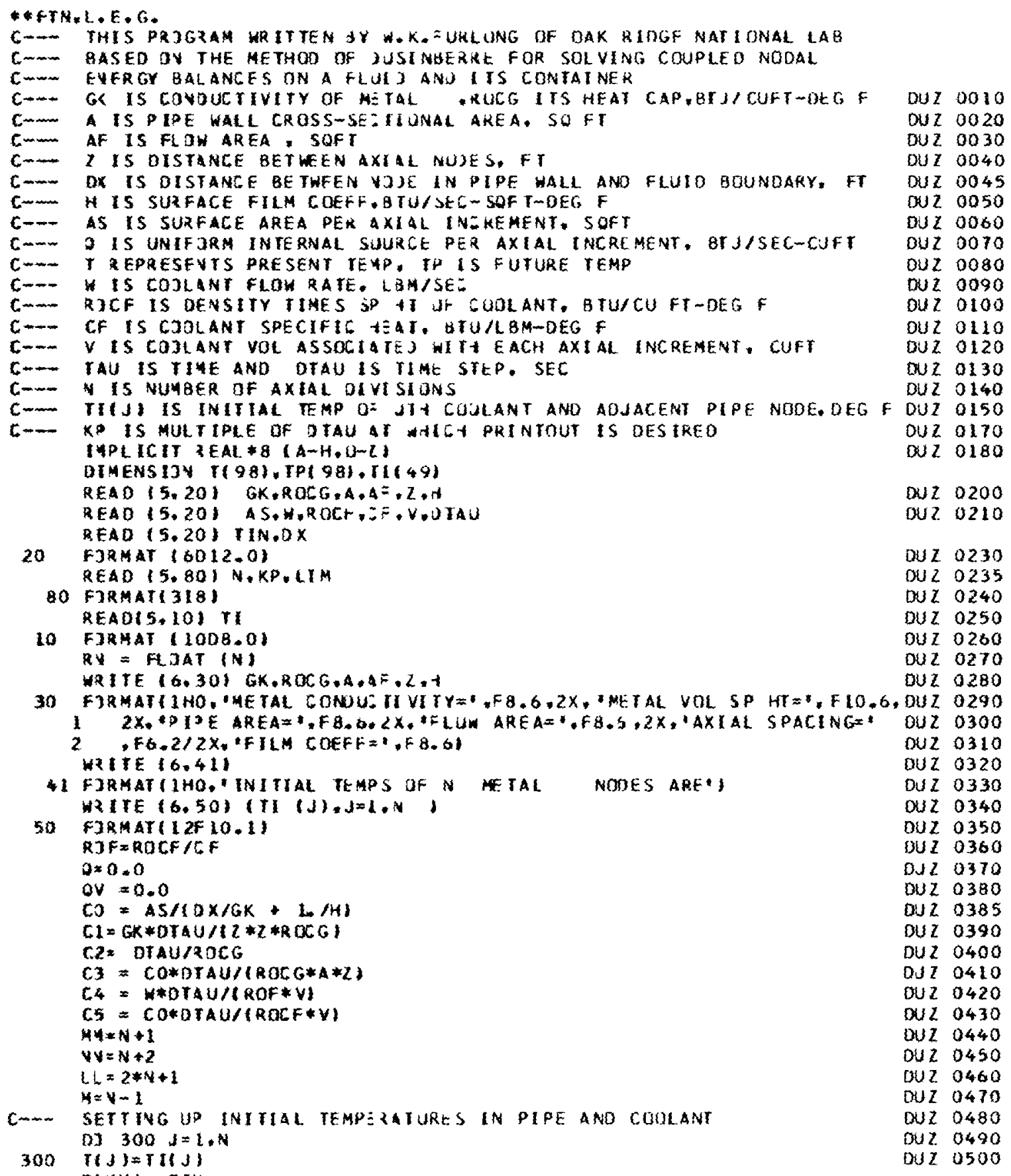


Table A.1 (continued)

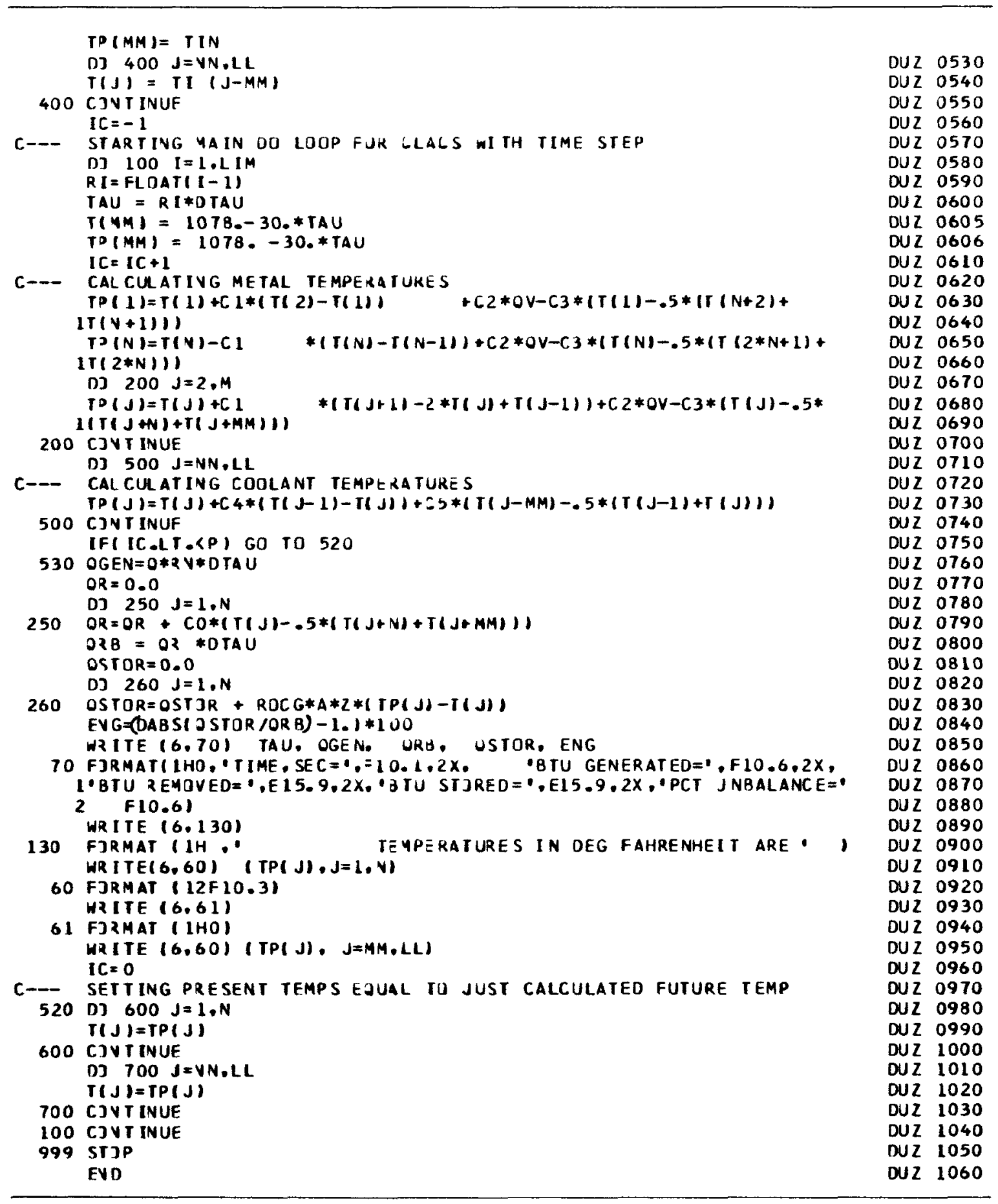


volume for the test facility was limited and in no way could the heat capacity of the real system be simulated. This being the case, some rise in sodium temperature was unavoldable as the fluid traversed the test section, receiving heat from both the pipe wall and the internal bladder. Engineering judgment dictated a target value of $2^{\circ} \mathrm{F} / \mathrm{in}$, as an acceptable axial gradient in the test section wall, recognizing that local gradients, $(\partial T / \partial Z)_{r, t}$, near the entrance would exceed that average value, particularly near $t=0$. We wanted to determine if the $2^{\circ} \mathrm{F} /$ in. value was attainable in practice. Another thermal problem in the test section concerned the depth of five thermocouple wells which we wanted to be sized to yield approximately equal $\Delta T^{\prime}$ 's between thermocouples.

the above themal calculations for the test section were made using the program HEATING $3,{ }^{2}$ which is based on the relaxation method. Initial estimates of the likely axial gradient were made by imposing (as a first approximation) a linear sodium temperature profile as a boundary condition over the 20 -in. gage length. This linear profile averaged $1.9^{\circ} \mathrm{F} / \mathrm{in}$. for the duration of a transient. With the sodium inlet temperature programed to drop at $30^{\circ} \mathrm{F} / \mathrm{sec}$ and the test section initially at $1100^{\circ} \mathrm{F}$, it was found that about $1400 \mathrm{Btu}$ was transferred into the sodium from the test section and bladdex during the transient and that the maximum local axial gradient in the test section was about $2.5^{\circ} \mathrm{F} / \mathrm{in}$., with the average gradient less than $2^{\circ} \mathrm{F} / \mathrm{in}$. The two values of $1400 \mathrm{Btu}$ and $38^{\circ} \mathrm{F}$ AT were the basis of sizing the temperature-graded portion of the pipe nest at $265 \mathrm{ft}$ of 2 1/2-in. sched-10 pipe.

Actual experimental data from the first four transients indicates an average of $1527 \mathrm{Btu}$ transferred with an avexage sodium $\Delta \mathrm{T}$ of $39^{\circ} \mathrm{F}$ and extremes of $15.2^{\circ} \mathrm{F} \Delta \mathrm{T}$ at the end of the first second to $54.5^{\circ} \mathrm{F} \Delta \mathrm{T}$ at the termination of a $10 \mathrm{msec}$ transient. The latter figure introduces axial gradients in the test section of $\sim 2.7^{\circ} \mathrm{F} / \mathrm{in}$., since the axial temperature profiles in the test section are similar to those in the sodium after the first 3 or $4 \mathrm{sec}$ of a 10-sec transient. The change in strain was estimated to be on the order of $2 \%$ for circumferential and $4 \%$ for axial components due to the axial gradient on the order of $2^{\circ} \mathrm{F} / \mathrm{in}$. Hence the effect on the desired strain data for ratchetting was considered minor and acceptable. 
The depths of thermocouple wells were determined from HEATING3 by calculating the radial temperature distributions in the test section wall and then determining those incremental distances that corresponded to equal $\Delta T^{\prime} s$ for the greatest percentage of the duration of a transient. Experimental results duplicate the expected radial distributions very closely.

Selected important thermal calculations, both on the test section and the pipe nest, were independently checked and corroborated using a different model and different analytical methods (see Appendix L).

\section{$\underline{\text { References }}$}

1. G. M. Dusinberre, Heat Transfer Calculations by Finite Differences, International Textbook Company, Scranton, Pa., 1961.

2. W. D. Turner and M. Siman-Tov, HEATING3 - An IBM 360 Heat Conduction Program, ORNL-TM-3208 (February 1971). 
$\bullet$

•

-

2

$\bullet$ 
Appendix B

COMPLETE LIST OF MECHANICAL DRAWINGS (LMFBR-TTTF) 


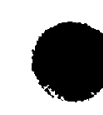

.

,

0 
Mechanica1 Drawings

\begin{tabular}{|c|c|}
\hline $\begin{array}{l}\text { Drawing } \\
\text { No. }\end{array}$ & Title \\
\hline M-10596-RM-001-E & General Assembly - Plan View \\
\hline $\mathrm{P}-10596-\mathrm{RM}-002-\mathrm{E}$ & Primary Piping - Assembly \\
\hline M-10596-RM-003-E & Sump Tank Sodium - Modifications \\
\hline M-10596-RM-004-E & Test Piece - Assembly and Details \\
\hline M-10596-RM-005-E & Orifice Section - Weldment and Details \\
\hline M-10596-RM-006-E & Sodium Source Tank - Weldment \\
\hline S-10596-RM-007-E & Support Structure - Weldment \\
\hline S-10596-RM-008-E & Shielding - Assemb1y - P1an View and Section A-A \\
\hline $\mathrm{M}-10596-\mathrm{RM}-009-\mathrm{E}$ & Test Piece Bladder - Weldment and Details \\
\hline$M-10596-R M-010-E$ & Sodium Source Tank - Subassembly and Details \\
\hline M-10596-RM-011-E & Thermal Capacitance Tank - Weldment and Details \\
\hline M-10596-RM-012-E & General Assembly - Views $A-A$ and $B-B$ \\
\hline P-10596-RM-013-E & Manometer Piping - Assemb1y \\
\hline P-10596-RM-014-E & Auxiliary Piping - Assembly \\
\hline $\mathrm{M}-10596-\mathrm{RM}-015-\mathrm{D}$ & Mason-Neilan Valve $21 / 2$ in. - Modifications \\
\hline P-10596-RM-016-E & Vapor Trap - Weldment and Pipe Details \\
\hline M-10596-RM-017-E & $\begin{array}{l}\text { Test Piece Oven and Auxiliary Components } \\
\text { Oven Assembly }\end{array}$ \\
\hline M-10596-RM-018-E & $\begin{array}{l}\text { Test Piece Oven and Auxiliary Components } \\
\text { Oven Details }\end{array}$ \\
\hline M-10596-RM-019-E & $\begin{array}{l}\text { Test Piece Oven and Auxiliary Components } \\
\text { Oven Details }\end{array}$ \\
\hline P-10596-RM-020-E & Economizer and Cold Trap Piping \\
\hline M-10596-RM-021-E & $\begin{array}{l}\text { Economizer and Cold Trap - Shielding and Drip } \\
\text { Pan Assembly }\end{array}$ \\
\hline $\mathrm{M}-10596-\mathrm{RM}-022-\mathrm{E}$ & Economizer and Cold Trap Piping - Details \\
\hline $\mathrm{S}-10596-\mathrm{RM}-023-\mathrm{E}$ & Support Structure - Details \\
\hline S-10596-RM-024-E & Support Structure - Details \\
\hline $\mathrm{P}-10596-\mathrm{RM}-025-\mathrm{E}$ & Primary Pipe Supports - Assembly \\
\hline M-10596-RM-026-C & T/E Receptacle Leak Test Fixture \\
\hline M-10596-RM-027-E & $\begin{array}{l}\text { Economizer and Cold Trap - Drip Pan Assembly and } \\
\text { Details }\end{array}$ \\
\hline
\end{tabular}




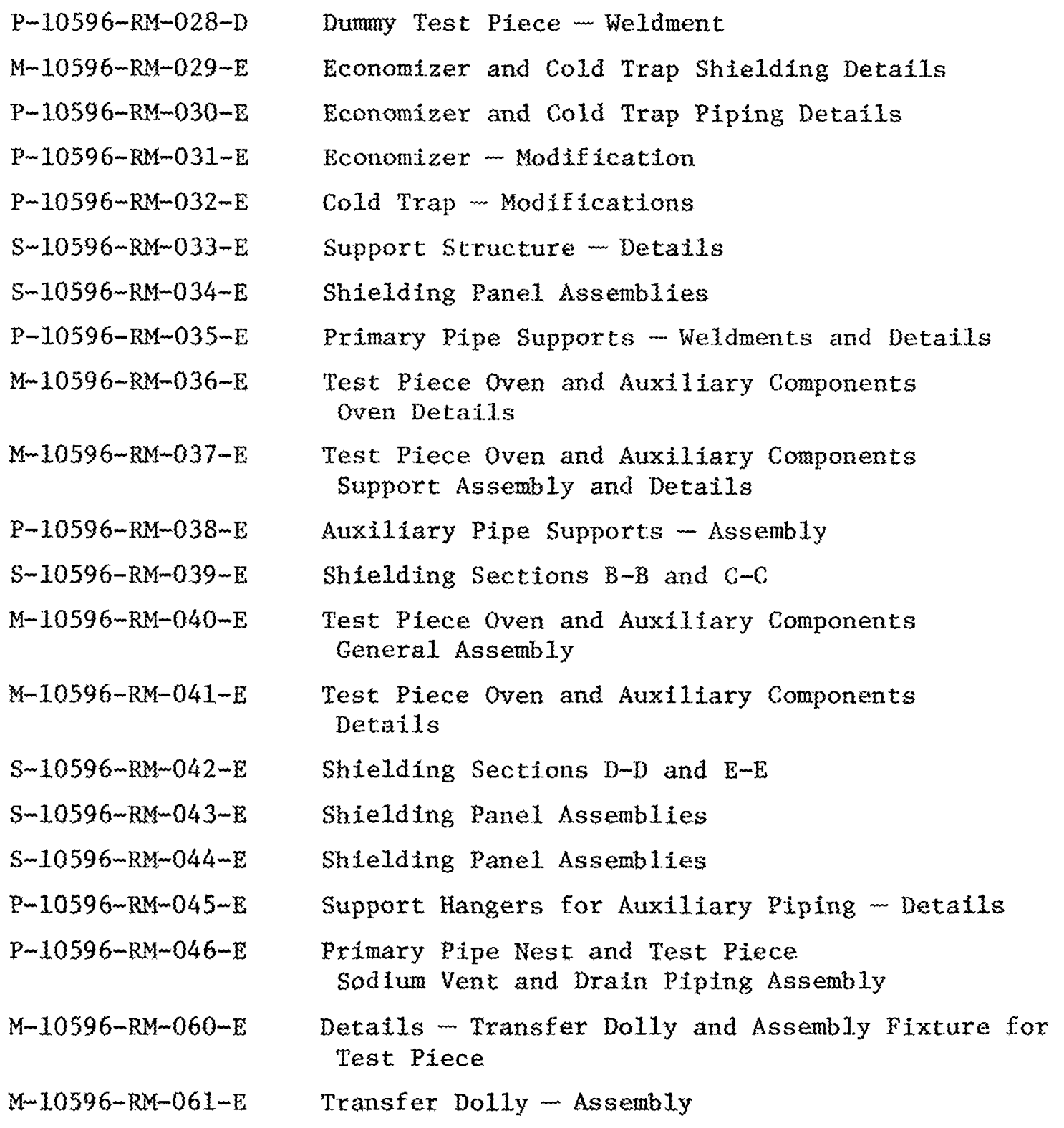


121

Appendix C

LIST OF INSTRUMENTATION AND CONTROL DRAWINGS (LMFBR-TTTF) 
$\bullet$

,

.

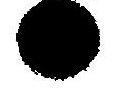


Instrumentation and Control Drawings

Drawing

No.

I-10596-QG-00

$-002$

$-003$

$-004$

$-005$

$-006$

$-007$

$-008$

$-009$

$-010$

$-011$

$-012$

$-013$

$-014$

$-015$

$-016$

$-017$

$-018$

$-019$

$-020$

$-021$

$-022$
Title

Instrument App1ication Diagram, Sheet 1 *

Instrument Application Diagram, Sheet 2*

Control Circuits, Sheet 1, Maintenance Elementary Diagram*

Contro1 Circuits, Sheet 2, Maintenance Elementary Diagram*

Control Circuits, Sheet 3, Maintenance Elementary Diagram

Miscellaneous Circuits, Sheet 1, Maintenance Elementary Diagram

Miscellaneous Circuits, Sheet 2, Maintenance Elementary Diagram

Annunciator Circuits, Maintenance Elementary Diagram*

Signal Paralleling Terminals

Instrument Cabinets, Front Elevation*

Instrument Cabinets, Rear Elevation

Instrument Cabinet, Panel Cutouts

Panel Cutouts and Cabinet 1 Details

Instrument Cabinets 4 and 5, Rear of Cabinet Piping Diagram

Cabinet 1 Wiring Table, Sheet 1

Cabinet 1 Wiring Table, Sheet 2

Instrument Cabinets 2 and 3, Wiring Diagram

Thermocouple Terminal Board, Wiring

Instrument Cabinet 4, Wiring Diagram

Instrument Cabinet 5, Wiring Diagram

Dextir System

Installation Details - Sheet 1 of 3, Instrument Air, Building Argon, Low-Pressure Argon and Nitrogen Supply

Installation Details - Sheet 2 of 3, High-Pressure Argon and Argon Reference Supplies - Elevation View

*Included in this appendix. 
-024 Installation betails - Sheet 3 of 3 , Bighmpressure Argon and Argon Reference Supplies … Sections A-A and $3-B$

-025 Typical themocouple Installation Detalls

-026 Thermocouple Tabulatson, Sheet 1 of 2

-027 Thermocouple Tabalation, Shest 2 of 2

-028 Cabinet 2 Relay tox Layout and Wiring Diagram 


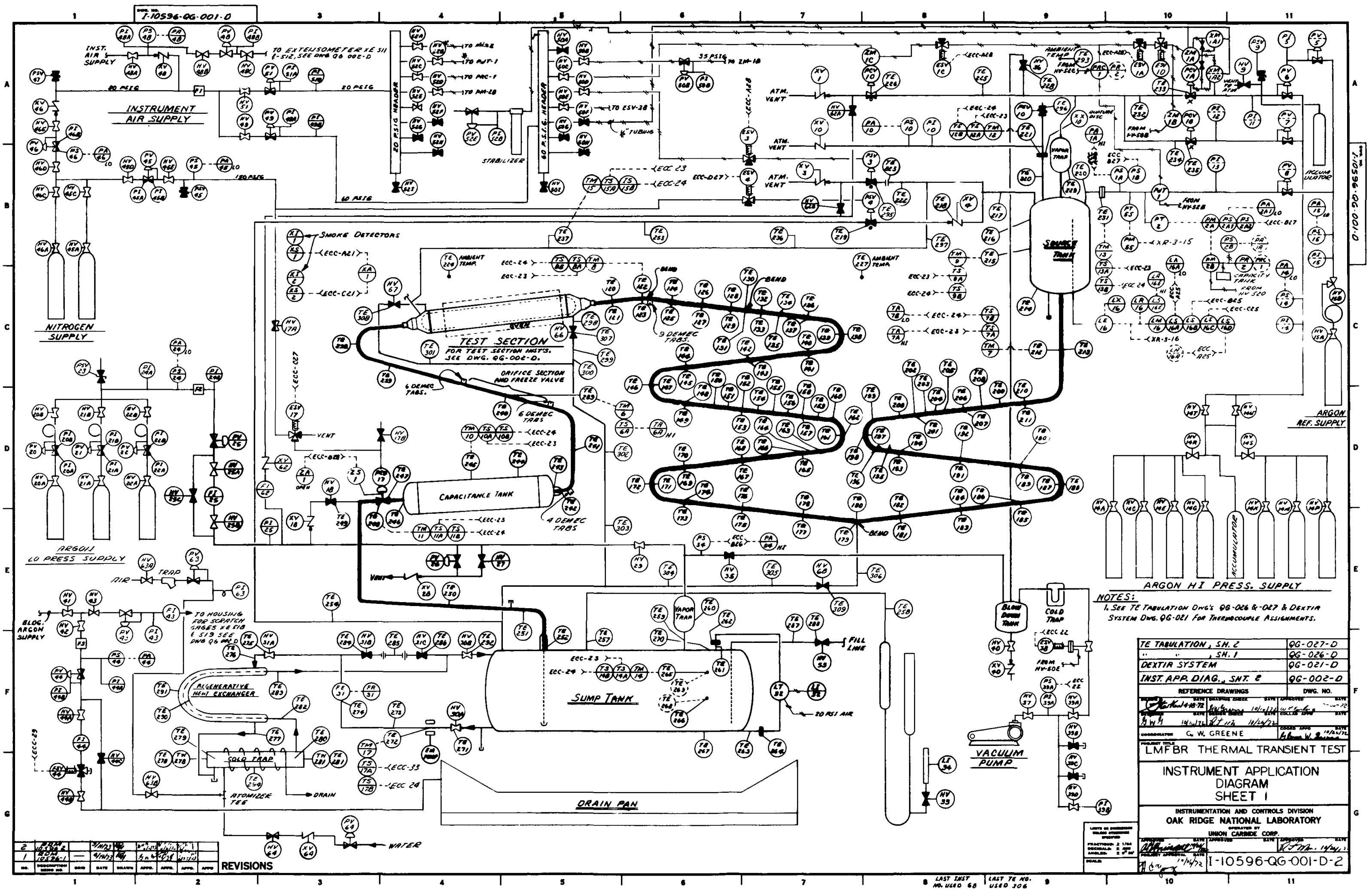




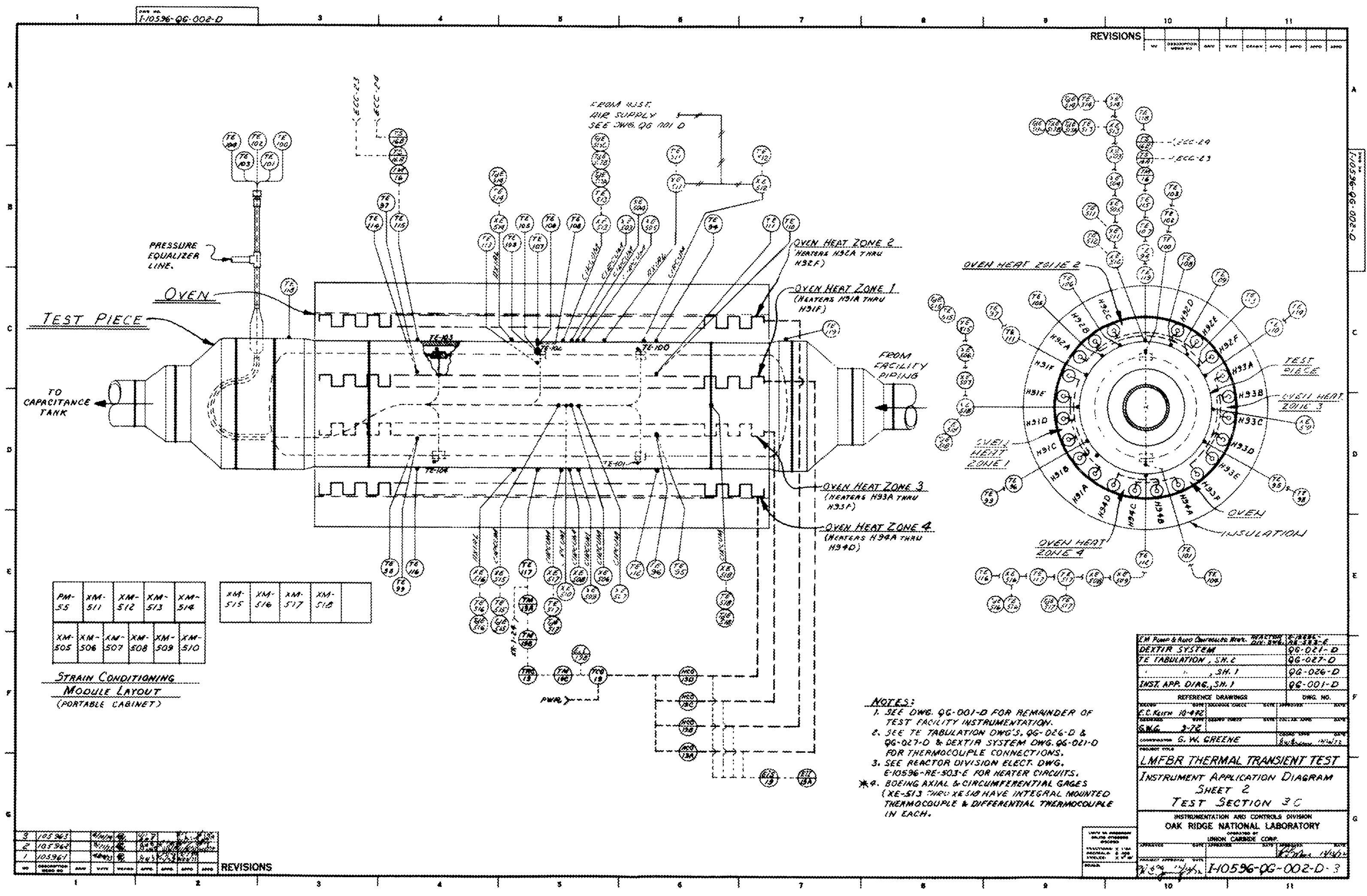

Fis. C.a. 


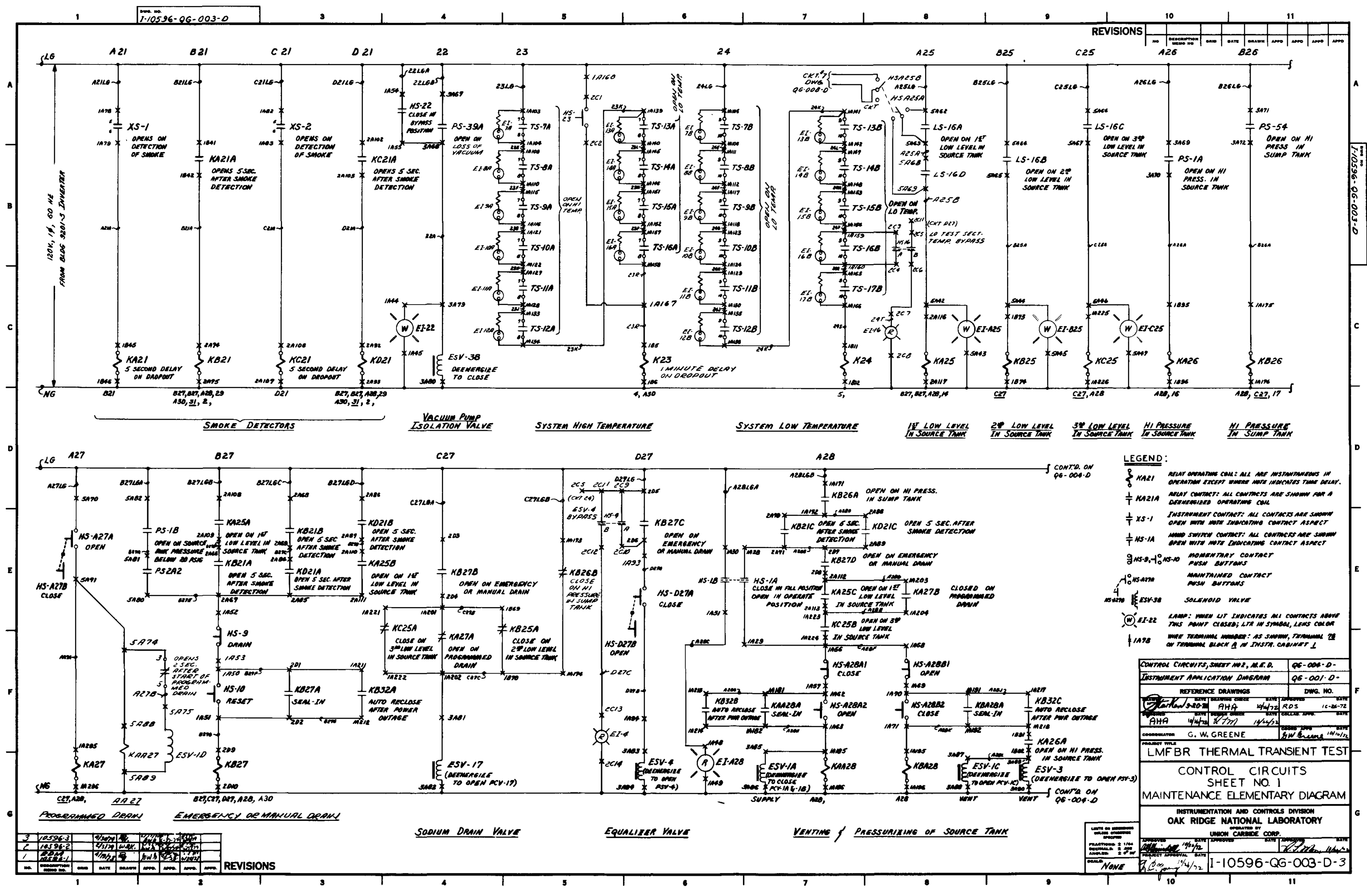

Fig. C. 3. 


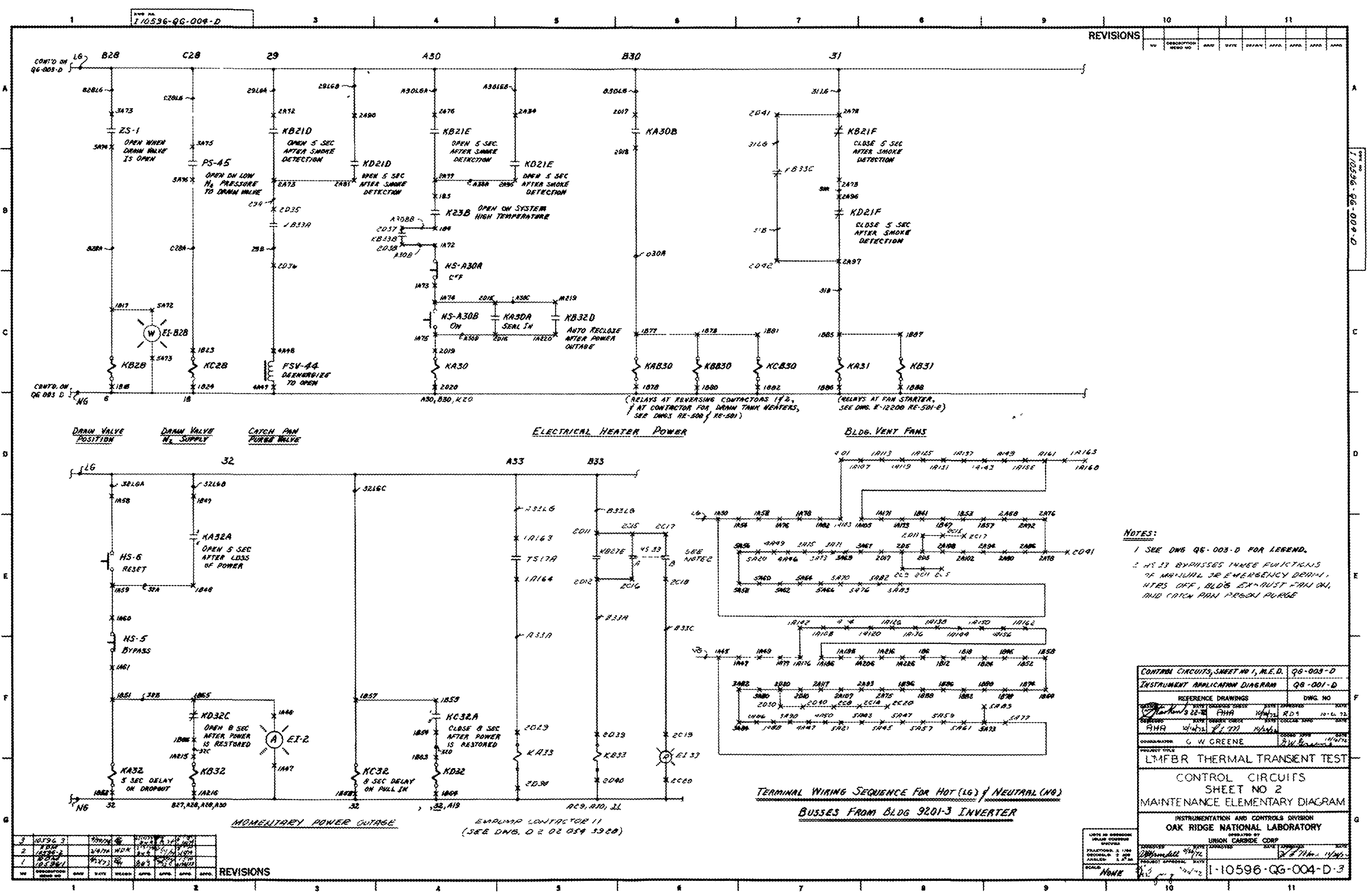

Fig. 0.4 . 


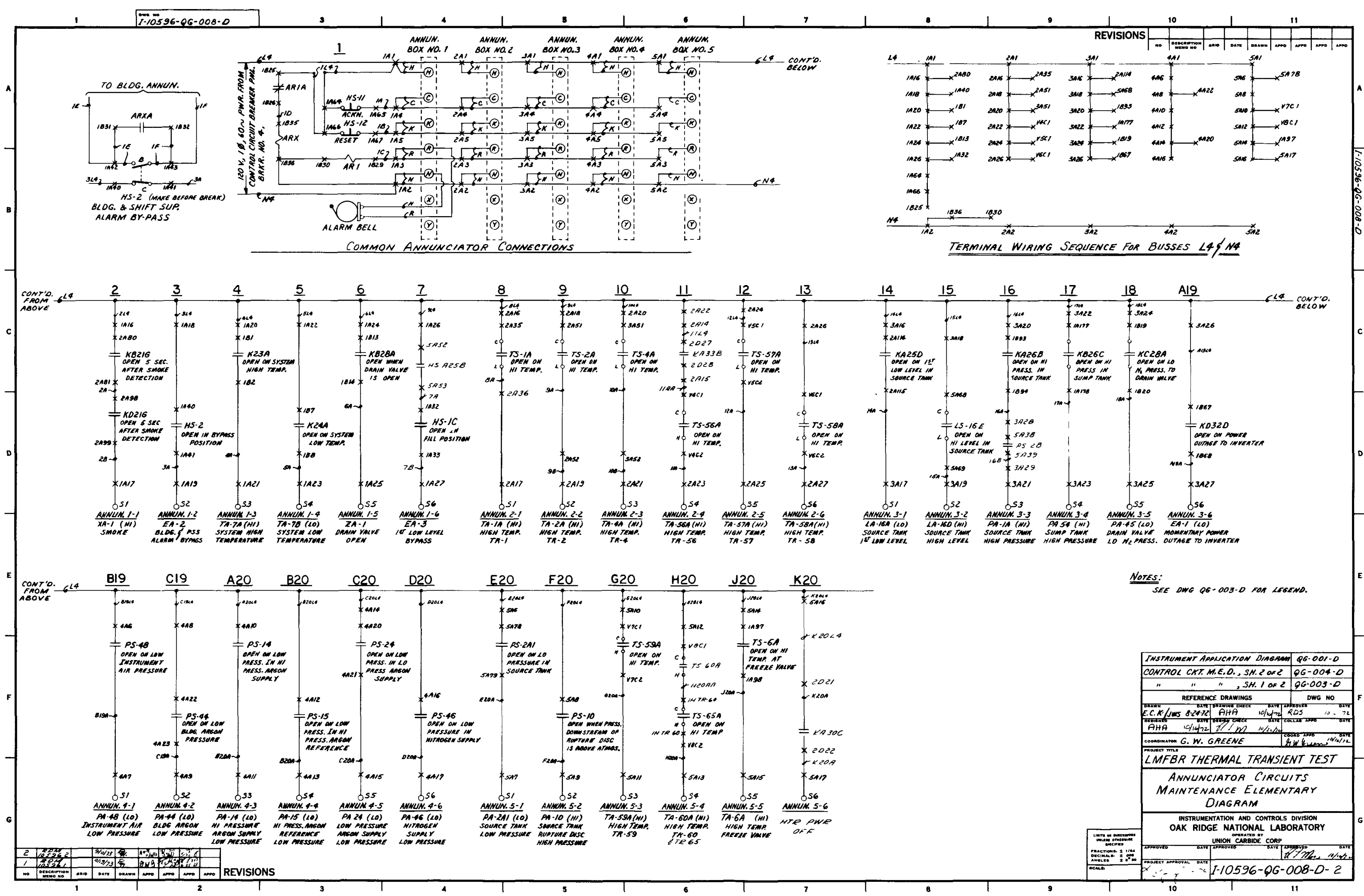

Fig. C. 5. 


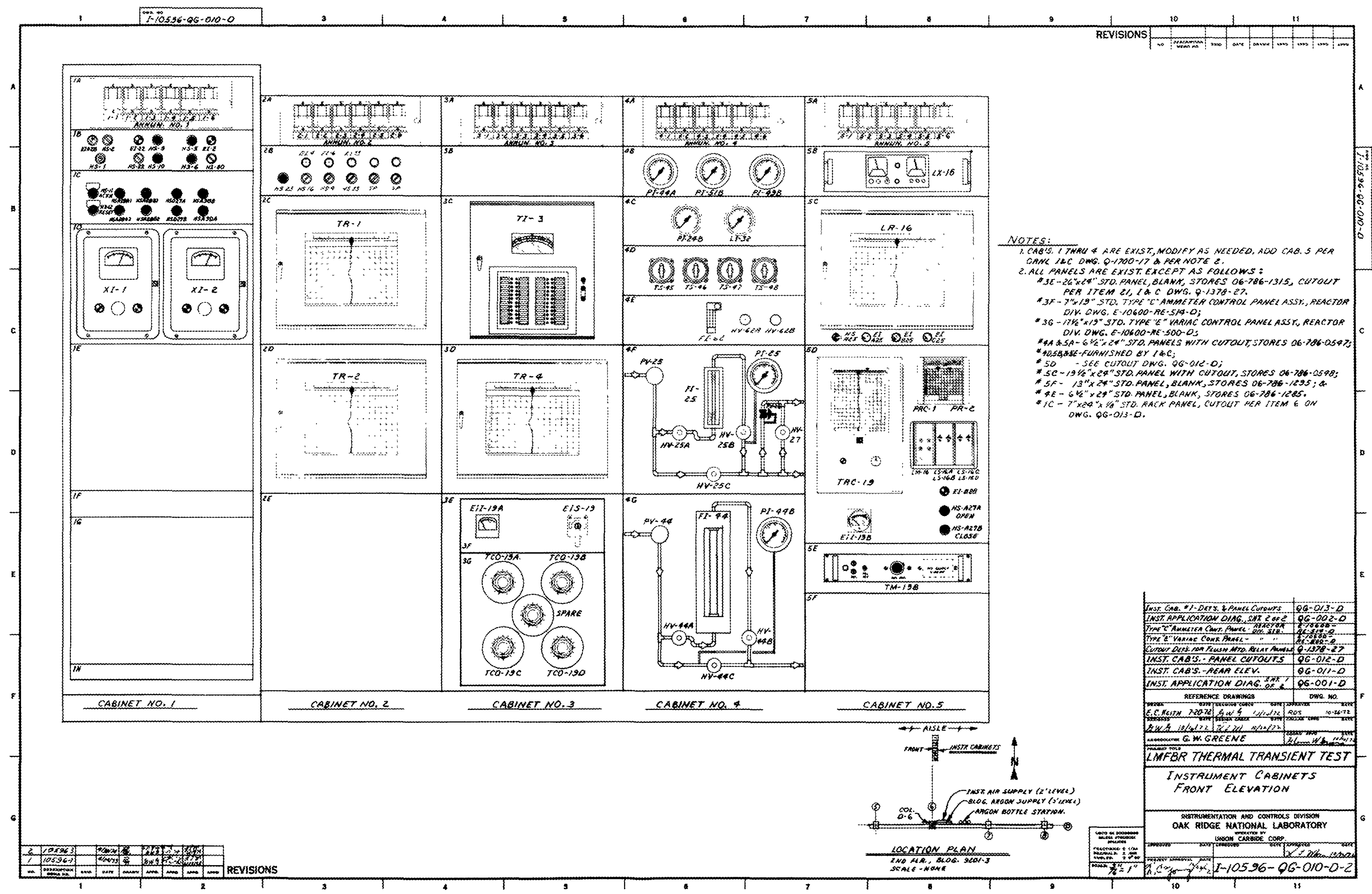


Appendix D

LIST OF ELECTRICAL DRAWINGS (LMFBR-TTTF) 


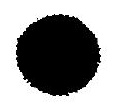

,

,

,

- 


\section{Electrical Drawings}

Drawing

No.

E-10596-RE-500-E

$-501-E$

$-502-E$

$-503-E$

$-504-E$

$-505-E$

-506-E

$-507-\mathrm{E}$

$-508-E$

$-509-\mathrm{E}$

$-510-E$

$-511-\mathrm{E}$

$-512-E$

$-513-\mathrm{E}$

$-514-E$

$-515-\mathrm{E}$

D-2-02-054-3928-B

E-10596-RE-516-E

$-517-\mathrm{E}$

$-518-\mathrm{E}$

$-519-\mathrm{C}$

E-10520-RE-520-E

\section{Title}

Elementary Wiring Diagrams, Sheet 1 , Variac Cabinets 1,2 , and 3

Elementary Wiring Diagrams, Sheet 2, Variac Cabinets 4, 5, 6, and 7

Elementary Wiring Diagrams, Sheet 3, Variac Cabinets 8 and 9

Elementary Wiring Diagram, Sheet 4, Electromagnetic Pump and Automatic Controlled Heaters

Heater and Thermocouple Layout, Sheet 1

Heater and Thermocouple Layout Details, Sheet 2

Heater Schedule

Variac Cabinet 1 Layout and Wiring Diagram

Variac Cabinet 2 Layout and Wiring Diagram

Variac Cabinet 2 Layout and Wiring Diagram

Variac Cabinet 4 Layout and Wiring Diagram

Variac Cabinet 5 Layout and Wiring Diagram

Variac Cabinet 6 Layout and Wiring Diagram

Variac Cabinet 7 Layout and Wiring Diagram

Variac Cabinet 8 Layout and Wiring Diagram

Variac Cabinet 9 Layout and Wiring Diagram

Electromagnetic Pump Wiring Details

Equipment and Cable Tray Layout

Equipment and Cable Tray Details

Grounding Schematic Diagram

Single Line Diagram

Alternating-Current Reliable Power Supply Schematic Diagram 
,

$+$

$\bullet$ 
Appendix E

ENGINEERING DATA FOR COLD TRAP AND SAMPLING STATION (LMFBR-TTTF) 
$\bullet$

.

• 


\section{Engineering Data for Cold Trap and Sampling Station}

Design pressure, psig
Operating pressure, psig
Design temperature, ${ }^{\circ} \mathrm{F}$
Fluid
Flow rate
Minimum cold trap holdup time
Minimum cold trap oxide capacity,
Ib Na ${ }^{0}$
Operating temperature
Cold trap
Material
Size
Packing
Cooling
Economizer
Material
Type
Size
Size

Connecting piping

Pump

Flowmeter

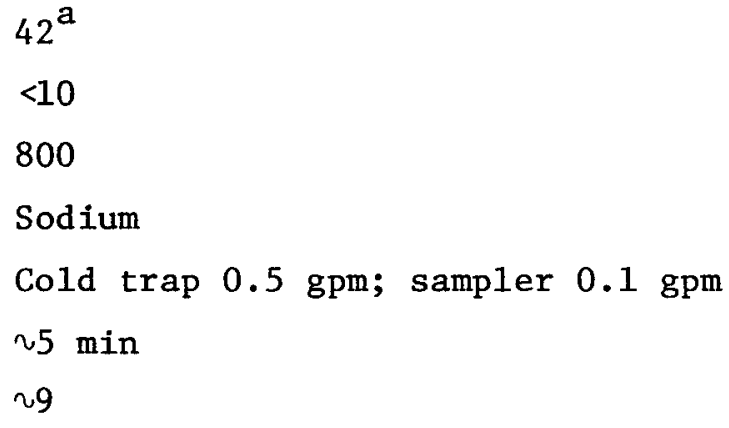

$42^{a}$

$<10$

800

Sodium

Cold trap $0.5 \mathrm{gpm}$; sampler $0.1 \mathrm{gpm}$ $\sim 5 \min$

$\sim 9$

System inlet $800^{\circ} \mathrm{F}$; system outlet $700^{\circ} \mathrm{F}$ Cold trap inlet $380^{\circ} \mathrm{F}$; cold trap outlet $290^{\circ} \mathrm{F}$

Incone1

4 in., sched-40 pipe, 60 in. long

Stainless steel demister

Instrument air at $\sim 22$ psig

Incone1

Concentric pipe

Outer pipe $11 / 4$ in., sched-40, 80 in. long

Inner pipe $1 / 2$ in., sched-40, 100 in. long

$1 / 2$ in., sched-40, 304 SS

Electromagnetic pump (Name plate data: General Electric Cat. 9159849 GR 6, single phase, $60 \mathrm{~Hz}, 250 \mathrm{~V}, 30 \mathrm{~A}$, rated flow $20 \mathrm{gpm}$ at 20 psi rise with fluid resistivity of 20 microhm-cm)

Performance on sodium limited to $150 \mathrm{~V}$ by mechanical stop on voltage control Calculated rating from 0 to $0.5 \mathrm{gpm}$ is 27 psi headrise; maximum sump tank pressure 15 psig; system design pressure 42 psig.

Electromagnetic type; size 1/2 in., sched-40, 304H

\footnotetext{
a Set principally by the pressure containing capability of the pump.
} 
•

.

- 
Appendix F .

MEMORANDA ON MOMENTARY OVERPRESSURE CAPABILITY OF SUMP TANK (LMFBR-TTTF) 
•

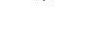

. 


\section{INTRA-LABORATORY CORRESPONDENCE \\ OAK RIDGE NATIONAL LABORATORY}

October 12,1972

To: File

Subject: Sump Tank Momentary Overpressure Capability, TTT (EJN-10596)

The design pressure of the sump tank has been specified as 15 psig on our drawing No. M-10596-RM-003-E, and the pneumatic test of 34 psig was based thereon. The value of 15 psig was certified in a review by G. W. Renfro of the tank when it was used in a previous job (Dwg. No. $M-12200-C D-016-D)$.

We do not wish to alter the design pressure of the tank. However, we recognize that a double failure (sodium control valve, part 2-6, Dwg. No. P-10596-RM-002-E, and gas supply valve, PCV-1A, part 5-7, Dwg. No. P-10596-RM-014-E, both fail in fully open position) would subject the tank momentarily to a pressure in excess of 15 psig. R. F. Bennett has extensively analyzed ${ }^{1}$ the double failure and concludes that the maximum pressure would be approximately 29 psig.

A calculation on the tank according to the rules of the ASME Code, Section VIII, indicates that the heads are limiting and that the maximum internal pressure would be $36 \mathrm{psig.} \mathrm{This} \mathrm{assumes} \mathrm{welds} \mathrm{with} \mathrm{unknown}$ inspection in the old head (one new head was added to tank for a previous job). In addition, the lower code-allowable stress of 8100 psi, current when Renfro made his review (1969), was used, based on 304L at $800^{\circ} \mathrm{F}$.

In summary, it is the opinion of both me and G. W. Renfro that the subject tank is capable of the momentary overpressure of 29 psig, as calculated by R. F. Bennett.

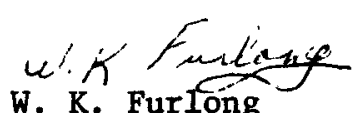

WKF $: z t$
cc: R. F. Bennett, Jr.
A. G. Grindeli
G. W. Renfro
L. V. Wilson
H. C. Young

\footnotetext{
${ }^{1}$ Memo to file dated October 9, 1972.
} 


\section{INTRA-LABORATORY CORRESPONDENCE \\ OAK RIDGE NATIONAL LABORATORY}

December 21, 1972

To:

A. G. Grindell

Subject: Momentary Overpressure of Sump Tank in Thermal Transient Test Due to Simultaneous Failure of Sodium Control Valve (Part 2-6, Dwg. No. P-10596-RM-002-E) and Gas Supply Valve PCV-1A (Part 5-7, Dwg. No. P-10596-RM-014-E) in the Open Positions

Previous calculations* of momentary sump tank overpressure for the Thermal Transient Loop had to be modified to incorporate resistances to flow in the argon supply bottle manifold.

Utllizing information provided by Mr. Floyd Fulsom of the Sherwood-Selpac Company for the Sherwood argon valve type $\mathrm{M}$, a $\mathrm{C}_{\mathrm{V}}$ of 0.34 was determined, and $a C_{\mathrm{V}}$ of 0.28 was found to represent pressure loss across the argon bottle valve, $3 \mathrm{ft}$ of $3 / 16 \mathrm{in}$. ID pigtail, and approximately $6 \mathrm{ft}$ of $\sim 1 / 2$ in. ID pipe used as a manifold. This $C_{V}$ value was incorporated as the upstream valve (A) in the previous solution.

Only one change was incorporated in the program. Mr. Harry Young informed me that I had wrongly included six orifice plates where there were only five This was corrected in the present min.

Six argon supply bottles appear to be sufficient to maintain a pressure of 800 psig upstream of valve PCV-lA during the period of required sodium flow. The maximum predicted pressure of the sump tank is 234.5 psig (see attached figure).

RFB:zt

Attachment

cc: S. E. Beall

W. K. Furlong

M. I. Lundin

L. V. Wilson

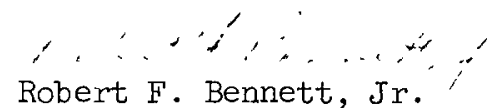

Robert F. Bennett, Jr.

*Memo to TTT file from R. F. Bennett, Jr., Oct. 9, 1972.

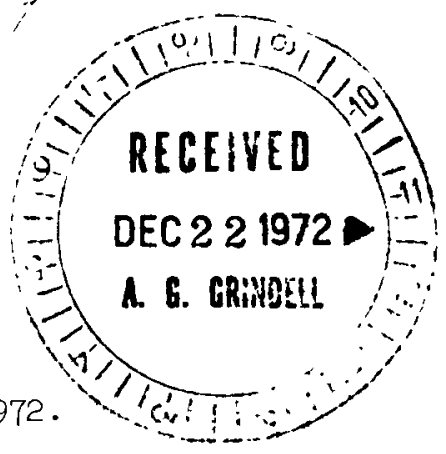




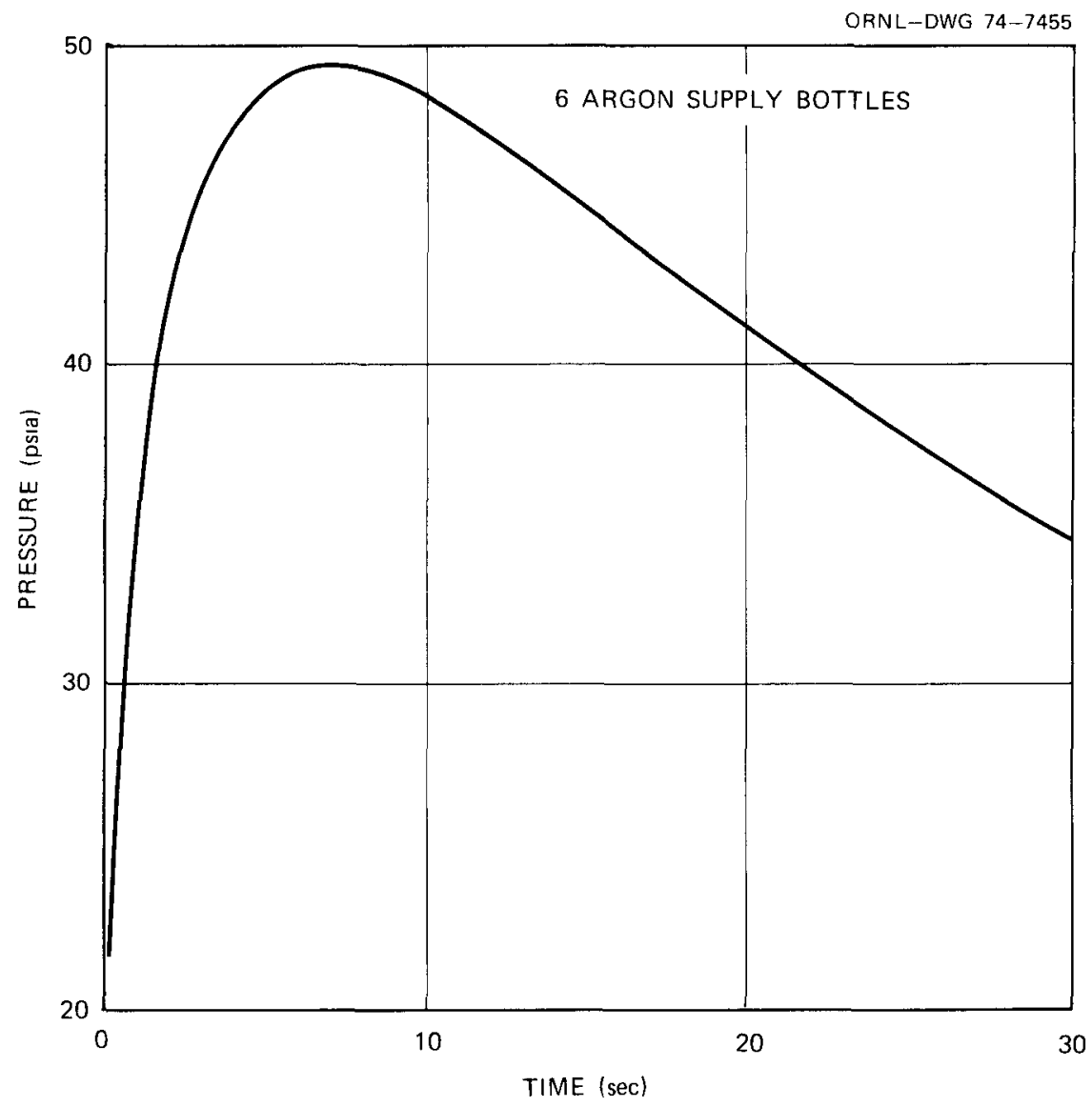

Fig. F.I. Initial sump tank pressure of 18 psia in equilibrium with 8 ft of manometer fluid (specific gravity $=1$ ). 
○

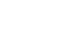


Appendix G

LIST OF INSTRUMENTS, CONTROLS, VALVES, AND PROTECTIVE DEVICES (LMFBR-TTTF) 
$\bullet$

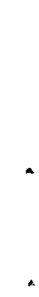
. . 


\begin{tabular}{|c|c|c|c|}
\hline $\begin{array}{l}\text { Instrument } \\
\text { No. }\end{array}$ & Service & Description & Location \\
\hline $\mathrm{ESV}-\mathrm{AA}$ & $\begin{array}{l}\text { Interrupts pneumatic signal to } \mathbb{Z M}-1 \mathrm{~A} \\
\quad \& \mathrm{ZM}-1 \mathrm{~B}\end{array}$ & $\begin{array}{l}\text { 3-way, NC, solenoid, Skinner } \\
\text { V } 53 \text { DBI } 050\end{array}$ & $\begin{array}{l}\text { In source tank } \\
\text { enclosure }\end{array}$ \\
\hline ESV-IC & Interrupts pneumatic signal to $Z \mathbb{M}-1 \mathrm{C}$ & $\begin{array}{l}\text { 3-way, NC, solenoid, Skinner } \\
\text { V } 53 \text { DBI } 050\end{array}$ & $\begin{array}{l}\text { In source tank } \\
\text { enclosure }\end{array}$ \\
\hline ESV-ID & $\begin{array}{l}\text { Switches pneumatic signal to } \mathrm{ZM}-1 \mathrm{~A} \\
\text { \& } \mathrm{ZM}-1 \mathrm{C} \text { from } \mathrm{PRC}-1 \text { to } \mathrm{PV}-52 \mathrm{E}\end{array}$ & $\begin{array}{l}\text { 3-way, NO, solenoid, Skinner } \\
\text { V } 54 \text { DBI } 100\end{array}$ & $\begin{array}{l}\text { In source tank } \\
\text { enclosure }\end{array}$ \\
\hline ESV -3 & $\begin{array}{l}\text { Interrupts pneumatic supply to } \\
\text { PSV }-3 \text { \& vents }\end{array}$ & $\begin{array}{l}\text { 3-way, } 3 / 8^{\prime \prime} \text { solenoid valve, } \\
\text { Skinner LP } 3 \mathrm{DB} 3150\end{array}$ & $\begin{array}{l}\text { In source tank } \\
\text { enclosure }\end{array}$ \\
\hline ESV -4 & $\begin{array}{l}\text { Interrupts pneumatic supply to } \\
\text { PSV }-4 \text { and vents }\end{array}$ & $\begin{array}{l}\text { 3-way, 3/8" solenoid valve, } \\
\text { Skinner LP 3DB } 3150\end{array}$ & $\begin{array}{l}\text { In source tank } \\
\text { enclosure }\end{array}$ \\
\hline ESV-17 & $\begin{array}{l}\text { Intermupts pneumatic supply to } \\
\text { PCV-17 and vents }\end{array}$ & $\begin{array}{l}\text { 3-way, 3/8" solenoid valve, } \\
\text { Skinner LP } 3 \mathrm{DB} 3150\end{array}$ & $\begin{array}{l}\text { On PCV-17 } \\
\text { operator }\end{array}$ \\
\hline ESV -38 & Isolates vacuum pump & $\begin{array}{l}\text { Air operated, solenoid } \\
\text { piloted valve, Temescal }\end{array}$ & Vacuum station \\
\hline EiI-19A & $\begin{array}{l}\text { Reads AC current to test section } \\
\text { over heaters }\end{array}$ & Triplett, Model 331-S & Panel 3F \\
\hline EiI-19B & $\begin{array}{l}\text { Indicates cont. volts to saturable } \\
\text { reactor }\end{array}$ & Weston, Model 301-57 & Panel 5D \\
\hline EiS-19 & Htr. current ind. selector switch & $\begin{array}{l}\text { Multi-pole, multi-pos., } \\
\text { GE, SB switch }\end{array}$ & Panel 3F \\
\hline $\mathrm{FE}-31$ & Cold trap sodium flow sensor & $\begin{array}{l}\text { Magnetic flowmeter } \\
\text { fabricated in-house }\end{array}$ & $\begin{array}{l}\text { Cold trap } \\
\text { enclosure }\end{array}$ \\
\hline$F I-25$ & Low pressure argon flowmeter & $\begin{array}{l}\text { Var. A. flowmeter, Brooks } \\
\text { type } 1110-06 \mathrm{ElB} 12\end{array}$ & Panel $4 \mathrm{~F}$ \\
\hline
\end{tabular}




\begin{tabular}{|c|c|c|c|c|}
\hline $\begin{array}{l}\text { Instrument } \\
\text { No. }\end{array}$ & Service & Description & & Iocation \\
\hline $\operatorname{PI}-43$ & Scratch gage purge flow indicator & $\begin{array}{l}\text { Var. A. Plowmeter, Ei } \\
\text { Porter } 132-\mathrm{G}\end{array}$ & ischer- & South wall \\
\hline FI- 44 & Drain pan argon flowmeter & $\begin{array}{l}\text { Var. A. flowmeter, Fi } \\
\text { Porter }\end{array}$ & ischer- & Pane $3 \mathrm{H}$ \\
\hline FI- 62 & Argon purge to check valves & $\begin{array}{l}\text { Vor. A. Plowmeter, } \\
\text { Porter } 1326\end{array}$ & scher- & Pane1 $4 \mathrm{E}$ \\
\hline$E R-31$ & Cold trap sodium flow recorder & $\begin{array}{l}\text { Honeywe11, Class } 15, \\
\text { point recorder }\end{array}$ & single & EN pump cabinet \\
\hline $\operatorname{EsV}-44$ & $\begin{array}{l}\text { Drain pan emergency axgon flood } \\
\text { valve }\end{array}$ & $\begin{array}{l}\text { ASCO solenoid valve, } \\
\text { Mo. } 8300 \mathrm{Bg} \text { a }\end{array}$ & cat. & Inside of Cab. 4 \\
\hline$B V-9$ & Argon accumulator vent & $\begin{array}{l}\text { I. P. March Corp., i/ } \\
\text { valve }\end{array}$ & $/ 2^{n}$ & $\begin{array}{l}\text { High pressure } \\
\text { argon station }\end{array}$ \\
\hline$B V-14 A$ & Argon cylinder valve & Integral with argon & oylinder & $\begin{array}{l}\text { High pressure } \\
\text { axgon station }\end{array}$ \\
\hline $\mathrm{HV}-34 \mathrm{C}$ & Argon cylinder valve & $"$ & $n$ & $"$ \\
\hline$H V-14 E$ & Argon cyijinder valve & $"$ & $u$ & $t$ \\
\hline $\mathrm{HV}-14 \mathrm{G}$ & Argon cylinder valve & $"$ & $"$ & $n$ \\
\hline$H V-14 K$ & Argon cylinder valve & $"$ & si & $" 1$ \\
\hline $\mathrm{HV}-14 \mathrm{M}$ & Argon cylinder valve & $n$ & $" 1$ & $"$ \\
\hline $3 V-14 P$ & Argon cylinder valve & $n$ & $" 1$ & $n$ \\
\hline HV $-14 R$ & High press. argon manifold valve & Victor No. 1125-0030 & & $u$ \\
\hline $\mathrm{HV}-34 \mathrm{~S}$ & $n$ & $"$ & & $" 1$ \\
\hline $\mathrm{HV}-14 \mathrm{~T}$ & $n$ & $" 1$ & & $n$ \\
\hline
\end{tabular}




\begin{tabular}{|c|c|c|c|}
\hline $\begin{array}{l}\text { Instrument } \\
\text { No. }\end{array}$ & Service & Description & Location \\
\hline $\mathrm{HV}-14 \mathrm{U}$ & High pressure argon manifold valve & Victor No. $1125-0030$ & $\begin{array}{l}\text { High pressure } \\
\text { argon station }\end{array}$ \\
\hline $\mathrm{HV}-15 \mathrm{~A}$ & Argon cylinder valve & $\begin{array}{l}\text { Integral with argon } \\
\text { cylinder }\end{array}$ & $\begin{array}{l}\text { High pressure } \\
\text { argon ref. }\end{array}$ \\
\hline $\mathrm{HV}-15 \mathrm{~B}$ & Argon ref. supply block valve & $\begin{array}{l}\text { Superior, } 3 / 4 " \text { XCGA } 580 \\
\text { cylinder valve }\end{array}$ & $\begin{array}{l}\text { High pressure } \\
\text { argon ref. }\end{array}$ \\
\hline $\mathrm{HV}-17 \mathrm{~A}$ & PCV-17 cylinder air throttle valve & Hoke No. P3211G4B & $\begin{array}{l}\text { Outside S. } \\
\text { enclosure wall }\end{array}$ \\
\hline $\mathrm{HV}-17 \mathrm{~B}$ & PCV-17 cylinder manual vent valve & Hoke No. P3211G4B & $\begin{array}{l}\text { On SE corner of } \\
\text { enclosure }\end{array}$ \\
\hline $\mathrm{HV}-18$ & PCV-17 line syphon break valve & Hoke THY -442 & Inside enclosure \\
\hline $\mathrm{HV}-2 \mathrm{OA}$ & Argon cylinder valve & Integral with argon cylinder & $\begin{array}{l}\text { Low press. argon } \\
\text { station }\end{array}$ \\
\hline $\mathrm{HV}-2 \mathrm{OB}$ & Low pressure argon station valve & Henry No. 5163 & $\begin{array}{l}\text { Low press, argon } \\
\text { manifold }\end{array}$ \\
\hline$H V-21 \mathrm{~A}$ & Argon cylinder valve & Integral with argon cylinder & $\begin{array}{l}\text { Low press. argon } \\
\text { station }\end{array}$ \\
\hline HV-21B & Low pressure argon station valve & Henry No. 5163 & $\begin{array}{l}\text { Low press. argon } \\
\text { manifold }\end{array}$ \\
\hline $\mathrm{HV}-22 \mathrm{~A}$ & Argon cylinder valve & Integral with argon cylinder & $\begin{array}{l}\text { Low press. argon } \\
\text { station }\end{array}$ \\
\hline $\mathrm{HV}-22 \mathrm{~B}$ & Low pressure argon station valve & Henry No. 5163 & $\begin{array}{l}\text { Low press. argon } \\
\text { manifold }\end{array}$ \\
\hline HV-25A & Sump tank argon supply block valve & Hoke RB 273 & Panel $4 \mathrm{~F}$ \\
\hline $\mathrm{HV}-25 \mathrm{~B}$ & Sump tank argon supply block valve & Hoke RB 273 & Panel $4 \mathrm{~F}$ \\
\hline
\end{tabular}




\begin{tabular}{|c|c|}
\hline $\begin{array}{c}\text { Instrument } \\
\text { No. }\end{array}$ & Service \\
\hline HV $-25 \mathrm{C}$ & Sump tank argon flowmeter by-pass \\
\hline HV -27 & Sump tank argon vent valve \\
\hline $\mathrm{HV}-29$ & Sump tank axcon block valve \\
\hline $\mathrm{HV}-30 \mathrm{~A}$ & Cola trap inlet block valve \\
\hline $\mathrm{HV}-3 \mathrm{OB}$ & Cold trap outlet block valve \\
\hline$H V-33 A$ & Economizer inlet block valve \\
\hline$H V-3 I B$ & Sodium sample block valve \\
\hline $\mathrm{EV}-31 \mathrm{C}$ & Sodium sample block valve \\
\hline HV -33 & Manometer level indicator block valve \\
\hline HV -35 & Sump tank blowdown line \\
\hline$H V-36$ & Source tank blowdown line \\
\hline FV -37 & Vacuum pump block valve \\
\hline $\mathrm{HV}-39 \mathrm{~A}$ & Vacuum header station valves \\
\hline $\mathrm{HV}-398$ & $n$ \\
\hline$H V-39 \mathrm{C}$ & $n$ \\
\hline$H V-390$ & $"$ \\
\hline
\end{tabular}

Hoke, RB 273

" $"$

Wupro $1 / 2 "$ SS SS-STW PSW-STE

Hoke, HY-4778

Hoke, $M X-477 B$

" $"$

Boke, THX-442

Hoke, IHY -442

Williams, Fig. 1e50, $1 / 2^{\prime \prime}$ brass

Nupro $1 / 2^{\prime \prime}$ SS

SS-STW PSW-STE

Hoke, $\mathrm{HY}-477 \mathrm{~B}$

Fulton-Sy Lphon, 30405

Veeco $5 / 8^{\prime \prime}$

Bellows-seal. (or equal)
Location

Panei 4 F

" $"$

Surmp tank rapor trap

Cold trap compartment

$\begin{array}{lll}n & n & n \\ " & n & 3 \\ n & n & n\end{array}$

Cold trap compart ment

Manometer level indicator

Sump tank blowdown line

Source tank blow down line

on vacuum pump

Vacuun manifola

" $"$ "

$\begin{array}{ll}n & n \\ n & n \\ n & n\end{array}$




\begin{tabular}{ll}
$\begin{array}{c}\text { Instrument } \\
\text { No. }\end{array}$ & \multicolumn{2}{c}{ Service } \\
\hline HV-40 & Blowdown tank vent valve \\
HV-41 & Building argon supply block valve \\
HV-42 & Building argon supply to drain pan \\
HV-43 & Bldg. argon supply to scratch gages \\
HV-44A & Drain pan argon flowmeter block valve \\
HV-44B & " " \\
HV-44C & Drain pan argon flowmeter bypass valve \\
HV-45A & Nitrogen cylinder valve \\
HV-45C & Nitrogen header station valve \\
HV-45D & Nitrogen header station valve \\
HV-45E & Nitrogen, l50 psig header, block \\
HV-46A & Nitrogen cylinder valve \\
HV-46C & Nitrogen header station valve \\
HV-46D & Nitrogen, 80 psig header, block valve \\
HV-46E & "
\end{tabular}

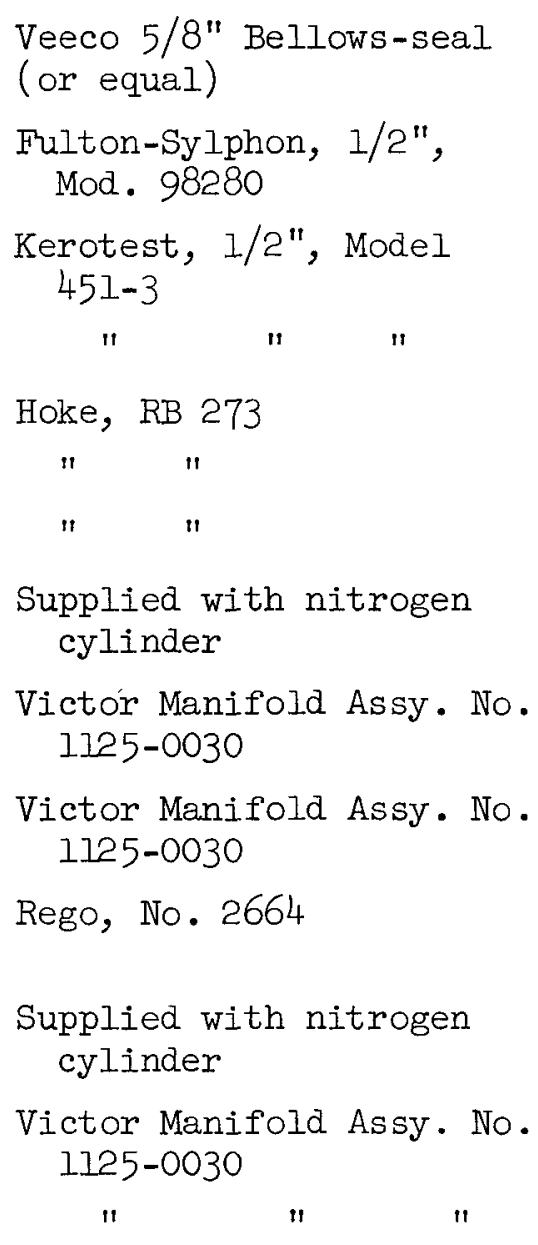

Victór Manifold Assy. No. 1]25-0030

Victor Manifold Assy. No. 1125-0030

Rego, No. 2664

Supplied with nitrogen cylinder

Victor Manifold Assy. No. $1125-0030$$$
\text { it }
$$

"

Rego, No. 2664
Location

Blowdown tank

Bldg. argon supply line

On wall south of enclosure

" "

Panel 4G

" $"$

11

Nitrogen station

Nitrogen station

Nitrogen station

Nitrogen station

$\begin{array}{ll}11 & \text { " } \\ 11 & \\ 11 & n\end{array}$




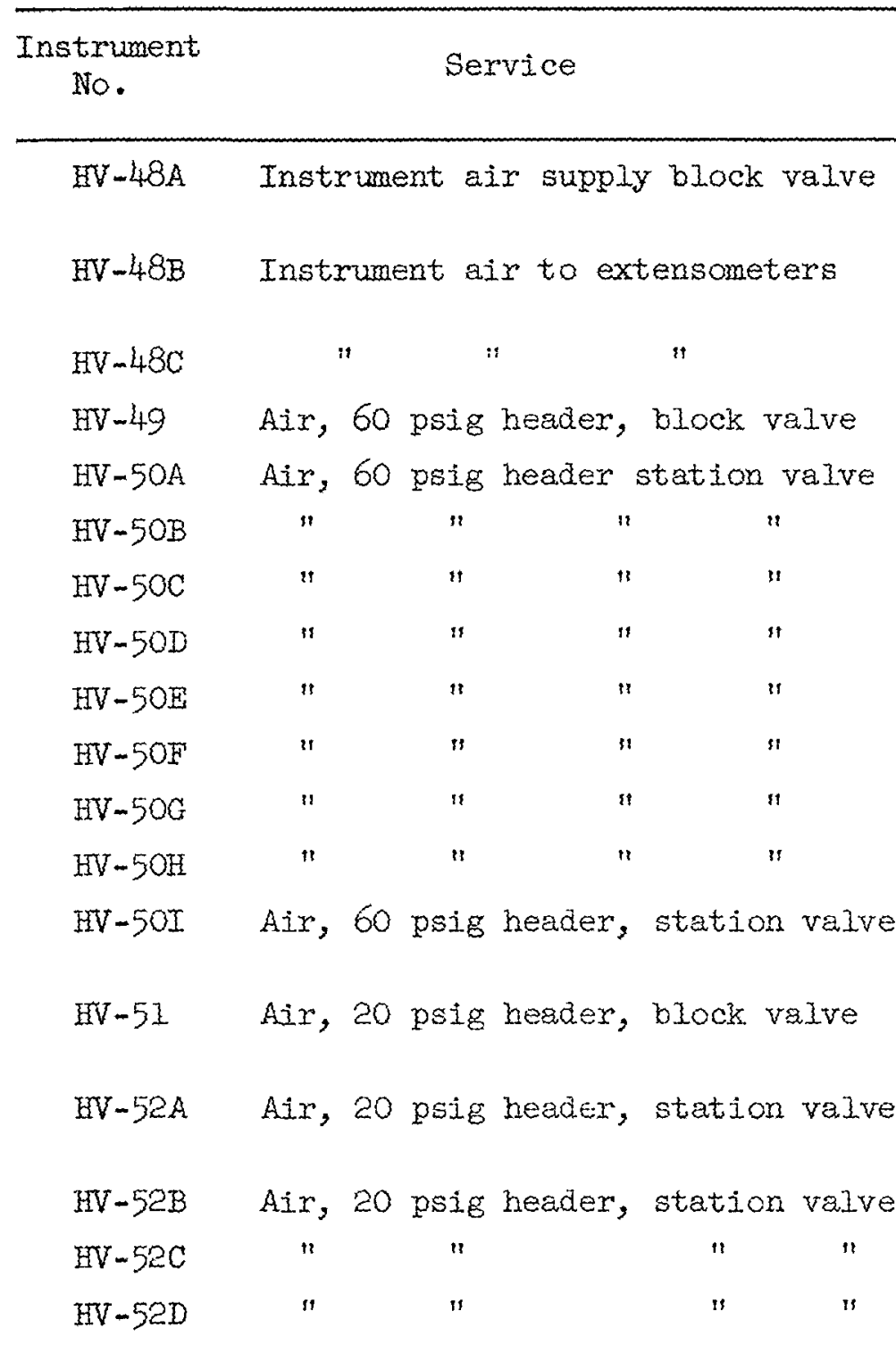

Description

Location

P\&O CO., Fig. IA

Powe11, Fig. 5IX

Bamona No. 18413

$\mathrm{Nibco} / \mathrm{Scott} \mathrm{No}$. T-256-AP

Parker-Hannifin NO. $4 \mathrm{~F}-\mathrm{V} 6 \mathrm{~L}-\mathrm{RB}$

$\begin{array}{ll}n & \text { " } \\ n & n \\ n & n \\ n & n \\ n & n\end{array}$

Parkex-Hannifin No. $4 F-V 6 E-R B$

Nibeo/Scott No. T-256-AP

Parker-Hannifin No. $4 F-V 6 I-R B$

$\begin{array}{ll}n & n \\ n & n\end{array}$

On wall south of enclosure

On wall south of enclosure

$\begin{array}{ll}n & n \\ n & n\end{array}$

60 psig air header

$\begin{array}{ll}n & n \\ n & n \\ n & n \\ n & n \\ n & n\end{array}$

60 psig air header

On wall south of enclosure

20 psig aix header

$\begin{array}{ll}n & n \\ " & n\end{array}$




\begin{tabular}{|c|c|c|c|}
\hline $\begin{array}{l}\text { Instrument } \\
\text { No. }\end{array}$ & Service & Description & Location \\
\hline $\mathrm{HV}-52 \mathrm{E}$ & Air, 20 psig header, station valve & Parker-Hannifin No. 4F-V6I-RB & 20 psig air header \\
\hline $\mathrm{HV}-52 \mathrm{~F}$ & $n " n$ & $"$ & $"$ \\
\hline $\mathrm{HV}-52 \mathrm{G}$ & $"$ & $"$ & $"$ \\
\hline $\mathrm{HV}-52 \mathrm{H}$ & $"$ & $"$ & $"$ \\
\hline$H V-52 I$ & $" 1$ & $"$ & $"$ \\
\hline HV -53 & Sump tank sodium fill block valve & Nupro, SS-8WW-PBW-TI & $\begin{array}{l}\text { Sump tank fill } \\
\text { line }\end{array}$ \\
\hline HV-62A & Argon purge to PCV-IC, block valve & Hoke No. P 3211 G4B & Panel 4E \\
\hline $\mathrm{HV}-62 \mathrm{~B}$ & Argon purge to PSV-3, block valve & $"$ & $"$ \\
\hline HV $-63 A$ & $\begin{array}{l}\text { Air to cold trap cooling coil, } \\
\text { block valve }\end{array}$ & $\begin{array}{l}\text { Lunkenheimer } 3 / 4^{\prime \prime} \text { steam } \\
\text { valve }\end{array}$ & $\begin{array}{l}\text { South end of } \\
\text { enclosure }\end{array}$ \\
\hline HV $-63 B$ & $n$ & $\begin{array}{l}\text { Henry, } 3 / 4 " \text { Globe Dwg. } \\
\quad \text { E 44244R4 }\end{array}$ & $n \quad " n$ \\
\hline HV -64 & $\begin{array}{l}\text { Water to cold trap cooling coil, } \\
\text { throttling valve }\end{array}$ & Hoke No. $1315 \mathrm{G} 4 \mathrm{~B}$ & $"$ \\
\hline HV -66 & Test piece drain valve & Hoke No. HY-477B & $\begin{array}{l}\text { Test piece drain } \\
\text { line }\end{array}$ \\
\hline HV -67 & Test piece argon vent valve & Hoke No. HY-477B & $\begin{array}{l}\text { Test piece vent } \\
\text { line }\end{array}$ \\
\hline HV -68 & Pipe nest sodium drain valve & $"$ & $\begin{array}{l}\text { Pipe nest drain } \\
\text { line }\end{array}$ \\
\hline HS-I & $\begin{array}{l}\text { "Manual Fill" source tank low } \\
\text { level bypass }\end{array}$ & $\begin{array}{l}\text { Key operated DPDT switch, } \\
\text { Allen-Bradley }\end{array}$ & Panel IB \\
\hline
\end{tabular}




\begin{tabular}{|c|c|c|c|}
\hline $\begin{array}{l}\text { Instrument } \\
\text { No. }\end{array}$ & Service & Description & Eocation \\
\hline HS-2 & Building alama bypass & $\begin{array}{l}\text { Make-before-break rotary } \\
\text { switch, Allen-Bradley }\end{array}$ & Panel IB \\
\hline HS -5 & $\begin{array}{l}\text { Momentaxy power outage relay } \\
\text { bypass }\end{array}$ & $\begin{array}{l}\text { Cutler-Hamer type } T, \\
\text { pushbutton switch }\end{array}$ & Panel iB \\
\hline $3 S-6$ & $\begin{array}{l}\text { Momentary power outage relay- } \\
\text { reset }\end{array}$ & $\begin{array}{l}\text { Cutier-Hammex type } T \text {, } \\
\text { pusbbutton switch }\end{array}$ & Panel IB \\
\hline KS -9 & Emergency or manual drain & $\begin{array}{l}\text { Cutler-Hamer Type T, } \\
\text { pushbutton switch }\end{array}$ & Panel iB \\
\hline HS-10 & Emergency or manual drain-reset & $\begin{array}{l}\text { Cutler-Harmer Type } T \text {, } \\
\text { puskbutton switeh }\end{array}$ & PaneI IB \\
\hline $\mathrm{HS}-33$ & Annunciator acknowledge & $\begin{array}{l}\text { Allen-Braaley, momentary } \\
\text { contacts, pushbutton sw. }\end{array}$ & Pane1 $1 \mathrm{C}$ \\
\hline HS -12 & Annunciator reset & $\begin{array}{l}\text { Allex-Bradiey, momeritary } \\
\text { contact, pushbutton sw. }\end{array}$ & Panel ic \\
\hline HS-22 & Vacuum pump isolation valve-bypass & $\begin{array}{l}\text { Allen Bxadjey, } 2 \text { pos. } \\
\text { rotary switch }\end{array}$ & Pane I IB \\
\hline HS-A25 & Source tank first low level selector & DPDI toggle switch & Pane1 5C \\
\hline $\mathrm{HS}-\mathrm{AP} 7 \mathrm{~A}$ & Programed arain control awitch - open & $\begin{array}{l}\text { Allen-Bradley, maintain } \\
\text { contacts, pusbbutton sw. }\end{array}$ & Panel 5D \\
\hline HS-ACTB & Programed drain control switch-close & $\begin{array}{l}\text { Allen-Bradley, maintain } \\
\text { contacts, pushbutton sw. }\end{array}$ & Pane1 50 \\
\hline HS-A28AI & $\begin{array}{l}\text { High pressure argon supply valve } \\
\text { switch - close }\end{array}$ & $\begin{array}{l}\text { Allen-Bradley, momentary } \\
\text { contacts, pusbbutton sw. }\end{array}$ & Panel IC \\
\hline HS-A28A2 & $\begin{array}{l}\text { High pressure argon supply valve } \\
\text { switch - Open }\end{array}$ & $\begin{array}{l}\text { Allen-Bradiey, momentaxy } \\
\text { pusbbutton switch }\end{array}$ & Pane1 10 \\
\hline
\end{tabular}




\begin{tabular}{|c|c|c|c|}
\hline $\begin{array}{l}\text { Instrument } \\
\text { No. }\end{array}$ & Service & Description & Location \\
\hline $\mathrm{HS}-\mathrm{A} 28 \mathrm{BI}$ & $\begin{array}{l}\text { High pressure argon vent valve switch } \\
\text { Open }\end{array}$ & $\begin{array}{l}\text { Allen-Bradley, momentary } \\
\text { contacts, pushbutton sw. }\end{array}$ & Panel IC \\
\hline $\mathrm{HS}-\mathrm{A} 28 \mathrm{B2}$ & $\begin{array}{l}\text { High pressure argon vent valve } \\
\text { switch - close }\end{array}$ & $\begin{array}{l}\text { Allen-Bradley, momentary } \\
\text { contacts, pushbutton sw. }\end{array}$ & Panel IC \\
\hline HS-D27A & $\begin{array}{l}\text { Equalizer valve control switch - } \\
\text { close }\end{array}$ & $\begin{array}{l}\text { Allen-Bradley, meintain } \\
\text { contacts, pushbutton sw. }\end{array}$ & Panel 1C \\
\hline HS-DETB & $\begin{array}{l}\text { Equalizer valve control switch - } \\
\text { open }\end{array}$ & $\begin{array}{l}\text { Allen-Bradley, maintain } \\
\text { contacts, pushbutton sw. }\end{array}$ & Panel IC \\
\hline $\mathrm{HS}-\mathrm{A} 30 \mathrm{~A}$ & $\begin{array}{l}\text { Electrical heater power control } \\
\text { switch - off }\end{array}$ & $\begin{array}{l}\text { Allen-Bradley, momentary } \\
\text { contacts, pushbutton sw. }\end{array}$ & Panel 1C \\
\hline $\mathrm{HS}-\mathrm{A} 3 \mathrm{OB}$ & $\begin{array}{l}\text { Electrical heater power control } \\
\text { switch - on }\end{array}$ & $\begin{array}{l}\text { Allen-Bradley, momentary } \\
\text { contacts, pushbutton sw. }\end{array}$ & Panel IC \\
\hline HS -80 & Vacuum pump power switch & $\begin{array}{l}\text { Allen-Bradley, } 2 \text { position } \\
\text { rotary switch }\end{array}$ & Panel IB \\
\hline$I A-16 \mathrm{~A}$ & Source tank low level alarm & $\begin{array}{l}\text { Tigerman Tel-Alarm circuit } \\
\text { 416NCLS2 }\end{array}$ & Panel $3 \mathrm{~A}$ \\
\hline LA-I6E & Source tank high level alarm & $\begin{array}{l}\text { Tigerman Tel-Alarm } \\
\quad \text { Circuit 4l6nCLS2 }\end{array}$ & Panel $3 \mathrm{~A}$ \\
\hline$L E-16$ & Source tank sodium level sensor & $\begin{array}{l}\text { Twin-I-Tube Dwg. } \\
\text { M-10596-RM-010-E }\end{array}$ & In source tank \\
\hline$L I-32$ & Sump tank sodium level indicator & $\begin{array}{l}\text { Ashcroft ( } 3 \text { to } 15 \text { psig) } \\
3-1 / 2^{\prime \prime} \text { rec. gage }\end{array}$ & Panel 4C \\
\hline$L I-34$ & Manometer tube oil level indicator & Sight tube indicator & On wall, first floor \\
\hline IM-16 & Source tank level signal conditioner & $\begin{array}{l}\text { Foxboro Type 693, EMF-to- } \\
\text { current converter }\end{array}$ & Panel 5D \\
\hline
\end{tabular}




\begin{tabular}{|c|c|c|c|}
\hline $\begin{array}{l}\text { Instrument } \\
\text { No. }\end{array}$ & Service & Description & Location \\
\hline$L R-16$ & Source tank sodium level recorder & $\begin{array}{l}\text { Honeywell Class } 15 \text {, single } \\
\text { point recorder }\end{array}$ & Panel 50 \\
\hline$I S-16 \mathrm{~A}$ & $\begin{array}{l}\text { Source tank sodiun first low level } \\
\text { switch* }\end{array}$ & $\begin{array}{l}\text { Foxboro Madel } 63 \mathrm{BP} \mathrm{BCI} \\
\text { alerm unit }\end{array}$ & Pane1 5D \\
\hline $25-16 B$ & $\begin{array}{l}\text { Source tank sodium second low } \\
\text { level switch }\end{array}$ & $\begin{array}{l}\text { Foxboro Model } 63 \mathrm{BP} \text { ECI } \\
\text { alarm unit }\end{array}$ & Pane1 5D \\
\hline $5 S-16 \mathrm{C}$ & $\begin{array}{l}\text { Source tank sodium thitrd low } \\
\text { level switeh }\end{array}$ & $\begin{array}{l}\text { Foxboro Model } 63 \mathrm{BP} \text { ECI } \\
\text { alarm unit }\end{array}$ & Panel 5D \\
\hline $1 S-360$ & $\begin{array}{l}\text { Source tank sodium first low } \\
\text { level switch* }\end{array}$ & $\begin{array}{l}\text { Foxboro Model } 63 \mathrm{BP} \text { BCI } \\
\text { zlarm unit }\end{array}$ & Panel 5D \\
\hline $\mathrm{IS}-16 \mathrm{E}$ & Source tank sodium high level switch & $\begin{array}{l}\text { Integraliy mounted switeh } \\
\quad \text { in } 1 R-16\end{array}$ & $\begin{array}{l}\operatorname{IR}-16 \\
\text { Pane } 5 \mathrm{C}\end{array}$ \\
\hline$I m-32$ & Sump tank sodium level transmitter & $\begin{array}{l}\text { Taylor Mod. X225TMllo3, } \\
\text { NaK filled } \mathrm{D} / \mathrm{P} \text { celi }\end{array}$ & $\begin{array}{l}\text { Outilide north end } \\
\text { of enclosure }\end{array}$ \\
\hline$I X-16$ & $\begin{array}{l}\text { Source tank sodium level detector } \\
\text { excitation }\end{array}$ & $\begin{array}{l}\text { NJE Model TR-18-3 reguzated } \\
\text { power supply }\end{array}$ & Panel 5B \\
\hline$P A-I A$ & Source tank high pressure alarm & $\begin{array}{l}\text { Tigerman Tel-Alarm } \\
\text { Circuit } 4 \text { I6nclúe }\end{array}$ & Panel 3A \\
\hline$P A-2 A l$ & Source tank low pressure alarm & $n$ & Pane1 $5 \mathrm{~A}$ \\
\hline$P A-10$ & Rupture disc failure alarm & $"$ & Panel $5 \mathrm{~A}$ \\
\hline$P A-14$ & $\begin{array}{l}\text { High pressure argon supply, low } \\
\text { pressure alarm }\end{array}$ & $"$ & Panel 4A \\
\hline$P A-15$ & $\begin{array}{l}\text { Argon ref. pressure supply, low } \\
\text { pressure alarm }\end{array}$ & $"$ & Pane1 $4 \mathrm{~A}$ \\
\hline
\end{tabular}

*Either LS-16A or LS-160, but not both, is active. 


\begin{tabular}{|c|c|c|c|}
\hline $\begin{array}{l}\text { Instrument } \\
\text { No. }\end{array}$ & Service & Description & Location \\
\hline$P A-24$ & $\begin{array}{l}\text { Low pressure argon supply, low } \\
\text { pressure alarm }\end{array}$ & $\begin{array}{l}\text { Tigerman Tel-Alarm Circuit } \\
\text { 4l6NCIS2 }\end{array}$ & Panel $4 \mathrm{~A}$ \\
\hline $\mathrm{PA}-44$ & $\begin{array}{l}\text { Building argon supply low pressure } \\
\text { alarm }\end{array}$ & $"$ & Panel $4 \mathrm{~A}$ \\
\hline$P A-45$ & $\begin{array}{l}\text { Nitrogen to PCV-17, low pressure } \\
\text { alarm }\end{array}$ & $"$ & Panel $3 \mathrm{~A}$ \\
\hline$P A-46$ & $\begin{array}{l}\text { Nitrogen supply, low pressure } \\
\text { alarm }\end{array}$ & $"$ & Panel $4 \mathrm{~A}$ \\
\hline PA-48 & $\begin{array}{l}\text { Building instrument air, low } \\
\text { pressure alarm }\end{array}$ & $"$ & Panel $4 \mathrm{~A}$ \\
\hline$P A-54$ & Sump tank high pressure alarm & $"$. & Panel 3A \\
\hline PCV-IA & Source tank argon inlet valve & $\begin{array}{l}\text { Annin Mod. } 3463 \text { with Domotor } \\
\text { acutator }\end{array}$ & Source tank inlet \\
\hline PCV-IB & Source tank argon inlet valve & $\begin{array}{l}\text { Fulton-Sylphon with bellows } \\
\text { actuator }\end{array}$ & Source tank inlet \\
\hline PCV-IC & Source tank argon vent valve & $\begin{array}{l}\text { Annin Mod. } 3460 \text { with Domotor } \\
\text { actuator }\end{array}$ & Source tank outlet \\
\hline PCV-17 & Sodium dump valve & Masoneilan with cylinder & $\begin{array}{l}\text { Downstream of } \\
\text { cap. tank }\end{array}$ \\
\hline PdT-I & Source tank pressure transmitter & $\begin{array}{l}\text { Foxboro Mod. 13HA, diff. } \\
\text { press. transmitter }\end{array}$ & $\begin{array}{l}\text { Source tank } \\
\text { enclosure }\end{array}$ \\
\hline$P I-5$ & Dome regulator dome press. indicator & $\begin{array}{l}\text { Ashcroft MS-MP-IC, Type } 1 \text {, } \\
\text { Class } 1,4-1 / 2 " \text { dia. }\end{array}$ & $\begin{array}{l}\text { Hi Press. argon } \\
\text { station }\end{array}$ \\
\hline PI-10 & Rupture disc failure indicator & U.S. Gauge, $2^{\prime \prime}$ dia. & $\begin{array}{l}\text { Downstream of } \\
\text { rupture disc. }\end{array}$ \\
\hline
\end{tabular}




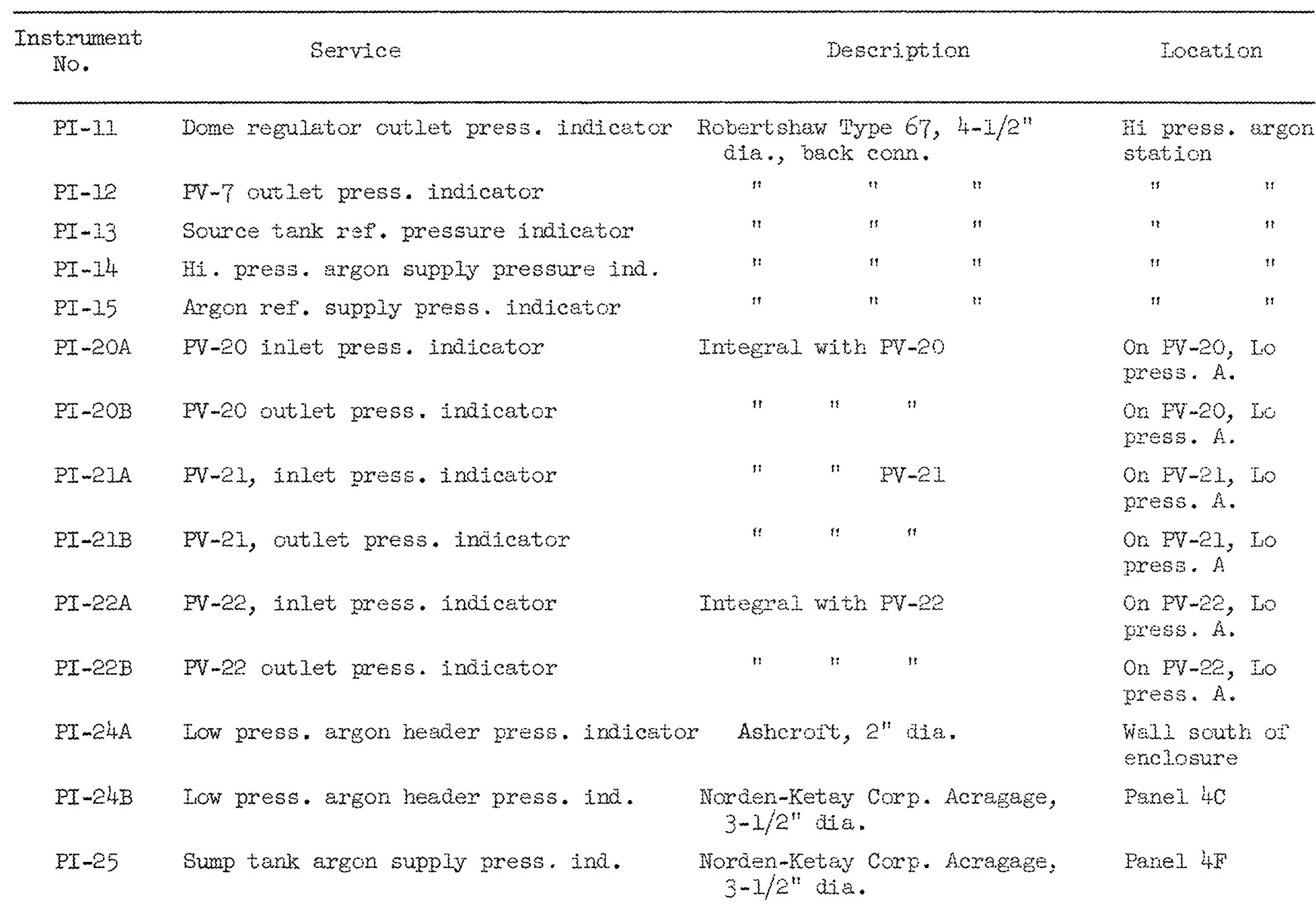




\begin{tabular}{|c|c|c|c|}
\hline $\begin{array}{l}\text { Instrument } \\
\text { No. }\end{array}$ & Service & Description & Location \\
\hline$P I-39 A$ & Vacuum system pressure indicator & $\begin{array}{l}\text { Hastings vacuum gage, Model } \\
\text { VC-3C }\end{array}$ & Vacuum station \\
\hline PI-39B & Vacuum system pressure indicator & $\begin{array}{l}\text { Asheroft No. 1379AC, compound, } \\
4-1 / 2^{\prime \prime} \text { dia. }\end{array}$ & Vacuum header \\
\hline$P I-43$ & Argon purge pressure indicator & Asheroft 2-1/2" dia. & $\begin{array}{l}\text { Wall south of } \\
\text { enclosure }\end{array}$ \\
\hline PI-44A & Building argon supply press. indicator & $\begin{array}{l}\text { Norden-Ketay Corp., Acragage, } \\
\text { 3-I/2" dia. }\end{array}$ & Panel 4B \\
\hline$P I-44 B$ & Drain pan argon supply press. indicator & $\begin{array}{l}\text { Norden-Ketay Corp., Acragage, } \\
3-1 / 2^{\prime \prime} \text { dia. }\end{array}$ & Panel 4G \\
\hline $\mathrm{PI}-45 \mathrm{~A}$ & PV-45 inlet press. indicator & $\begin{array}{l}\text { Integral with PV-45, } \\
2-1 / 2^{\prime \prime} \text { dia. }\end{array}$ & $\begin{array}{l}\text { Nitrogen bottle } \\
\text { station }\end{array}$ \\
\hline$P I-45 B$ & PV-45 outlet press. indicator & $\begin{array}{l}\text { Integral with PV-45, } \\
2-1 / 2^{\prime \prime} \text { dia. }\end{array}$ & $\begin{array}{l}\text { Nitrogen bottle } \\
\text { station }\end{array}$ \\
\hline$P I-46 B$ & PV-46 outlet press. indicator & $\begin{array}{l}\text { Integral with PV-46, } \\
2-1 / 2^{\prime \prime} \text { dia. }\end{array}$ & $\begin{array}{l}\text { Nitrogen bottle } \\
\text { station }\end{array}$ \\
\hline $\mathrm{PI}-48 \mathrm{~A}$ & Bldg. inst. air supply press. ind. & $\begin{array}{l}\text { Norden-Ketay Corp., Acragage } \\
3-1 / 2^{\prime \prime} \text { dia. }\end{array}$ & $\begin{array}{l}\text { On wall south } \\
\text { of enclosure }\end{array}$ \\
\hline$P I-48 B$ & $\begin{array}{l}\text { Air cooled extensometer supply } \\
\text { indicator }\end{array}$ & Integral with PV-48, 2" dia. & $\begin{array}{l}\text { On wall south } \\
\text { of enclosure }\end{array}$ \\
\hline $\mathrm{PI}-49 \mathrm{~A}$ & $\begin{array}{l}\text { Air to } 60 \text { psig header press. } \\
\text { indicator }\end{array}$ & Integral with PV-49, 2" dia. & $\begin{array}{l}\text { On wall south } \\
\text { of enclosure }\end{array}$ \\
\hline$P I-49 B$ & 60 psig air header press. indicator & $\begin{array}{l}\text { Norden-Ketay Corp. Acragage, } \\
3-1 / 2^{\prime \prime} \text { dia. }\end{array}$ & Panel 4B \\
\hline PI-50B & 35 psig air supply press. indicator & $\begin{array}{l}\text { Integral with PV-50B, Ashcroft } \\
2^{\prime \prime} \text { dia. }\end{array}$ & $\begin{array}{l}\text { On wall south } \\
\text { of enclosure }\end{array}$ \\
\hline
\end{tabular}




\begin{tabular}{|c|c|c|c|}
\hline $\begin{array}{l}\text { Instrument } \\
\text { No. }\end{array}$ & Service & Descrìption & Location \\
\hline$P I-51 \mathrm{~A}$ & $\begin{array}{l}20 \text { psig air hesder pressure } \\
\text { indicator }\end{array}$ & $\begin{array}{l}\text { Integral wath PV-5.A, Asherost, } \\
2^{\prime \prime} \text { dia. }\end{array}$ & $\begin{array}{l}\text { On wall south of } \\
\text { enclosure }\end{array}$ \\
\hline $\operatorname{PI}-51 B$ & 20 psis air headar pressure & $\begin{array}{l}\text { Norten-Ketay Coxp:" } \\
\text { Acragage, } 3-1 / 2 " \text { dia. }\end{array}$ & Eanel $4 \mathrm{~B}$ \\
\hline$P T-52 B$ & $\begin{array}{l}\text { Manual loading station curput } \\
\text { presswe indicator }\end{array}$ & $\begin{array}{c}\text { Moore Proaucte, } 3389-8 \text {, } \\
\text { integral with } 9 V-5 ?\end{array}$ & $\begin{array}{l}\text { on wall souts } \\
\text { of enclosure }\end{array}$ \\
\hline$P I-63$ & Cold trap air pressure indicator & Crosby, $3-1 / 2^{\prime \prime} d i$ & $\begin{array}{l}\text { On south wall } \\
\text { of enclosure }\end{array}$ \\
\hline $2 A-2 A$ & $\begin{array}{l}\text { Source tank preasure signal } \\
\text { conditioner }\end{array}$ & $\begin{array}{l}\text { Bell \& Howell Type i8-112A, } \\
\text { resistance transmitter }\end{array}$ & Cabinet 5 \\
\hline$M-2 B$ & $\begin{array}{l}\text { Source tank pressure aignal } \\
\text { modifier }\end{array}$ & $\begin{array}{l}\text { Foxboro Mod. 69pA-1, current- } \\
\text { to-air converter }\end{array}$ & Cabinet 5 \\
\hline$P Q 4-55$ & $\begin{array}{l}\text { Source tanir pressure signal } \\
\text { conătioner }\end{array}$ & $\begin{array}{l}\text { Endsveo Mod. i4 } 40 \text { with Mod. } \\
\text { 447a. IA ceara }\end{array}$ & Strain inst. cab. \\
\hline $\mathfrak{P R}-2$ & Souxce tank pressure recordex & $\begin{array}{l}\text { Foxboro } \mathrm{k} / 53 \text { dual-pen } \\
\text { recorder }\end{array}$ & Pane 150 \\
\hline $2 \mathrm{RC}-3$ & $\begin{array}{l}\text { Source tank pressure recorder- } \\
\text { controllar }\end{array}$ & $\begin{array}{l}\text { Foxboro } M / 53 \text { ree. With } \\
M / 58 \text { controller }\end{array}$ & Panel 50 \\
\hline$P S-1 A$ & Source tank high pressure alaxm & Meletron Made1 $472 \tilde{F}^{2}$ & $\begin{array}{l}\text { In valve nest } \\
\text { enclosure }\end{array}$ \\
\hline$P S-1 B$ & Source tank low pxessure interlock & Meletron Modes $472 \mathrm{E}$ & $\begin{array}{l}\text { In velve nest } \\
\text { anclosure }\end{array}$ \\
\hline PS-2AI & $\begin{array}{l}\text { Source tank low pressure olarm } \\
\text { switeh }\end{array}$ & Integral with PM-2A & $\begin{array}{l}\mathrm{Cab} \cdot 5 \\
(\mathrm{PM}-2)\end{array}$ \\
\hline$P S-2 A 2$ & Source tark low press. iriterlock & Integral with PM-eA & $C a b \cdot 5(B M-2)$ \\
\hline
\end{tabular}




\begin{tabular}{|c|c|c|c|}
\hline $\begin{array}{l}\text { Instrument } \\
\quad \text { No. }\end{array}$ & Service & Description & Location \\
\hline PS-10 & Rupture disc failure alarm switch & Meletron Model BIT Al2SS & $\begin{array}{l}\text { On south wall of } \\
\text { enclosure }\end{array}$ \\
\hline PS -14 & $\begin{array}{l}\text { Argon supply low pressure alarm } \\
\text { switch }\end{array}$ & Meletron Mod. 372 & $\begin{array}{l}\text { Argon supply } \\
\text { aux. panel }\end{array}$ \\
\hline PS-15 & $\begin{array}{l}\text { Argon ref. supply low pressure } \\
\text { alarm switch }\end{array}$ & Meletron Mod. 312 & $\begin{array}{l}\text { Argon supply } \\
\text { aux. panel }\end{array}$ \\
\hline PS -24 & $\begin{array}{l}\text { Low pressure argon header low } \\
\text { pressure switch }\end{array}$ & Barksdale Mod. DITA 150 & Cabinet 4 \\
\hline PS-39A & $\begin{array}{l}\text { Vacuum system high pressure } \\
\text { interlock }\end{array}$ & Integral with PI-39A & Vacuum station \\
\hline$P S-44$ & $\begin{array}{l}\text { Building argon low pressure } \\
\text { alarm switch }\end{array}$ & Barksdale Mod. DITA 150 & Cabinet 4 \\
\hline$P S-45$ & $\begin{array}{l}\text { Nitrogen to PCV-17, low pressure } \\
\text { alarm switch }\end{array}$ & Meletron Mod. 372 & $\begin{array}{l}\text { On wall south } \\
\text { of enclosure }\end{array}$ \\
\hline PS -46 & $\begin{array}{l}\text { Nitrogen supply low pressure } \\
\text { alarm switch }\end{array}$ & Meletron Mod. 372 & $\begin{array}{l}\text { On wall south } \\
\text { of enclosure }\end{array}$ \\
\hline PS- 48 & $\begin{array}{l}\text { Building instrument air low } \\
\text { pressure alarm switch }\end{array}$ & Meletron Mod. 312 & $\begin{array}{l}\text { On wall south } \\
\text { of enclosure }\end{array}$ \\
\hline$P S-54$ & $\begin{array}{l}\text { Sump tank high pressure } \\
\text { alarm switch }\end{array}$ & Barksdale Mod. DIT-HI8-P8 & $\begin{array}{l}\text { On north wall of } \\
\text { enclosure }\end{array}$ \\
\hline PSV -3 & Source tank argon fast vent & $\begin{array}{c}\text { Annin Mod. } 6420, \text { with } \\
\text { cylinder actuator }\end{array}$ & $\begin{array}{l}\text { In valve nest } \\
\text { enclosure }\end{array}$ \\
\hline PSV-4 & $\begin{array}{l}\text { Source tank - sump tank } \\
\text { equalizer valve }\end{array}$ & $\begin{array}{l}\text { Hoke } H Y-477 \mathrm{~B} \text { with cylinder } \\
\text { actuator }\end{array}$ & $\begin{array}{l}\text { In valve nest } \\
\text { enclosure }\end{array}$ \\
\hline
\end{tabular}




\begin{tabular}{|c|c|c|c|}
\hline $\begin{array}{l}\text { Inst xument } \\
\text { No. }\end{array}$ & Service & Description & Eocation \\
\hline PSV-9 & $\begin{array}{l}\text { High pressure argon regulator } \\
\text { relief valve }\end{array}$ & Circle Seal Mod. $5133 \mathrm{~T}-\mathrm{Mp}$ & $\begin{array}{l}\text { High pressure axgon } \\
\text { station }\end{array}$ \\
\hline$P S V-10$ & Source tarik pressure rejief valve & $\begin{array}{l}\text { Farris, } 3-1 / 2 \text { F } 2-1 / 2 \text { type } \\
2663 z\end{array}$ & Atop souree tank \\
\hline PSV -45 & 150 psig ritrogen supply reliet & Circle Seai Mod. 5159B-2MP & $\begin{array}{l}\text { WaIl south of } \\
\text { enclosure }\end{array}$ \\
\hline $\operatorname{psv}-47$ & 80 psig nitrogen supply relief & Circle seal Moc. 51598-2MP & $\begin{array}{l}\text { Wall south of } \\
\text { enciosure }\end{array}$ \\
\hline$P M-2$ & Source tanik sec. pressure transducer & $\begin{array}{l}\text { Consolidated Wlectrodynamies } \\
\text { Comp. Type } 4-313 \text {-0001- } \\
\text { loooG }\end{array}$ & $\begin{array}{l}\text { In valve nest } \\
\text { enclosure }\end{array}$ \\
\hline PV -5 & Source tank inlet argon pilot regulator & $\begin{array}{l}\text { Grove Mod. } 15 \text { Lan, Fig. } \\
\text { logeg H P2A }\end{array}$ & $\begin{array}{l}\text { High pressure } \\
\text { argon station }\end{array}$ \\
\hline PV -6 & Source tanik inlet argon dome regulator & $\begin{array}{l}\text { Grove Moa. } 402 \mathrm{~s} \text {, Fig. } \\
\text { li216P08TK }\end{array}$ & $\begin{array}{l}\text { High pressure } \\
\text { argon station }\end{array}$ \\
\hline PV -7 & Source tank inlet verniex areon regulator & $\begin{array}{l}\text { Grove Mod. } 15 \mathrm{LGH}, \text { Fig. } \\
\text { 11216P087K }\end{array}$ & $\begin{array}{l}\text { High pressure } \\
\text { argon station }\end{array}$ \\
\hline EV -8 & $\begin{array}{l}\text { Source vank argon reference pressure } \\
\text { regulator }\end{array}$ & $\begin{array}{l}\text { Grove Moa. } 15 I X G \text {, Fig. } \\
11304 \text { F Pe8 }\end{array}$ & $\begin{array}{l}\text { High pressure } \\
\text { argon station }\end{array}$ \\
\hline$P V-20$ & $\begin{array}{l}\text { Argon low pressure argon supply } \\
\text { gas cylinder regulator }\end{array}$ & $\begin{array}{l}\text { Dual gage argon cylinder } \\
\text { regulator }\end{array}$ & $\begin{array}{l}\text { Low pcessure } \\
\text { axgon station }\end{array}$ \\
\hline
\end{tabular}




\begin{tabular}{|c|c|c|c|}
\hline $\begin{array}{l}\text { Instrument } \\
\text { No. }\end{array}$ & Service & Description & Location \\
\hline PV -21 & $\begin{array}{l}\text { Argon low pressure argon supply } \\
\text { gas cylinder regulator }\end{array}$ & $\begin{array}{l}\text { Dual gage argon cylinder } \\
\text { regulator }\end{array}$ & $\begin{array}{l}\text { Low pressure } \\
\text { argon station }\end{array}$ \\
\hline PV-22 & $"$ & $"$ & $"$ \\
\hline PV-25 & Low pressure argon final regulator & $\begin{array}{l}\text { Norgren Mod. 11-002-051 } \\
\quad \text { (or equal) }\end{array}$ & Panel 4F \\
\hline PV-26 & Sump tank back press. regulator & Fisher-Governor $289 \mathrm{H}-42$ & Cabinet 4 \\
\hline PV -43 & Scratch gage argon purge flow reg. & Fisher-Governor Mod. $67 \mathrm{P}$ & $\begin{array}{l}\text { On wall south of } \\
\text { enclosure }\end{array}$ \\
\hline PV -44 & $\begin{array}{l}\text { Bldg. argon supply drain pan flood } \\
\text { regulator }\end{array}$ & $\begin{array}{l}\text { Norgren Mod. } 11-002-003 \\
\quad \text { (or equal) }\end{array}$ & Panel 4G \\
\hline PV -45 & 150 psig nitrogen supply regulator & Victor No. VTS7OOME & Nitrogen station \\
\hline PV -46 & 60 psig nitrogen supply regulator & Victor No. VTS7OOME & Nitrogen station \\
\hline PV -48 & Extensometer cooling air regulator & $\begin{array}{l}\text { Norgren Mod. 11-002-007 } \\
\quad \text { (or equal) }\end{array}$ & $\begin{array}{l}\text { On wall south of } \\
\text { enclosure }\end{array}$ \\
\hline PV -49 & 60 psig air header regulator & $\begin{array}{l}\text { Norgren Mod. } 11-002-007 \\
\quad \text { (or equal) }\end{array}$ & $\begin{array}{l}\text { On wall south of } \\
\text { enclosure }\end{array}$ \\
\hline$P V-50 B$ & 35 psig air to $\mathrm{PCV}-1 \mathrm{~B}$ regulator & Moore Products Mod. 40-100 & $\begin{array}{l}\text { On wall south of } \\
\text { enclosure }\end{array}$ \\
\hline PV -51 & 20 psig air header regulator & Moore Products Mod. 40-30 & $\begin{array}{l}\text { On wall south of } \\
\text { enclosure }\end{array}$ \\
\hline$P V-52 E$ & Manual loading station to PCV-IA & Moore Products Mod. 40-30M & $\begin{array}{l}\text { On Col. S of } \\
\text { enclosure }\end{array}$ \\
\hline PV -63 & Cold trap cooling air regulator & Masoneilan No. $11-11$ & $\begin{array}{l}\text { On south wall } \\
\text { of enclosure }\end{array}$ \\
\hline
\end{tabular}




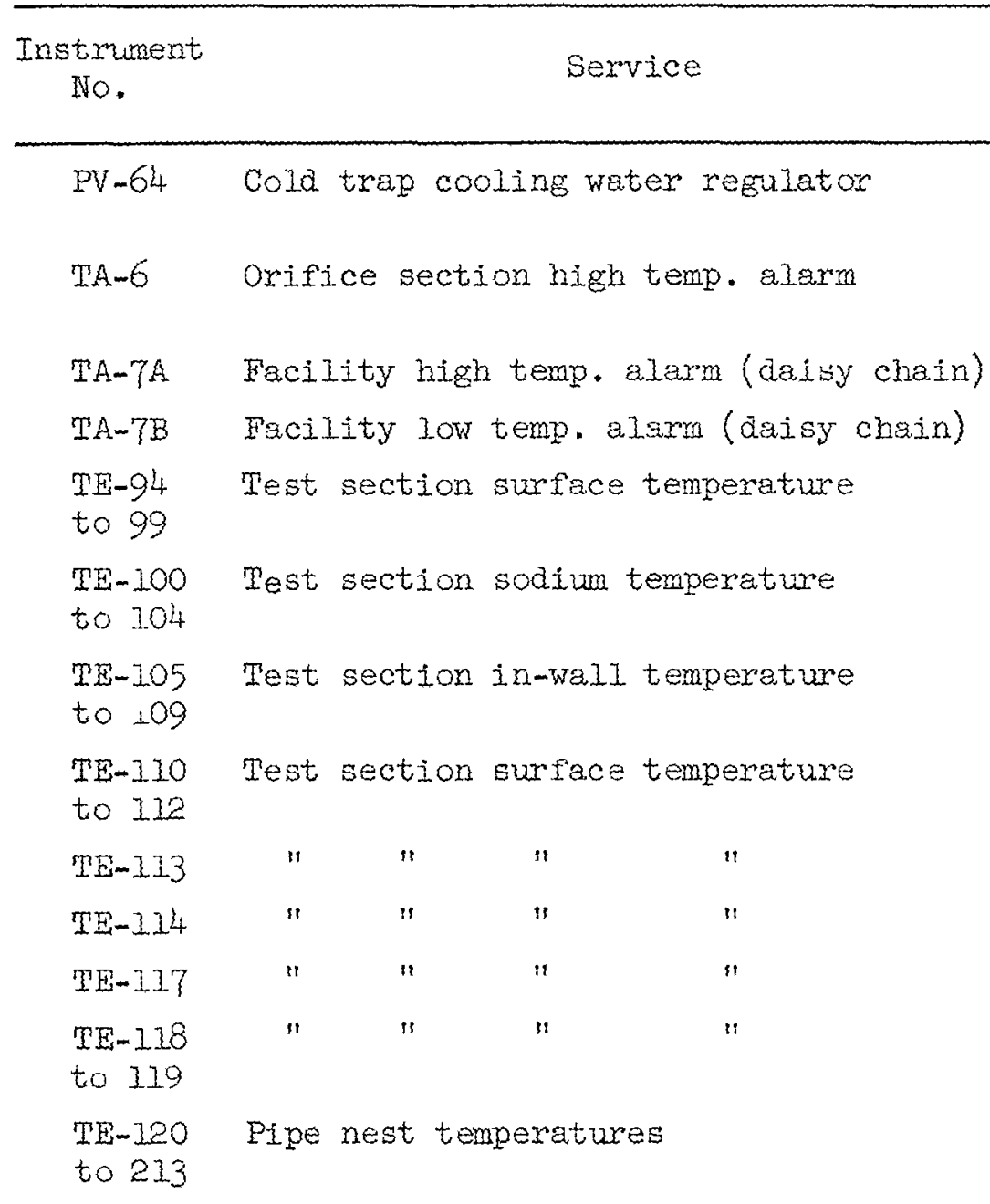

Description

Irocation

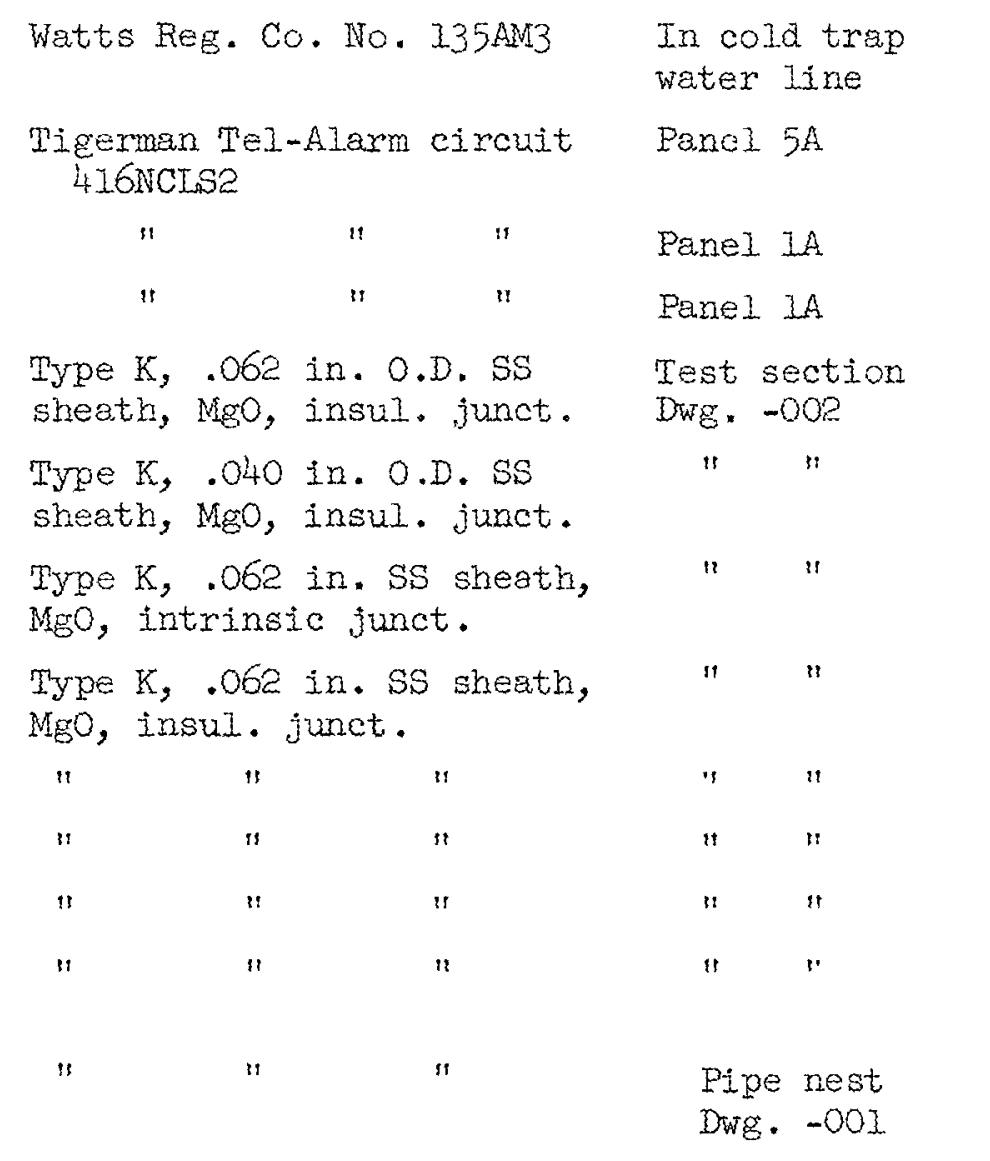




\begin{tabular}{|c|c|c|c|c|}
\hline $\begin{array}{l}\text { Instrument } \\
\text { No. }\end{array}$ & Service & Descriptio & & Location \\
\hline $\begin{array}{l}\text { TE-214 } \\
\text { to } 306\end{array}$ & Miscellaneous temperatures & $\begin{array}{l}\text { Type K, .062 in. S } \\
\text { Mgo, insul junct }\end{array}$ & S sheath, & Dwg. - -001 \\
\hline $\begin{array}{l}\mathrm{TE}-511 \\
\& 512\end{array}$ & Air cooled extensometer temperature & $"$ & $" 1$ & $\begin{array}{l}\text { Test section } \\
\text { dwg. }-002\end{array}$ \\
\hline $\begin{array}{l}\text { TE- } 513 \\
\text { to } 518\end{array}$ & Boeing gage temperatures & $\begin{array}{l}\text { Platinel, intrinsi } \\
\text { Type } \mathrm{K} \text { extension }\end{array}$ & c junct. & $"$ \\
\hline $\begin{array}{l}\text { TdE }-513 \\
\text { to } 518\end{array}$ & Boeing gage differential temp. & $\begin{array}{l}\text { Platinel, insul. } \mathrm{J} \\
\text { Type } \mathrm{K} \text { extension }\end{array}$ & unct. & $"$ \\
\hline$T I-3$ & System temperature indicator & $\begin{array}{l}\text { Honeywell } \mathrm{Cl} .15 \mathrm{p} \\
\text { indicator, } 48 \text {-poin }\end{array}$ & recision & Panel 3C \\
\hline TM-6 & $\begin{array}{l}\text { Orifice section temp. signal } \\
\text { conditioner }\end{array}$ & $\begin{array}{l}\text { Bell \& Howell Type } \\
\text { temp. transmitter }\end{array}$ & $18-110 \mathrm{~A}$ & Cabinet 1 \\
\hline $\mathrm{TM}-7$ & $\begin{array}{l}\text { Source tank sodium outlet temp. } \\
\text { signal cond. }\end{array}$ & $\begin{array}{l}\text { Bell \& Howell Type } \\
\text { temp. controller }\end{array}$ & 18-110A & Cabinet 1 \\
\hline $\mathrm{TM}-8$ & $\begin{array}{l}\text { Pipe nest outlet temp. signal } \\
\text { cond. }\end{array}$ & $" 1$ & $"$ & Cabinet 1 \\
\hline TM-9 & Source tank temp. sig. cond. & $n$ & $"$ & Cabinet 1 \\
\hline TM-10 & Capacitance tank temp. sig. cond. & $"$ & $n$ & $"$ \\
\hline TM-11 & Sodium drain valve temp. sig. cond. & $"$ & $"$ & $"$ \\
\hline TM-12 & Rupture disc temp. sig. cond. & 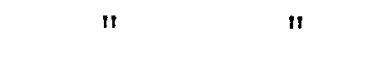 & " & " \\
\hline TM-13 & Pressure seal temp. sig. cond. & $"$ & $"$ & $"$ \\
\hline $\mathrm{TM}-14$ & Sump tank temp. sig. cond. & $"$ & $"$ & $"$ \\
\hline TM-15 & Bladder equalizer line temp. sig. cond. & $"$ & $"$ & $" 1$ \\
\hline$T M-16$ & Test section temp. sig. cond. & $"$ & $n$ & $"$ \\
\hline $\mathrm{TM}-17$ & E.M. pump temp. sig. cond. & $"$ & $"$ & $"$ \\
\hline
\end{tabular}




\begin{tabular}{|c|c|c|c|}
\hline $\begin{array}{l}\text { Tnstrument } \\
\text { No. }\end{array}$ & Service & Descriptiun & Lecution \\
\hline$T M-39 A$ & $\begin{array}{l}\text { Test section temp. themocouple } \\
\text { reference }\end{array}$ & $\begin{array}{l}\text { Consolidated Ohmic Devices } \\
\text { Mod. MDC } 383-1\end{array}$ & Cabtnet 5 \\
\hline $3 M-19 B$ & $\begin{array}{l}\text { Test aection temp. millivolt } \\
\text { suppression }\end{array}$ & $\begin{array}{l}\text { Mulivolt supply fabricated } \\
\text { in-kouse }\end{array}$ & PaneI 5 \\
\hline $3 M-190$ & $\begin{array}{l}\text { WRC-19 (controjler) output } \\
\text { amplifiex }\end{array}$ & $\begin{array}{c}\text { Finco Reg. Mod. MlesH } \\
\text { mignetic ampizfier }\end{array}$ & Cabinet 5 \\
\hline$n R-1$ & Pipe nest temp. recorder & $\begin{array}{l}\text { Honeywe } 11 \text { Class } 15 \text {, } 36 \text {-point } \\
\text { recorder }\end{array}$ & Panel 2C \\
\hline$T R-2$ & Pipe nest termp. recorder & $\begin{array}{l}\text { Honeyweil Class 15, 16-point } \\
\text { recorder }\end{array}$ & Panel aD \\
\hline TR-4 & $\begin{array}{l}\text { High temp. sodium system temp. } \\
\text { recordex }\end{array}$ & $\begin{array}{l}\text { Honeywell Class } 15, \text { 26-point } \\
\text { recorder }\end{array}$ & Panel sD \\
\hline$T R-56$ & $\begin{array}{l}\text { Misc. system temp. recordex } \\
\text { recorder }\end{array}$ & $\begin{array}{l}\text { Eoneyweli Class } 35, \text { 16-point } \\
\text { recorder }\end{array}$ & Varzae Cab. No. 4 \\
\hline$T R-57$ & Misc. system temp. recorder & $\begin{array}{l}\text { Honeywell Class } 15, \text { 16-point } \\
\text { recorder }\end{array}$ & Variac Cab. Mo. 3 \\
\hline$T R-58$ & Misc. system temp. recorder & $\begin{array}{l}\text { Honeywe } 11 \text { Class } 15,12 \text {-point } \\
\text { xecurdex }\end{array}$ & Variac Cab. No. 6 \\
\hline$T R-59$ & Mise. system temp. recorder & $\begin{array}{l}\text { Honeytein diass 35, 16-point } \\
\text { recorder }\end{array}$ & Variac Cab. Wo. \\
\hline$T R-60$ & Mise. system temp. recorder & $\begin{array}{l}\text { Honeywell Class } 35, \text { 12-point } \\
\text { recorder }\end{array}$ & Vartac Cab. No. 6 \\
\hline$T R-65$ & Misc. system temp. recoraer & $\begin{array}{l}\text { Honeywoll Class 15, 16-point } \\
\text { recorder }\end{array}$ & $V$ riac Cab. Ho. 9 \\
\hline TRC- 19 & Test secticn temp. control3er & $\begin{array}{l}\text { Leeds \& Morthrup Nod. H } \\
\text { Rec. W/CAw controller }\end{array}$ & Pane: 5D \\
\hline
\end{tabular}




\begin{tabular}{|c|c|c|c|}
\hline $\begin{array}{l}\text { Instrument } \\
\text { No. }\end{array}$ & Service & Description & Location \\
\hline TS-6A & $\begin{array}{l}\text { Orifice section high temp. alarm } \\
\text { switch }\end{array}$ & Integral with TM-6 & Cabinet 1 \\
\hline TS-7A & $\begin{array}{l}\text { Source tank sodium outlet high } \\
\text { temp. alarm switch }\end{array}$ & Integral with TM-7 & " \\
\hline TS-7B & $\begin{array}{l}\text { Source tank sodium outlet low } \\
\text { temp. alarm switch }\end{array}$ & Integral with TM-7 & $"$ \\
\hline TS-8A & $\begin{array}{l}\text { Pipe nest outlet high temp. } \\
\text { alarm switch }\end{array}$ & Integral with TM-8 & $" 1$ \\
\hline TS $-8 \mathrm{~B}$ & $\begin{array}{l}\text { Pipe nest outlet low temp. } \\
\text { alarm switch }\end{array}$ & Integral with TM-8 & $"$ \\
\hline TS-9A & Source tank high temp. alarm sw. & Integral with TM-9 & $"$ \\
\hline TS-9B & Source tank low temp. alarm sw. & $"$ & $"$ \\
\hline TS-10A & $\begin{array}{l}\text { Capacitance tank high temp. } \\
\text { alarm switch }\end{array}$ & Integral with TM-10 & " \\
\hline TS-1OB & $\begin{array}{l}\text { Capacitance tank low temp. } \\
\text { alarm switch }\end{array}$ & $"$ & $"$ \\
\hline $\mathrm{TS}-I \perp \mathrm{A}$ & $\begin{array}{l}\text { Sodium drain valve high temp. } \\
\text { alarm switch }\end{array}$ & Integral with TM-1l & $"$ \\
\hline TS-IIB & $\begin{array}{l}\text { Sodium drain valve low temp. } \\
\text { alarm switch }\end{array}$ & $n$ & $"$ \\
\hline TS-12A & Rupture disc high temp. alarm sw. & Integral with TM-12 & $"$ \\
\hline TS-12B & Rupture disc low temp. alarm sw. & $"$ & $"$ \\
\hline $\mathrm{TS}-13 \mathrm{~A}$ & Pressure seal high temp. alarm sw. & Integral with TM-13 & $"$ \\
\hline TS-13B & Pressure seal low temp. alarm sw. & $"$ & $"$ \\
\hline
\end{tabular}


Instrument

No.

Sexvice

Description

Location

TS-I4A Sump tank high temp. alarm switch

Integral with $\mathrm{TM}_{14}$

Cabinet 1

TS-14B Sump tank low temp. alarm switch

ms-15A Bladder equalizer line high temp. alarm switch

TS-15B Bladder equalizer line low temp. alarm switch

TS-16A Test section high temp. alarm sw.

TS-16B Test section low temp. alarm sw.

TS-17A E.M. pump kigh temp. alarm sw.

TS-17B E.M. pump high temp. alam sw.

Ts-45 Thermocouple selector switch

TS-46 Thermocouple selector switch

TS -47 Thermocouple selector switch

TS-48 Thermocouple selector switch

XA-1 PCV-I7 valve open alarm

XE-503 Test section strain, circumferential thru 510

XE-511 Test section strain, axial

XE-512 Test section strain, circumferential

Integral with TM-15

11

Integral with TM-16

"

"I

Integral with TM-17

11

":

Lewis Engr. Co. Type 10520

11

"

is

$"$

"s

11

Pigerman Te1-Alarm circuit $416 \mathrm{NCISe}$

Microdot high temp. strain gage

Air cooled extensometer

Air cooled extensometer
Panel $4 D$

"

"

"

Panel IA

Test section

1"

" 


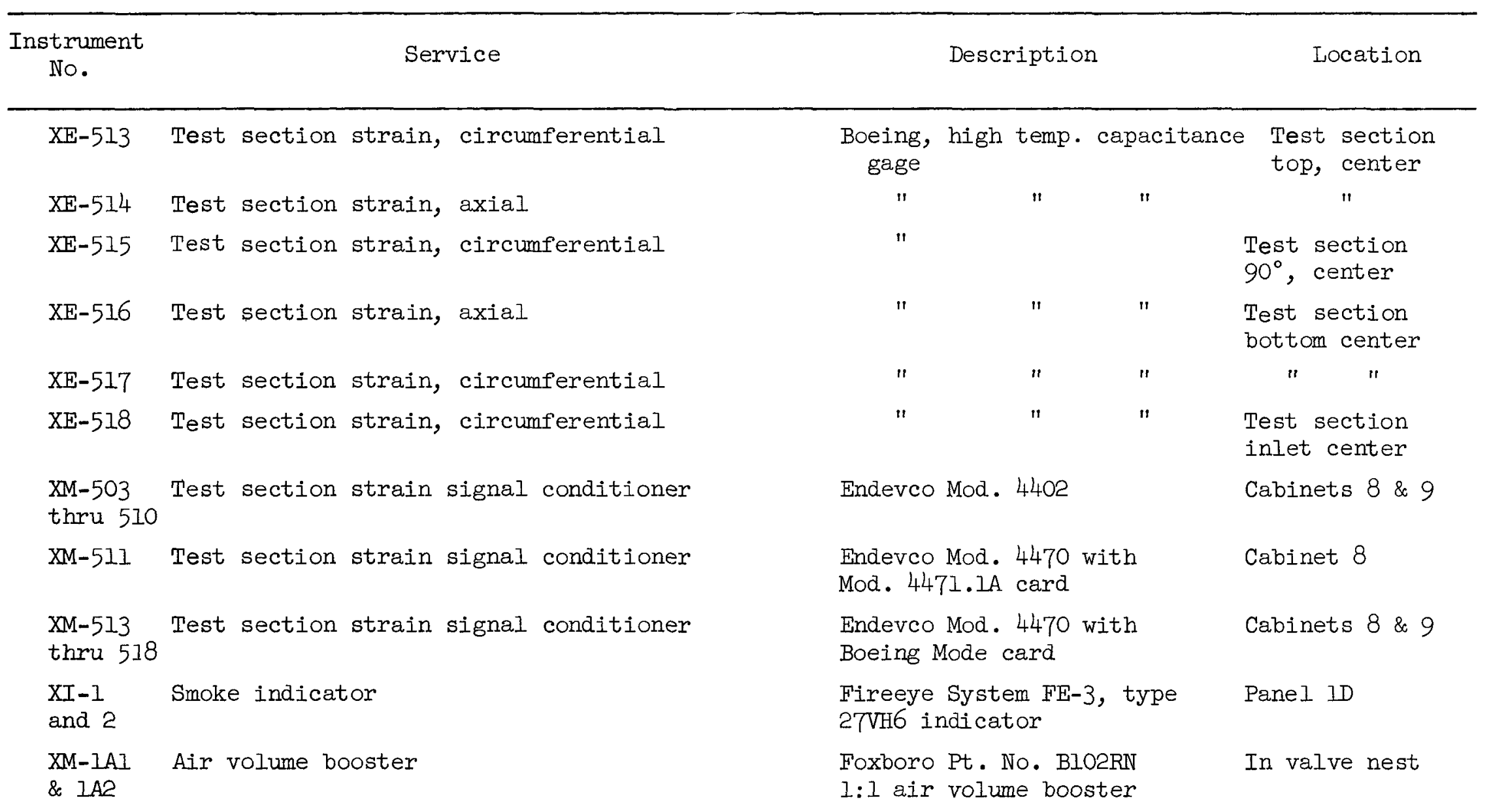




\begin{tabular}{|c|c|c|c|}
\hline $\begin{array}{l}\text { Instrument } \\
\text { No. }\end{array}$ & Service & Description & Location \\
\hline$X S-1$ & Smoke alarm switch & Integral with XI-I & $\begin{array}{l}\text { Panel ID } \\
\qquad(X I-1)\end{array}$ \\
\hline$x S-2$ & Smoke alarm switch & Integral with XI-2 & $\begin{array}{l}\text { Pane } 1 \text { id } \\
(X x-2)\end{array}$ \\
\hline$X V-1$ & Source tank argon vent check valve & $\begin{array}{l}\text { Check-ALI No } \\
\text { UN-10 OSO-SS-N-INCO-X }\end{array}$ & $\begin{array}{l}\text { Valve nest } \\
\text { enclosure }\end{array}$ \\
\hline$X V-3$ & $\begin{array}{l}\text { Source tank fast argon vent check } \\
\text { valve }\end{array}$ & $\begin{array}{l}\text { Check-A11. No } \\
\text { UN-10-100-SS-B-A286 }\end{array}$ & $\begin{array}{l}\text { Valve nest } \\
\text { enclosure }\end{array}$ \\
\hline$x V-4$ & Equalizer line check valve & $\begin{array}{l}\text { Check-AII No. } \\
\text { UN-10-050-SS-M-IHCO X }\end{array}$ & $\begin{array}{l}\text { Valve nest } \\
\text { enclosure }\end{array}$ \\
\hline$X V-10$ & Rupture disc excess flow valve & $\begin{array}{l}\text { Supplied as paxt of } \\
X X-10 \text { safety head }\end{array}$ & $\begin{array}{l}\text { Valve nest } \\
\text { enclosure }\end{array}$ \\
\hline$X V-18$ & Sodium valve syphon break check valve & $\begin{array}{l}\text { Hoke } 6113 \text { Mes } \\
\text { (or equas) }\end{array}$ & $\begin{array}{l}\text { Inside } \\
\text { enclosure }\end{array}$ \\
\hline$X V-28$ & Sump tank vent check valve & Circle Seal 259B-4PP & Cabinet is \\
\hline$X V-40$ & Blow down tank check valve & $\begin{array}{l}\text { Check-AI1 No } \\
\text { UN-10-050-SS-RI-INCO-X }\end{array}$ & Vacuum station \\
\hline$x V-46$ & $\begin{array}{l}\text { Nitrogen supply isolation check } \\
\text { valve }\end{array}$ & $\begin{array}{l}\text { Hoke } 6133 \text { arts } \\
\text { (or equal) }\end{array}$ & $\begin{array}{l}\text { On wall south } \\
\text { of enckosure }\end{array}$ \\
\hline$X V-48$ & $\begin{array}{l}\text { Builaing instrument aix isolation } \\
\text { check valve }\end{array}$ & $\begin{array}{l}\text { Hoke } 6113 \mathrm{M} 4 \mathrm{~B} \\
(\text { or equal) }\end{array}$ & $\begin{array}{l}\text { On wall south } \\
\text { enclosure }\end{array}$ \\
\hline$x V-62$ & Argon purge isolation check valve & $\begin{array}{l}\text { Circle seal No. } \\
2591-2 p P \text { (or equal) }\end{array}$ & Cabinet 4 \\
\hline$X V-64$ & Cooling water check valve & $\begin{array}{l}\text { Wibco-Scott, T413B, } 1 / 2^{\prime \prime} \\
\text { swing check (or equal) }\end{array}$ & $\begin{array}{l}\text { On S.W. conner } \\
\text { of enclosure }\end{array}$ \\
\hline
\end{tabular}




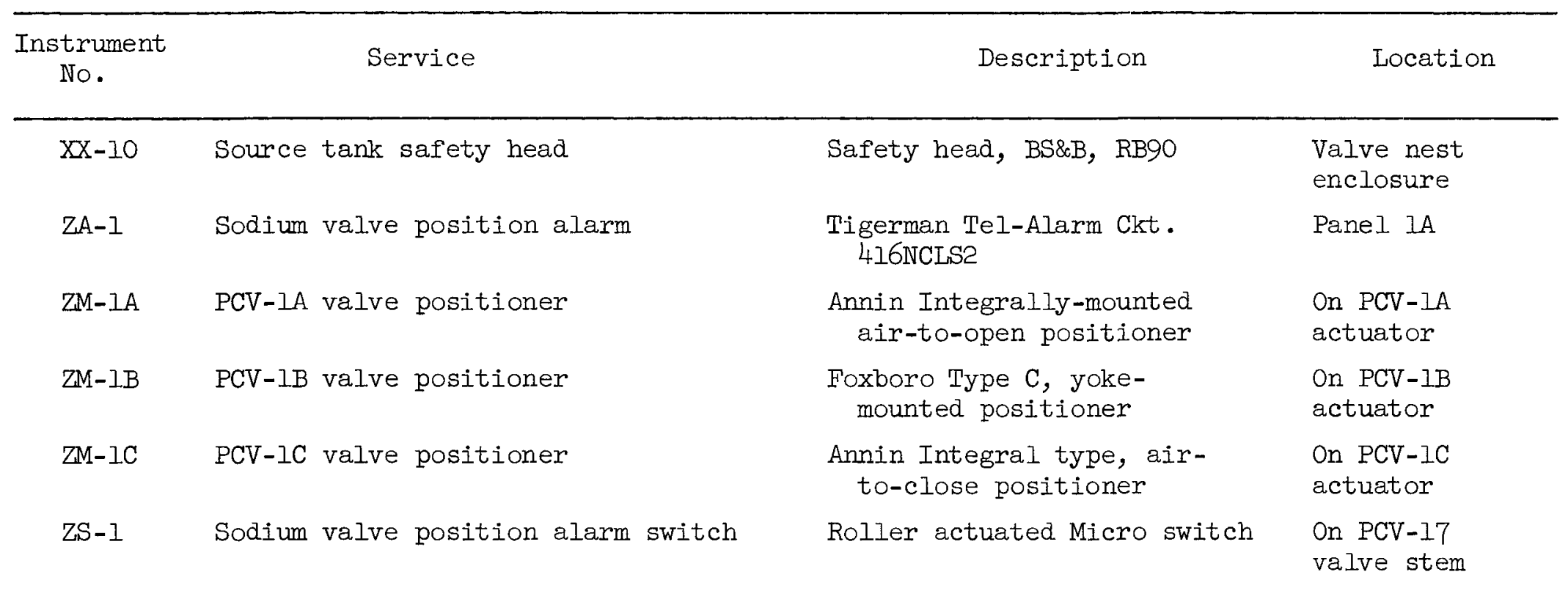


$\bullet$

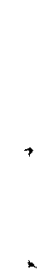


Appendix $\mathrm{H}$

LIST OF CONDITIONS LEADING TO SCRAMS, PARTIAL SCRAMS, AND ALARMS (LMFBR-TTTF) 
○

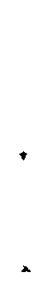


Conditions Leading to Scrams, Partial Scrams, and Alarms

\begin{tabular}{|c|c|c|c|c|c|}
\hline Parameter & $\begin{array}{l}\text { Component } \\
\text { or } \\
\text { location }\end{array}$ & Condition & Scram & $\begin{array}{c}\text { Partial } \\
\text { scram }\end{array}$ & $\begin{array}{l}\text { Alarm } \\
\text { only }\end{array}$ \\
\hline Smoke & Inside enclosure & Detected & Yes & & \\
\hline \multirow[t]{6}{*}{ Temperature } & Test section & High & No & Yes & \\
\hline & & Low & No & No & Yes \\
\hline & Sodium system & High & No & Yes & \\
\hline & & Low & No & No & Yes \\
\hline & Sump tank & High & No & Yes & \\
\hline & & Low & No & No & Yes \\
\hline \multirow[t]{4}{*}{ Pressure } & Source tank & High & No & Yes & \\
\hline & & Low & No & No & Yes \\
\hline & Sump tank & High & No & Yes & \\
\hline & A11 gas supplies & Low & No & No & Yes \\
\hline Liquid level & Source tank & High & No $b$ & No & Yes $^{a}$ \\
\hline & & Low & Yes & Yes & \\
\hline \multirow[t]{2}{*}{ Power } & Normal system & Off & No & No & $\mathrm{No}^{\mathrm{C}}$ \\
\hline & Control power system & off & Yes & & \\
\hline Position & Drain valve & Open & & & Yes \\
\hline
\end{tabular}

${ }^{a}$ Only used during filling system with sodium.

${ }^{b}$ Only if concurrent with smoke.

${ }^{c}$ Diesel generator normally takes over the load within $20 \mathrm{sec}$; if it fails to take over, low-temperature alarms will operate as soon as alarm power is available. 


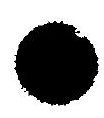

.

.

○ 
Appendix I

INSTRUMENTATION AND CONTROLS: SET POINTS (LMFBR-TTTF) 
○

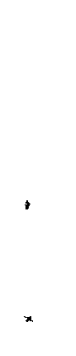

.

$\bullet$ 
Instrumentation and Controls Set Points

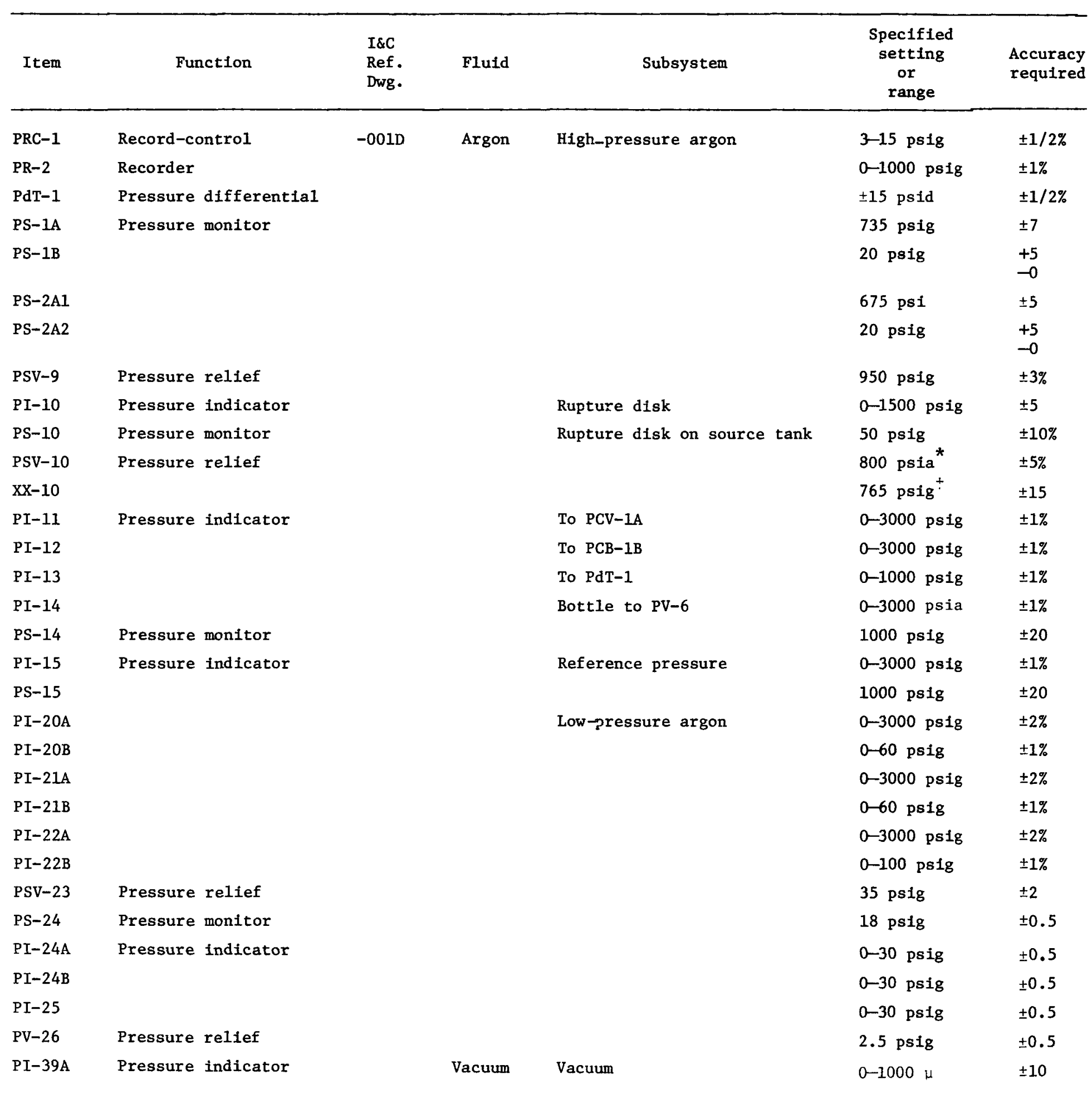

*At $300^{\circ} \mathrm{F}$.

tBased on rupture test of one typical disk of 6 . 


\begin{tabular}{|c|c|c|c|c|c|c|}
\hline Item & Function & $\begin{array}{l}\text { I\&C } \\
\text { Ref. } \\
\text { Dwg. }\end{array}$ & Fluid & Subsystem & $\begin{array}{l}\text { Specified } \\
\text { setting } \\
\text { or } \\
\text { range }\end{array}$ & $\begin{array}{l}\text { Accuracy } \\
\text { required }\end{array}$ \\
\hline PS-39A & Pressure monitor & -0010 & Vacuum & To Temescal valve & $\sim 100 \mu$ & \pm 10 \\
\hline$P I-39 B$ & Pressure indicator & & & Vacuum & $30-\mathrm{in} . \mathrm{Hg}$ to $30 \mathrm{psig}$ & $\pm 1 \%$ \\
\hline PS-44 & Pressure/flow monitor & & Argon & Bldg. argon-pan flood & 70 psig & \pm 5 \\
\hline$P I-44 A$ & Pressure indicator & & & & $0-160 \mathrm{psig}$ & $\pm 2 \%$ \\
\hline PI-44B & & & & & $0-30$ psig & $\pm 2 \%$ \\
\hline PS-45 & Pressure monitor & & $\mathrm{N}_{2}$ & $\mathrm{Na}$ valve operator & 130 psig & \pm 2 \\
\hline PSV-45 & Pressure relief & & & & 160 psig & \pm 2 \\
\hline PI-45A & Pressure indicator & & & $\mathrm{N}_{2}$ supply & $0-3000$ psig & $\pm 2 \%$ \\
\hline$P I-45 B$ & & & & $\mathrm{Na}$ valve operator & $0-400$ psig & $\pm 1 \%$ \\
\hline PS-46 & Pressure monitor & & & $\mathbb{N}_{2}$ supply & 1500 psig & \pm 20 \\
\hline PI-46B & Pressure indicator & & Instrument air $/ \mathrm{N}_{2}$ & Instrument air & $0-400 \mathrm{psig}$ & $\pm 1 \%$ \\
\hline PSV-47 & Pressure relief & & & & 100 psig & \pm 5 \\
\hline PS-48 & Pressure monitor & & Instrument air & & 75 psig & \pm 5 \\
\hline PI-49A & Pressure indicator & & & Instrument air, 60 psig & $0-100$ psig & $\pm 2 \%$ \\
\hline PI-49B & & & & & $0-100$ psig & $\pm 2 \%$ \\
\hline PI-50B & & & & Instrument air, 30 psig & $0-100$ psig & $\pm 2 \%$ \\
\hline PI-51A & & & & Instrument air, 20 psig & $0-30 \mathrm{psig}$ & $\pm 2 \%$ \\
\hline PI-51B & & & & & $0-30 \mathrm{psig}$ & $\pm 2 \%$ \\
\hline PS-54 & Pressure monitor & & Argon & Sump tank & 5 psig & \pm 0.5 \\
\hline ZS-1 & Stem movement & & & $\mathrm{Na}$ valve operator & $1 / 8$ in. open & $\pm 1 / 16$ \\
\hline $\mathrm{XS}-1$ & Smoke detector & & & Smoke detector & Open at $30 \%$ scale & $\pm 5 \%$ \\
\hline $\mathrm{XS}-2$ & & & & & $"$ & $\pm 5 \%$ \\
\hline LR-16 & Level recorder & & Sodium & Source tank & $\begin{array}{l}10-0 \mathrm{mV} \\
0-100 \%\end{array}$ & $\pm 1 / 4 \%$ \\
\hline LS-16A & First low leve1 (steady) & & & & $84 \%$ of tube length & $\pm 1 \%$ \\
\hline LS-16B & Second low level & & & & $19.4 \% \quad "$ & $"$ \\
\hline LS-16C & Third low level & & & & $11 \% \quad "$ & $"$ \\
\hline LS-16A & First low level (transient) & & & & $81 \% \quad "$ & $"$ \\
\hline LS-16D & Maximum 1eve1 & & & & $87.4 \% \quad "$ & $"$ \\
\hline FI-25 & Flow indicator & & Argon & Sump tank & $200 \mathrm{cc} / \mathrm{min}$ & $\pm 5 \%$ \\
\hline FR-31 & Flow recorder & & Sodium & Cold trap & $\begin{array}{l}0-1 \mathrm{mV} \\
0-100 \%\end{array}$ & $\pm 1 \%$ \\
\hline LI-32 & Level indicator & & Instrument air & Sump tank & $\begin{array}{l}3-15 \text { psig } \\
0-100 \%\end{array}$ & \pm 0.2 \\
\hline LI-34 & & & Hercolube & Relief manometer & $\begin{array}{l}92 \mathrm{in} \text { or } 6.1 \mathrm{psig} \\
18 \mathrm{ft} \text { or } 15.1 \mathrm{psig}\end{array}$ & \pm 2 in. $₹$ \\
\hline FI-44 & Flow indicator & & Argon & Building argon-pan flood & $3.9 \mathrm{scfm}$ & $\pm 5 \%$ \\
\hline
\end{tabular}

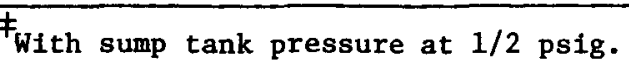


Instrumentation and Controls Temperature Set Points

\begin{tabular}{|c|c|c|c|c|c|c|}
\hline Item & Function & $\begin{array}{l}\text { Drawing } \\
\text { No. }\end{array}$ & $\begin{array}{c}\text { In } \\
\text { cabinet }\end{array}$ & $\begin{array}{l}\text { Specified } \\
\text { range } \\
\text { of } \\
\text { accuracy }\end{array}$ & $\begin{array}{c}\text { Specified } \\
\text { set } \\
\text { point }\end{array}$ & $\begin{array}{l}\text { Relay } \\
\text { or } \\
\text { switch } \\
\text { No. }\end{array}$ \\
\hline TR-1 & Recorder & $-026 \mathrm{D}$ & $\mathrm{I} \& \mathrm{C} 2$ & $2000^{\circ} \mathrm{F}$ & $\mathrm{High}, 1130^{\circ} \mathrm{F}$ & TS-IA \\
\hline TR-2 & Recorder & $"$ & $I \& \mathrm{C} 2$ & $2000^{\circ} \mathrm{F}$ & $"$ & $-2 A$ \\
\hline $\mathrm{TI}-3$ & Indicator & $"$ & $\mathrm{I} \& \mathrm{C} 3$ & $2000^{\circ} \mathrm{F}$ & & \\
\hline$T R-4$ & Recorder & $"$ & I\&C 3 & $2000^{\circ} \mathrm{F}$ & High, $1130^{\circ} \mathrm{F}$ & $-4 A$ \\
\hline TRC-19 & Recorder controller & $"$ & $I \& \mathrm{C} 5$ & $\pm 1 \mathrm{mV}$ & & \\
\hline TR- 56 & Recorder & $-027 D$ & Var. 4 & & High, $850^{\circ} \mathrm{F}$ & $-56 A$ \\
\hline TR- 57 & Recorder & $"$ & Var. 5 & & $"$ & $-57 A$ \\
\hline $\mathrm{TR}-58$ & Recorder & $"$ & Var. 6 & & $"$ & $-58 A$ \\
\hline$T R-59$ & Recorder & $"$ & Var. 7 & & $\mathrm{High}, 350^{\circ} \mathrm{F}$ & $-59 A$ \\
\hline TR-60 & Recorder & $"$ & Var. 8 & & $"$ & $-60 A$ \\
\hline $\mathrm{TM}-6$ & Modifier & $-026 D$ & $\mathrm{I} \& \mathrm{C} \quad 1$ & & $\mathrm{High}, 850^{\circ} \mathrm{F}$ & $-6 A$ \\
\hline TM-7 & Modifier & $"$ & $"$ & & $\begin{array}{l}\text { High, } 1130^{\circ} \mathrm{F} \\
\text { Low, } 650^{\circ} \mathrm{F}\end{array}$ & $\begin{array}{l}-7 \mathrm{~A} \\
-7 \mathrm{~B}\end{array}$ \\
\hline $\mathrm{TM}-8$ & Modifier & $"$ & $"$ & & $\begin{array}{l}\text { High, } 1130^{\circ} \mathrm{F} \\
\text { Low, } 650^{\circ} \mathrm{F}\end{array}$ & $\begin{array}{l}-8 A \\
-8 B\end{array}$ \\
\hline TM-9 & Modifier & $"$ & $"$ & & $\begin{array}{l}\text { High, } 1130^{\circ} \mathrm{F} \\
\text { Low, } 650^{\circ} \mathrm{F}\end{array}$ & $\begin{array}{l}-9 A \\
-9 B\end{array}$ \\
\hline TM-10 & Modifier & $"$ & $"$ & & $\begin{array}{l}\text { High, } 850^{\circ} \mathrm{F} \\
\text { Low, } 650^{\circ} \mathrm{F}\end{array}$ & $\begin{array}{l}-10 A \\
-10 B\end{array}$ \\
\hline TM-11 & Modifier & $"$ & $"$ & & $\begin{array}{l}\text { High, } 850^{\circ} \mathrm{F} \\
\text { Low, } 650^{\circ} \mathrm{F}\end{array}$ & $\begin{array}{l}-11 \mathrm{~A} \\
-11 \mathrm{~B}\end{array}$ \\
\hline $\mathrm{TM}-12$ & Modifier & $"$ & $"$ & & $\begin{array}{l}\text { High, } 350^{\circ} \mathrm{F} \\
\text { Low, } 250^{\circ} \mathrm{F}\end{array}$ & $\begin{array}{l}-12 \mathrm{~A} \\
-12 \mathrm{~B}\end{array}$ \\
\hline $\mathrm{TM}-13$ & Modifier & $"$ & $"$ & & $\begin{array}{l}\text { High, } 350^{\circ} \mathrm{F} \\
\text { Low, } 250^{\circ} \mathrm{F}\end{array}$ & $\begin{array}{l}-13 A \\
-13 B\end{array}$ \\
\hline TM-14 & Modifier & $"$ & $"$ & & $\begin{array}{l}\text { High, } 850^{\circ} \mathrm{F} \\
\text { Low, } 650^{\circ} \mathrm{F}\end{array}$ & $\begin{array}{l}-14 \mathrm{~A} \\
-14 \mathrm{~B}\end{array}$ \\
\hline TM-15 & Modifier & $"$ & $"$ & & $\begin{array}{l}\text { High, } 1130^{\circ} \mathrm{F} \\
\text { Low, } 650^{\circ} \mathrm{F}\end{array}$ & $\begin{array}{l}-15 A \\
-15 B\end{array}$ \\
\hline TM-16 & Modifier & $"$ & $"$ & & $\begin{array}{l}\text { High, } 1115^{\circ} \mathrm{F} \\
\text { Low, } 1085^{\circ} \mathrm{F}\end{array}$ & $\begin{array}{l}-16 A \\
-16 B\end{array}$ \\
\hline $\mathrm{TM}-17$ & Modifier & $"$ & $"$ & & $\begin{array}{l}\text { High, } 1115^{\circ} \mathrm{F} \\
\text { Low, } 1085^{\circ} \mathrm{F}\end{array}$ & $\begin{array}{l}-17 A \\
-17 B\end{array}$ \\
\hline
\end{tabular}


○

•

.

.

.

.

$\bullet$ 
Appendix $\mathrm{J}$

PROGRAMMED DRAIN CHECK LIST (LMFBR-TTTF) 
• 


\section{Programmed Drain Check List}

\section{Action}

1. Check that all shields are in place.

2. Check that vents are open via HV-62A.

$$
\text { via HV-62B. }
$$

3. Check that PRC-1 is in automatic.

4. Check that five argon bottle valves are open.

5. Check that all four Victor header valves are open.

6. Check that any jumpers are as required.

7. Check Hercolube level in.).

8. Check that HV-18 has been operated to break syphon below PCV-17.

9. Check sodium level on LR-16 (_ \%).

10. Check second low level setting on LS-16B $\%)$ $\%$ on LR-16).

11. Pressurize system to 700 psig psig).

12. Record argon pressures:

\begin{tabular}{llll} 
Before & After & Before After \\
drain & drain & drain & drain \\
\hline
\end{tabular}

PI-11

PI-14

PI-12

PI-15

PI-13

13. Vent accumulator downstream of $P V-6$ and recheck PI-11.

14. Check sump tank pressure (_ psig).

15. Record pipe nest temperatures.

16. Check temperature at body of sodium shutoff valve $\mathrm{TE}-248=$ 
17. Push Dextix buttons, place new cycle No. in digital box.

18. Check other Dextir users before setting Dextir on continuous; see 29 .

19. Check that Sanborn is ramy.

20. Record PCVulA loading station pressure (to timed solenoia on output of P(C-1 to P(V-1A). psig)

21. Check that $X-Y$ and /or recorders plotters are ready.

22. Check that ANSGAN is raady and on $0.2-\sec$ scan.

23. Tutn swteh HS-1 to bypass.

24. Place one man at manual operator on PCV 17.

25. Check that handwhan on pev-17 is in correct position.

26. Place chart drive in LF-I6 in fast speed.

27. Place Sanborn chart drive in fast speed.

28. Place X-Y plotter pen down.

29. Place Dextir box 95 on continuous scan.

30. Push programmed drain button.

31. Adjust test section oven heater control.

32. Turn pipe nest Variacs 31 to 70 to 0 and reduce Vartaca $35,20,72$, and 75 .

33. After drain, reset programed drain button.

34. Close four high-pressure argon bothle valves.

35. Record pressures, step 12.

36. Remove, identify, process, and file high-speed data records.

37. Put Dextir on $15-$ min scan through heatup to $1100^{\circ} \mathrm{F}$.

38. At $1100^{\circ} \mathrm{F}$, put Dextix on 1 -hr scan.

39. At $1100^{\circ} \mathrm{F}$, change Bextir dightal box to creep cycle No. 


\section{Backup Action if PCV-17 Fails to Close}

\section{Action}

1. Push programmed drain close button.

2. Close PCV-17 manual1y.

3. Push high-pressure gas-close button HS-A28A1.

4. Close two Victor valves in vertical header.
Performed

by 
、

•

*

、

- 
Appendix K

RAISING SODIUM IN SOURCE TANK BY EVACUATION (LMFBR-TTTF) 
-

,

,

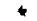

$\checkmark$

$\bullet$ 


\section{Raising Sodium in Source Tank by Evacuation}

\section{Action}

1. Put gas controller PRC-1 in manual and vent to 0 pressure.

2. Put jumper 2D5-2D6 in PSV-4 circuit D-27.

3. Put PCV-17 on manual operator.

4. Push PCV-17 open button HS-9.

5. Open $\mathrm{HV}-62 \mathrm{~A}$ and $\mathrm{B}$ to vent valves.

6. Crack HV-36, check pressure at PI-39, vent off via PRC-1 to $\sim 1 / 2$ psia. Check temperature at HV-36 on TE-228 on TA59-12.

7. Fully open HV-36.

8. Open vacuum valve HV-37 and evacuate system to 225 in. $\mathrm{Hg}$ on PI-39.

9. Reclose HV-36.

10. Pressurize 1ine to HV-36 to 2 psig via HV-35.

11. Crack PCV-17 with chain wheel, fill to $487 \%$ on LR-16, then manually close PCV-17.

12. Reclose PCV-17 with push button HS-10. Check that sump tank pressure remains positive during fill.

13. Disengage PCV-17 handwheel, push in knob, leave handwheel in disengage position.

14. Pressurize system to $\sim 20$ psig by manually raising set point on PRC-1.

15. Recheck for correct leve1 on LR-16.

16. Close HV-62A and B. 
17. Adjust reference pressure regulator pVm8 until red pen is midscale on $\mathrm{PRC}-1$; then switch PRC-1 from manual to automatic. (Note: If red pen is downscale, raise reference pressure to bring red pen upscale.)

18. Rajse pressure by valving in one bottle of argon at a time and slowly raising reference pressure regulator PV-8; read system pressure on PI-13. (Note: While system is at low pressure, use low pressure bottles to conserve argon.)

19. Remove jumper $2 D 5$ to 206 and go to procedure for break ing siphon below sodium valve. 
Appendix L

INDEPENDENT REVIEW OF IMPORTANT THERMAL AND STRESS CALCULATIONS FOR THE TTTF 


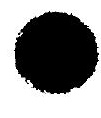

4

$\bullet$ 
TTT FACILITY THERMAL DESIGN REVIEW

W. K. Sartory

$\underline{\text { Summary }}$

This analysis indicates that an adequate approximation to the desired sodium temperature ramp can be obtained with a pipe nest of the present design. The location of the minimum temperature in the nest (which corresponds to the position of minimum elevation and is therefore built into the hardware) does not appear to be critical because adjustments in temperature on both sides of the minimum can have a similar effect to actual displacement of the minimum.

Combined thermal and inelastic structural analysis indicates no ratchetting or plastic cycling in the loop except in the test section itself.

\section{Introduction}

The ORNL Thermal Transient Test Facility consists of a sodium source tank, pipe nest, test section, orifice run, and a thermal capacitance tank with an adapter to carry the hot sodium into the cold tank (see Fig. 1). Other components of the facility are not considered in this analysis.

\section{Thermal Transient Analysis}

One purpose of this analysis is to determine the transient heat transfer in the piping system, including the test section itself. In the test section there are two pipe walls in contact with the sodium - the test pipe and a core or bladder. The following equations were used to determine the transient sodium temperature within the test section.

Neglecting axial heat conduction in comparison with axial convection, we have, for sodium heat balance, test wall heat balance, and bladder heat balance, respectively: 
OPNL - OWG $7: B A Q 1$

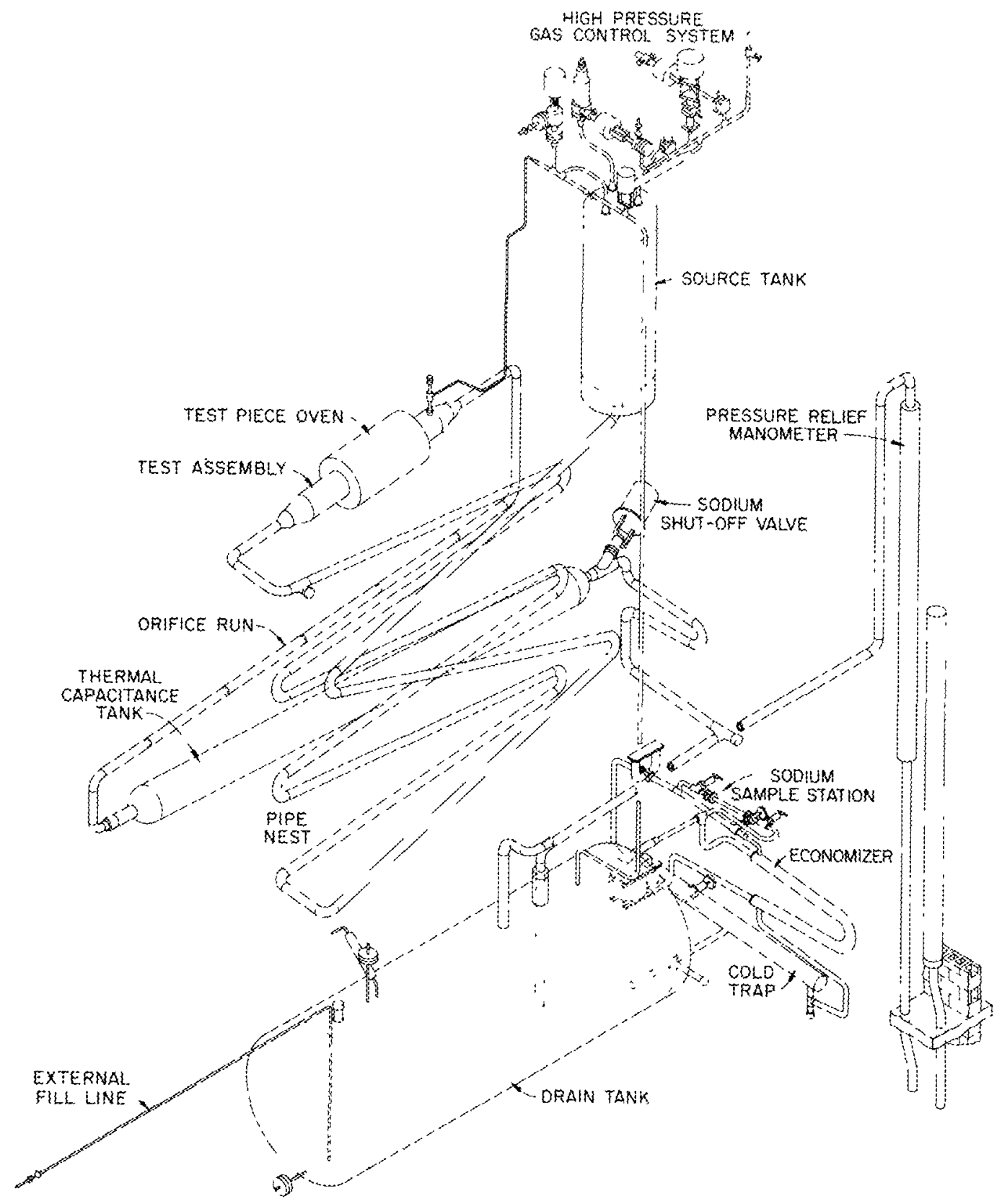

Wig. 1. Schematic of the Themal Transient Test Facility, showing arrangercent of principal facility components and connecting piping.

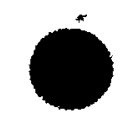




$$
\begin{gathered}
A_{N} \rho_{N} C_{p_{N}}\left(\frac{\partial N}{\partial t}+V \frac{\partial N}{\partial z}\right)=\pi D_{B} h_{B}(B-N)+\pi D_{W} h_{W}(W-N), \\
A_{W} \rho_{W} C_{p_{W}}\left(\frac{\partial W}{\partial t}\right)=-\pi D_{W} h_{W}(W-N), \\
A_{B} \rho_{B} C_{p_{B}} \frac{\partial B}{\partial t}=-\pi D_{B} h_{B}(B-N),
\end{gathered}
$$

where

$$
\begin{aligned}
& \mathrm{A}_{\mathrm{N}}=\text { cross-sectional area for sodium flow, } \\
& \rho_{\mathrm{N}}=\text { density of sodium, } \\
& \mathrm{C}_{\mathrm{p}_{\mathrm{N}}}=\text { heat capacity of sodium, } \\
& \mathbf{N}=\text { temperature of sodium, } \\
& \mathrm{V}=\text { mean velocity of sodium (slug flow is assumed), } \\
& z=\text { axial coordinate, } \\
& \mathrm{t}=\text { time, } \\
& D_{B}=\text { outer diameter of bladder, } \\
& h_{B}=\text { heat transfer coefficient from bladder wall to sodium } \\
& \mathrm{D}_{\mathrm{W}}=\text { test wall inner diameter, } \\
& \mathrm{h}_{\mathrm{W}}=\text { heat transfer coefficient from test wall to sodium } \\
& \text { (modified to include the thermal resistance corre- } \\
& \text { sponding to half the wall thickness), } \\
& \mathrm{W}=\text { test wall temperature averaged through the wall thickness, } \\
& \rho_{W}, \rho_{B}=\text { density of stainless steel, } \\
& \mathrm{C}_{\mathrm{p}_{\mathrm{W}}}, \mathrm{C}_{\mathrm{p}_{\mathrm{B}}}=\text { heat capacity of stainless steel. }
\end{aligned}
$$


The above equations, which were used to determine the sodiun temperature and not the temperature distribution within a wall, do not take into account the transient through the thickness of the wall except by the incorporation of half of the thermal resistance of the wall into the film coefficients. Collecting coefficients, Eqs. (1), (2), and (3) becorne:

$$
\begin{gathered}
\frac{\partial N}{\partial t}+V \frac{\partial N}{\partial z}=\gamma(W-N)+\alpha(B-N), \\
\frac{\partial W}{\partial t}=-B(W-N), \\
\frac{\partial B}{\partial t}=-\delta(B-N) .
\end{gathered}
$$

To determine the heat transfer in the pipe upstream or downstream of the test section, the same equations can be used by setting $\alpha=0$ and deleting $\mathrm{Eq} .\left(3^{*}\right)$.

\section{Pipe Nest Starting Temperature}

We choose the coordinate system so that $z \approx 0$ at the exit of the pipe nest, $z<0$ upstream of the exit, and $t=0$ at the start of the quench.

At the test section entxance $(z=0)$, we require the sodium temperam ture history:

$$
N(t, 0)=\begin{array}{lr}
1100-30 t\left({ }^{\circ} \mathrm{F}\right) & 0 \leq t \leq 10 \mathrm{sec} \\
800^{\circ} \mathrm{F} & 10 \leq t
\end{array}
$$

At the staxt of the quench $(t=0)$, the pipe wall is at equilibrium with the local sodium temperature:

$$
W(0, z)=N(0, z) \quad z \leq 0
$$


Using the finite-difference scheme described in the Appendix, Eqs. $\left(1^{\prime}\right)$ and $\left(2^{\prime}\right)$ were solved to determine the starting temperature $N(0, z)$ for $\gamma=0.7347$ per sec, $\beta=0.9043$ per sec, and $V=8.546 \mathrm{fps}$. The result is shown in Fig. 2 as a plot of $N(0, z)$ vs $(-z)$. From the exit of the nest to a point about $15 \mathrm{ft}$ upstream of the exit, the plot shows some downward curvature. From $15 \mathrm{ft}$ to about $86 \mathrm{ft}$ upstream of the exit, the plot is essentially linear and the temperature drops over $200^{\circ} \mathrm{F}$ below the minimum required temperature at the exit. At distances greater than $86 \mathrm{ft}$ upstream of the exit, the calculation predicts that violent oscillations in temperature are required. The sodium, which is initially $86 \mathrm{ft}$ upstream of the nest exit, enters the test section at $t=10 \mathrm{sec}$, and the oscillations are required to stop the quench instantaneously. Since such extreme oscillations in temperature are impossible, it will evidently be necessary to settle for a more gradual termination of the quench.

Some trial-and-error calculations have been made to determine what degree of approximation to the desired sodium temperature ramp is feasible.

ORNL-DWG $74-7449$

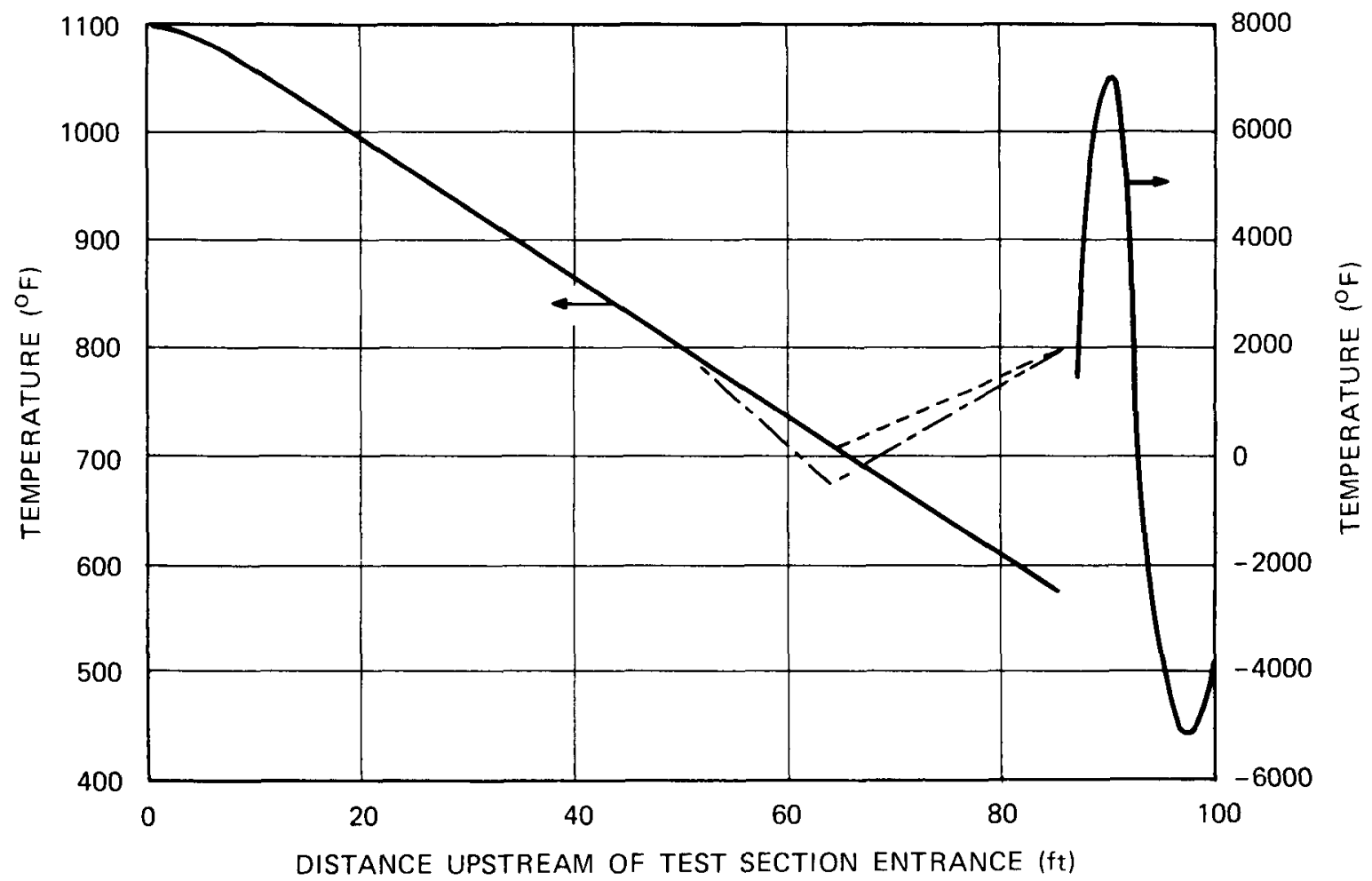

Fig. 2. Pipe nest starting temperature distribution. 
Using the calculated nest starting temperature up to 64 ft, and then ramping the temperature back to $800^{\circ} \mathrm{F}$ at $86 \mathrm{ft}$ (see dashed line, Fig. 2), the uppex curve shown in Fig. 3 was obtained by foward integration of Eqs. (1) and (2). The calculated temperature 1 s very close to the desired ramp up to $8 \mathrm{sec}$, but at $10 \mathrm{sec}$ it is about $11^{\circ} \mathrm{F}$ high. A temperature undershoot of about $26^{\circ} \mathrm{F}$ follows the quench.

In the present destgn, an accurate reproduction of the dowramp is considered to be of somewhat greater importance than elimination of the undershoot. The downramp approximation can be improved by shifting the temperature minimum farther upstream. An alternative possibility is to reduce the temperature in the region near the minimum.

Using the starting temperature given by the lower dashed curve of Fig. 2, the calculated temperature at the test section entrance is as shown on the lowest curve of Fig. 3. The calculated temperature is within about $\pm 2^{\circ}$ of the desired ramp for $0 \leq t \leq 10 \mathrm{sec}$, but undershoots by about $40^{\circ} \mathrm{F}$.

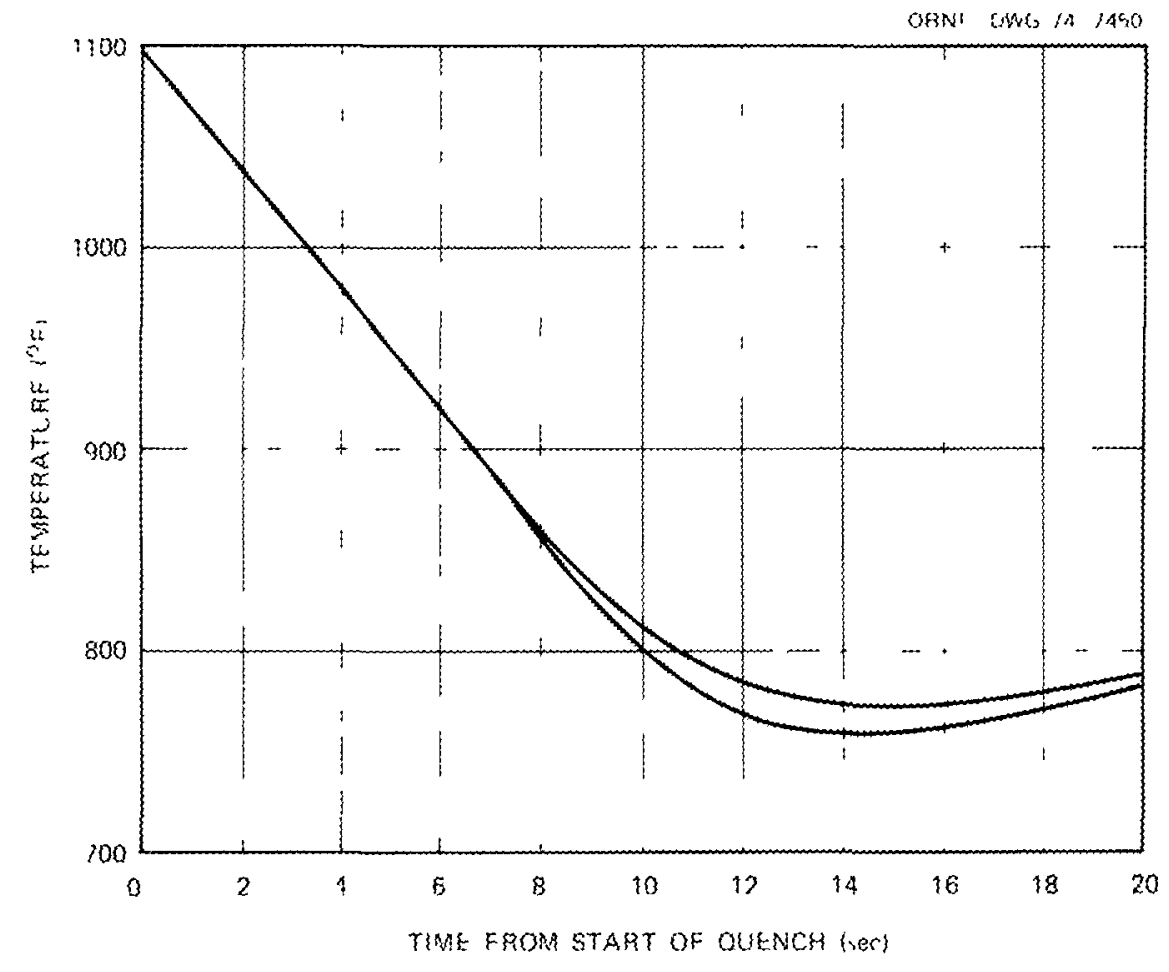

Fig. 3. west section inlet cooknt temporature. 
The results can probably be improved further by using steeper ramps of shorter duration, but no further calculations have been made.

Transient temperature calculations have also been made for the overall piping system, including the pipe nest, test section, and orifice run. These calculations use a coarser finite-difference grid and are cruder than those used for the nest starting temperature design.

Initially, the test section was assumed to be at a constant temperature of $1100^{\circ} \mathrm{F}$. The pipe downstream of the test section was assumed to contain a linear temperature ramp from $1100^{\circ} \mathrm{F}$ at the test section exit to $800^{\circ} \mathrm{F}$ at the thermal capacitance tank entrance. The pipe nest contained the starting temperature of the upper dashed curve of Fig. 2 .

Figure 4 shows the calculated transient sodium temperature at the entrance to the thermal capacitance tank. The temperature rises from $800^{\circ} \mathrm{F}$ to over $1035^{\circ} \mathrm{F}$ at an initial rate of over $100^{\circ} \mathrm{F} / \mathrm{sec}$ and then decreases more slowly.

Figure 5 shows the axial gradient of the sodium temperature in the test section (averaged across a $31 / 2-\mathrm{ft}$ length). It reaches a maximum of about $2^{\circ} \mathrm{F} / \mathrm{in}$. The temperature at the downstream end of the test section falls progressively farther behind the temperature at the entrance through most of the quench. The severity of the quench, therefore, decreases noticeably toward the downstream end of the test section.

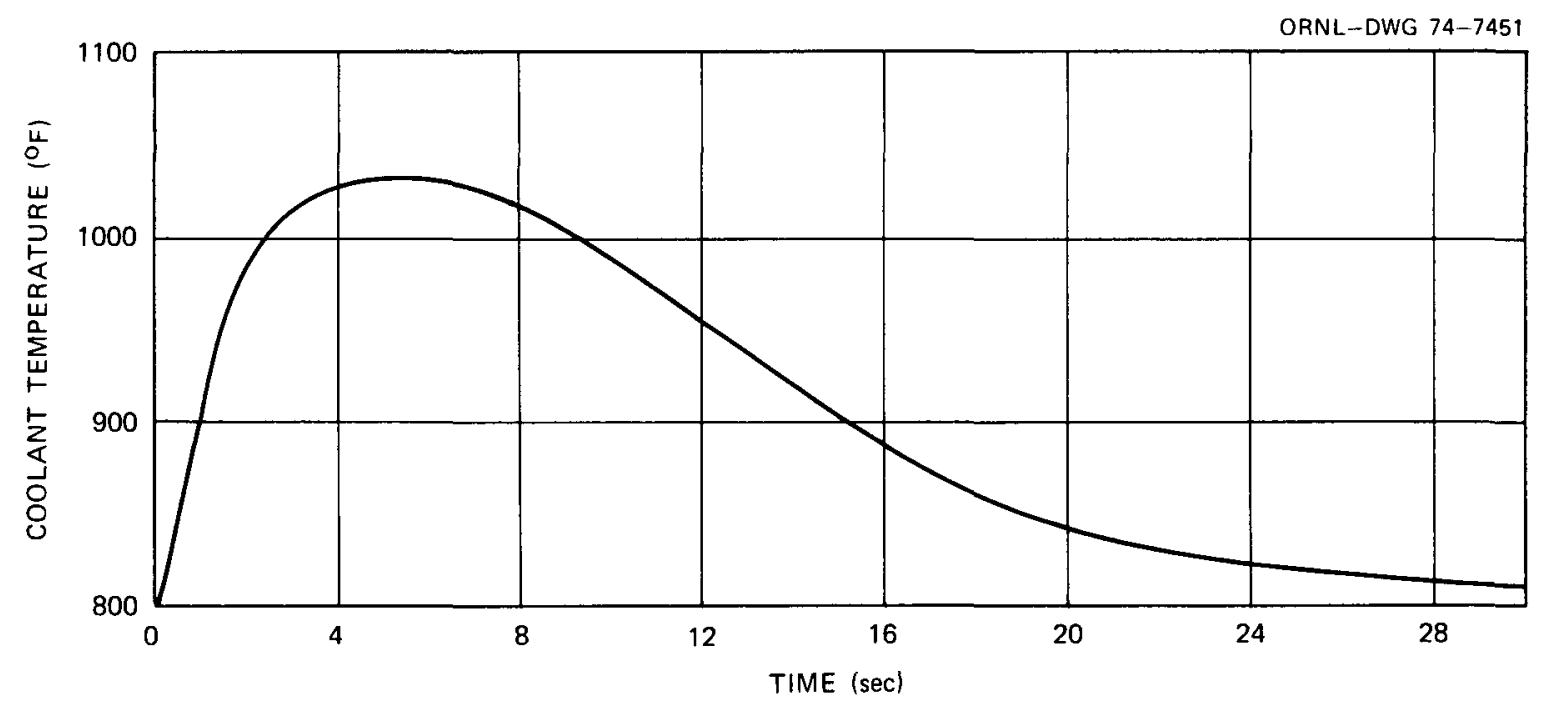

Fig. 4. Transient coolant temperature at the adapter. 


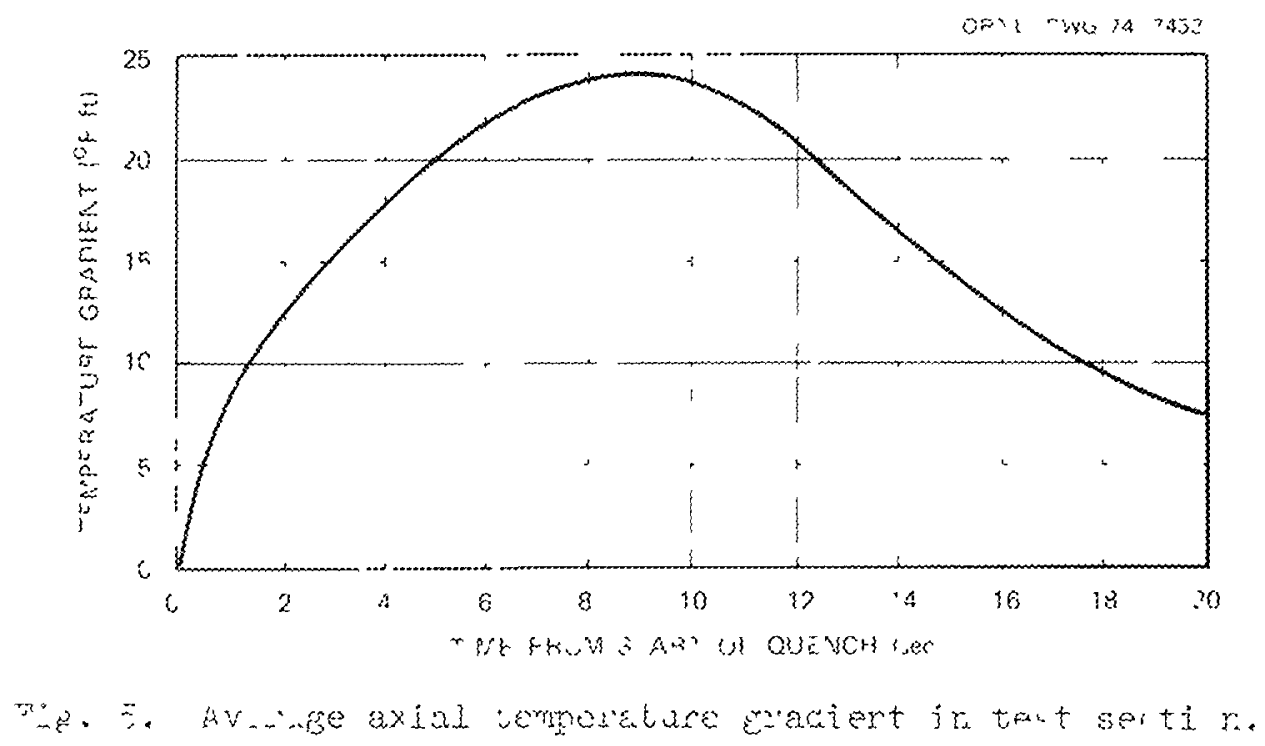

In a few locations the trancient tant fachlity has boun subjected to inelastic structural analyseg to determine this effect of a repeated quench. For these analysen, the constibutive equations recommended in okNmmin-3602 (Rei. 1) and material properties from the IMFHK Malerlals Handbook were

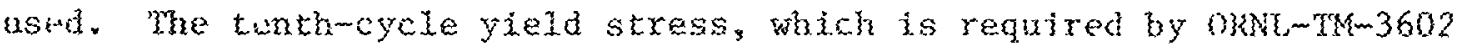
but not given in the handbook, was taken on the hasis ot very limited data to be twice the virgin yisld stress. Analyses have been carried out for the pipe nest just upstream of the lest section, the pipe just down stram of the test section, the pige just upstram of the themal capacitance tank. and tor the adapter use co convey the hot sodiun into ths: cold thermal capacitance tank.

tho thermal and structural pipe ratchetcing calculations were carried out using the compter cole PLACRE.? A grid of 16 elements through the thickness of the pipe wall was used.

whe pipe just rostream and jum downtram of the test section was found not to yle d during the quench. The pipe just upatream of the thermal capacitancu lank did yield burng the themal upramp of the first cycl.t, hut did not undergo revarse ylelding during the dowramp, and did not ratchet. Cyclic hardening did not occur according to the rukes of ORRE $-T M \sim 3602$. 
Figure 6 shows the finite-element grid used for the structural analysis of the adapter. The structure is axisymmetric. The open space within the grid is filled with sodium and is connected to the inside of the pipe by a narrow slit at the tapered end of the adapter which does not show in the figure. For the structural analysis, the clearance in the slit was assumed to be sufficient that the inner and outer sections of the adapter could move independently without interference at the tapered end. For the thermal analysis, the slit was ignored, and the sodium in the open space was subdivided into additional elements. The structural grid used 809 elements and the thermal grid 912 elements. The adapter is welded into the end cap of the thermal capacitance tank. The end cap was simulated by rigidly constraining the nodes along the weld.

In the thermal analysis the inside surface of the pipe was subjected to forced convection to sodium with a transient temperature given by the curve of Fig. 4 and a heat transfer coefficient of $28.33 \mathrm{Btu}$ in. ${ }^{-2} \mathrm{hr}^{-1}$ $\left({ }^{\circ} \mathrm{F}\right)^{-1}$. In addition, the outer surface of the adapter, which is in contact with sodium in the thermal capacitance tank, was considered to be

ORNL-DWG $74-7453$

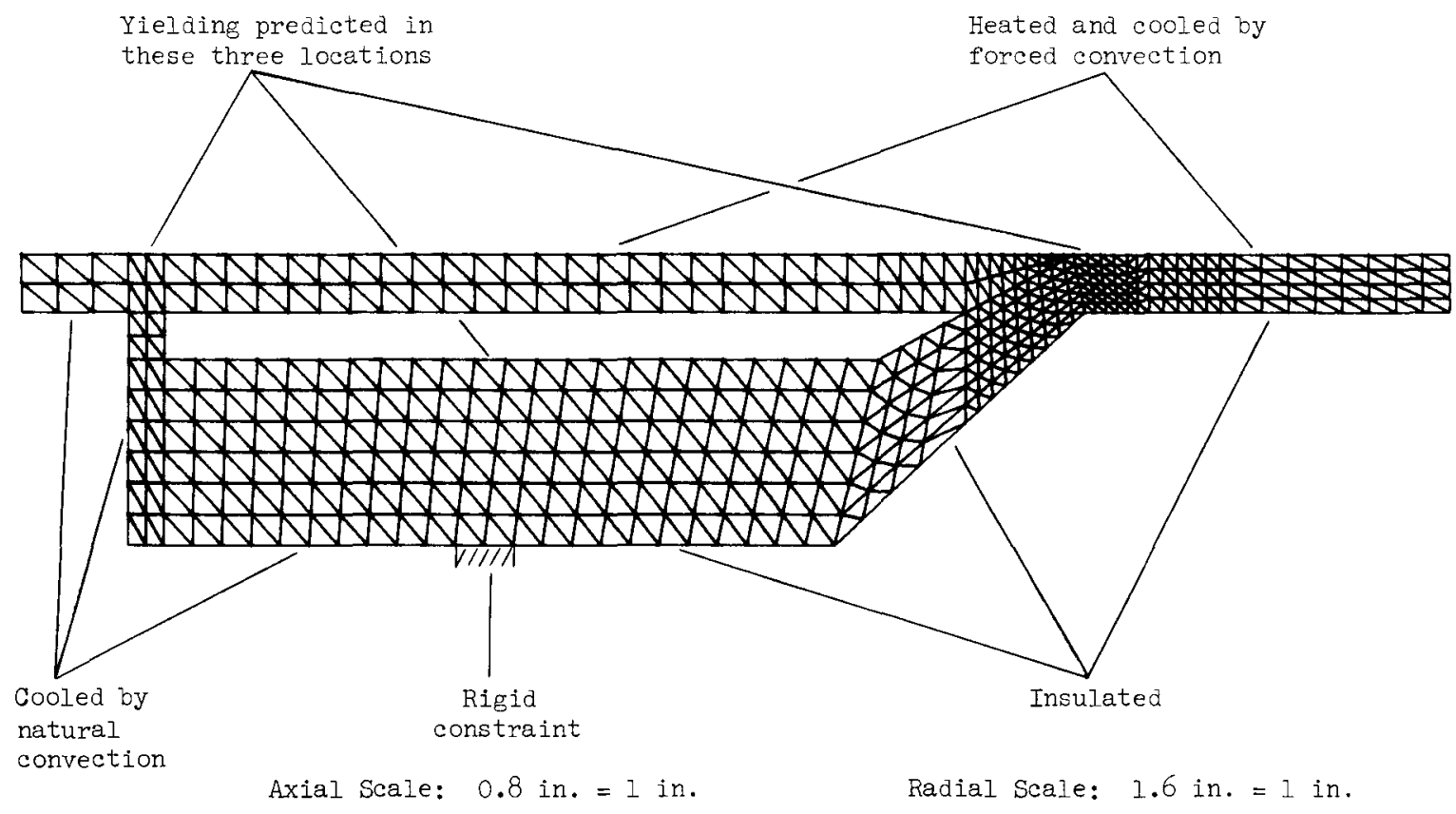

Fig. 6. Adapter finite-element grid. 
cooled by natural convection using a heat transfer coefficient of 5 Btu in. ${ }^{-2} h x^{-1}\left({ }^{\circ} \mathrm{F}\right)^{-1}$. If the sodium within the thermal capacitance tank were well mixed, its temperature could rise by 10 or $15^{\circ} \mathrm{F}$ during the transient. However, the rate at which the temperature spreads backward to the adapter surface is not obvious. For this analysis, the sodium in the tank was assumed to remain at $800^{\circ} \mathrm{F}$. The outer surface of the adapter which 1 ies outside of the tank was assumed to be insulated.

The thermal analysis was carried out using a finitemelement computer program developed at onNL by Spoormaker, ${ }^{3}$ and the structural analysis was carried out with the program PLACRE.?

In the present analysis, most of the inner surface failed to yield. Thts occurred because only two pairs of elements were used across the thickness of the pipe wall along much of the length. It is clear from the pipe analysis using 16 elements across the wall that a thin layer on the innex surface does yield. The present analysis predicted yielding at the inner surface at both ends of the adapter where the radial expansion of the pipe cannot occur freely.

Yielding occurred during the up transient $(0.045 \%$ plastic strain) where the pipe is welded to a flat circular plate inside the thermal capacitance tank. During the down transient, the opposite side of the yield surface was not reached (i.e., cyclic plastic hardening did not accur according to the rules of ORNL-TM-3602), manly because the plate is cooled by sodium within the tank and does not heat or expand much.

At the opposite end of the adapter, yielding occurred during the up transient on the inside surface of the pipe near the taper $(0.07 \%)$. Thts is partly because of the finer grid and partly because the tapered section of the adapter restricts the free expansion of the pipe. In this region, the opposite side of the yield surface was reached during the down tran sient. According to the rules of ORNL-TM 3602, this does not result in reverse plastic strain, but rather causes cyclic hardening of the material of the element. The much larger yield surface of the hardened material was not reached.

A small amount of yielding $(0.004 \%$ strain) occurred late in the up transient at the surface opposite the rigid constraint simulating attachment to the end cap of the thermal capacitance tank. The yield surface 
was not reached again during the down transient. Because of the slight amount of yielding predicted, it seems likely that the compliance of the cap will be sufficient to avoid yielding at this location.

The adapter is subjected to the thermal transient without internal pressure. It is then pressurized to $700 \mathrm{psi}$ and held for $500 \mathrm{hr}$ at $800^{\circ} \mathrm{F}$. No creep calculation was included in the present analysis because of the low hold temperature. The adapter was pressurized at the end of the transient, but no further yielding occurred.

Only one cycle was included in the analysis. Since no reverse yielding occurred, additional cycles are not likely to cause further yielding. Thus, neither ratchetting nor cyclic yielding are predicted for the adapter. If the cyclic plastic hardening rules of ORNL-TM-3602 had not been used, some cyclic yielding at the inner surface near the taper would have occurred but no ratchetting would result.

\section{References}

1. C. E. Pugh et al., Currently Recommended Constitutive Equations for Inelastic Design Analysis of FFTF Components, ORNL-TM-3602 (September 1972).

2. W. K. Sartory, "Finite Element Program Documentation," High-Temperature Structural Design Methods for LMFBR Components Quart. Progr. Rep. Dec. 31, 1971, ORNL-TM-3736, P. 66.

3. J. L. Spoormaker, Oak Ridge National Laboratory, unpublished interna1 document (Sept. 11, 1970). 
Appendix

Finite Difference Formulations

\section{Backward integration}

The nest design problem involving backward integration from the desired temperature history at the downstream end of the nest to determino the nost starting temperature required only Eqs. (1') and $\left(2^{\prime}\right)$ with $\alpha=0$ (no bladier):

$$
\begin{gathered}
\frac{\partial N}{\partial t}+V \frac{\partial N}{\partial z}=\gamma(W-N), \\
\frac{\partial W}{\partial t}=-8(W-N) .
\end{gathered}
$$

These differential equations were approxinated using forward time differences and backward space difterence.

$$
\begin{aligned}
& \frac{N_{j}^{k+1}-N_{j}^{k}}{\Delta t}+v \frac{N_{j}^{k}-N_{j}^{k}}{\Delta z}=\gamma\left(W_{j}^{k} \cdots N_{j}^{k}\right), \\
& \frac{w_{j}^{k+1}-W_{j}^{k}}{\Delta t}=-B\left(w_{j}^{k}-N_{j}^{k}\right),
\end{aligned}
$$

where

$$
\begin{aligned}
& \mathrm{k}_{3}^{k}=N[(k-1) \Delta t,(j-j) \Delta z-x], \\
& W_{j}^{k}=W[(k-1) \Delta t,(j-1) \Delta z-\ell], \\
& \ell=\text { total length of nest for calculation. }
\end{aligned}
$$

Equations $(A \sim 3)$ and $(A \sim 4)$ may be rearranged to give

$$
\begin{gathered}
N_{j-1}^{k}=N_{j}^{k}-\frac{V \Delta z}{\Delta t}\left(N_{j}^{k+1}-N_{j}^{k}\right)+\gamma \Delta t\left(W_{j}^{k}-N_{j}^{k}\right), \\
W_{j}^{k+1} \approx W_{j}^{k}-B \Delta\left(W_{j}^{k}-N_{j}^{k}\right) .
\end{gathered}
$$


The boundary conditions are $\mathrm{N}_{\mathrm{j}_{\max }}^{\mathrm{k}}$, specified by desired temperature history:

$$
W_{j}^{1}=N_{j}^{1}
$$

The solution was carried out with a triangular grid of mesh points, as illustrated in Fig. A-1. (The grid in the figure is unrealistically coarse. The total number of mesh points used for the calculations was about 0.5 million for the complete triangle.)

Referring to the figure, for $j=7: w_{7}^{k}, k=1,7$, was calculated using Eqs. $(A-8)$ and $(A-6)$. Then for $j=6: N_{6}^{k}, k=1$, 6 , was calculated using Eq. $(A-5)$ and $W_{6}^{k}, k=1,6$, was calculated using Eqs. (A-8) and $(A-6)$, etc.

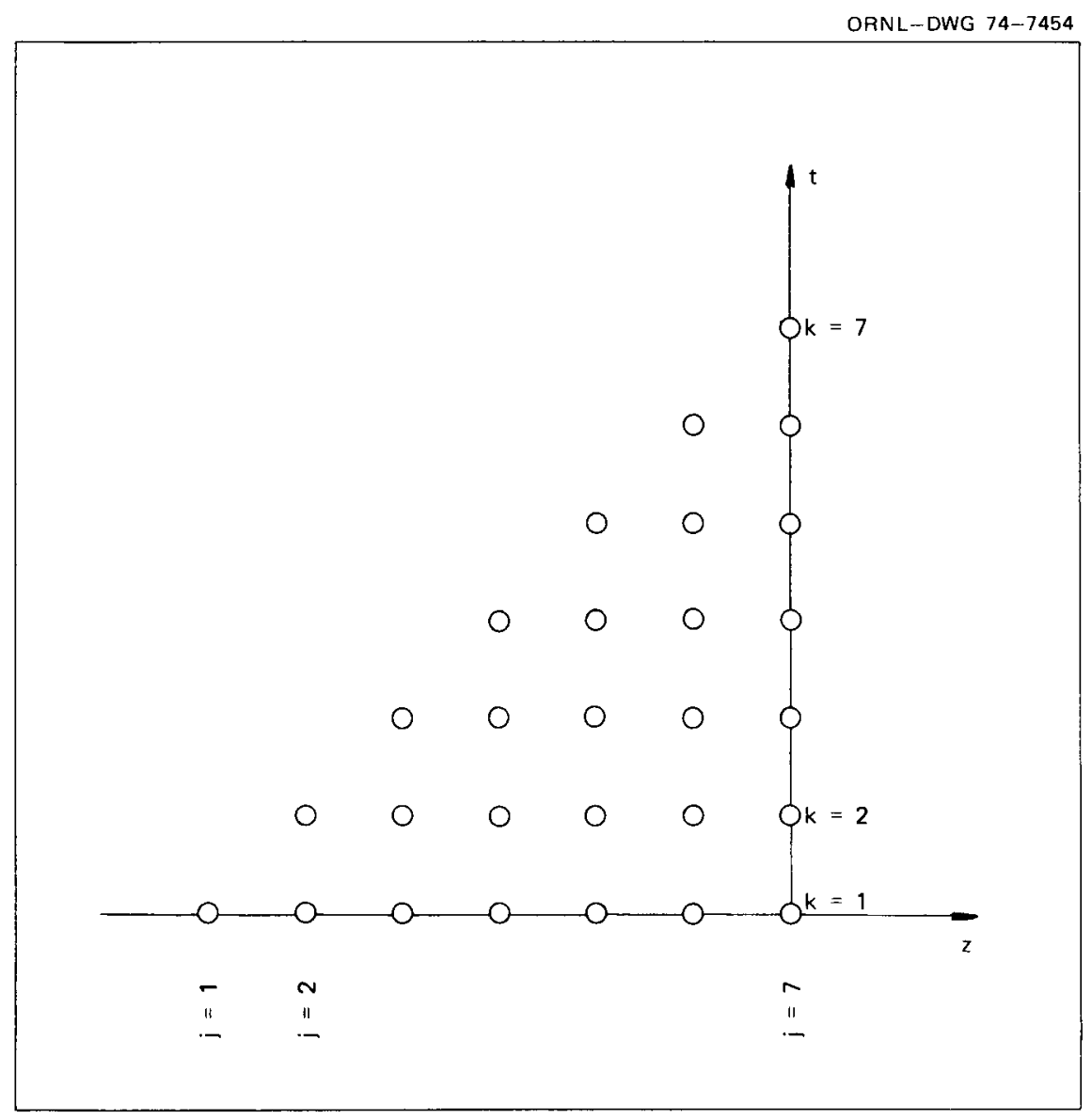

Fig. A-l. Sketch of finite-difference grid. 
For the solution of these equations, it is satisfactory to use a mesh size ratio:

$$
\frac{\Delta t V}{\Delta z}=1.0
$$

$A$ mest size $\Delta t=0.03$ sec was used.

\section{Torward integration}

Forward integration was used for the test section as well as the pipe nest and orifice rum, so that (in general) all three equations $\left(1^{\prime}\right)$, $\left(2^{\prime}\right)$, and $\left.\left(3^{\wedge}\right)\right\}$ must be included.

Equation $\left(1^{*}\right)$ was approximated using a forward time and backward space difference:

$$
\frac{N^{k+1}-N_{j}^{k}}{\Delta t}+v \frac{N_{j}^{k}-N_{j}^{k}-1}{\Delta z}=\gamma\left(w_{j}^{k}-N_{j}^{k}\right)+\left(8_{j}^{k}-N_{j}^{k}\right) \text {. }
$$

Backwaril time differences were used for Eqs. $\left(2^{\circ}\right)$ and $\left(3^{\prime}\right)$ :

$$
\begin{aligned}
& \frac{w_{j}^{k+1}-w_{j}^{k}}{\Delta t}=-3\left(w_{j}^{k+1}-N_{j}^{k+1}\right) \\
& \frac{B^{k+1}-b^{k}}{\Delta t}=-3\left(B_{j}^{k+1}-N_{j}^{k+1}\right)
\end{aligned}
$$

Te initial conditions are

$$
\begin{gathered}
\mathbb{N}_{j}^{l}=N[0,(j-l) \Delta z-l] \text { (specisied), } \\
W_{j}^{l}=N_{j}^{l}, \\
B_{j}^{l}=N_{j}^{l} .
\end{gathered}
$$

Equations $(A-9),(A-10)$, and $(A \sim 11)$ may be rearranged to give

$$
N_{j}^{k+1}=N_{j}^{k}-\frac{V \Delta t}{\Delta z}\left(N_{j}^{k}-N_{j-j}^{k}\right)+\Delta t \gamma\left(B_{j}^{k}-N_{j}^{k}\right)+\Delta t \alpha\left(B_{j}^{k}-N_{j}^{k}\right)
$$




$$
\begin{aligned}
& W_{j}^{k+1}=\left(W_{j}^{k}+\Delta t \beta N_{j}^{k+1}\right) /(1+\Delta t \beta), \\
& B_{j}^{k+1}=\left(B_{j}^{k}+\Delta t \delta N_{j}^{k+1}\right) /(1+\Delta t \delta) .
\end{aligned}
$$

These equations were solved for $k=2$ by: $N_{j}^{2}, j=2, \ldots$, was calculated from Eq. (A-15) after $\mathrm{N}_{j}^{2}$ was known; $w_{j}^{2}, j=2, \ldots$, was calculated from Eq. $(A-16)$; and $B_{j}^{2}, j=2, \ldots$, was calculated from Eq. (A-17) and similarly for $k=3,4, \ldots$.

For these difference equations, it is necessary to use a mesh size ratio somewhat less than unity, and $\Delta t V / \Delta z=0.7$ was found satisfactory. 

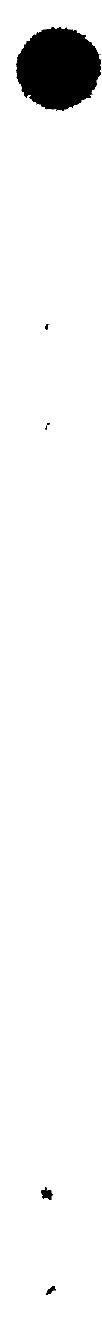

• 
ORNL-TM-4607

UC-79, $-79 e,-79 h,-79 k$

INTERNAL DISTRIBUTION

1. A. H. Anderson

2. R. L. Battiste

3. R. J. Beaver

4. J. J. B1ass

5. S. E. Bolt

6. C. R. Brinkman

7. J. W. Bryson

8. J. P. Callahan

9. D. D. Cannon

10. R. D. Cheverton

11. C. J. Claffey

12. N. E. Clapp

13. D. L. Clark

14. J. A. Clinard

15. C. W. Collins

16. J. A. Conlin

17-21. J. M. Corum

22. W. B. Cottrel1

23. J. S. Crowell

24. F. L. Culler

25. W. G. Dodge

26. G. G. Fee

27. W. F. Ferguson

28. M. H. Fontana

29. A. P. Fraas

30. R. M. Fuller

31. W. K. Furlong

32. W. R. Ga11

33. P. A. Gnadt

34. G. W. Greene

35. W. L. Greenstreet

36-40. A. G. Grindell

41. R. C. Gwaltney

42. W. O. Harms

43. R. E. Helms

44. H. W. Hoffman

45. L. N. Howe11

46. W. R. Huntley

47. S. K. Iskander

48. P. R. Kasten
49. R. T. King

50. K. C. Liu

51. D. B. Lloyd

52. M. I. Lundin

53. R. N. Lyon

54. R. E. MacPherson

55. W. R. Martin

56. W. J. McAfee

57. H. E. McCoy

58-62. H. C. McCurdy

63. C. K. McGlothlan

64. J. R. McGuffey

65. L. E. McNeese

66. J. G. Merk1e

67. C. A. Mills

68. R. L. Moore

69. S. E. Moore

70. F. H. Neill

71. P. Patriarca

72. T. W. Pickel

73. C. E. Pugh

74. M. Richardson

75. D. N. Robinson

76. W. K. Sartory

77. Myrtleen Sheldon

78. G. M. Slaughter

79. J. E. Smith

80. I. Spiewak

81. R. D. Stulting

82. R. W. Swindeman

83. D. B. Trauger

84. J. R. Weir

85. G. D. Whitman

86. L. V. Wilson

87. G. T. Yahr

88-92. H. C. Young

93. ORNL Patent office

94-95. Central Research Library

96. Document Reference Section

97-99. Laboratory Records Department 100. Laboratory Records (RC) 
SUBCONTRACTORS AND CONSULTANTS

101. Atomics Intemational, P.0. Box 309, Canoga Park, CA 91304, Attn: R. I. Jetter

102-104. Babeock \& Wheox Company, P.O. Box 835, Allance, ow 44601, Aten: W. E. Leyda

C. C. Schultz

D. B. Vanfossen

105-107. Battelle Memorial Institute, 505 King Ave., Columbus, OH 43201, Attn: C. E. Jaske

E. C. Rodabaugh

G. H. Workman

108 109. Brown University, Providence, MI 02912

Attn: W. N. Findley

110. The Catholic University of America, Washington, D.C. 20017, Attn: A. J. Durelli

111. Pennsylvana State University, University Park, PA 16802, Attn: S. Y. Zamrik

112. A. E. Carden, University of Alabana, University, Al 36586

113. R. H. Gallagher, Corneli University, Ithaca, NY 14850

114. W. J. O'Donne11, O'Donne11 and Associates, Inc., 5100 Centre Ave, Pittsburgh, PA 15232

115. E. T. Onat, Yale University, New Haven, CT 06520

116. S. S. Manson, Case Western Institute, Cleveland, of 44300

117. L. F. Coffin, General Electric Company, P.0. Box 8, Schenectady, NY 12301

\section{EXTERNAL DISTRIBUTION}

118-119. Mirector, Division of Reactor Research and Development, USAEC, Washington, 30.C. 20545

120. Dlrector, Reactor Division, USAEC, ORO

121. Research and Technical Support Division, USAEC, ORO

122-414. Given distribution as shown in TrD 4500 under categories UC$79,-79 e,-79 \mathrm{~h},-79 \mathrm{k}$ 